\title{
Metabolic aspects of cis and trans polyunsaturated fatty acids from the diet
}

Citation for published version (APA):

Vermunt, S. (2001). Metabolic aspects of cis and trans polyunsaturated fatty acids from the diet. [Doctoral Thesis, Maastricht University]. Datawyse. https://doi.org/10.26481/dis.20010927sv

Document status and date:

Published: 01/01/2001

DOI:

10.26481/dis.20010927sv

Document Version:

Publisher's PDF, also known as Version of record

\section{Please check the document version of this publication:}

- A submitted manuscript is the version of the article upon submission and before peer-review. There can be important differences between the submitted version and the official published version of record.

People interested in the research are advised to contact the author for the final version of the publication, or visit the DOI to the publisher's website.

- The final author version and the galley proof are versions of the publication after peer review.

- The final published version features the final layout of the paper including the volume, issue and page numbers.

Link to publication

\footnotetext{
General rights rights.

- You may freely distribute the URL identifying the publication in the public portal. please follow below link for the End User Agreement:

www.umlib.nl/taverne-license

Take down policy

If you believe that this document breaches copyright please contact us at:

repository@maastrichtuniversity.nl

providing details and we will investigate your claim.
}

Copyright and moral rights for the publications made accessible in the public portal are retained by the authors and/or other copyright owners and it is a condition of accessing publications that users recognise and abide by the legal requirements associated with these

- Users may download and print one copy of any publication from the public portal for the purpose of private study or research.

- You may not further distribute the material or use it for any profit-making activity or commercial gain

If the publication is distributed under the terms of Article $25 \mathrm{fa}$ of the Dutch Copyright Act, indicated by the "Taverne" license above, 
Metabolic aspects of cis and trans polyunsaturated fatty acids from the diet 


\section{itrim IIUTI}

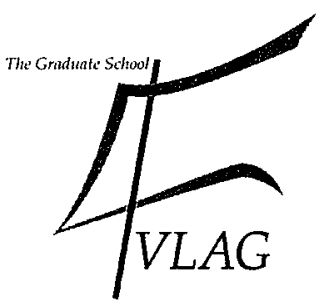

The study presented in this thesis was performed at the Nutrition and Toxicology Research Institute Maastricht (NUTRIM), which participates in the Graduate School VLAG-2 (Food Technology, Agrobiotechnology, Nutrition and Health Sciences) accredited by the Royal Netherlands Academy of Arts and Sciences.

Omslag: Martin van der Vaart (foto), Susan Vermunt Productie: Datawyse, Maastricht

(c) Susan Vermunt, Maastricht, 2001

ISBN 9090150161 


\title{
Metabolic aspects of cis and trans polyunsaturated fatty acids from the diet
}

\author{
PROEFSCHRIFT
}

ter verkrijging van de graad van doctor aan de Universiteit Maastricht, op gezag van de Rector Magnificus, Prof. Dr. A.C. Nieuwenhuizen Kruseman, volgens het besluit van het College van Decanen, in het openbaar te verdedigen op donderdag 27 september 2001 om 12.00 uur

door

Susanne Hanneke Francisca Vermunt

Geboren op 14 juli 1970 te Prinsenbeek 


\section{Promotores:}

Prof. Dr. G. Hornstra

Prof. Dr. Ir. R.P. Mensink

\section{Beoordelingscommissie:}

Prof. Dr. Ir. W.H.M. Saris (voorzitter)

Prof. Dr. T.W.A. de Bruin

Dr. J.F.C. Glatz

Prof. Dr. Ir. M.B. Katan (Wageningen Universiteit)

Prof. Dr. B. Koletzko (University of Munchen)

Financial support by the Netherlands Heart Foundation and the Dr. Ir. Van de Laar Stichting for the publication of this thesis is gratefully acknowledged.

Additionally, the author wishes to express her gratitude to TNO Food and Nutrition Research for their financial support. 
Aan mijn ouders

Voor Paul 



\section{Contents}

1 General introduction

2 The metabolism of linoleic acid in healthy subjects after intake of a single dose of ${ }^{13} \mathrm{C}$ linoleic acid

3 Effects of dietary $\alpha$-linolenic acid on the conversion and oxidation of ${ }^{13} \mathrm{C} \alpha$-linolenic acid

4 Incorporation of ${ }^{13} \mathrm{C} \alpha$-linolenic acid and their longer chain

metabolites into human erythrocytes

$5 \quad$ Relationship between mRNA levels for $\Delta 5, \Delta 6$ and $\Delta 9$ desaturases in mononuclear blood cells and the liver

$6 \quad$ Health effects of trans fatty acids

7 The effect of dietary trans $\alpha$-linolenic acid on plasma lipids and platelet fatty acid composition: the TRANSLinE study

8 Dietary trans $\alpha$-linolenic acid from deodorized vegetable oil and plasma lipids and lipoproteins in healthy men: the TRANSLinE Study

$9 \quad$ General discussion

Fatty acid nomenclature and abbreviations

Summary

Samenvatting

Dankwoord

Curriculum vitae

Publications 

General introduction 
Fat contributes for on average $36 \%$ of the energy intake in the total Dutch population, of which $7 \%$ of energy is from polyunsaturated fatty acids (PUFAs) (1). Dietary PUFA, which are mainly incorporated into triacylglycerols and phospholipids, are essential components of membranes, play a role in the production of energy, and some are precursors of eicosanoids (2). Furthermore, PUFAs may have beneficial effects on serum lipids and lipoproteins and their overall effect is that they may reduce the risk for coronary heart disease (CHD) (3-5). In contrast, a high total or saturated fat intake may increase the risk for $\mathrm{CHD}(4,6)$. In the Netherlands, it is therefore advised to consume maximal $30-35 \%$ of energy from fat, of which less than $10 \%$ from saturated fat (7). Moreover, an expert panel recently advised to eat fish once a week or to consume $200 \mathrm{mg}$ marine n-3 PUFA (eicosapentaenoic acid (EPA) plus docosahexaenoic acid (DHA)) daily (5). A daily intake of $2 \mathrm{~g}$ or $1 \%$ of energy $\alpha-$ linolenic acid has been recommended as well (5).

The aim of this chapter is to introduce the essential fatty acids linoleic acid and $\alpha$-linolenic acid. First, the structure and nomenclature of these fatty acids are explained, and the synthesis of longer chain polyunsaturated fatty acids (LCPs) derived from essential fatty acids as well as the degradation of essential fatty acids by $\beta$-oxidation are discussed. Special attention will be paid to nutritional factors that may influence essential fatty acid metabolism. Because stable isotopes are pre-eminently suitable for studying human in vivo fatty acid metabolism, advantages and disadvantages of this technique are discussed. Furthermore, determination of desaturase gene expression in human tissues is considered. Finally, the contribution of trans fatty acids to the diet and the effects of trans fatty acids on plasma lipids are discussed briefly. An extensive overview of the health aspects of trans fatty acids is given in chapter 6 . This chapter will be closed by giving an outline of this thesis.

\section{FATTY ACIDS}

Fatty acids consist of a chain of carbon atoms (C-atoms) connected by single or double bonds, with at one end a methyl group $\left(\mathrm{CH}_{3}\right.$-group) and at the other end a carboxyl-group ( $\mathrm{COOH}$-group). Saturated fatty acids have no double bonds, monounsaturated fatty acids have one double bond and PUFAs have two or more double bonds. The unsaturated fatty acids belong to either the $\alpha$-linolenic $(n-3)$, linoleic (n-6), palmitoleic (n-7), or oleic (n-9) acid family, in which the first double bond is located between the $3^{\text {rd }}$ and $4^{\text {th }}, 6^{\text {th }}$ and $7^{\text {th }}, 7^{\text {th }}$ and $8^{\text {th }}$, or $9^{\text {th }}$ and $10^{\text {th }}$ carbon atom, respectively, as counted from the methyl-end of the carbon chain. The position of the double bonds may also be counted from the carboxyl-end of the molecule, which is symbolized as ' $\Delta$ '. Chain elongation and desaturation always occur between the carboxyl-group and its nearest double bond. Consequently, the position of the first double bond from the methyl-end will not change during conversion reactions, and fatty acids will not change in 'families' as a result of metabolism. 
Double bonds may occur in two configurations, the cis- and the transconfiguration. In the cis-configuration the hydrogen atoms (H-atoms) adjacent to the double bond are located at the same side of an imaginary 'plane' through the double bond. This form is the most common in nature. In the trans-configuration both $\mathrm{H}$ atoms adjacent to the double bound are located at opposite sides of the double bond. Figure 1.1 shows linoleic acid $(C 18: 2 n-6)$, which belongs to the $n-6$ family, $\alpha$-linolenic acid (C18:3n-3), which belongs to the $n-3$ family, and one of the trans isomers of $\alpha$ linolenic acid (C18:3n-3 $\Delta 9 c, 12 c, 15 t r)$.

Fatty acids of the n-7 and n-9 family can be synthesized de novo in most cells. Linoleic and $\alpha$-linolenic acid can not be synthesized de novo by human cells, because they lack $\Delta 12$ - and $\Delta 15$ desaturases. Therefore, these fatty acids are called essential fatty acids (EFAs) and must be provided in the diet. Trans fatty acids are only formed de novo as an intermediate in the $\beta$-oxidation. Nearly all trans fatty acids in human tissues originate from the diet.

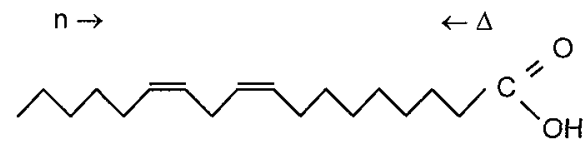

linoleic acid $(C 18: 2 n-6 \Delta 9 c, 12 c)$

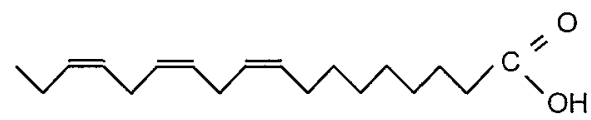

$\alpha$-linolenic acid $(C 18: 3 n-3 \Delta 9 c, 12 c, 15 c)$

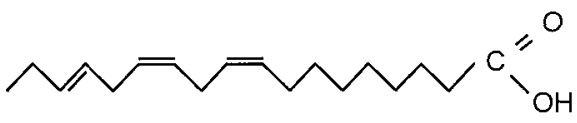

trans $\alpha$-linolenic acid $(C 18: 3 n-3 \Delta 9 c, 12 c, 15 t r)$

Figure 1.1 Chemical structure of linoleic, and cis- and trans $\alpha$-linolenic acid

\section{METABOLISM OF ESSENTIAL FATTY ACIDS}

\section{Desaturation and elongation}

In the human body, fatty acids can by converted by alternate desaturation and elongation reactions. The conversions of the $\alpha$-linolenic, linoleic, palmitic, and stearic acids into their longer chain metabolites are shown in figure 1.2. 


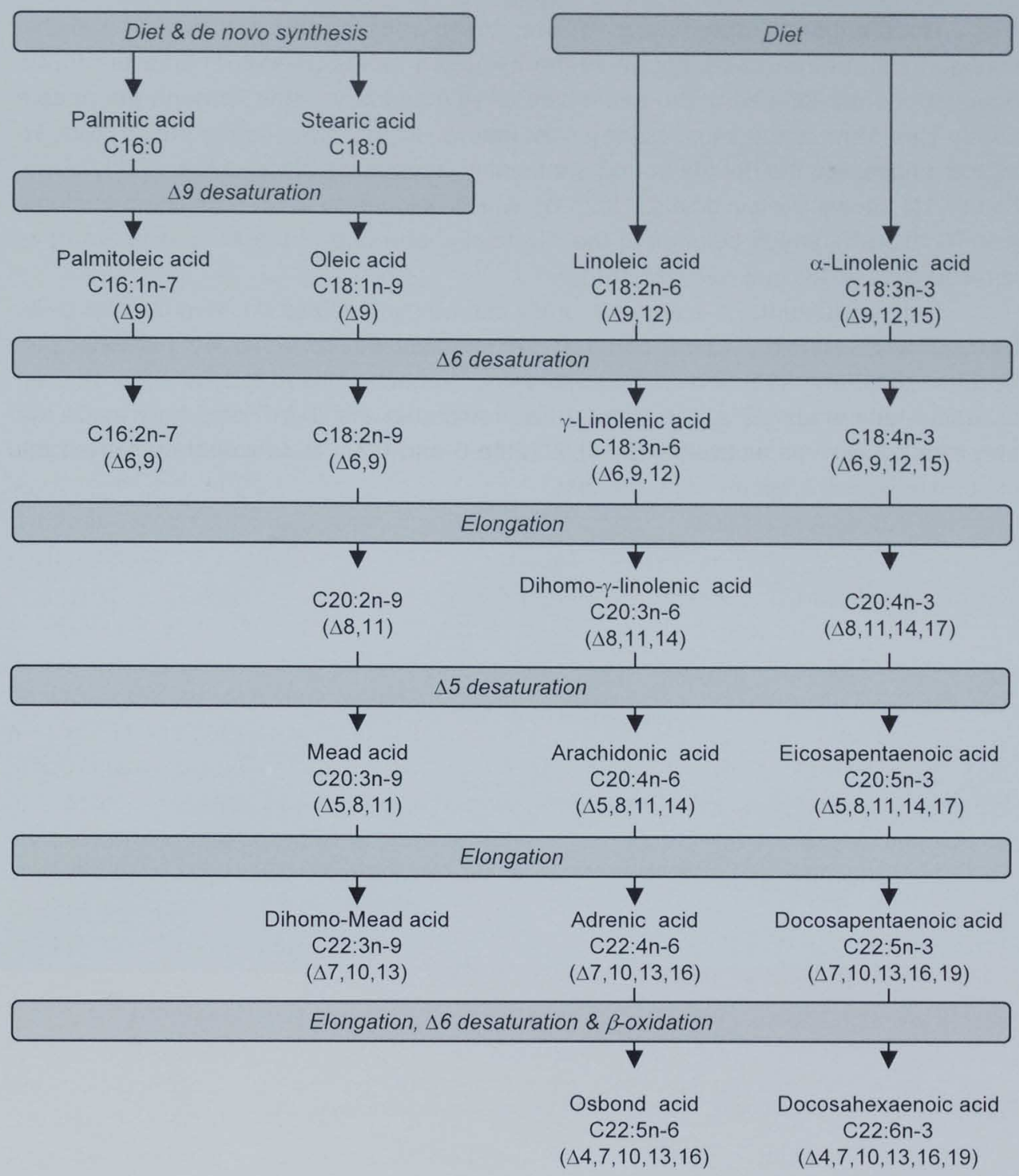

Figure 1.2 Conversion pathways of fatty acids

Humans have three desaturase enzymes, $\Delta 9-, \Delta 6-$, and $\Delta 5$-desaturases, of which $\Delta 9$ desaturase is not involved in the conversion of essential fatty acids. Delta 6 desaturase introduces a double bond at the $\Delta 6$ position when this fatty acid has already a double bond at the $\Delta 9$ position, while $\Delta 5$ desaturase introduces a double 
bond at the $\Delta 5$ position when the $\Delta 11$ and $\Delta 8$ positions are already desaturated. The desaturases are each part of three separate desaturase systems. These desaturase systems are embedded in microsomal membranes, and involve three integral components, the desaturase, NADH cytochrome- $b_{5}$ reductase and cytochrome- $b_{5}$. The desaturase is the rate limiting reaction in the desaturase system (8).

Recently, the human $\Delta 6$ and $\Delta 5$ desaturase genes have been sequenced $(9,10)$, and mRNAs from these genes were found in many human tissues including skeletal muscle, lung, placenta, kidney and pancreas. mRNA levels of both desaturases, however, are highest in the liver, heart and brain (10). Also, in vitro animal studies, using radioactive labeled fatty acids, showed high desaturation activity in the liver (11). The $\Delta 6$ desaturase activity has been reported to be the rate limiting reaction for the synthesis of arachidonic acid and EPA from linoleic acid and $\alpha$-linolenic acid, respectively (12-14). C22:4n-6 and C22:5n-3 are not converted into C22:5n- 6 and $C 22: 6 n-3$ by a $\Delta 4$ desaturase and elongase, but by three reactions, two elongation steps followed by $\Delta 6$-desaturation in microsomes, and a peroxisomal shortening (15). It has been suggested that this $\Delta 6$ desaturase may be different from the one that converts $\alpha$-linolenic and linoleic acid (16).

Elongation results in the incorporation of a two-carbon unit from malonylCoA into the activated fatty acid chain proximal to the carboxyl group (17). The elongation system is located on the membrane of endoplasmatic reticulum of many animal tissues, like liver, brain, kidney, small intestine, placenta, lung etcetera $(17,18)$. In addition, in vitro elongation has been observed in many mammalian cell lines $(19,20)$. Besides in endoplasmatic reticulum, elongation has also been observed in mitochondria and peroxisomes of rats $(21,22)$. The elongase enzyme system requires several enzymes, anaerobic conditions, adenosine triphosphate (ATP), and a reduced pyridine nucleotide (NADPH) (23). Apparently, PUFAs and saturated fatty acids are elongated by different enzymes (24). The rate of elongation is faster with an increased degree of unsaturation and with shorter chain length (25).

Conversion of essential fatty acids has been investigated mainly in in vitro and animal studies, while human in vivo studies are limited. In one of the first human in vivo studies ${ }^{14} \mathrm{C}$ labeled linoleic acid was used to investigate its conversion into arachidonic acid in normo- and hyperlipidemic adult males (26). A later study used deuterated fatty acids to investigate incorporation of linoleic and $\alpha$-linolenic acid and their LCPs in plasma lipids of healthy adults (27). In infants, ${ }^{13} \mathrm{C}$ enrichment of dihomo-y-linolenic acid and arachidonic acid in plasma was observed after administration of corn oil (28), which has a relatively high ${ }^{13} \mathrm{C}$ linoleic acid content. This study showed that infants are also capable to convert linoleic and $\alpha$-linolenic acid into LCPs. None of the previous studies combined the conversion and oxidation of labeled fatty acids, which is however only possible when ${ }^{13} \mathrm{C}$ labeled fatty acids are used, neither did they examine the incorporation of fatty acids into tissue membranes. 
The longer chain more unsaturated fatty acid products of $\alpha$-linolenic and linoleic acid can be incorporated into intracellular and plasma membranes, and are precursors of a wide range of eicosanoids. Dietary $n-3$ and $n-6$ fatty acids are incorporated into membranes as phospholipids and its content in cellular membranes reflects dietary intake $(29,30)$. Both $n-3$ and $n-6$ fatty acids are essential as structural components and are related to membrane functions like membrane fluidity, osmotic fragility, permeability for metabolites, degranulation of vesicles, activity of membrane bound enzymes and receptors and the transduction of electrical signals.

Eicosanoids (prostanoids, leukotrienes and hydroxy fatty acids) are formed enzymatically by oxygenation of the $\mathrm{C} 20$ fatty acids dihomo- $\gamma$-linolenic acid $(C 20: 3 n-6)$, arachidonic acid (C20:4n-6), and EPA (C20:5n-3). Figure 1.3 shows the formation of eicosanoids from arachidonic acid. Eicosanoids are active in the cardiovascular system. For example, the antithrombotic prostacyclin $\left(\mathrm{PGI}_{2}\right)$ is a highly potent vasodilator and inhibitor of platelet aggregation, while the prothrombotic thromboxane $\mathrm{A}_{2}\left(\mathrm{TxA}_{2}\right)$ is a strong vasoconstrictor causing aggregation of platelets. In normal hemostasis, the syntheses of these eicosanoids are in balance.

\section{Factors influencing desaturase activity}

Conversion rates of $\alpha$-linolenic and linoleic acid may be affected by nutritional and hormonal factors, and by age. Inhibition of desaturases may result in decreased levels of LCPs, which may even become inadequate. Knowledge of factors that affect activities of desaturases is therefore needed to determine appropriate intakes of $\alpha$ linolenic and linoleic acid and their LCPs. Indeed, it may be necessary to increase the intake of LCPs in several populations at risk (5).

Effects of nutritional factors influencing desaturase activities have been reviewed several times $(2,8,23,31)$. The studies described in these reviews, however, were mainly animal and in vitro studies. Briefly, $\Delta 6$ desaturase activity is activated by essential fatty acid deficiency, while it is depressed by fasting, and n-3 and n-6 LCPs. Competition between fatty acids exists, since $n-3$ and $n-6$ fatty acids are converted by the same desaturase enzymes, however, $\Delta 6$ desaturase has a higher affinity for $\alpha$ linolenic acid as for linoleic acid. It was also reported that $\Delta 5$ desaturase activity is increased on essential fatty acid deficiency. Results, however, were contradictory.

Only one human in vivo study investigated diet effects on conversion rates of essential fatty acids. It was reported that dietary linoleic acid reduced the conversion of both deuterated linoleic and $\alpha$-linolenic acid in healthy adults (27).

\section{B-Oxidation}

Fatty acids can be degraded by $\beta$-oxidation and are thus an important source of energy for the human body. For $\beta$-oxidation, the activated fatty acids are dehydrogenated at the carboxyl side, after which two carbons (acetyl-CoA) are split off. Thereafter, the acyl-CoA residue can be dehydrogenated again until the fatty acid is degraded completely. The degradation of unsaturated fatty acids needs two 
additional enzymes, $\triangle 3$-cis- $\triangle 2$-trans enoyl-CoA isomerase and 3-hydroxyacyl-CoA epimerase. AcetylCoA can enter the Krebs cycle to be oxidized to $\mathrm{CO}_{2}$ and $\mathrm{H}_{2} \mathrm{O}$. The electrons removed in the two hydrogenation steps move to oxygen via the respiratory chain, accompanied by oxidative phosphorylation of ADP (32).

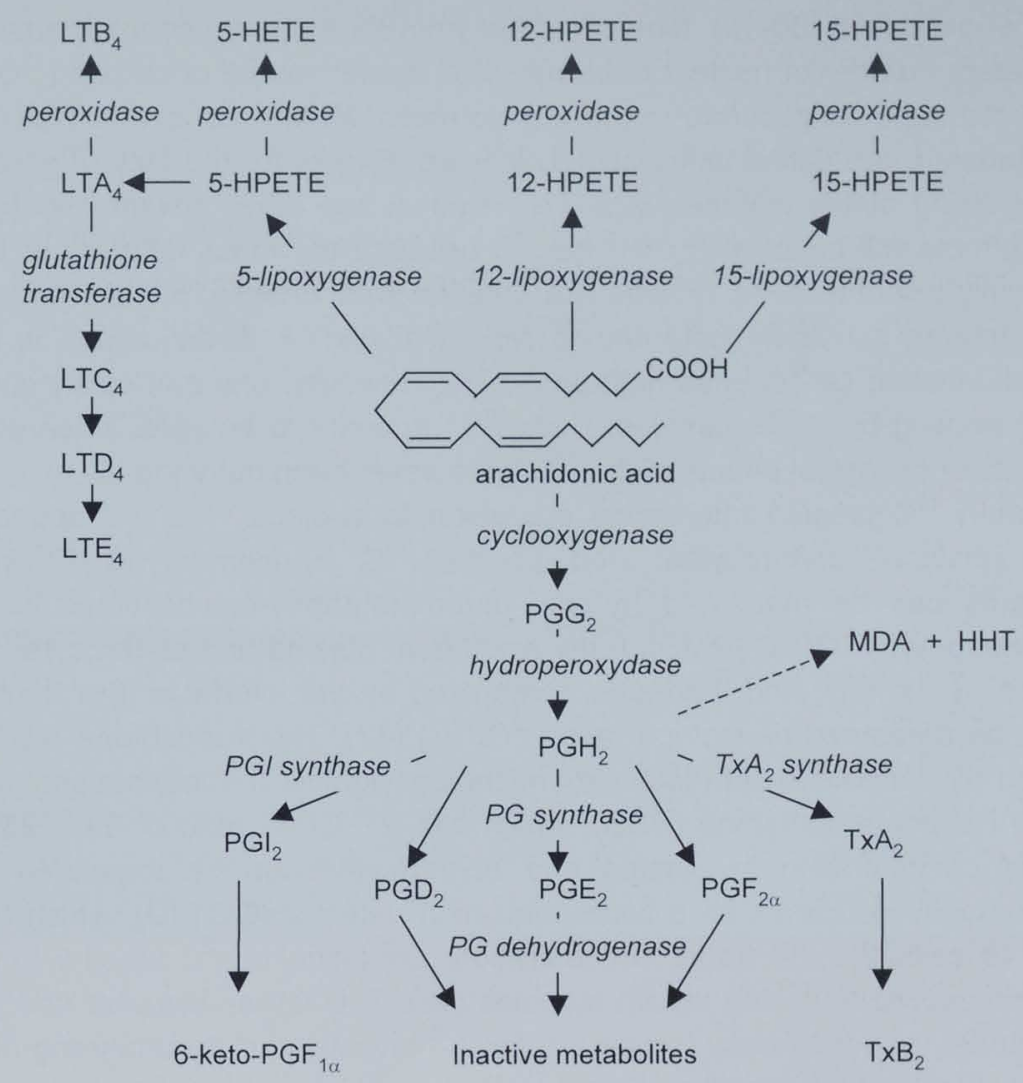

Figure 1.3 Formation of eicosanoids from arachidonic acid

Most dietary fatty acids are oxidized for energy via $\beta$-oxidation in mitochondria, while the peroxisomal system is used for the $\beta$-oxidation of very long chain fatty acids, prostaglandines and dicarboxylic acids $(32,33)$. Indeed, n-3 and n-6 C22 and C24 fatty acids are retroconverted into $\mathrm{C} 20$ fatty acids by peroxisomes of human fibroblasts via $\beta$-oxidation (34). Whole body oxidation of fatty acids may vary $(35) .{ }^{13} \mathrm{C}$ Oleic acid is oxidized at a faster rate than ${ }^{13} \mathrm{C}$ linoleic acid, which is oxidized at a faster rate than ${ }^{13} \mathrm{C}$ stearic acid. 


\section{TECHNIQUES TO STUDY IN VIVO FATTY ACID METABOLISM IN HUMANS}

\section{Stable isotopes}

Only until the introduction of stable isotopes, human fatty acid metabolism was mainly measured in in vitro studies. Emken and coworkers were the first who used stable isotopes of hydrogen (deuterium) to study the conversion of series of trans isomers of oleic acid (36-40). Isotopes differ from their normal counterparts (tracee) by a different number of nuclear neutrons. The stable isotope of carbon $\left({ }^{12} \mathrm{C}\right)$ is ${ }^{13} \mathrm{C}$, in which the superscript refers to the atomic mass. Molecules in which all $\mathrm{C}$-atoms are ${ }^{13} \mathrm{C}$ labeled, are called uniformly (U) labeled. Except for the lack of exposure to radiation, using stable isotopes in in vivo studies has other advantages (41). The isotopic effects will be smaller than for ${ }^{14} \mathrm{C}$ because the mass differences between the naturally predominating isotope are smaller. Furthermore, it is possible to use different tracers simultaneously and to repeat dosing. A disadvantage is that the natural abundance of ${ }^{13} \mathrm{C}$ is as high as $1.11 \%$. However, one can easily correct for this by collecting baseline samples. Using ${ }^{13} \mathrm{C}$ appears to be safe, since unwanted side effects or biological effects of the ${ }^{13} \mathrm{C}$ have never been detected (41).

When ${ }^{13} \mathrm{C}$ labeled fatty acids are given to subjects, ${ }^{13} \mathrm{C}$ will appear in for example plasma, erythrocytes, and breath. ${ }^{13} \mathrm{C}$ Enrichment $\left(\delta^{13} \mathrm{C}\right)$ in these components can be measured by gas chromatography-combustion-isotope ratio mass spectrometry (GC-C-IRMS). Fatty acids from plasma and erythrocytes are first separated by the $\mathrm{GC}$, and thereafter combusted by the interface. The formed $\mathrm{CO}_{2}$ can then be measured as isotope ratio $\left({ }^{13} \mathrm{C} /{ }^{12} \mathrm{C}\right)(42)$. The true isotope ratio can be calculated by normalizing the isotopic enrichment against the international standard Pee Dee Belemate limestone (PDB), which has a ${ }^{13} \mathrm{C} /{ }^{12} \mathrm{C}$ ratio of 0.0112372 . The fatty acid concentration in plasma and erythrocytes can be measured by gas chromatography coupled with a flame ionization detector (GC/FID), which makes it possible to calculate the tracer concentration. Oxidation of ${ }^{13} \mathrm{C}$ labeled fatty acids may be measured by taking breath samples (43). This is non-invasive and painless for volunteers, and very easy to perform for the investigator. By analyzing also total $\mathrm{CO}_{2}$ production, oxidation of the ${ }^{13} \mathrm{C}$ labeled fatty acids can be calculated as well.

\section{Desaturase gene expression in human tissues}

Since desaturases and elongase are essential for the conversion of essential fatty acids into LCPs and eventually into eicosanoids, studying their gene expressions may be helpful to clarify fatty acid metabolism. Human $\Delta 9, \Delta 6$, and $\Delta 5$ desaturase have been cloned and characterized $(9,10,44)$. As reported, desaturase mRNAs are found in many human tissues, but are most abundant in the liver (10). This and several other organs and tissues are, however, not suitable to investigate in human studies. Alternatively, desaturase mRNAs can be measured in human leukocytes, in which $\Delta 6$ desaturase activity has been found (45). It is, however important to know whether the gene expressions in liver and leukocytes are related. If so, regulation of 
$\Delta 6$ desaturase in leukocytes may be measured in future research in order to predict regulation of $\Delta 6$ desaturase in the liver. The amino acid sequence of human elongase has not been reported yet.

\section{TRANS FATTY ACIDS}

\section{Intake of trans fatty acids}

The daily total trans fatty acid intake in the Netherlands is about $4.8 \mathrm{~g}(1.5 \%$ of energy) in men and $3.8 \mathrm{~g}$ (1.6\% of energy) in women (46). In Europe, the daily total trans fatty acid intake varies between $0.5 \%$ of energy in Italy to $2.0 \%$ of energy in Iceland (46). Most trans fatty acids are trans monounsaturated fatty acids. In fact, more than $80 \%$ of total trans fatty acids is elaidic acid (C18:1 $\Delta 9$ tr). Furthermore, more than $10 \%$ of the trans fatty acids is trans linoleic acid. Trans $\alpha$-linolenic acid and trans monounsaturated fatty acids other than elaidic acid also contribute to the trans intake. Trans monounsaturated fatty acids are mainly formed by bacteria in the first stomach (rumen) of ruminant animals and by industrial hydrogenation, while trans polyunsaturated fatty acids are mainly formed during the deodorization process. In US vegetable oils, the degree of trans-isomerization of linoleic acid and $\alpha$-linolenic acid may be up to $3.3 \%$ and $37.1 \%$, respectively (47). In addition, some trans polyunsaturated fatty acids are formed during deep-frying (48). Increment of the dietary $\alpha$-linolenic acid intake as recommended (5), may thus increase the intake of trans $\alpha$-linolenic acid.

\section{Effects of trans fatty acids on the plasma lipid profile}

A high plasma total cholesterol level is associated with an increased risk for CHD. In addition, the distribution of cholesterol among lipoproteins is important: low density lipoprotein (LDL) cholesterol increases CHD risk, and high density lipoprotein (HDL) cholesterol is associated with a decreased risk (49). An important parameter to predict risk for $\mathrm{CHD}$ is the total to $\mathrm{HDL}$ cholesterol ratio (50). This ratio reflects the risk when an increased total or LDL cholesterol level is combined with a lowered HDL cholesterol level. In the Netherlands, this ratio is used to predict CHD risk (7). Increased fasting triacylglycerol concentrations are also associated with an increased CHD risk (51).

Trans monounsaturated fatty acids have been found to influence plasma lipoprotein levels negatively. In fact, each additional percent of dietary energy as trans monounsaturated fatty acids at expense of oleic acid results in an increase in LDL cholesterol levels of $0.040 \mathrm{mmol} / \mathrm{l}$, a decrease in HDL cholesterol levels of 0.013 $\mathrm{mmol} / \mathrm{l}$, and an increase in triacylglycerol levels by $0.013 \mathrm{mmol} / \mathrm{l}(52)$. The effects of trans polyunsaturated fatty acids on serum lipids and lipoproteins are not yet known. 


\section{OUTLINE OF THE THESIS}

The in vivo essential fatty acid metabolism has not been extensively studied in human subjects, neither did previous studies investigate both oxidation and elongation. Furthermore, effects of trans polyunsaturated fatty acids on risk parameters of $\mathrm{CHD}$ have not been investigated yet.

Therefore, this thesis was aimed at:

* investigating the in vivo metabolism of $n-3$ and $n-6$ fatty acids in healthy subjects

* examining the effects of trans $\alpha$-linolenic acid on plasma lipids and lipoproteins

These issues have been investigated in four studies. The first study focused on linoleic acid metabolism, while effects of dietary composition on $\alpha$-linolenic acid metabolism has been investigated in the second study. The third study investigated mRNA levels for $\Delta 5, \Delta 6$ and $\Delta 9$ desaturases in human liver and mononuclear blood cells. Finally, the fourth study was a large intervention study, which examined the nutritional and health impact of TRANS $\alpha$-Linolenic acid in European men: the TRANSLinE Study.

Chapter 2 focuses on the oxidation and conversion of ${ }^{13} \mathrm{C}$ linoleic acid into its long chain metabolites in healthy subjects. Chapter 3 describes the effects of dietary $\alpha$ linolenic acid on the oxidation and conversion of ${ }^{13} \mathrm{C} \alpha$-linolenic acid into its longer chain more unsaturated fatty acids. Enrichments of ${ }^{13} \mathrm{C}$ labeled fatty acids in plasma and ${ }^{13} \mathrm{C}$ recovery in breath $\mathrm{CO}_{2}$ are presented. Incorporation of ${ }^{13} \mathrm{C}$ labeled fatty acids into erythrocytes after intake of a single bolus of ${ }^{13} \mathrm{C} \alpha$-linolenic acid is discussed in chapter 4 .

In chapter 5, the relationship between mRNA levels for $\Delta 5, \Delta 6$ and $\Delta 9$ desaturase in mononuclear blood cells and the liver are presented.

Chapter 6 gives an overview of the metabolism and health effects of trans fatty acids. Chapter 7 describes the effects of dietary trans $\alpha$-linolenic acid on plasma lipids and platelet fatty acid composition of the TRANSLinE-study. In chapter 8, effects of trans $\alpha$-linolenic acid on plasma lipids and lipoproteins of the TRANSLinEstudy in healthy men are discussed.

Finally, the main results of the four studies are discussed in chapter 9. 


\section{REFERENCES}

1. Voedingscentrum. Zo eet Nederland, 1998. Resultaten van de Voedselconsumptiepeiling 1998. Den Haag, The Netherlands: Voedingscentrum, 1998.

2. Kinsella JE. $\alpha$-Linolenic acid: functions and effects on linoleic acid metabolism and eicosanoid-mediated reactions. In: Advances in Food and Nutrition Research (Kinsella JE, ed.) San Diego: Academic Press, 1991:1-1843.

3. De Lorgeril M, Renaud $S$, Mamelle $N$, et al. Mediterranean alpha-linolenic acid-rich diet in secondary prevention of coronary heart disease. Lancet 1994;343:1454-1459.

4. Ascherio A, Rimm EB, Giovannucci EL, Spiegelman D, Stampfer M, and Willett WW. Dietary fat and risk of coronary heart disease in men: cohort follow up study in the United States. Brit Med J 1996;313:84-90.

5. De Deckere EAM, Korver O, Verschuren PM, and Katan MB. Health aspects of fish and n-3 polyunsaturated fatty acids from plant and marine origin. Eur J Clin Nutr 1998;52:749-753.

6. Pietinen $P$, Ascherio $A$, Korhonen $P$, et al. Intake of fatty acids and risk of coronary heart disease in a cohort of Finnish men. Am J Epidemiol 1997;145:876-887.

7. Centraal begeleidingsorgaan voor de intercollegiale toetsing. Consensus Cholesterol. Utrecht, the Netherlands: CBO/MWR, 1998.

8. Brenner RR. Nutritional and hormonal factors influencing desaturation of essential fatty acids. Prog Lipid Res 1981;20:41-47.

9. Cho HP, Nakamura M, and Clarke SD. Cloning, expression, and nutritional regulation of the mammalian $\Delta-6$ desaturase. J Biol Chem 1999;274:471-477.

10. Cho HP, Nakamura M, and Clarke SD. Cloning, expression, and fatty acid regulation of the human $\Delta-5$ desaturase. J Biol Chem 1999;274:37335-37339.

11. Brenner RR. The desaturation step in the animal biosynthesis of polyunsaturated fatty acids. Lipids 1971;6:567-575.

12. Marcel $\mathrm{YL}$, Christiansen $\mathrm{K}$, and Holman RT. The preferred metabolic pathway from linoleic acid to arachidonic acid in vitro. Biochim Biophys Acta 1968;164:25-34.

13. Bernert JT, and Sprecher H. Study to determine the role rates of chain elongation and desaturation play in regulating the unsaturated fatty acid composition of rat liver lipids. Biochim Biophys Acta 1975;398:354-363.

14. Hagve TA, and Christophersen BO. Effect of dietary fats on arachidonic acid and eicosapentaenoic acid biosynthesis and conversion to $\mathrm{C}_{22}$ fatty acids in isolated rat liver cells. Biochim Biophys Acta 1984;796:205-217.

15. Voss A, Reinhart M, Sankarappa $S$, and Sprecher $H$. The metabolism of $7,10,13,16,19$ docosapentaenoic acid to $4,7,10,13,16,19$-docosahexaenoic acid in rat liver is independent of a 4-desaturase. J Biol Chem 1991;266:19995-20000.

16. Marzo I, Alava MA, Piñeiro A, and Naval J. Biosynthesis of docosahexaenoic acid in human cells: evidence that two different $\Delta 6$-desaturase activities may exist. Biochim Biophys Acta 1996;1301:263-272.

17. Cinti DL, Cook L, Nagi MN, and Suneja SK. The fatty acid chain elongation system of mammalian endoplasmic reticulum. Prog Lipid Res 1992;31:1-51.

18. Nugteren $\mathrm{DH}$. The enzymic chain elongation of fatty acids by rat-liver micorsomes. Biochim Biophys Acta 1965;106:280-290.

19. Spector AA, Mathur SN, Kaduce TL, and Hyman BT. Lipid nutrition and metabolism of cultured mammalian cells. Prog Lipid Res 1981;19:155-186. 
20. Rosenthal MD. Fatty acid metabolism in isolated mammalian cells. Prog Lipid Res 1987;26:87-124.

21. Mimouni V, Christiansen EN, Blond JP, Ulmann L, Poisson JP, and Bezard J. Elongation and desaturation of arachidonic and eicosapentaenoic acids in rat liver. Effect of clofibrate feeding. Biochim Biophys Acta 1991;1086:349-353.

22. Lee WNP, Lim S, Bassilian S, Berger E, and Edmond J. Fatty acid cycling in human hepatoma cells and the effects of troglitazone. J Biol Chem 1998;273:20929-20934.

23. Brenner RR. Factors influencing fatty acid chain elongation and desaturation. In: The Role of Fats in Human Nutrition (Vergroesen AJ and Crawford $\mathrm{M}$, eds.) London: Academic Press, 1989:46-79.

24. Sprecher H. Biochemistry of essential fatty acids. Prog Lipid Res 1981;20:13-24.

25. Naughton JM. Supply of polyenoic fatty acids to the mammalian brain: The ease of conversion of the short-chain essential fatty acids to their longer chain polyunsaturated metabolites in liver, brain, placenta and blood. Int J Biochem 1981;13:21-32.

26. Nichaman MZ, Olson RE, and Sweeley CC. Metabolism of linoleic acid- $1-{ }^{14} \mathrm{C}$ in normolipemic and hyperlipemic humans fed linoleate diets. Am J Clin Nutr 1967;20:1070-1083.

27. Emken EA, Adlof RO, and Gulley R. Dietary linoleic acid influences desaturation and acylation of deuterium-labeled linoleic and linolenic acids in young adult males. Biochim Biophys Acta 1994;1213:277-288.

28. Demmelmair $H, \vee$ Schenck $U$, Behrendt $E$, Sauerwald $T$, and Koletzko B. Estimation of arachidonic acid synthesis in full term neonates using natural variation of ${ }^{13} \mathrm{C}$ content. $J$ Pediatr Gastroenterol Nutr 1995;21:31-36.

29. Prisco D, Filippini $M$, Francalanci $I$, et al. Effect of $n-3$ polyunsaturated fatty acid intake on phospholipid fatty acid composition in plasma and erythrocytes. Am J Clin Nutr 1996;63:925932.

30. Vidgren HM, Agren JJ, Schwab U, Rissanen T, Hänninen $O$, and Uusitupa M. Incorporation of n-3 fatty acids into plasma lipid fractions, and erythrocte membranes and platelet during dietary supplementation with fish, fish oil, and docosahexaenoic acid-rich oil among healthy young men. Lipids 1997;32:697-705.

31. Bézard J, Blond JP, Bernard $A$, and Clouet $P$. The metabolism and availability of essential fatty acids in animal and human tissues. Reprod Nutr Dev 1994;34:539-568.

32. Schulz H. Beta oxidation of fatty acids. Biochim Biophys Acta 1991;1081:109-120.

33. Osmundsen $\mathrm{H}$, Bremer $\mathrm{J}$, and Pedersen $\mathrm{Jl}$. Metabolic aspects of peroxisomal $\beta$-oxidation. Biochim Biophys Acta 1991;1085:141-158.

34. Christensen $E$, Woldseth $B$, Hagve TA, et al. Peroxisomal $\beta$-oxidation of polyunsaturated long chain fatty acids in human fibroblasts. The polyunsaturated and saturated long chain fatty acids are retroconverted by the same acyl-CoA oxidase. Scand J Clin Lab Invest 1993;53:6174.

35. Jones PJH, Pencharz PB, and Clandinin MT. Whole body oxidation of dietary fatty acids: implications for energy utilization. Am J Clin Nutr 1985;42:769-777.

36. Emken EA, Rohwedder WK, Dutton $\mathrm{HJ}$, et al. Incorporation of deuterium labeled cis- and trans-9-octadecenoic acid in humans: plasma, erythrocyte, and platelet neutral lipids. Metabolism 1979;28:575-583.

37. Emken EA, Dutton HJ, Rohwedder WK, Rakoff $H$, and Adlof RO. Distribution of deuteriumlabeled cis and trans-12-octadecemoic acids in human plasma and lipoprotein lipids. Lipids 1980;15:864-871. 
38. Emken EA, Adlof RO, Rohwedder WK, and Gulley RM. Incorporation of deuterium-labeled trans- and cis-13-octadecenic acids in human plasma lipids. J Lipid Res 1983;24:34-46.

39. Emken EA, Rohwedder WK, Adlof RO, DeJarlais W, and Gulley RM. Absorption and distribution of deuterium-labeled trans- and cis-11-octadecenoic acid in human plasma and lipoprotein lipids. Lipids 1986;21:589-595.

40. Emken EA, Adlof RO, Rohwedder WK, and Gulley RM. Incorporation of trans-8- and cis-8octadecenoic acid isomers in human plasma and lipoprotein lipids. Lipids 1989;24:61-9.

41. Koletzko B, Sauerwald T, and Demmelmair H. Safety of stable isotope use. Eur J Pediatr 1997;156:12-17.

42. Goodman KJ, and Brenna JT. High sensitivity tracer detection using high-precision gas chromatography-combustion isotope ratio mass spectrometry and highly enriched $\left[\mathrm{U}-{ }^{13} \mathrm{C}\right]-$ labeled precursors. Anal Chem 1992;64:1088-1095.

43. Schoeller DA, Schneider JF, Solomons NW, Watkins JB, and Klein PD. Clinical diagnosis with the stable isotope ${ }^{13} \mathrm{C}$ in $\mathrm{CO}_{2}$ breath tests: methodology and fundamental considerations. $J$ Lab Clin Med 1977;90:412-421.

44. Li J, Ding SF, Habib NA, Fermor BF, Wood CB, and Gilmour RS. Partial characterization of a CDNA for human stearoyl-CoA desaturase and changes in its mRNA expression in some normal and malignant tissues. Int J Cancer 1994;57:348-352.

45. Cunnane SC, Keeling PWN, Thompson RPH, and Crawford MA. Linoleic acid and arachidonic acid metabolism in human peripheral blood leucocytes: comparison with the rat. Brit $J$ Nutr 1984;51:209-217.

46. Hulshof KFAM, van Erp-Baart MA, Anttolainen $M$, et al. Intake of fatty acids in Western Europe with emphasis on trans fatty acids: The TRANSFAIR study. Eur $J$ Clin Nutr 1999;53:143-157.

47. O'Keefe S, Gaskins-Wright S, Wiley $V$, and Chen IC. Levels of trans geometrical isomers of essential fatty acids in some unhydrogenated U.S. vegetable oils. J Food Lipid 1994;1:165176.

48. Grandgirard A, Bourre JM, Julliard F, et al. Incorporation of trans long-chain n-3 polyunsaturated fatty acids in rat brain structures and retina. Lipids 1994;29:251-258.

49. Castelli WP, Garrison RJ, Wilson PWF, Abbott RD, Kalousdian S, and Kannel WB. Incidence of coronary heart disease and lipoprotein cholesterol levels. JAMA 1986;265:2835-2838.

50. Kinosian B, Glick H, and Garland G. Cholesterol and Coronary Heart Disease: predicting risks by levels and ratios. Ann Intern Med 1994;121:641-647.

51. Austin MA. Plasma triglyceride and coronary heart disease. Arterioscler Thromb 1991;11:2-14.

52. Katan MB, Mensink RP, and Zock PL. Trans fatty acids and their effects on lipoproteins in humans. Ann Rev Nutr 1995;15:473-493. 



\section{2}

The metabolism of linoleic acid in healthy subjects after intake of a single dose of ${ }^{13} \mathrm{C}$ linoleic acid

SHF Vermunt, RP Mensink, AMG Simonis, AJM Wagenmakers, G Hornstra

Based on: European Journal of Clinical Nutrition, 2001;55:321-326 


\section{ABSTRACT}

The objective of the study was to investigate the in vivo oxidation of ${ }^{13} \mathrm{C}$ linoleic acid $\left({ }^{13} \mathrm{C} 18: 2 \mathrm{n}-6\right)$ and its conversion into longer chain polyunsaturates (LCPs) in healthy subjects. Blood samples were collected from six subjects, three men and three women, before (fasted) and 7, 11 (non-fasted), 24, 48, 72, 168 and 336 hours (fasted) after ingestion of a single bolus of $45 \mathrm{mg}$ uniformly labeled ${ }^{13} \mathrm{C}$ linoleic acid dissolved in $8 \mathrm{~g}$ olive oil. In three subjects, breath was also sampled and $\mathrm{CO}_{2}$ production measured every hour during the first 12 hours. Subjects consumed their habitual diets. Plasma ${ }^{13} \mathrm{C}$ enrichments were measured by gas chromatographycombustion-isotope ratio mass spectrometry and fatty acid compositions by gas chromatography coupled with a flame ionization detector.

The tracer/tracee ratio (TTR) of C18:2n-6 in plasma total lipids was already increased 5 hours after tracer intake. The mean peak amount $\left( \pm\right.$ sem) of ${ }^{13} \mathrm{C} 18: 2 \mathrm{n}-6$ (3.4 $\pm 0.8 \mathrm{mg} ; 7.6 \%$ of tracer dose) was found after about 17 hours, ${ }^{13} \mathrm{C} 18: 3 \mathrm{n}-6$ (0.018 $\pm 0.008 \mathrm{mg} ; 0.04 \%$ of tracer dose) after 7 to 48 hours, and ${ }^{13} \mathrm{C} 20: 3 \mathrm{n}-6(0.028$ $\pm 0.011 \mathrm{mg} ; 0.06 \%$ of tracer dose) after 48 to 336 hours. Time to peak TTRs of arachidonic acid (C20:4n-6) varied between subjects and peak amounts were on average $0.05 \%$ of tracer dose. The proportion of ${ }^{13} \mathrm{C}$ linoleic acid recovered in breath after 12 hours ranged between $16.8 \%$ and $25.1 \%$.

These findings suggest that a single bolus of $45 \mathrm{mg}{ }^{13} \mathrm{C}$ linoleic acid can be used to study the oxidation of ${ }^{13} \mathrm{C}$ linoleic acid. However, because of the low TTRs for $\mathrm{C} 20: 4 \mathrm{n}-6$, a higher dose is recommended for studying the conversion of ${ }^{13} \mathrm{C}$ linoleic acid into arachidonic acid. In addition, since only about $35 \%$ of the tracer was found in plasma total lipids and as ${ }^{13} \mathrm{CO}_{2}$ in breath, it might be necessary to study other accessible lipid fractions as well to determine the overall conversion of linoleic acid. 


\section{INTRODUCTION}

Arachidonic acid (C20:4n-6) is a major precursor of eicosanoids, which have important physiological and pathological functions in humans like in the regulation of inflammatory processes, immunological reactions and platelet aggregation. Arachidonic acid can be derived from the diet, but can also be synthesized, mainly in the liver, by alternate desaturation and elongation of dietary linoleic acid (C18:2n-6). These conversion reactions, however, have been investigated mainly in in vitro and animal studies. To what extent linoleic acid is converted into its longer chain more unsaturated metabolites in man is only partially known.

A few studies have examined the in vivo metabolism of linoleic acid in humans. In 1967, Nichaman et al. reported the in vivo oxidation and conversion of ${ }^{14} \mathrm{C}$ labeled linoleic acid into arachidonic acid in normo- and hyperlipidemic males (1). More recently, the conversion of deuterated linoleic acid has been demonstrated in three human studies (2-4). In these studies, however, large doses of deuterated linoleic acid were administered, which may have decreased the dietary $n-3$ to $n-6$ fatty acid ratio considerably. Because linoleic acid and $\alpha$-linolenic acid compete for the same $\Delta 6$ desaturase, the key enzyme in the conversions of linoleic and $\alpha$ linolenic acids into their respective longer chain polyunsaturated fatty acids (LCPS), high doses of labeled linoleic acid may have an unwanted impact on conversion reactions and, consequently, substrate inhibition may occur (2).

Other previous studies have used ${ }^{13} \mathrm{C}$ labeled linoleic acid to investigate in lactating women linoleic acid oxidation and the appearance of $n-6$ fatty acids in milk (5). Also, the conversion of ${ }^{13} \mathrm{C}$ linoleic acid has been studied in infants (6-10). How the results in these special groups compare to those of the general population is not known. In addition, previous studies did not combine the conversion and appearance in plasma, and oxidation of ${ }^{13} \mathrm{C}$ linoleic acid. Therefore, the aim of this study is to examine both oxidation of ${ }^{13} \mathrm{C}$ linoleic acid and its conversion into LCPs in normal healthy adults.

\section{SUBJECTS AND METHODS}

\section{Subjects}

Six healthy volunteers, three men and three women, participated in this study. The subjects were aged between 21 and 30 years (mean \pm sem; $25.7 \pm 1.2$ years), weighed 58.1 to $78.1 \mathrm{~kg}$ (mean $68.3 \pm 3.3 \mathrm{~kg}$ ) and had body mass indexes (BMI) between 18.8 and $28.3 \mathrm{~kg} / \mathrm{m}^{2}$ (mean $22.2 \pm 1.3 \mathrm{~kg} / \mathrm{m}^{2}$ ). None of the subjects used medication known to affect lipid metabolism. All subjects were apparently healthy, as indicated by a general questionnaire. Three of the participants smoked, one man and two women. Furthermore, two women used oral contraceptives. The protocol had 
been approved by the local ethical committee and all subjects gave their written informed consent. The study was performed during the summer of 1996.

\section{Experimental design}

After an overnight fast, subjects came to the department at 8.00 a.m. First, a blood sample of $10 \mathrm{ml}$ was collected. Thereafter, the $\mathrm{CO}_{2}$ production of three subjects was measured by indirect calorimetry (Sensormedics 2900; Sensormedics, Anaheim, CA, USA or Oxycon $\beta$; Mijnhardt, the Netherlands), after which a breath sample was taken. Breath samples were stored in vacutainers (Becton \& Dickinson, Meylan, France). All six subjects then received a single bolus of uniformly labeled ${ }^{13} \mathrm{C}$ linoleic acid (isotopic purity $>98 \%{ }^{13} \mathrm{C} 18: 2 \mathrm{n}-6$, chemical purity $>95 \%$; Martek Biosciences Corporation, Columbia, MD) as methylester at a dose of $45 \mathrm{mg}$ dissolved in $8 \mathrm{~g}$ olive oil. Blood samples were collected every 2 hours, and breath samples (three subjects) hourly during the first 12 hours. Further fasting blood samples were collected after $24,48,72,96$ and 168 hours, and after 336 hours a final blood sample was collected.

Two hours after receiving the ${ }^{13} \mathrm{C}$ linoleic acid, subjects were allowed to eat breakfast ad libitum. During the first day, they stayed at the department and food, which subjects were allowed to consume ad libitum, was available for the whole day. Use of coffee or drinks containing caffeine was prohibited during the first day only, because of the possible stimulating effect of caffeine on lipolysis and lipid oxidation (11).

\section{Blood sampling and analysis}

Until 12 hours after ${ }^{13} \mathrm{C}$ linoleic acid administration, blood was sampled in an EDTA containing tube through a Teflon catheter (Baxter Quick Cath, Dupont, Ireland) or in a vacuum tube using a 1.2-mm needle (Strauss Kanule; Luer, Wächtersbach, Germany) with the volunteer in a recumbent position. Subjects were free to choose the method of sampling. The catheter was flushed every hour with $1 \mathrm{ml}$ of a heparin solution (0.5 IU heparin-sodium; Leo Pharmaceutical Products BV, Weesp, the Netherlands). The other fasting blood samples were taken with a vacuum tube. Plasma for ${ }^{13} \mathrm{C}$ enrichment analyses and analyses of fatty acid composition of plasma total lipids was obtained by centrifugation at $2000 \times \mathrm{g}$ for 15 minutes at $4^{\circ} \mathrm{C}$, within one hour of venipuncture. Plasma samples were quickly snap-frozen and stored at $-80^{\circ} \mathrm{C}$.

Lipids from plasma were extracted (12), using tri-heptadecanoic acid (C17:0) as an internal standard. Thereafter, lipid extracts were hydrolyzed and the resulting fatty acid methylated (13). The absolute fatty acid composition in plasma total lipids was analyzed using a gas chromatograph with a flame ionization detector (GC/FID) (Perkin Elmer, Norwalk, Connecticut, USA) as described elsewhere (14).

${ }^{13} \mathrm{C}$ Enrichments of individual fatty acid methyl esters (FAMEs) in total lipids from plasma and in breath were analyzed with a gas chromatograph (Varian 3400) coupled with an isotope ratio mass spectrometer (GC-C-IRMS; Finnigan MAT 252, 
Bremen, Germany) via a combustion interface. Samples were injected on a $50 \mathrm{~m}$ column (BPX70, $0.33 \mathrm{~mm}, 0.25 \mu \mathrm{m}$ film thickness; SGE, Austin, Texas, USA) at a temperature of $250^{\circ} \mathrm{C}$. Helium gas was used as a carrier (injector inlet pressure 124 $\mathrm{kPa}$ ). Enrichments of C18:2n-6, C18:3n-6, C20:3n-6, C20:4n-6, C22:4n-6 and $\mathrm{C} 22: 5 \mathrm{n}-6$ were determined in one run. The GC-oven was programmed at $160^{\circ} \mathrm{C}$ for $10 \mathrm{~min}$ (rise of $1^{\circ} \mathrm{C} \mathrm{min}$ ), then $190^{\circ} \mathrm{C}$ for $14 \mathrm{~min}$ (rise of $30^{\circ} \mathrm{C} \mathrm{min}^{-1}$ ), and finally $260^{\circ} \mathrm{C}$ for $25 \mathrm{~min}$.

\section{Calculations}

The difference between the tracer/tracee ratio $\left(T T R ;{ }^{13} \mathrm{C} /{ }^{12} \mathrm{C}\right.$ ratio) of the individual FAMEs and a known reference standard was expressed as the delta $\left(\delta^{13} \mathrm{C}\right)$. The true TTR of the FAME was then calculated by normalizing the isotopic enrichment $\left(\delta^{13} \mathrm{C}\right)$ against the international standard Pee Dee Belemate limestone (PDB), which has a TTR of 0.0112372 . The concentration of a ${ }^{13} \mathrm{C}$ labeled fatty acid was calculated with the true TTR and the plasma concentration of that particular fatty acid. It was assumed that during fatty acid elongation the two carbon-atom fragments added after elongation were not enriched above background. Absolute amounts (in $\mathrm{mg}$ ) of plasma fatty acids in the body were calculated based on a plasma volume of $4.5 \%$ of body weight (15).

Recovery of ${ }^{13} \mathrm{C}$ in breath derived from ${ }^{13} \mathrm{C}$ linoleic acid during the first 12 hours after tracer intake was calculated from the TTR in breath and the absolute $\mathrm{CO}_{2}$ production.

Values of subjects were averaged, and presented as means \pm standard errors.

\section{RESULTS}

On the basis of the first three subjects, whose results are presented in figure 2.1 , it was decided to measure the ${ }^{13} \mathrm{C}$ enrichments of LCPs in plasma total lipids only at $t=0,7$ (plasma of $t=6$ and $t=8$ hours pooled), 11 (plasma of $t=10$ hours and $t=12$ hours pooled), 24, 48, 72, 168 and 336 hours for the other three subjects so as to reduce the number of analyses to a more manageable number. In order to compare the results of the first three subjects with the others, the data from $t=6$ hours and $t=8$ hours and from $t=10$ hours and $t=12$ hours were averaged. 


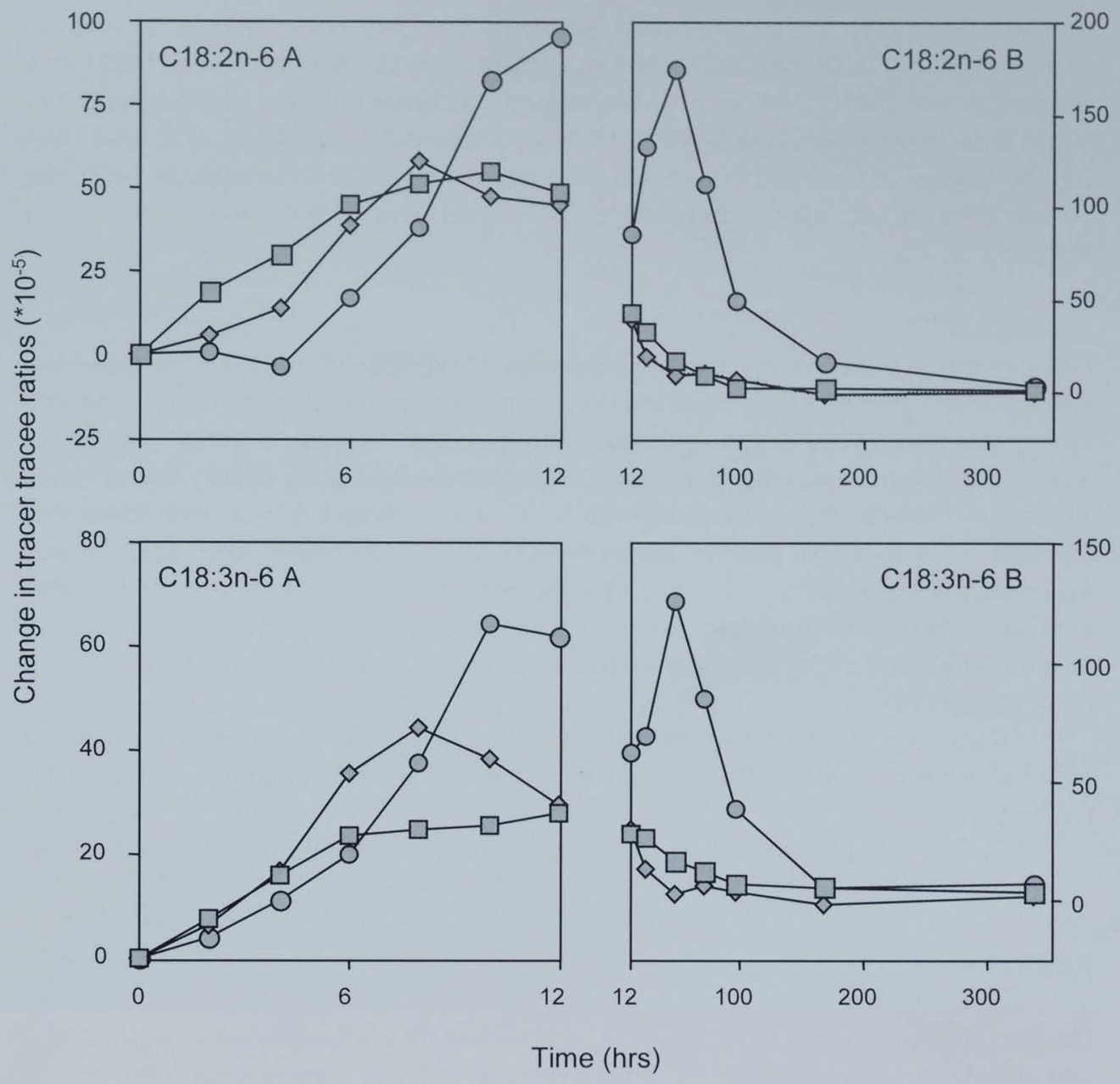

Figure 2.1 Plasma ${ }^{13} \mathrm{C}$ enrichments, corrected for baseline values, of $C 18: 2 n-6$ and $C 18: 3 n-6$ after a single dose of ${ }^{13} \mathrm{C}$ linoleic acid for three subjects over the first 12 hours $(A)$ and in the period between 12 and 336 hours (B)

Tracer/tracee ratios

Peak tracer/tracee ratios (TTR) of C18:2n-6 in plasma total lipids were obtained within the first 12 hours for five subjects and after 48 hours for one subject, with a mean of $107.8 * 10^{-5} \pm 22.6 * 10^{-5}$ after 17 hours (median 11 hours; table 2.1). Mean peak TTR was the highest for C18:2n-6. Peak TTRs of C18:3n-6 were reached after 7 to 48 hours, with a mean of $46.3 * 10^{-5} \pm 16.9 * 10^{-5}$ after 25 hours (median 18 hours). Peak TTRs of C20:3n-6 were reached after 48 to 72 hours for five subjects 
and after 336 hours for one subject, and was on average $16.3 * 10^{-5} \pm 5.0 * 10^{-5}$. Time to peak TTRs of $\mathrm{C} 20: 4 n-6$ varied between the subjects and were rather low. TTRs of C22:4n-6 and C22:5n-6 were very low as well, and TTRs exceeding background enrichments were observed in three subjects only.

Table 2.1 Mean ( \pm sem) peak tracer/tracee ratios (TTR) and time to peak TTR (hours) of C18:2n-6 and its longer chain more unsaturated fatty acids after a bolus dose of $45 \mathrm{mg}{ }^{13} \mathrm{C}$ linoleic acid $(n=6)$

\begin{tabular}{|c|c|c|c|c|c|c|c|c|c|c|}
\hline \multirow{3}{*}{$\frac{\text { Fatty acid }}{C 18: 2 n-6}$} & \multicolumn{5}{|c|}{$\operatorname{TTR}\left({ }^{\star} 10^{-5}\right)$} & \multicolumn{5}{|c|}{ Time to peak TTR (hours) } \\
\hline & \multirow{2}{*}{$\begin{array}{l}\text { Mean } \\
107.8\end{array}$} & \multirow{2}{*}{$\begin{array}{l} \pm \text { sem } \\
\pm 22.6\end{array}$} & \multicolumn{3}{|c|}{ Range } & \multirow{2}{*}{$\frac{\text { Mean } \pm}{16.5 \pm}$} & \multirow{2}{*}{$\begin{array}{r}\text { sem } \\
6.3\end{array}$} & \multicolumn{2}{|r|}{ Range } & \multirow{2}{*}{$\frac{\text { Median }}{11}$} \\
\hline & & & 48.7 & to & 196.6 & & & 7 & to 48 & \\
\hline$C 18: 3 n-6$ & 46.3 & \pm 16.9 & 14.3 & to & 125.7 & $24.8 \pm$ & $\pm \quad 7.7$ & 7 & to 48 & 18 \\
\hline$C 20: 3 n-6$ & 16.3 & \pm 5.0 & 6.6 & to & 39.0 & $104.0 \pm$ & $\pm \quad 46.6$ & 48 & to 336 & 60 \\
\hline$C 20: 4 n-6$ & 3.0 & \pm 0.6 & 1.1 & to & 5.3 & $154.3 \pm$ & $\pm \quad 62.3$ & 7 & to 336 & 120 \\
\hline$C 22: 4 n-6^{a}$ & 2.5 & \pm 0.5 & 1.5 & to & 3.3 & $75.7 \pm$ & \pm 47.4 & 48 & to 96 & 48 \\
\hline$C 22: 5 n-6^{a}$ & 4.0 & \pm 1.4 & 2.5 & to & 6.8 & $80.0 \pm$ & 16.0 & 11 & to 168 & 96 \\
\hline
\end{tabular}

${ }^{a}$ Detected in three subjects only

\section{Plasma fatty acid concentrations}

Mean fasted $n-6$ fatty acid concentrations in plasma total lipids were the highest for C18:2n-6 (953 $\pm 52 \mathrm{mg} / \mathrm{l} ; 32.54 \pm 1.12 \%$ of total fatty acids) and C20:4n-6 (195 \pm 10 $\mathrm{mg} / \mathrm{l} ; 6.73 \pm 0.40 \%$ of total fatty acids). Mean fasted plasma concentrations were 9.3 $\pm 1.4 \mathrm{mg} / \mathrm{l}(0.31 \pm 0.02 \%$ of total fatty acids) for C18:3n-6, $44.0 \pm 3.0 \mathrm{mg} / \mathrm{l}$ (1.50 \pm $0.09 \%$ of total fatty acids) for C20:3n-6, $6.3 \pm 0.2 \mathrm{mg} / \mathrm{l}(0.22 \pm 0.01 \%$ of total fatty acids) for $\mathrm{C} 22: 4 \mathrm{n}-6$, and $6.9 \pm 0.5 \mathrm{mg} / \mathrm{l}(0.24 \pm 0.03 \%$ of total fatty acids) for c22:5n-6.

Absolute amounts of plasma ${ }^{13} \mathrm{C}$ labeled fatty acids

Absolute amounts (in $\mathrm{mg}$ ) of ${ }^{13} \mathrm{C} 18: 2 \mathrm{n}-6$ started to increase almost directly after tracer intake (figure 2.2). After 168 hours most of the ${ }^{13} \mathrm{C} 18: 2 \mathrm{n}-6$ had disappeared from the plasma, but only after 336 hours values had nearly returned to baseline. Appearance of ${ }^{13} \mathrm{C} 18: 3 \mathrm{n}-6$ in the plasma occurred almost at the same time as that of ${ }^{13} \mathrm{C} 18: 2 \mathrm{n}-6$. At the end of the study, plasma levels of ${ }^{13} \mathrm{C} 18: 3 \mathrm{n}-6$ had almost returned to baseline. The mean amount of plasma ${ }^{13} \mathrm{C} 20: 3 \mathrm{n}-6$ increased slowly over time until after 72 hours, whereafter it declined. After 336 hours, most subjects had still considerable amounts of ${ }^{13} \mathrm{C} 20: 3 \mathrm{n}-6$ in plasma as compared to their peak. ${ }^{13} \mathrm{C} 20: 4 \mathrm{n}-6$ appeared rather quickly in plasma and continued to increase until after 336 hours. Amounts of ${ }^{13} \mathrm{C} 22: 4 n-6$ and ${ }^{13} \mathrm{C} 22: 5 n-6$ were very small, and are, therefore, not shown in figure 2.2 . 

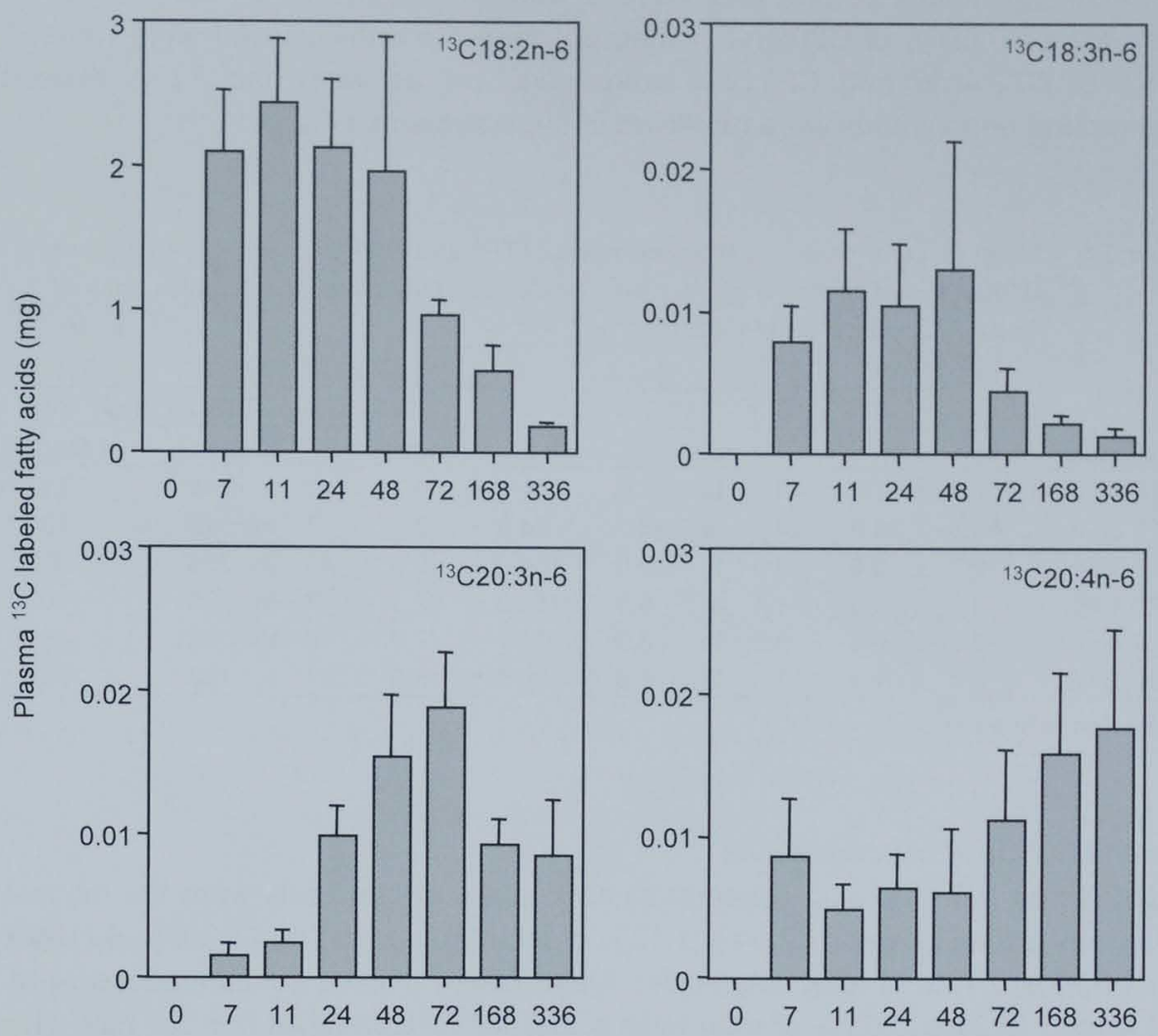

Time (hrs)

Figure 2.2 Mean ( \pm sem) absolute amounts (in mg) of plasma ${ }^{13} \mathrm{C} 18: 2 n-6,{ }^{13} \mathrm{C} 18: 3 n-6,{ }^{13} \mathrm{C} 20: 3 n-6$ and ${ }^{13} \mathrm{C} 20: 4 n-6$ after a single dose of ${ }^{13} \mathrm{C}$ linoleic acid during the course of the study. Values were calculated based on a plasma volume of $4.5 \%$ of body weight (15).

The mean peak absolute amount of ${ }^{13} \mathrm{C} 18: 2 \mathrm{n}-6$ in plasma was $3.4 \pm 0.8 \mathrm{mg}$, which was $7.6 \%$ of the tracer dose (figure 2.3). Peak amounts of ${ }^{13} \mathrm{C} 18: 3 \mathrm{n}-6$ were 0.003 to $0.057 \mathrm{mg}$, with a mean amount of $0.018 \pm 0.008 \mathrm{mg}(0.04 \%$ of tracer dose $)$. The mean peak amount of ${ }^{13} \mathrm{C} 20: 3 \mathrm{n}-6$ was $0.028 \pm 0.011 \mathrm{mg}$, which was only about $0.06 \%$ of the tracer dose. The peak amount of ${ }^{13} \mathrm{C} 20: 3 \mathrm{n}-6$ varied between 0.010 and $0.079 \mathrm{mg}$. Peak amounts of ${ }^{13} \mathrm{C} 20: 4 \mathrm{n}-6$ ranged between 0.009 and $0.048 \mathrm{mg}$, which was on average only $0.04 \%$ of the given dose of ${ }^{13} \mathrm{C}$ linoleic acid. The peak amount of ${ }^{13} \mathrm{C} 18: 3 \mathrm{n}-6$ plus ${ }^{13} \mathrm{C} 20: 3 \mathrm{n}-6$ plus ${ }^{13} \mathrm{C} 20: 4 n-6$ was $0.15 \%$ of the tracer dose and $2.0 \%$ of the peak amount of ${ }^{13} \mathrm{C} 18: 2 \mathrm{n}-6$. 


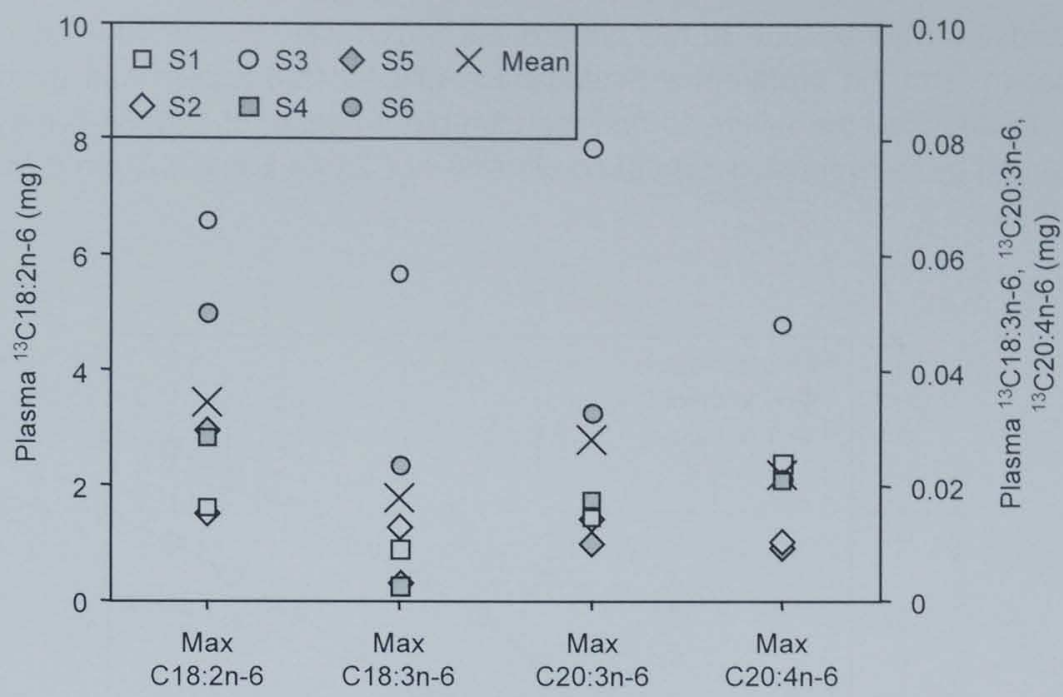

Figure 2.3. Individual ( $\mathrm{S} 1$ to $\mathrm{S} 6$ ) and mean ( \pm sem) peak amounts (in $\mathrm{mg}$ ) of plasma ${ }^{13} \mathrm{C} 18: 2 \mathrm{n}-6$, ${ }^{13} \mathrm{C} 18: 3 \mathrm{n}-6,{ }^{13} \mathrm{C} 20: 3 \mathrm{n}-6$ and ${ }^{13} \mathrm{C} 20: 4 \mathrm{n}-6$ after a single dose of ${ }^{13} \mathrm{C}$ linoleic acid. Values were calculated based on a plasma volume of $4.5 \%$ of subjects body weight (15).

\section{Oxidation}

Breath samples were measured in three subjects. Peaks in ${ }^{13} \mathrm{C}$ enrichment in breath were reached after 3 to 5 hours and ranged from $7 \%$ to $12 \%$ (data not shown). Figure 2.4 shows the recovery of ${ }^{13} \mathrm{C}$ in breath derived from ${ }^{13} \mathrm{C}$ linoleic acid at various time points during the first 12 hours after tracer intake. After 6 hours, total ${ }^{13} \mathrm{C}$ recovery ranged between $11.9 \%$ and $17.4 \%$, while after 12 hours total recovery of the tracer had increased to $16.8 \%$ to $25.1 \%$.

\section{DISCUSSION}

This study demonstrates that conversion of ${ }^{13} \mathrm{C} 18: 2 \mathrm{n}-6$ into ${ }^{13} \mathrm{C} 18: 3 \mathrm{n}-6$ starts almost immediately after tracer intake. The peak TTR of ${ }^{13} \mathrm{C} 18: 3 n-6$ was much higher than that of ${ }^{13} \mathrm{C} 20: 3 n-6$. However, because of the smaller pool of plasma $\mathrm{C} 18: 3 n-6$ relative to $\mathrm{C} 20: 3 n-6$, absolute peak amounts of ${ }^{13} \mathrm{C} 18: 3 n-6$ were lower than those of ${ }^{13} \mathrm{C} 20: 3 \mathrm{n}-6$. The small pool of $\mathrm{C} 18: 3 \mathrm{n}-6$ may be due to the rapid elongation step of $\mathrm{C} 18: 3 n-6$ into $\mathrm{C} 20: 3 n-6$, as suggested from rat studies (16). From animal studies using radioactive isotopes, it is known that $\mathrm{C} 20: 4 n-6$ can be converted into $\mathrm{C} 22: 4 \mathrm{n}-6$ and C22:5n-6 $(16,17)$. However, we hardly found any ${ }^{13} \mathrm{C}$ enrichment in plasma of these latter two fatty acids. This is in agreement with results of Emken et al. $(2,3)$. 
These findings may be due to the preferential $\beta$-oxidation of $C 22: 4 n-6$ rather than esterification, and the preferential esterification of $C 20: 4 n-6$ rather than $\beta$-oxidation (18-20). In addition, the failure to find measurable amounts of C22:5n-6 may have been caused by the very slow rate of conversion of C22:4n-6 into C22:5n-6 as found for rats (16).

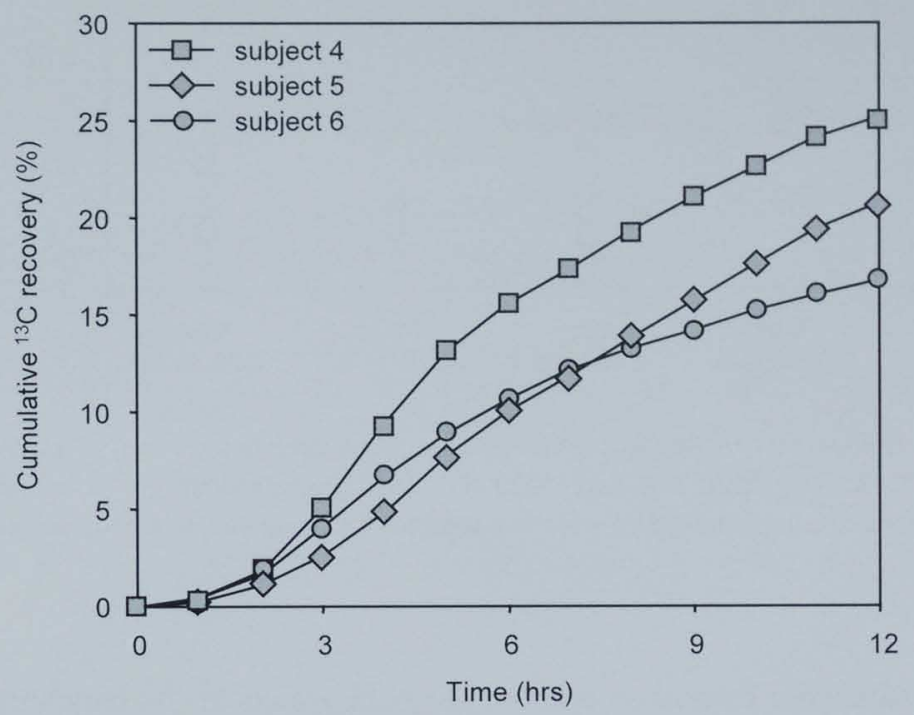

Figure 2.4 Cumulative ${ }^{13} \mathrm{C}$ recovery in breath after a single dose of ${ }^{13} \mathrm{C}$ linoleic acid for three subjects during the first 12 hours

Mean time to peak TTR was 17 hours for $\mathrm{C} 18: 2 n-6$, and 104 hours for C20:3n-6. The mean peaks of these fatty acids, however, were both affected by one extreme value from different subjects. Without these outliers, mean time to peak TTRs were 10 and 58 hours. Medians were 11 and 60 hours, respectively. Peak ${ }^{13} \mathrm{C}$ enrichment of C18:2n-6 in milk of lactating women was reached 12 hours after ingestion of $1 \mathrm{mg}{ }^{13} \mathrm{C}$ linoleic acid/kg body weight (5), which corresponds with our plasma results. Time to peak ${ }^{13} \mathrm{C}$ enrichment of $\mathrm{C} 20: 3 \mathrm{n}-6$ was 12 to 24 hours in milk of lactating women (5). Thus, ${ }^{13} \mathrm{C} 18: 2 \mathrm{n}-6$ seems to appear at the same time in plasma and human milk, while the peak in ${ }^{13} \mathrm{C} 20: 3 n-6$ was reached earlier in human milk (5) as compared to plasma. Appearance of the ${ }^{13} \mathrm{C}$ labeled fatty acids in plasma of lactating women, which is not investigated in the study of Demmelmair et al (5), may however be different from that of non-lactating subjects. 
Peak ${ }^{13} \mathrm{C}$ enrichments in breath were obtained 3 to 5 hours after intake of the labeled linoleic acid, which agree well with the time to peak ${ }^{13} \mathrm{C}$ enrichments in breath after ${ }^{13} \mathrm{C}$ linoleic acid administration to lactating women (5). Total recovery in breath $\mathrm{CO}_{2}$ for lactating women was $18 \%$ to $24 \%$, depending on the week of lactation (5), which is comparable with our results.

In the present study, about $21 \%$ of the ingested ${ }^{13} \mathrm{C}$ linoleic acid was recovered in breath, while the peak amount of ${ }^{13} \mathrm{C}$ linoleic acid in plasma was about $8 \%$. Furthermore, a small percentage was detected as its longer chain metabolites in plasma. Since Emken et al. have demonstrated that on average $92 \%$ of the linoleic acid may be absorbed (2), a large part of the tracer is still missing. Parts of the tracer may be incorporated into membranes or stored in adipose tissue reserves. Recently, it has been demonstrated that many human tissues express $\Delta 5$ and $\Delta 6$ desaturase, of which liver, brain and heart are the most abundant (21). This may thus suggest that these tissues contain part of the tracer as well. Furthermore, one third of the ${ }^{13} \mathrm{CO}_{2}$ derived from tracer oxidation may not be excreted in breath (22). Part of the tracer may be incorporated into products of the tricarboxylic acid cycle or fixated in the bicarbonate pool $(23,24)$.

All participants had received the same dose of ${ }^{13} \mathrm{C}$ linoleic acid. However, amounts of ${ }^{13} \mathrm{C}$ linoleic acid and its ${ }^{13} \mathrm{C}$ labeled LCPS varied considerably between the subjects. In a recent similar study with ${ }^{13} \mathrm{C} \alpha$-linolenic acid (14), we found a significant negative correlation between plasma ${ }^{13} \mathrm{C}$ LCPs and the ${ }^{13} \mathrm{C}$ elimination with breath $\mathrm{CO}_{2}$. In the present study, in the three subjects of whom ${ }^{13} \mathrm{C}$ elimination was known, the subject with the highest amounts of ${ }^{13} \mathrm{C} \mathrm{LCPs} \mathrm{had} \mathrm{also} \mathrm{the} \mathrm{lowest}{ }^{13} \mathrm{C}$ elimination by breath and vise versa. Variation in plasma ${ }^{13} \mathrm{C}$ LCPs between subjects may thus, at least partly, be explained by variation in ${ }^{13} \mathrm{C}$ elimination by breath. Furthermore, time courses of the appearance of ${ }^{13} \mathrm{C}$ labeled fatty acids were different between subjects. In the subject with the highest amounts of ${ }^{13} \mathrm{C}$ labeled $n-6$ fatty acids, time to peak amounts was the longest. Possibly, absorption of essential fatty acids and/or activity of desaturase or elongase enzymes is different from that of the other subjects.

In conclusion, a single bolus of $45 \mathrm{mg}$ of ${ }^{13} \mathrm{C}$ linoleic acid can be used to study the oxidation of ${ }^{13} \mathrm{C}$ linoleic acid. Plasma ${ }^{13} \mathrm{C}$ enrichments of $\mathrm{C} 20: 4 n-6$, however, were rather low and even near detection limit in some subjects. A higher dose of ${ }^{13} \mathrm{C}$ linoleic acid is therefore recommended for the study of the conversion into arachidonic acid. Results of plasma total lipids and ${ }^{13} \mathrm{CO}_{2}$ recovery in breath suggest that a considerable part of the tracer is still missing. In order to detect larger parts of the tracer, other accessible lipid fractions, like erythrocytes should also be included in future research. In addition, since $\Delta 6$ desaturation is the rate-limiting step in the conversion of linoleic and $\alpha$-linolenic acid, measurement of mRNA levels of $\Delta 6$ desaturase, which has been sequenced recently (25), may help to study determinants of the n-3 and n-6 fatty acid metabolism in future research. 


\section{REFERENCES}

1. Nichaman $\mathrm{MZ}$, Olson RE, and Sweeley CC. Metabolism of linoleic acid-1 $-{ }^{14} \mathrm{C}$ in normolipemic and hyperlipemic humans fed linoleate diets. Am J Clin Nutr 1967;20:1070-1083.

2. Emken EA, Adlof RO, and Gulley RM. Dietary linoleic acid influences desaturation and acylation of deuterium-labeled linoleic and linolenic acids in young adult males. Biochim Biophys Acta 1994;1213:277-288.

3. Emken EA, Adlof RO, Duval SM, and Nelson GJ. Effect of dietary arachidonic acid on metabolism of deuterated linoleic acid by adult male subjects. Lipids 1998;33:471-480.

4. Emken EA, Adiof RO, Duval SM, and Nelson GJ. Effect of dietary docosahexaenoic acid on desaturation and uptake in vivo of isotope-labeled oleic, linoleic, and linolenic acids by male subjects. Lipids 1999;34:785-791.

5. Demmelmair $\mathrm{H}$, Baumheuer $\mathrm{M}$, Koletzko $\mathrm{B}$, Dokoupil $\mathrm{K}$, and Kratl G. Metabolism of $\mathrm{U}^{13} \mathrm{C}$ labeled linoleic acid in lactating women. J Lipid Res 1998;39:1389-1396.

6. Demmelmair $H, v$ Schenck $U$, Behrendt $E$, Sauerwald $T$, and Koletzko B. Estimation of arachidonic acid synthesis in full term neonates using natural variation of ${ }^{13} \mathrm{C}$ content. $J$ Pediatr Gastroenterol Nutr 1995;21:31-36.

7. Carnielii VP, Wattimena DJL, Luijendijk IHT, Boerlage A, Degenhart HJ, and Sauer PJJ. The very low birth weight premature infant is capable of synthesizing arachidonic and docosahexaenoic acids from linoleic and linolenic acids. Pediatr Res 1996;40:169-174.

8. Salem N, Wegher B, Mena P, and Uauy R. Arachidonic and docosahexaenoic acids are biosynthesized from their 18-carbon precursors in human infants. Proc Natl Acad Sci USA 1996;93:49-54.

9. Sauerwald TU, Hachey DL, Jensen $C L$, Chen $H$, Anderson RE, and Heird WC. Effect of dietary $\alpha$-linolenic acid intake on incorporation of docosahexaenoic and arachidonic acids into plasma phospholipids of term infants. Lipids 1996;31:131-135.

10. Szitanyi $\mathrm{P}$, Koletzko $\mathrm{B}$, Mydlilova $\mathrm{A}$, and Demmelmair $\mathrm{H}$. Metabolism of ${ }^{13} \mathrm{C}$-labeled linoleic acid in newborn infants during the first week of life. Pediatr Res 1999;45:669-673.

11. Astrup A, Toubro S, Cannon S, Hein P, Breum L, and Madson J. Caffeine: a double-blind, placebo-controlled study of its thermogenic, metabolic, and cardiovascular effects in healthy volunteers. Am J Clin Nutr 1990;51:759-767.

12. Folch J, Lees $M$, and Sloane Stanley G. A simple method for the isolation and purification of total lipids from animal tissues. J Biol Chem 1957;226:497-509.

13. Lepage $G$ and Roy $C C$. Direct transesterification of all classes of lipids in a one-step reaction. $J$ Lipid Res 1986;27:114-120.

14. Vermunt SHF, Mensink RP, Simonis AMG, and Hornstra G. Effects of dietary $\alpha$-linolenic acid on the conversion and oxidation of ${ }^{13} \mathrm{C} \alpha$-linolenic acid. Lipids 2000;35:137-142.

15. Gregersen MI and Rawson RA. Blood volume. Physiol Rev 1959;39:307-342.

16. Bernert JT and Sprecher $H$. Study to determine the role rates of chain elongation and desaturation play in regulating the unsaturated fatty acid composition of rat liver lipids. Biochim Biophys Acta 1975;398:354-363.

17. Mohammed BS, Sankarappa S, Geiger $M$, and Sprecher $H$. Reevaluation of the pathway for the metabolism of 7,10,13,16-docosatetraenoic acid to 4,7,10,13,16-docosapentaenoic acid in rat liver. Arch Biochem Biophys 1995;317:179-184.

18. Verdino B, Blank ML, Privett $O S$, and Lundberg WO. Metabolism of $4,7,10,13,16-$ Docosapentaenoic acid in the essential fatty acid-deficient rat. J Nutr 1964;83:234-238. 
19. Sprecher $\mathrm{H}$. The total synthesis and metabolism of $7,10,13,16$-docosatetraenoate in the rat. Biochim Biophys Acta 1967;144:296-304.

20. Sprecher H, Luthria DL, Mohammed BS, and Baykousheva SP. Reevaluation of the pathways for the biosynthesis of polyunsaturated fatty acids. J Lipid Res 1995;36:2471-2477.

21. Cho HP, Nakamura MT, and Clarke SD. Cloning, expression, and fatty acid regulation of the human $\Delta-5$ desaturase. J Biol Chem 1999;274:37335-37339.

22. Jones AE, Stolinski M, Smith RD, Murphy JL, and Wootton SA. Effect of fatty acid chain length and saturation on the gastrointestinal handling and metabolic disposal of dietary fatty acids in women. Br J Nutr 1999;81:37-43.

23. Sidossis LS, Coggan AR, Gastaldelli A, and Wolfe RR. Pathway of free fatty acid oxidation in human subjects. Implications for tracer studies. J Clin Invest 1995;95:278-284.

24. Leijssen DPC and Elia M. Recovery of ${ }^{13} \mathrm{CO}_{2}$ and ${ }^{14} \mathrm{CO}_{2}$ in human biocarbonate studies: a critical review with original data. Clin Sci 1996;91:665-677.

25. Cho HP, Nakamura MT, and Clarke SD. Cloning, expression, and nutritional regulation of the mammalian $\Delta 6$ desaturase. J Biol Chem 1999;274:471-477. 

Effects of dietary $\alpha$-linolenic acid on the conversion and oxidation of ${ }^{13} \mathrm{C} \alpha$-linolenic acid

SHF Vermunt, RP Mensink, AMG Simonis, G Hornstra

Based on: Lipids 2000;35:137-142 


\section{ABSTRACT}

The effects of a diet rich in $\alpha$-linolenic acid versus an oleic acid rich diet on the oxidation of uniformly labeled ${ }^{13} \mathrm{C} \alpha$-linolenic acid and its conversion into longer chain polyunsaturates (LCPs) were investigated in vivo in healthy human subjects. Volunteers received a diet rich in oleic acid $(n=5)$ or a diet rich in $\alpha$-linolenic acid $(n=7 ; 8.3 \mathrm{gram} /$ day) for 6 weeks prior as well as during the study. After 6 weeks, subjects were given $45 \mathrm{mg}$ of ${ }^{13} \mathrm{C} \alpha$-linolenic acid dissolved in olive oil. Blood samples were collected at $t=0,5,11,24,96$, and 336 hours. Breath was sampled and $\mathrm{CO}_{2}$ production was measured each hour for the first 12 hours.

The mean ( \pm sem) maximal absolute amount of ${ }^{13} \mathrm{C}$-eicosapentaenoic acid (EPA) in plasma total lipids was $0.04 \pm 0.01 \mathrm{mg}$ in the $\alpha$-linolenic acid group, which was significantly lower $(P=0.01)$ than the amount of $0.12 \pm 0.03 \mathrm{mg}{ }^{13} \mathrm{C}$-EPA in the oleic acid group. Amounts of ${ }^{13} \mathrm{C}$-docosapentaenoic acid (DPA) and ${ }^{13} \mathrm{C}$ docosahexaenoic acid (DHA) tended to be lower as well. The mean proportion of labeled $\alpha$-linolenic acid recovered as ${ }^{13} \mathrm{CO}_{2}$ in breath after 12 hours was $20.4 \%$ in the $\alpha$-linolenic acid group and $15.7 \%$ in the oleic acid group, which was not significantly different $(P=0.12)$. The cumulative recovery of ${ }^{13} \mathrm{C}$ from ${ }^{13} \mathrm{C} \alpha$-linolenic acid in breath during the first 12 hours was negatively correlated with the maximal amounts of plasma ${ }^{13} \mathrm{C}$-EPA $(r=-0.58, P=0.047)$ and ${ }^{13} \mathrm{C}$-DPA $(r=-0.63, P=0.027)$, but not of ${ }^{13} \mathrm{C}$ DHA ( $r=-0.49, P=0.108)$.

In conclusion, conversion of ${ }^{13} \mathrm{C} \alpha$-linolenic acid into its LCPs may be decreased on diets rich in $\alpha$-linolenic acid, while oxidation of ${ }^{13} \mathrm{C} \alpha$-linolenic acid is negatively correlated with its conversion into LCPs. In a few pilot samples, low ${ }^{13} \mathrm{C}$ enrichments of n-3 LCPs were observed on a diet rich in EPA/DHA as compared to oleic acid. 


\section{INTRODUCTION}

Eicosapentaenoic acid (EPA; C20:5n-3) and docosahexaenoic acid (DHA; C22:6n-3) are important structural membrane components and play a major role in many physiological processes (1). These longer chain polyunsaturated fatty acids (LCPs) are not only provided by the diet, but can also be formed by alternate desaturation and elongation of $\alpha$-linolenic acid (C18:3n-3), the parent essential fatty acid from the $\mathrm{n}-3$ family. However, it is largely unknown to what extent this happens in man.

From in vitro and rat studies with radioactive isotopes it has been suggested that the conversion of $\alpha$-linolenic acid is positively related to the amount of substrate ( $\alpha$-linolenic acid), but negatively to that of their LCPs (EPA and DHA) $(2,3)$. These results, however, have not been confirmed by others $(4,5)$.

In man, EPA and docosapentaenoic acid (DPA; C22:5n-3) concentrations increase after $\alpha$-linolenic acid consumption $(6,7)$, while DHA concentrations are hardly affected (8). Fatty acid compositions of tissues, however, give no information about the origin of the fatty acids or their availability for conversion reactions. The introduction of stable isotopes has now created better opportunities to examine the in vivo metabolism of essential fatty acids in humans. So far, a few studies with deuterated $\alpha$-linolenic acid in adults (9-11) and in infants (12), and some studies with ${ }^{13} \mathrm{C}$ labeled $\alpha$-linolenic acid in infants (13-15) have been carried out. These studies, however, only focused on the chain elongation and desaturation of $\alpha$-linolenic acid, although it is also possible to measure oxidation at the same time when ${ }^{13} \mathrm{C}$ labeled fatty acids are used.

In the present study, we have therefore investigated the in vivo conversion of uniformly labeled ${ }^{13} \mathrm{C} \alpha$-linolenic acid into its LCPs and its oxidation in healthy adults. In particular, the effects of a diet rich in $\alpha$-linolenic acid versus a diet rich in oleic acid on ${ }^{13} \mathrm{C} \alpha$-linolenic acid metabolism have been examined. Finally, the relationship between the oxidation of ${ }^{13} \mathrm{C} \alpha$-linolenic acid and the conversion into LCPs was studied. The effects of dietary EPA plus DHA on ${ }^{13} \mathrm{C} \alpha$-linolenic acid metabolism were examined in a pilot study.

\section{SUBJECTS AND METHODS}

\section{Subjects}

Fifteen subjects, both men and women (age between 21 and 66 years), who participated in an intervention trial on the effects of $\alpha$-linolenic acid and EPA/DHA on various cardiovascular risk markers (16), were asked to participate in this study. All subjects were healthy as indicated by a medical questionnaire and had fasting serum total cholesterol concentrations below $7.5 \mathrm{mmol} / \mathrm{l}$ and serum triacylglycerols below $3.0 \mathrm{mmol} / \mathrm{l}$. None of the volunteers used medication or a diet known to affect fatty acid metabolism. Five of the participants smoked. Three younger women used oral 
contraceptives, while the elderly women were post menopausal. The protocol had been approved by the local ethical committee and informed written consent was obtained from each volunteer.

\section{Diets and experimental design}

After a run-in period of 3 weeks, in which all subjects consumed an oleic acid rich diet, the subjects were randomly allocated to three groups. The first group received for the next 7 weeks the same diet as during the run-in period $(n=5)$, the second group received a diet rich in $\alpha$-linolenic acid $(n=7)$, while the third group received a diet rich in EPA plus DHA ( $n=3)$. $\alpha$-Linolenic acid and EPA/DHA replaced oleic acid. Fatty acids were provided as margarine from which also pies, cakes and chocolatepaste were prepared. Subjects had to consume $30 \mathrm{~g}$ of the experimental fat daily. In order not to change energy intakes, the volunteers were required to replace their usual margarine, pastries and sandwich spread by the experimental products provided in this study. Subjects in the oleic acid and $\alpha$-linolenic acid groups were not allowed to consume fatty fish during the whole study. Furthermore, subjects were urged not to change their background diets. The fatty acid compositions of the experimental margarines, which were prepared by Unilever Research Vlaardingen, the Netherlands, have been presented elsewhere (16).

During the run-in and the experimental period, subjects recorded their food intake during the whole day for 3 consecutive days, 1 weekend and 2 week days. After the food diary had been checked by a dietitian, foods were coded, and energy and nutrient intakes were calculated using the Dutch food composition table (17).

At week 9 , subjects came to the department at 8.00 a.m. after a fasting period of 12 hours. First, a $10 \mathrm{ml}$ blood sample was taken, whereafter $45 \mathrm{mg}$ of uniformly labeled ${ }^{13} \mathrm{C} \alpha$-linolenic acid (isotopic purity $>95 \%{ }^{13} \mathrm{C} 18: 3 \mathrm{n}-3$ ) was given as a methylester (Martek Biosciences Corporation, Columbia, MD, USA) dissolved in $8 \mathrm{~g}$ olive oil. Subjects were then given a breakfast, which consisted of two slices of white bread with jam. Two hours after ${ }^{13} \mathrm{C} \alpha$-linolenic acid intake, a second blood sample was taken, after which the subjects were allowed to eat and drink according to their respective dietary regimes. During the day, subjects stayed at the department and food was provided for the whole day. Other, non fasting, blood samples were collected 2, 4, 6, 8, 10 and 12 hours after the intake of labeled $\alpha$-linolenic acid, while fasting samples were taken after $24,48,72,96$, and 168 hours. Subjects then returned to their usual diets and one week later a final fasting blood sample was taken at $t=336$ hours. At the same time points of blood sampling (except at $t=336$ hours and during the first day at $t=3,5,7,9$ and 11 hours) a breath sample was taken. For this, subjects breathed for 5 minutes into the SensorMedics (SensorMedics 2900 analyzer, Anaheim, CA, USA) in order to stabilize their breathing. For the next 5 minutes, $\mathrm{CO}_{2}$ production was registered after which a breath sample was taken. Breath samples were stored in vacutainers (Becton \& Dickinson, Meylan, France). 
Blood sampling and analysis

Until 12 hours after ${ }^{13} \mathrm{C} \alpha$-linolenic acid administration, blood $(10 \mathrm{ml})$ was sampled in an EDTA tube through a Teflon catheter (Baxter Quick Cath Dupont, Ireland) or a vacuum tube using a 1.2-mm needle (Strauss Kanule; Luer, Wächtersbach, Germany) with the volunteer in a recumbent position. The catheter was flushed every hour with $1 \mathrm{ml}$ heparin solution (0.5 IU heparin-sodium; Leo Pharmaceutical Products BV, Weesp, the Netherlands). The next fasting blood samples were taken with a vacuum tube. Plasma for ${ }^{13} \mathrm{C}$ enrichment analyses and analyses of fatty acid composition of total plasma lipids was obtained by centrifugation at $2000 \times \mathrm{g}$ for 15 minutes at $4^{\circ} \mathrm{C}$, within one hour of venipuncture. Plasma samples were snap-frozen and stored at $-80^{\circ} \mathrm{C}$.

Lipids from plasma were extracted (18), using tri-heptadecanoate (C17:0) as an internal standard. Thereafter, lipid extracts were hydrolyzed and the resulting fatty acids methylated (19). The absolute fatty acid composition in plasma total lipids was analyzed using a gas chromatograph with a flame ionization detector (GC/FID) (Perkin Elmer Autosystem, Norwalk, Connecticut, USA). Fatty acid methyl esters (FAMEs) were separated using a $50 \mathrm{~m}$ column (CP-SIL88, $0.25 \mathrm{~mm}, 0.20 \mu \mathrm{m}$ film thickness; Chrompack, Middelburg, the Netherlands) with an injection temperature of $300^{\circ} \mathrm{C}$. Helium gas was used as a carrier (injector inlet pressure $130 \mathrm{kPa}$ ). The oven was programmed from $160^{\circ} \mathrm{C}$ to $230^{\circ} \mathrm{C}$ in 3 temperature steps $\left(160^{\circ} \mathrm{C}\right.$ for $10 \mathrm{~min}$, rise of $3.2^{\circ} \mathrm{C} \mathrm{min}^{-1}, 190^{\circ} \mathrm{C}$ for $15 \mathrm{~min}$, rise of $5^{\circ} \mathrm{C} \mathrm{min}^{-1}, 230^{\circ} \mathrm{C}$ for $37 \mathrm{~min}$ ).

${ }^{13} \mathrm{C}$ enrichments of individual FAMEs in total lipids from plasma and of $\mathrm{CO}_{2}$ in breath were analyzed with a gas chromatograph (Varian 3400) coupled to an isotope ratio mass spectrometer (IRMS; Finnigan MAT 252, Bremen, Germany) via a combustion interface. Samples were injected on a $50 \mathrm{~m}$ column (BPX70, $0.33 \mathrm{~mm}$, $0.25 \mu \mathrm{m}$ film thickness; SGE, Austin, Texas, USA) at a temperature of $250^{\circ} \mathrm{C}$. Helium gas was used as a carrier (injector inlet pressure $124 \mathrm{kPa}$ ). For complete separation of the peaks, enrichments of the FAMEs were determined in two separate runs, as shown in the chromatograms in figure 3.1. For $\mathrm{C} 18: 3 n-3, \mathrm{C} 20: 5 n-3$ and $\mathrm{C} 22: 6 \mathrm{n}-3$, the oven was programmed from $185^{\circ} \mathrm{C}$ for $35 \mathrm{~min}$ (rise of $30^{\circ} \mathrm{C} \mathrm{min}{ }^{-1}$ ) to $260^{\circ} \mathrm{C}$ for $33 \mathrm{~min}$ (figure $3.1 \mathrm{~A}$ ), and for $\mathrm{C} 22: 5 \mathrm{n}-3$ from $205^{\circ} \mathrm{C}$ for $20 \mathrm{~min}$ (rise of $30^{\circ} \mathrm{C} \mathrm{min}{ }^{-1}$ ) to $260^{\circ} \mathrm{C}$ for $25 \mathrm{~min}$ (figure $3.1 \mathrm{~B}$ ). The ${ }^{13} \mathrm{C} /{ }^{12} \mathrm{C}$ ratios were determined with a precision of $\delta_{\mathrm{PDB}}<1 \%$, while the reproducibility of the standard was $\delta_{\mathrm{PDB}}<1 \%$. 
Temperature program(A)

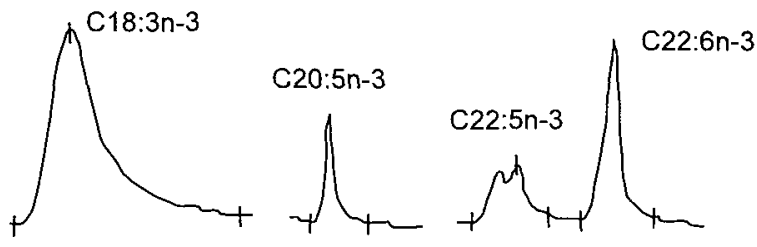

Temperature program $(B)$

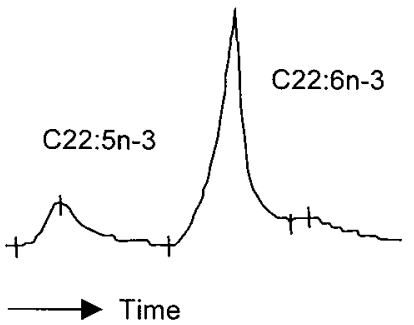

Figure 3.1 Chromatograms showing the complete separation of the $C 18: 3 n-3, C 20: 5 n-3,22: 5 n-3$ and $\mathrm{C} 22: 6 \mathrm{n}-3$ peaks using GC-C-IRMS. Temperature program (A): from $185^{\circ} \mathrm{C}$ for $35 \mathrm{~min}$ (rise of $30^{\circ} \mathrm{C} \mathrm{min}^{-1}$ ) to $260^{\circ} \mathrm{C}$ for $33 \mathrm{~min}$ for separation of $\mathrm{C} 18: 3 \mathrm{n}-3, \mathrm{C} 20: 5 \mathrm{n}-3$ and $\mathrm{C} 22: 6 \mathrm{n}-3$; Temperature program $\left(\mathrm{B}\right.$ ): from $205^{\circ} \mathrm{C}$ for $20 \mathrm{~min}$ (rise of $30^{\circ} \mathrm{C} \mathrm{min}$ ) to $260^{\circ} \mathrm{C}$ for $25 \mathrm{~min}$ for separation of $\mathrm{C} 22: 5 \mathrm{n}-3$.

\section{Calculations}

The difference between the ${ }^{13} \mathrm{C} /{ }^{12} \mathrm{C}$ ratio of the samples and a known reference standard was expressed as the delta $\left(\delta^{13} \mathrm{C}\right)$. The true ratio of the sample was then calculated by normalizing the isotopic enrichment $\left(\delta^{13} \mathrm{C}\right)$, against the international standard Pee Dee Belemate limestone (PDB), which has a ${ }^{13} \mathrm{C} /{ }^{12} \mathrm{C}$ ratio of 0.0112372 . The concentration of a ${ }^{13} \mathrm{C}$ labeled fatty acid was calculated by correction for the plasma concentration of this particular fatty acid. It was assumed that during fatty acid elongation the two carbon-atom fragments added after elongation were not enriched above background. Absolute amounts of total body plasma fatty acids were calculated based on a plasma volume of $4.5 \%$ of body weight (20).

Oxidation of ${ }^{13} \mathrm{C} \alpha$-linolenic acid was calculated from the ${ }^{13} \mathrm{C} /{ }^{12} \mathrm{C}$ ratio in breath and the absolute $\mathrm{CO}_{2}$ production. From the second day after intake of ${ }^{13} \mathrm{C} \alpha$-linolenic acid onwards, the $\mathrm{CO}_{2}$ production was estimated only once a day. Since the determination of total ${ }^{13} \mathrm{CO}_{2}$ production during the day requires regular measurements of both ${ }^{13} \mathrm{C}$ enrichment and $\mathrm{CO}_{2}$ production during the day, ${ }^{13} \mathrm{CO}_{2}$ production was calculated for the first 12 hours only. 


\section{Statistical analyses}

Results for the EPAVDHA group were not statistically analyzed as plasma ${ }^{13} \mathrm{C}$ enrichments in $n-3$ fatty acids of only two subjects could be measured. Values of subjects within the other groups were averaged, and presented as means \pm standard errors. For each subject changes were calculated by subtracting baseline values $(t=0)$. Differences between the oleic acid group and the $\alpha$-linolenic acid group were tested with the Mann Whitney $U$ test. Spearman correlation coefficients were calculated to examine the relationship between the cumulative recovery of ${ }^{13} \mathrm{CO}_{2}$ in breath, derived from $\alpha$-linolenic acid, and the maximal amount of plasma ${ }^{13} \mathrm{C}$ labeled $\mathrm{n}-3$ fatty acids. P-values are two-tailed, and differences were considered statistically significant when $P<0.05$.

\section{RESULTS}

The mean daily energy and nutrient intakes are shown in table 3.1. The mean supplemented daily $\alpha$-linolenic acid intake was significantly higher in the $\alpha$-linolenic acid group $(8.3 \pm 1.3 \mathrm{~g} ; 3.1 \pm 0.4 \%$ of energy) as compared to the oleic acid group. Furthermore, the intake of protein and total polyunsaturated fatty acids differed between the groups.

First, plasma ${ }^{13} \mathrm{C}$ enrichments of all 13 plasma samples of four randomly chosen subjects, one or two from each intervention group, were analyzed. Results of one subject from the $\alpha$-linolenic acid group and one of the oleic acid group are shown in figure 3.2. For $\alpha$-linolenic acid, results are presented for the first 24 hours only, because values had nearly returned to baseline within one day. Results of EPA, DPA and $\mathrm{DHA}$ are presented for 336 hours. Based on these results it was decided to analyze only samples from $t=0,24,96$ and 336 hours for the other 11 subjects so as to reduce the number of analyses to a more manageable quantity. In addition, samples from $t=4$ hours and $t=6$ hours, and from $t=10$ hours and $t=12$ hours were pooled and analyzed. These samples are denoted as $t=5$ hours and $t=11$ hours. In order to compare the results of the first four subjects with the others, the data from $t=4$ hours and $t=6$ hours, and from $t=10$ hours and $t=12$ hours were averaged. 
Table 3.1 Mean ( \pm sem) energy and nutrient intake at baseline on diets rich in oleic acid or $\alpha$ linolenic acid

\begin{tabular}{|c|c|c|c|c|c|c|}
\hline \multirow[b]{2}{*}{ Energy (MJ/day) } & \multicolumn{3}{|c|}{$\begin{array}{l}\text { Oleic acid group } \\
\qquad(n=5)\end{array}$} & \multicolumn{3}{|c|}{$\begin{array}{l}\text { ALA group } \\
(n=7)\end{array}$} \\
\hline & 9.5 & \pm & 1.1 & 9.9 & \pm & 0.6 \\
\hline Protein (En\%) & 15.0 & \pm & 0.5 & 12.4 & \pm & $0.8^{*}$ \\
\hline Fat $(E n \%)$ & 36.0 & \pm & 2.7 & 38.3 & \pm & 0.8 \\
\hline SAFA & 12.1 & \pm & 1.2 & 12.1 & \pm & 0.5 \\
\hline MUFA & 15.5 & \pm & 1.6 & 14.5 & \pm & 0.7 \\
\hline PUFA & 6.0 & \pm & 0.7 & 8.8 & \pm & $0.7^{*}$ \\
\hline Linoleic acid & 4.1 & \pm & 0.7 & 4.5 & \pm & 0.9 \\
\hline Carbohydrates (En\%) & 43.1 & \pm & 3.1 & 46.9 & \pm & 1.6 \\
\hline Alcohol (En\%) & 6.1 & \pm & 1.5 & 2.5 & \pm & 0.7 \\
\hline Cholesterol (mg/MJ) & 16.1 & \pm & 2.1 & 16.8 & \pm & 3.1 \\
\hline Dietary fiber (g/MJ) & 2.6 & \pm & 0.5 & 1.8 & \pm & 0.2 \\
\hline
\end{tabular}

* Denotes a significant difference between groups: $P<0.05$.

\section{Enrichments}

The changes in ${ }^{13} \mathrm{C}$ enrichments of $\alpha$-linolenic acid, EPA, DPA and DHA are shown in figure 3.3. Maximum changes in ${ }^{13} \mathrm{C}$ enrichment of $\alpha$-linolenic acid were reached after 5 hours, followed by a rapid decrease. After 24 hours, changes in ${ }^{13} \mathrm{C}$ enrichment were still about $15 \%$ of the maximal changes. Values had returned to baseline after 336 hours (data not shown). The mean maximum ${ }^{13} \mathrm{C}$ enrichment of $\alpha$ linolenic acid relative to baseline in the $\alpha$-linolenic acid group was only $37 \%$ of that in the oleic acid diet. The ${ }^{13} \mathrm{C}$ enrichment peaks of EPA relative to baseline were much lower and were reached 19 hours later than those of $\alpha$-linolenic acid. In the $\alpha$ linolenic acid group, maximum changes in ${ }^{13} \mathrm{C}$ enrichments of EPA were $43 \%$ of those in the oleic acid group. The ${ }^{13} \mathrm{C}$ enrichments of DPA hardly changed between 24 and 96 hours in the $\alpha$-linolenic acid group. As compared to the oleic acid group, maximum changes in ${ }^{13} \mathrm{C}$ enrichment were $40 \%$ in the $\alpha$-linolenic acid group. After 336 hours, ${ }^{13} \mathrm{C}$ enrichments of EPA and DPA had nearly returned to baseline values in both groups. Ninety-one hours after the ${ }^{13} \mathrm{C}$ enrichment peak of $\alpha$-linolenic acid, ${ }^{13} \mathrm{C}$ enrichment of DHA plateaued in both groups until after 336 hours. The order of appearance of ${ }^{13} \mathrm{C}$ labeled $\alpha$-linolenic acid, EPA, DPA and DHA in plasma was thus in accordance with the conversion of ${ }^{13} \mathrm{C} \alpha$-linolenic acid into its LCPs. 

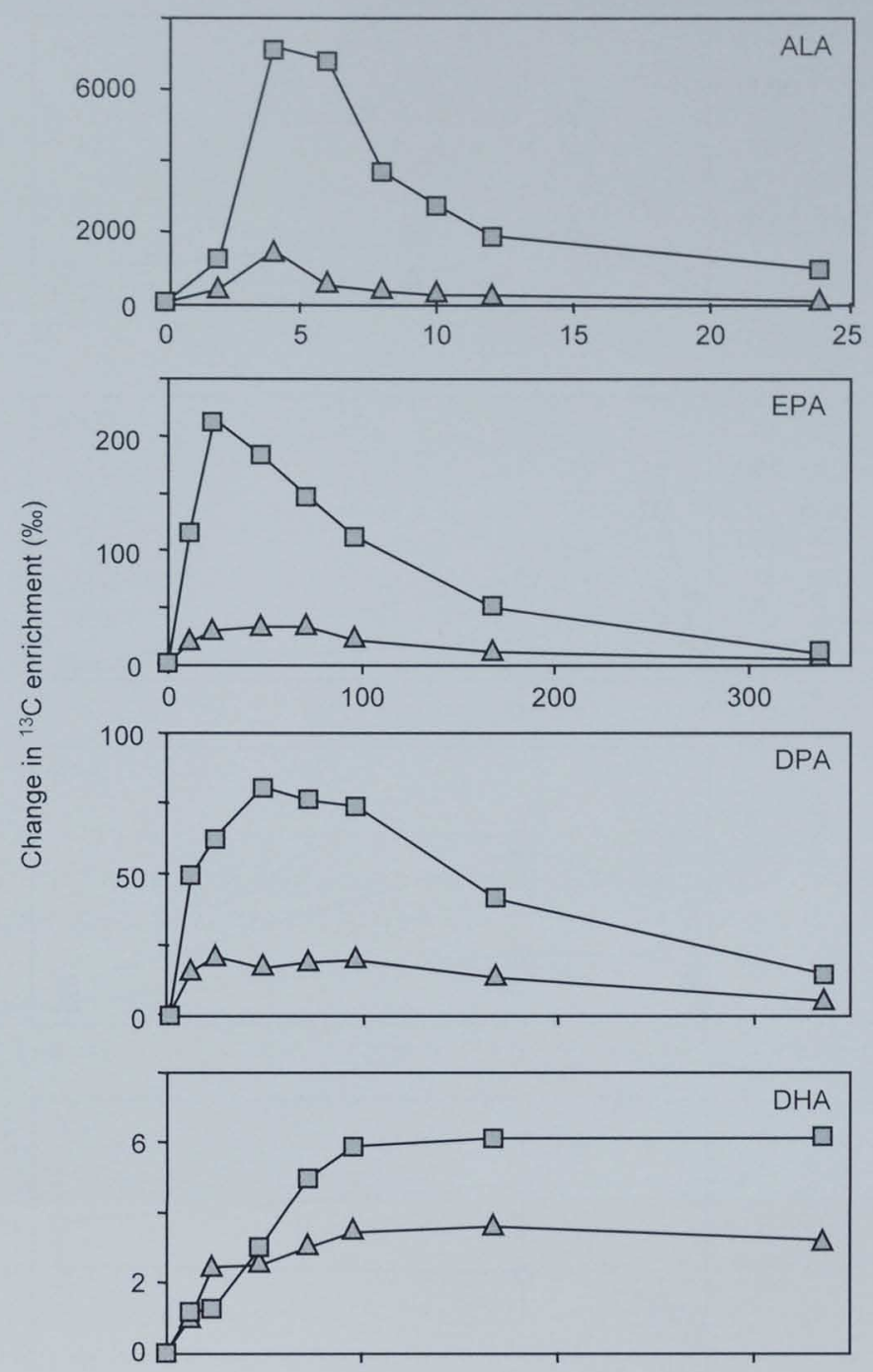

Time (hrs)

Figure 3.2 Changes in plasma ${ }^{13} \mathrm{C}$ enrichments of $\alpha$-linolenic acid, EPA, DPA and DHA after intake of a single dose of ${ }^{13} \mathrm{C} \alpha$-linolenic acid on diets rich in oleic acid ( $\square$ ), or $\alpha$-linolenic acid $(\Delta)$ of two randomly chosen volunteers 

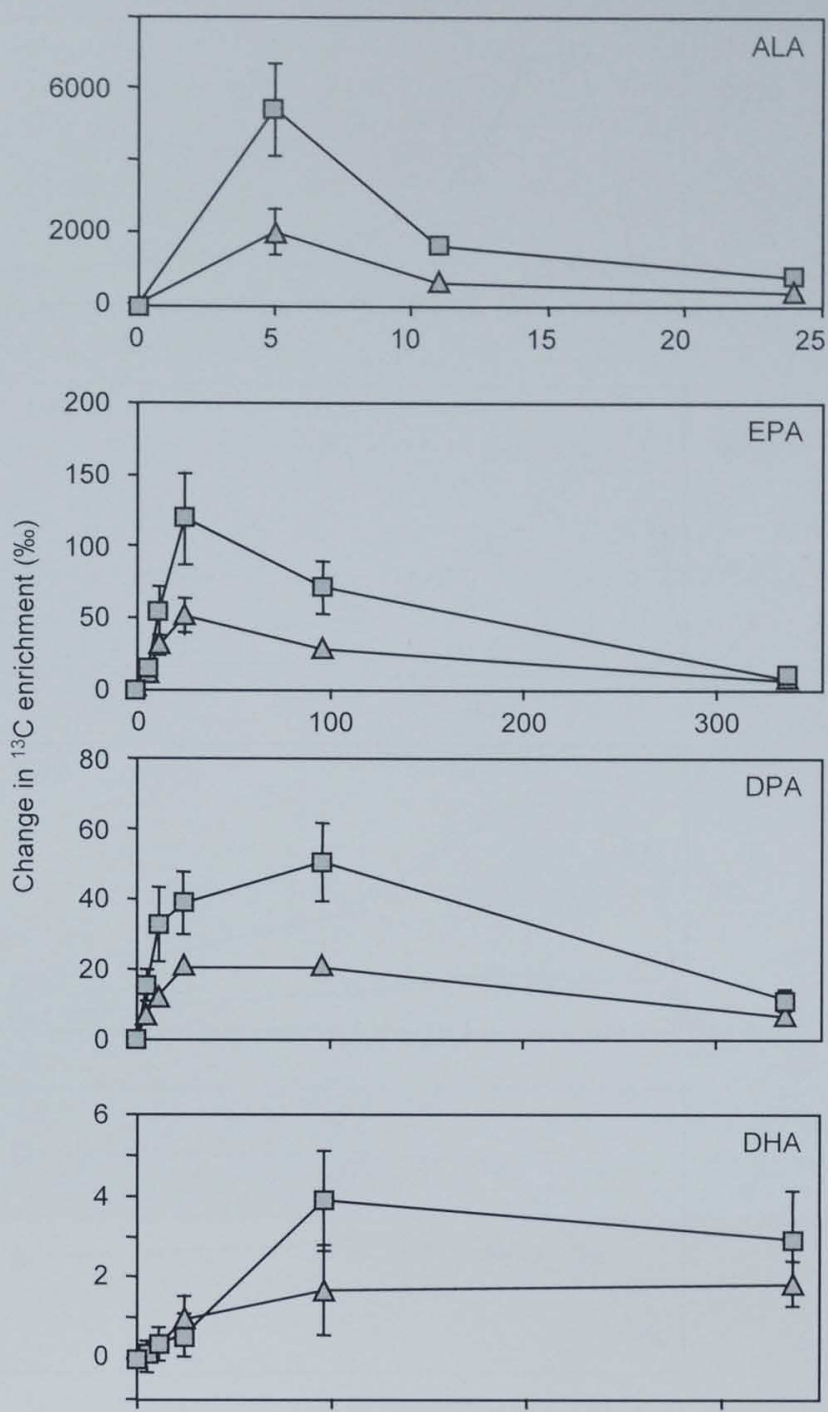

Time (hrs)

Figure 3.3 Mean ( \pm sem) changes in plasma ${ }^{13} \mathrm{C}$ enrichments of $\alpha$-linolenic acid, EPA, DPA and DHA after intake of a single dose of ${ }^{13} \mathrm{C} \alpha$-linolenic acid on diets rich in oleic acid $(\square)$ or $\alpha$-linolenic acid $(\Delta)$

\section{Plasma total fatty acid concentrations}

Proportions of total $\alpha$-linolenic acid in plasma total lipids at baseline were $0.91 \pm$ $0.35 \%$ of total fatty acids in the oleic acid group and $1.12 \pm 0.17 \%$ of total fatty acids 
in the $\alpha$-linolenic acid group. Plasma total EPA, DPA and DHA concentrations were $0.77 \pm 0.12,0.55 \pm 0.06$, and $1.61 \pm 0.12 \%$ of total fatty acids for the oleic acid group and $0.63 \pm 0.11,0.48 \pm 0.07$, and $1.37 \pm 0.13 \%$ of total fatty acids for the $\alpha$-linolenic acid group, respectively.

\section{Absolute amounts of plasma labeled fatty acids}

Figure 3.4 shows the individual maximal absolute amounts of whole body plasma ${ }^{13} \mathrm{C}$ $\mathrm{n}-3$ fatty acids. The mean maximal amounts of plasma ${ }^{13} \mathrm{C} \alpha$-linolenic acid were $4.4 \pm$ $0.7 \mathrm{mg}(9.8 \%$ of the given dose) on the oleic acid diet and $2.8 \pm 0.6 \mathrm{mg}(6.2 \%)$ on the $\alpha$-linolenic acid diet $(P=0.22)$. Mean maximal amounts of ${ }^{13} \mathrm{C}$-EPA were significantly lower in the $\alpha$-linolenic acid group $(0.04 \pm 0.01 \mathrm{mg})$ as compared to the oleic acid group $(0.12 \pm 0.03 \mathrm{mg})(P=0.01)$. Values of ${ }^{13} \mathrm{C}$-DPA and ${ }^{13} \mathrm{C}$-DHA were very low, and were somewhat lower on the $\alpha$-linolenic acid rich diet compared to the oleic acid rich diet $(P=0.17$ and $P=0.17$, respectively).
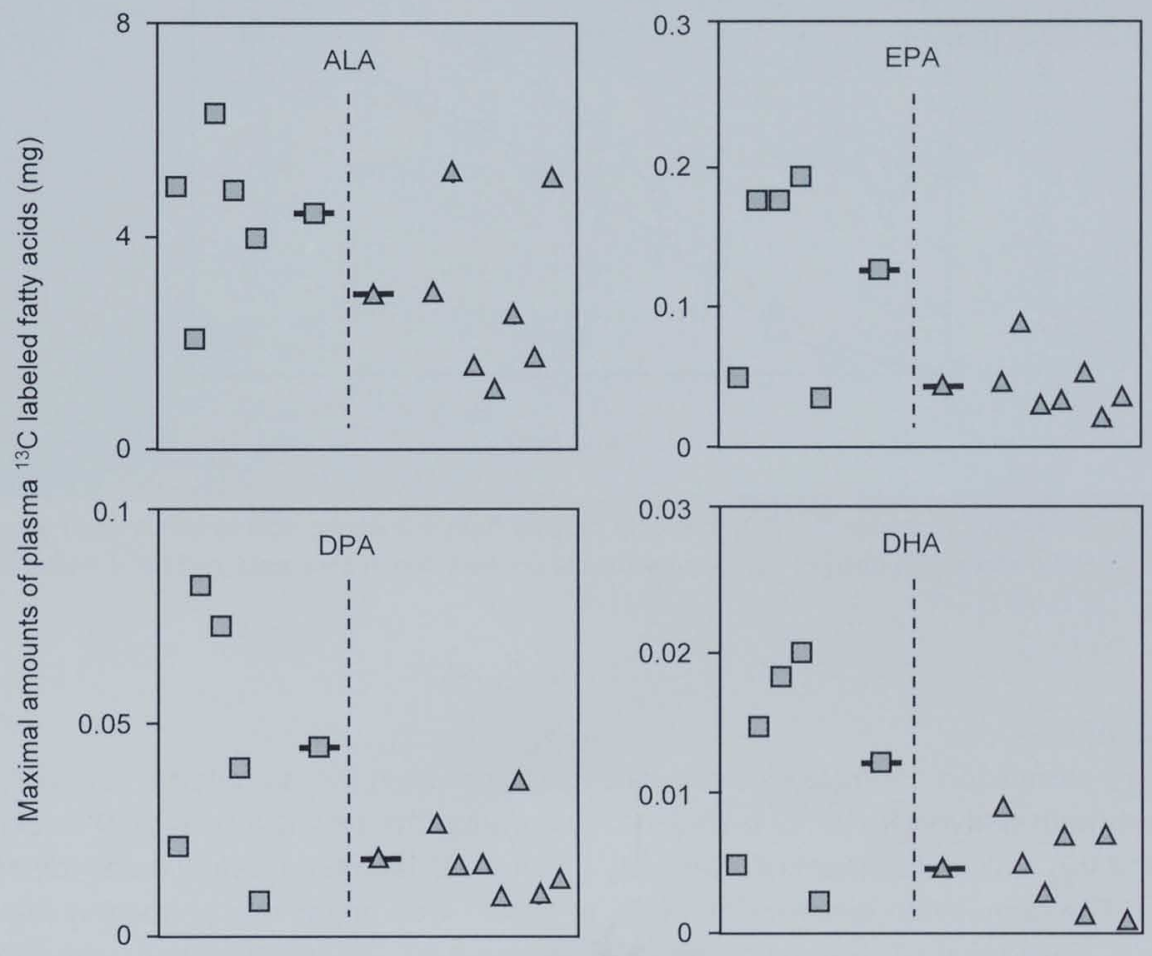

Figure 3.4 Individual absolute amounts of plasma ${ }^{13} \mathrm{C}$ labeled $\alpha$-linolenic acid, EPA, DPA and DHA after intake of a single dose of ${ }^{13} \mathrm{C} \alpha$-linolenic acid on diets rich in oleic acid $(\square$; mean $\square$ - ) or $\alpha$-linolenic acid $(\Delta ;$ mean $-\Delta$ ) 


\section{Oxidation}

During the first 12 hours maximum ${ }^{13} \mathrm{C}$ enrichments in breath were $11.2 \pm 2.5 \%$ in the oleic acid group and $12.6 \pm 1.7 \%$ in the $\alpha$-linolenic acid group, and were reached after about 5 hours. Thereafter, ${ }^{13} \mathrm{C}$ enrichment decreased, until $3.8 \pm 0.5 \%$ and $4.7 \pm$ $0.9 \%$ respectively after 12 hours (data not shown). The cumulative recovery of ${ }^{13} \mathrm{C}$ in breath derived from ${ }^{13} \mathrm{C} \alpha$-linolenic acid during the first 12 hours after intake is presented in figure 3.5. After 12 hours, the mean recovery of ${ }^{13} \mathrm{C}$ was not significantly different on the $\alpha$-linolenic acid rich diet $(20.4 \pm 0.8 \%)$ as compared to the oleic acid rich diet $(15.7 \pm 2.3 \%)(P=0.12)$.

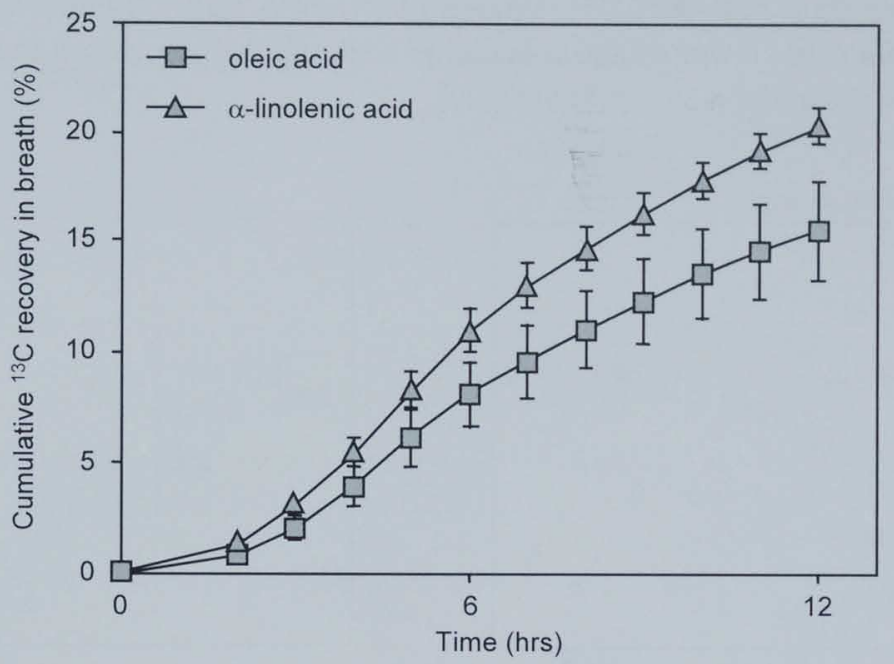

Figure 3.5 Cumulative recovery of ${ }^{13} \mathrm{CO}_{2}$ in breath derived from $\alpha$-linolenic acid (mean \pm sem) after intake of a single dose of ${ }^{13} \mathrm{C} \alpha$-linolenic acid on diets rich in oleic acid $(n=5)$ or $\alpha$-linolenic acid $(n=7)$

\section{Correlations}

Spearman correlation coefficients were calculated between the cumulative recovery of ${ }^{13} \mathrm{C}$ in breath derived from ${ }^{13} \mathrm{C} \alpha$-linolenic acid during the first 12 hours after tracer intake and the maximal amount of total body plasma ${ }^{13} \mathrm{C}$ labeled $\mathrm{n}-3$ fatty acids for all subjects. The cumulative recovery of ${ }^{13} \mathrm{CO}_{2}$ in breath was negatively correlated with plasma ${ }^{13} \mathrm{C}$-EPA $(r=-0.58, P=0.047)$ and ${ }^{13} \mathrm{C}$-DPA $(r=-0.63, P=0.027)$, but not with ${ }^{13} \mathrm{C}$ $\alpha$-linolenic acid $(r=0.05, P=0.888)$ and ${ }^{13} \mathrm{C}-\mathrm{DHA}(r=-0.49, \mathrm{P}=0.108)$. The maximal amounts of plasma ${ }^{13} \mathrm{C} \alpha$-linolenic acid, ${ }^{13} \mathrm{C}$-EPA, ${ }^{13} \mathrm{C}$-DPA and ${ }^{13} \mathrm{C}$-DHA did not correlate with each other. 


\section{EPA/DHA-group}

The daily supplemented intake in the EPA/DHA group was $0.9 \mathrm{~g}(0.5 \%$ of energy) for EPA and $0.5 \mathrm{~g}(0.3 \%$ of energy) for DHA.

Conversion of ${ }^{13} \mathrm{C} \alpha$-linolenic acid could not be measured in one woman of the EPA/DHA group, due to problems during preparation of FAMEs. Maximum changes in ${ }^{13} \mathrm{C}$ enrichment of $\alpha$-linolenic acid $(2427 \%$ ) and EPA $(5.1 \%)$ were reached at the same time as in the $\alpha$-linolenic and oleic acid group, while changes were lower for EPA. Values had returned to baseline after 336 hours. Changes in ${ }^{13} \mathrm{C}$ enrichments of DPA were very low $(2.8 \%)$, and that of DHA were zero.

The proportions of total $\alpha$-linolenic acid, EPA, DPA and DHA in plasma total lipids at baseline were $0.56,3.09,0.71$, and $2.40 \%$, respectively. Maximal amounts of ${ }^{13} \mathrm{C} \alpha$-linolenic acid, ${ }^{13} \mathrm{C}$-EPA, and ${ }^{13} \mathrm{C}$-DPA were $2.1 \mathrm{mg}, 3.4 * 10^{-2} \mathrm{mg}$, and $5.1 * 10^{-3}$ $\mathrm{mg}$, respectively. The cumulative recovery of ${ }^{13} \mathrm{C} \alpha$-linolenic acid in breath during the first 12 hours after intake was $24.8 \%$.

\section{DISCUSSION}

In this study with healthy adults, maximal absolute amounts of labeled EPA in plasma were significantly lower in the $\alpha$-linolenic acid group as compared to the oleic acid group, after intake of a single oral dose of uniformly labeled ${ }^{13} \mathrm{C} \alpha$-linolenic acid. Although maximal absolute amounts of labeled DPA and DHA were not lowered on the $\alpha$-linolenic acid rich diet, our conversion data may suggest that the metabolism of dietary $\alpha$-linolenic acid depends on its intake.

Effects of $\alpha$-linolenic acid on the conversion of $\alpha$-linolenic acid in vivo have never been reported in humans before. Dietary linoleic acid, however, inhibits the conversion of deuterated linoleic acid (9), while a diet rich in arachidonic acid has no significant effect on the conversion of deuterated linoleic acid into arachidonic acid (21). This suggests that the reduced conversion of deuterated linoleic acid is caused by linoleic acid from the diet.

$\alpha$-Linolenic acid is converted into C18:4n-3 by $\Delta 6$ desaturation, subsequently elongated into $\mathrm{C} 20: 4 n-3$, from which EPA can be formed by $\triangle 5$ desaturation. EPA is converted into DHA via two elongation steps, followed by another $\triangle 6$ desaturation step and one cycle of $\beta$-oxidation (22). The $\Delta 6$ desaturation of $\alpha$-linolenic acid has been suggested to be the rate limiting step in the conversion of $\alpha$-linolenic acid. We are unable to decide whether or not $\alpha$-linolenic acid affects the $\Delta 6$ or $\Delta 5$ desaturase activity, because plasma concentrations of $C 18: 4 n-3$ and $C 20: 4 n-3$ were too low to detect ${ }^{13} \mathrm{C}$ enrichments.

Our experimental design did not allow to quantify the conversion of $\alpha$-linolenic acid. One commonly used method is to calculate area under the curves (21). We think, however, that this method is not applicable in our study, since after administration of a single dose of ${ }^{13} \mathrm{C}$ labeled $\alpha$-linolenic acid the distribution of ${ }^{13} \mathrm{C}$ 
n-3 fatty acids over the various tissue lipids have not reached a steady state. In addition, the slow appearance and disappearance rates of the tracer in plasma may indicate that these processes are not sequential, but overlap. Therefore, the area under the curve does not reflect the amount of ${ }^{13} \mathrm{C}$ labeled fatty acids converted (23).

From rat studies it is known that the activity of enzymes involved in the mitochondrial and peroxisomal fatty acid oxidation are increased by dietary EPA (24). The effects of dietary $\alpha$-linolenic acid on $\alpha$-linolenic acid oxidation in men are, however, not known. In the present study, the mean proportion of ${ }^{13} \mathrm{C}$ labeled $\alpha$ linolenic acid recovered as ${ }^{13} \mathrm{CO}_{2}$ in breath after 12 hours was slightly, although not significantly, higher in the $\alpha$-linolenic acid group compared to the oleic acid group, suggesting that the oxidation of ${ }^{13} \mathrm{C} \alpha$-linolenic acid may not be inhibited by dietary $\alpha$ linolenic acid.

We hardly found any ${ }^{13} \mathrm{C}$ enrichment of $n-3$ LCPs on a diet rich in EPA/DHA. However, the plasma total EPA and DHA concentrations were increased on an EPA/DHA rich diet as compared to values on an oleic acid or $\alpha$-linolenic acid rich diet. This suggests that plasma EPA and DHA were mainly derived from dietary sources. Absolute amounts of ${ }^{13} \mathrm{C}$-LCPs were very low, suggesting that conversion of ${ }^{13} \mathrm{C} \alpha$-linolenic acid may be lowered on dietary EPA/DHA. As suggested before (25), the conversion of ${ }^{13} \mathrm{C} \alpha$-linolenic acid may be inhibited by dietary EPA plus DHA. However, because of the small number of subjects in this group, results should be interpreted with caution. Recently, our suggestion was confirmed by Emken et al., who found decreased accumulation of deuterated n-3 LCPs on a diet enriched in DHA (11).

We observed negative correlations between the recovery in breath of ${ }^{13} \mathrm{CO}_{2}$ derived from ${ }^{13} \mathrm{C} \alpha$-linolenic acid after 12 hours and the maximal amounts of plasma ${ }^{13} \mathrm{C}$-EPA and ${ }^{13} \mathrm{C}$-DPA in plasma total lipids. The correlation between the ${ }^{13} \mathrm{CO}_{2}$ recovery and ${ }^{13} \mathrm{C}-\mathrm{DHA}$ amounts failed to reach statistical significance. If results of the EPA/DHA group are, however, also incorporated into the analysis, the negative correlations between the oxidation and conversion of ${ }^{13} \mathrm{C} \alpha$-linolenic acid become stronger. Even ${ }^{13} \mathrm{C}-\mathrm{DHA}$ is now significantly correlated with the ${ }^{13} \mathrm{CO}_{2}$ recovery $\left(r=-0.63, P=0.008\right.$ ). The lack of significantly lower amounts of ${ }^{13} \mathrm{C}-\mathrm{DPA}$ and ${ }^{13} \mathrm{C}-\mathrm{DHA}$ on the $\alpha$-linolenic acid group as compared to the oleic acid group, could also be due to the limited number of subjects.

Except for $\alpha$-linolenic acid, differences in energy and nutrient intakes between the treatment groups were small. We, therefore, suggest that conversion of ${ }^{13} \mathrm{C} \alpha$ linolenic acid into LCPs may be lowered by dietary $\alpha$-linolenic acid, while oxidation of ${ }^{13} \mathrm{C} \alpha$-linolenic acid is negatively correlated with its conversion into LCPs. The preliminary results on an EPA/DHA rich diet showed very low amounts of ${ }^{13} \mathrm{C}$-LCPS, suggesting that conversion of ${ }^{13} \mathrm{C} \alpha$-linolenic acid may also be lowered on dietary EPA/DHA. Therefore, it seems very interesting to examine this issue in more detail in further studies. 


\section{REFERENCES}

1. Kinsella JE. $\alpha$-Linolenic acid: functions and effects on linoleic acid metabolism and eicosanoid-mediated reactions. In: Advances in Food and Nutrition Research (Kinsella JE, ed.) San Diego: Academic Press, 1991:1-184.

2. Bordoni A, Lopez-Jimenez JA, Spanò C, Biagi P, Horrobin DF, and Hrelia S. Metabolism of linoleic and $\alpha$-linolenic acids in cultured cardiomyocytes: Effect of different $n-6$ and $n-3$ fatty acid supplementation. Mol Cell Biochem 1996;157:217-222.

3. Christiansen EN, Lund JS, Rortveit T, and Rustan AC. Effect of dietary n-3 and n-6 fatty acids on fatty acid desaturation in rat liver. Biochim Biophys Acta 1991;1082:57-62.

4. Alaniz de MJT and De Gómez Dumm INT. Role of fatty acids of n-3 and n-6 series on $\alpha-$ linolenic acid desaturation and chain elongation in HTC cells. Mol Cell Biochem 1990;93:7785.

5. Cao JM, Blond JP, Juaneda P, Durand G, and Bézard J. Effect of low levels of dietary fish oil on fatty acid desaturation and tissue fatty acids in obese and lean rats. Lipids 1995;30:825832.

6. Chan JK, McDonald BE, Gerrard JM, Bruce VM, Weaver BJ, and Holub BJ. Effect of dietary $\alpha$-linolenic acid and its ratio to linoleic acid on platelet and plasma fatty acids and thrombogenesis. Lipids 1993;28:811-817.

7. Mantzioris E, James MJ, Gibson RA, and Cleland LG. Differences exist in the relationships between dietary linoleic and $\alpha$-linolenic acids and their respective long-chain metabolites. $A m$ $J$ Clin Nutr 1995;61:320-324.

8. Gerster $\mathrm{H}$. Can adults adequately convert $\alpha$-linolenic acid $(18: 3 n-3)$ to eicosapentaenoic acid (20:5n-3) and docosahexaenoic acid (22:6n-3)? Internat J Vit Nutr Res 1998;68:159-173.

9. Emken EA, Adlof RO, and Gulley RM. Dietary linoleic acid influences desaturation and acylation of deuterium-labeled linoleic and linolenic acids in young adult males. Biochim Biophys Acta 1994;1213:277-288.

10. Salem N, Pawlosky R, Wegher B, and Hibbeln J. In vivo conversion of linoleic acid to arachidonic acid in human adults. Prostaglandins Leukot Essen Fatty Acids 1999;60:407-410.

11. Emken EA, Adlof RO, Duval SM, and Nelson GJ. Effect of dietary docosahexaenoic acid on desaturation and uptake in vivo of isotope-labeled oleic, linoleic, and linolenic acids by male subjects. Lipids 1999;34:785-791.

12. Salem N, Wegher $B$, Mena $P$, and Uauy $R$. Arachidonic and docosahexaenoic acids are biosynthesized from their 18-carbon precursors in human infants. Proc Natl Acad Sci USA 1996;93:49-54.

13. Carnielli VP, Wattimena DJL, Luijendijk IHT, Boerlage A, Degenhart HJ, and Sauer PJJ. The very low birth weight premature infant is capable of synthesizing arachidonic and docosahexaenoic acids from linoleic and linolenic acids. Pediatr Res 1996;40:169-174.

14. Sauerwald TU, Hachey DL, Jensen CL, Huiming C, Anderson RE, and Heird WC. Effect of dietary $\alpha$-linolenic acid intake on incorporation of docosahexaenoic and arachidonic acids into plasma phospholipids of term infants. Lipids 1996;31:131-135.

15. Sauerwald TU, Hachey DL, Jensen $C L$, Chen $H$, Anderson RE, and Heird WC. Intermediates in endogenous synthesis of $\mathrm{C} 22: 6 \omega 3$ and $\mathrm{C} 20: 4 \omega 6$ by term and preterm infants. Pediatr Res 1997;41:183-187.

16. Wensing AGCL, Mensink RP, and Hornstra G. Effects of dietary n-3 polyunsaturated fatty acids from plant and marine origin on platelet aggregation in healthy elderly subjects. Brit $J$ Nutr 1999;82:183-191. 
17. Stichting NEVO. NEVO tabel, Nederlands voedingsstoffenbestand (Dutch food composition table). Den Haag, the Netherlands: Voorlichtingsbureau voor de Voeding, 1989.

18. Folch J, Lees $\mathrm{M}$, and Sloane Stanley $\mathrm{GH}$. A simple method for the isolation and purification of total lipids from animal tissues. J Biol Chem 1957;226:497-509.

19. Lepage $G$, and Roy CC. Direct transesterification of all classes of lipids in a one-step reaction. $J$ Lipid Res 1986;27:114-120.

20. Gregersen Mi, and Rawson RA. Blood volume. Physiol Rev 1959;39:307-342.

21. Emken EA, Adlof RO, Duval SM, and Nelson GJ. Effect of dietary arachidonic acid on metabolism of deuterated linoleic acid by adult male subjects. Lipids 1998;33:471-480.

22. Voss A, Reinhart $M$, Sankarappa $S$, and Sprecher $H$. The metabolism of $7,10,13,16,19-$ docosapentaenoic acid to $4,7,10,13,16,19$-docosahexaenoic acid in rat liver is independent of a 4-desaturase. J Biol Chem 1991;266:19995-20000.

23. Demmelmair $H$, Iser B, Rauh-Pfeiffer A, and Koletzko B. Comparison of bolus versus fractionated oral applications of $\left[{ }^{13} \mathrm{C}\right]$-linoleic acid in humans. Eur J Clin Invest 1999;29:603609.

24. Aarsland $A$, Lundquist $M$, Borretsen $B$, and Berge RK. On the effect of peroxisomal $\beta$ oxidation and carnitine palmitoyltransferase activity by eicosapentaenoic acid in lever and heart from rats. Lipids 1990;25:546-548.

25. Vermunt SHF, Mensink RP, Simonis AMG, and Hornstra G. Effects of age and dietary n-3 fatty acids on the metabolism of $\left[{ }^{13} \mathrm{C}\right]-\alpha$-linolenic acid. Lipids 1999;34:S127. 


\section{4}

Incorporation of ${ }^{13} \mathrm{C} \alpha$-linolenic acid and its longer chain metabolites into human erythrocytes

SHF Vermunt, RP Mensink, AMG Simonis, G Hornstra 


\section{ABSTRACT}

Effects of dietary $\alpha$-linolenic acid versus oleic acid on the incorporation of ${ }^{13} \mathrm{C} \alpha$ linolenic acid and its longer-chain polyunsaturates (LCPS) into human erythrocytes were investigated in vivo in healthy subjects. Volunteers received diets rich in $\alpha-$ linolenic $(n=7)$ or oleic acid $(n=5)$ for 6 weeks prior as well as during the study. After 6 weeks, subjects were given $45 \mathrm{mg}{ }^{13} \mathrm{C} \alpha$-linolenic acid dissolved in olive oil. Blood samples were collected at $t=0,5,11,24,96$, and 336 hours.

Baseline proportions of $\mathrm{C} 18: 3 \mathrm{n}-3$ were higher for the $\alpha$-linolenic acid group $(0.33 \%$ of total fatty acids) than for the oleic acid group $(0.10 \%$ of total fatty acids; $\mathrm{P}<0.0001)$. Median proportions of ${ }^{13} \mathrm{C} 18: 3 n-3,{ }^{13} \mathrm{C} 20: 5 n-3,{ }^{13} \mathrm{C} 22: 5 n-3$ and ${ }^{13} \mathrm{C} 22: 6 n-3$ were highest after $11,48,336$ and 336 hours, respectively. Median proportions in the oleic acid and $\alpha$-linolenic acid group were $1.06 * 10^{-3}$ and 0.83 * $10^{-3} \%$ of total fatty acids for ${ }^{13} \mathrm{C} 18: 3 \mathrm{n}-3,0.31 * 10^{-3}$ and $0.09 * 10^{-3} \%$ of total fatty acids for ${ }^{13} \mathrm{C} 20: 5 n-3,0.17 * 10^{-3}$ and $0.16 * 10^{-3} \%$ of total fatty acids for ${ }^{13} \mathrm{C} 22: 5 n-3$, and $0.04 * 10^{-3}$ and $0.05 * 10^{-3} \%$ of total fatty acids for ${ }^{13} \mathrm{C} 22: 6 \mathrm{n}-3$, respectively. These proportions did not significantly differ between the groups.

We conclude that ${ }^{13} \mathrm{C} \alpha$-linolenic acid and its LCPs are incorporated into human erythrocytes, which is already evident after 5 hours for ${ }^{13} \mathrm{C} \alpha$-linolenic acid. Values of ${ }^{13} \mathrm{C}$ labeled $\alpha$-linolenic acid, ${ }^{13} \mathrm{C} 20: 5 n-3$ and ${ }^{13} \mathrm{C} 22: 5 n-3$ were higher in the oleic acid group, but differences with the $\alpha$-linolenic acid group did not reach statistical significance. From a few pilot samples the effect of a diet rich in eicosapentaenoic plus docosahexaenoic acid was not obvious. Results of a separate experiment, demonstrated that at least a part of the ${ }^{13} \mathrm{C} n-3$ fatty acids was truly incorporated into the erythrocyte and not simply adsorbed as nonesterified fatty acids to the membrane. 


\section{INTRODUCTION}

$\alpha$-Linolenic acid is the ultimate dietary precursor of the longer chain polyunsaturated fatty acids (LCPs) of the n-3 family, eicosapentaenoic acid (EPA) and docosahexaenoic acid (DHA). These essential fatty acids are important for membrane structure as major components of phospholipids, while EPA is also a precursor of eicosanoids. Except for being incorporated into tissue phospholipids or converted into longer chain metabolites and/or into eicosanoids, dietary n-3 fatty acids may also be stored in adipose tissue or oxidized via $\beta$-oxidation $(1,2)$. However, not all of these processes can be extensively investigated in humans, because of the limited accessibility of certain tissues.

One way to investigate the incorporation of dietary essential fatty acids into membranes is to determine the fatty acid composition of erythrocytes, which can be collected in a relatively easy way. From human intervention studies it is now known that fish oil consumption increases the proportions of EPA and DHA in erythrocytes $(3,4)$. In neonatal baboons dietary DHA appeared more efficiently in erythrocytes as compared to DHA derived from dietary $\alpha$-linolenic acid (5). Whether $n-3$ longer chain metabolites derived from dietary $\alpha$-linolenic acid are incorporated into human erythrocytes is not known. In addition, effects of dietary background on the incorporation of $\mathrm{n}-3$ fatty acids into erythrocytes have not been investigated.

In a previous study, we have examined the effects of dietary $\alpha$-linolenic acid on the conversion and oxidation of ${ }^{13} \mathrm{C} \alpha$-linolenic acid in healthy volunteers (6). Based on plasma analyses, we concluded that $\alpha$-linolenic acid is converted into its LCPs in humans. Furthermore, dietary $\alpha$-linolenic acid decreased the absolute amount of EPA derived from ${ }^{13} \mathrm{C} \alpha$-linolenic acid. Because of an increased elimination of ${ }^{13} \mathrm{CO}_{2}$ in breath after tracer ingestion, we concluded that part of the ${ }^{13} \mathrm{C}$ labeled $\alpha$-linolenic acid had been oxidized as well. However, only about $25 \%$ of the tracer was found in plasma total lipids and breath $\mathrm{CO}_{2}(6)$, while about $92 \%$ of the $\alpha$ linolenic acid is absorbed (7). Thus, a substantial part of the tracer is missing, and we hypothesized that some ${ }^{13} \mathrm{C}$ labeled fatty acids had been incorporated into membranes. Fortunately, we had also collected erythrocytes during this study (6) and we now present results of the incorporation of ${ }^{13} \mathrm{C} \alpha$-linolenic acid and its longer chain metabolites into erythrocytes. In addition, effects of dietary $\alpha$-linolenic acid on this incorporation were studied as well.

\section{SUBJECTS AND METHODS}

\section{Subjects}

Fifteen men and women (age between 21 and 66 years), participated (6). All subjects were healthy as indicated by a medical questionnaire and had normal serum total cholesterol and triacylglycerol levels. None of the volunteers used medication or a 
diet known to affect serum lipids. Five of the participants smoked. Three women used oral contraceptives, while five women were post menopausal. The protocol had been approved by the local ethical committee and informed written consent was obtained from each volunteer.

\section{Diets and experimental design}

The study consisted of two consecutive periods. During a 3-weeks run-in period, subjects consumed an oleic acid-rich diet. Thereafter, subjects were randomly allocated to three groups. The first group received for the next 7 weeks the same diet as during the run-in period $(n=5)$, the second group received a diet rich in $\alpha$-linolenic acid ( $8.3 \mathrm{gram} / \mathrm{day} ; \mathrm{n}=7)$, while the third group received a diet rich in EPA (0.9 gram/day) plus DHA ( 0.5 gram/day; $n=3$ ). $\alpha$-Linolenic acid and EPA/DHA replaced oleic acid. Fatty acids were provided as margarine from which also pies, cakes and chocolate-paste were prepared.

At week 9 , subjects came to the department at 8.00 a.m. after a fasting period of 12 hours. First, a $10 \mathrm{ml}$ blood sample was taken, whereafter $45 \mathrm{mg}$ of uniformly labeled ${ }^{13} \mathrm{C} \alpha$-linolenic acid (isotopic purity $>98 \%{ }^{13} \mathrm{C} 18: 3 \mathrm{n}-3$, chemical purity $>95 \%$ ) was given as a methylester (Martek Biosciences Corporation, Columbia, MD, USA) dissolved in $8 \mathrm{~g}$ olive oil. Further blood samples were collected every 2 hours during the first 12 hours (non-fasted) and after 24, 48, 72, 96, 168, and 336 hours (overnight-fasted). After 168 hours, subjects returned to their usual diets. After tracer intake, a breakfast consisting of two slices of white bread with jam was given. Two hours after tracer intake, subjects were allowed to eat and drink according to their respective dietary regimen. During the first day, the volunteers stayed at the department and food was provided during the whole day. Use of coffee or drinks containing caffeine was prohibited during the first day only, because of the possible stimulating effect of caffeine on lipolysis and lipid oxidation (8). A detailed description of the study design has been published before (6).

\section{Blood sampling and analysis}

Until 12 hours after tracer administration, blood was sampled in an EDTA tube through a Teflon catheter (Baxter Quick Cath, Dupont, Ireland) or in a vacuum tube using a 1.2-mm needle (Strauss Kanule; Luer, Wächtersbach, Germany) with the volunteer in a recumbent position. Subjects were free to choose the method of sampling. The catheter was flushed every hour with a $1 \mathrm{ml}$ heparin solution $(0.5 \mathrm{IU}$ heparin-sodium; Leo Pharmaceutical Products BV, Weesp, the Netherlands). The other fasting blood samples were taken with a vacuum tube. Erythrocytes for ${ }^{13} \mathrm{C}$ enrichment analyses and analyses of fatty acid composition of erythrocyte total lipids were obtained by centrifugation at $2000 \times \mathrm{g}$ for 15 minutes at $4^{\circ} \mathrm{C}$, within one hour of venipuncture. After plasma was separated, the erythrocytes were washed twice with a physiological salt solution. Washed erythrocyte samples were snap-frozen and stored at $-80^{\circ} \mathrm{C}$. 
Within 1 week, lipids from erythrocytes were extracted (9), using triheptadecanoic acid (C17:0) as an internal standard. Thereafter, lipid extracts were hydrolyzed and the resulting fatty acids methylated (10). The fatty acid composition in erythrocyte total lipids was analyzed using a gas chromatograph with a flame ionization detector (GC/FID) (Perkin Elmer, Norwalk, Connecticut, USA) as described before (6).

${ }^{13} \mathrm{C}$ Enrichments of individual fatty acid methyl esters (FAMEs) in total lipids from erythrocytes were analyzed with a gas chromatograph (Varian 3400) coupled with an isotope ratio mass spectrometer (GC-C-IRMS; Finnigan MAT 252, Bremen, Germany) via a combustion interface, as described before (6).

\section{Calculations}

The difference between the ${ }^{13} \mathrm{C} /{ }^{12} \mathrm{C}$ ratio of the individual FAME and a known reference standard was expressed as the delta $\left(\delta^{13} \mathrm{C}\right)$. The true ratio of the FAMEs was then calculated by normalizing the isotopic enrichment $\left(\delta^{13} \mathrm{C}\right)$, against the international standard Pee Dee Belemate limestone, which has a ${ }^{13} \mathrm{C} /{ }^{12} \mathrm{C}$ ratio of 0.0112372 . Proportions of ${ }^{13} \mathrm{C}$ labeled fatty acids were calculated by correction for the proportions of that particular fatty acid in the erythrocyte. It was assumed that during fatty acid elongation the two carbon-atom fragments added after elongation were not enriched above background.

\section{Statistical analyses}

For each subject, changes in ${ }^{13} \mathrm{C} /{ }^{12} \mathrm{C}$ ratios were calculated by subtracting baseline values ( $t=0$ hours). Differences between the oleic acid group and the $\alpha$-linolenic acid group were tested with the Mann Whitney $U$ test. Spearman correlation coefficients were calculated to examine the relationship between the maximal proportion of erythrocyte ${ }^{13} \mathrm{C}$ labeled $\mathrm{n}-3$ fatty acids (as \% of total fatty acids), and the cumulative recovery of ${ }^{13} \mathrm{CO}_{2}$ derived from ${ }^{13} \mathrm{C} \alpha$-linolenic acid in breath and the maximal proportion of plasma ${ }^{13} \mathrm{C}$ labeled $\mathrm{n}-3$ fatty acids (as $\%$ of total fatty acids). Maximal proportions represent the proportion of ${ }^{13} \mathrm{C}$ fatty acids (as $\%$ of total fatty acids) at the time of maximal enrichment. Results of breath (as \% recovery) and plasma (in $\mathrm{mg}$ ) have been published before (6). P-values are two-tailed, and differences were considered statistically significant when $P<0.05$. Because of small group size $(n=3)$, results of the EPA/DHA group were not statistically analyzed. Values are presented as medians and as means \pm standard errors.

\section{Additional experiment}

In a small additional experiment, we examined whether the ${ }^{13} \mathrm{C}$ labeled fatty acids were indeed incorporated into the erythrocytes, or adsorbed to the erythrocyte membrane as non-esterified fatty acids. For this purpose, one healthy woman (aged 29, BMI $19.6 \mathrm{~kg} / \mathrm{m}^{2}$, non-smoker), consuming her habitual diet, participated. After a fasting period of 12 hours, the subject came to the department at 8.00 a.m. for a 
blood sample $(30 \mathrm{ml})$. Thereafter, $45 \mathrm{mg}$ of uniformly labeled ${ }^{13} \mathrm{C} \alpha$-linolenic acid was given dissolved in $8 \mathrm{~g}$ olive oil, similarly as in the main study. During the whole day, the subject was allowed to eat and drink according to her self-chosen dietary regimes. Further blood samples were collected in vacuum EDTA tubes at $t=5$ hours (non fasted) and $t=24$ hours (overnight-fasted). Erythrocytes were obtained by centrifugation at $2000 \times \mathrm{g}$ for 15 minutes at $4^{\circ} \mathrm{C}$, within 1 hour of venipuncture. After plasma was separated, the erythrocytes were washed three times on ice with a physiological salt solution containing fatty acid free bovine serum albumin (BSA) (2 $\mathrm{g} / \mathrm{l})$ (Sigma-Aldrich, Steinheim, Germany) and phloretin $(0.4 \mathrm{mM}$ ) (Sigma-Aldrich, Steinheim, Germany). Since phloretin blocks the influx and efflux of fatty acids across the membrane (11-13), addition of fatty acid free BSA plus phloretin to the physiological salt solution will only remove the non-esterified fatty acids adsorbed to the erythrocyte membrane. Consequently, detected ${ }^{13} \mathrm{C}$ labeled fatty acids will reflect the fatty acids truly incorporated into the erythrocyte. Washing erythrocytes with a physiological salt solution only, as done in the main study, will not remove adsorbed fatty acids. Washed erythrocytes samples were snap-frozen and stored at $-80^{\circ} \mathrm{C}$. Total lipids in erythrocytes were analyzed as described above.

\section{RESULTS}

Based on ${ }^{13} \mathrm{C}$ enrichments in plasma, as published before (6), we decided to analyze only erythrocyte samples of $t=0,24,48$, and 336 hours. Furthermore, samples from $t=4$ hours and $t=6$ hours, and from $t=10$ hours and $t=12$ hours were pooled before analyses, and named $t=5$ hours and $t=11$ hours, respectively.

\section{Erythrocyte fatty acid compositions}

At baseline $(\mathrm{t}=0)$, proportions of $\mathrm{C} 18: 3 \mathrm{n}-3$ were higher in the $\alpha$-linolenic acid group (median of $0.31 \%$ of total fatty acids) than in the oleic acid group $(0.10 \%$ of total fatty acids; $P<0.0001$ ) (table 4.1). Proportions of $C 20: 5 n-3, C 22: 5 n-3$ and C22:6n-3, as well as of saturated fatty acids, monounsaturated fatty acids and total trans fatty acids did not differ significantly between the groups. 
Table 4.1 Baseline fatty acid compositions of erythrocytes (\% of total fatty acids) on diets rich in oleic acid or $\alpha$-linolenic acid

\begin{tabular}{|c|c|c|c|c|}
\hline \multirow{2}{*}{$\begin{array}{l}\text { Fatty acids } \\
\text { SAFA }\end{array}$} & \multicolumn{2}{|r|}{$\begin{array}{c}\text { Oleic acid } \\
n=5\end{array}$} & \multicolumn{2}{|r|}{$\begin{array}{l}\mathrm{ALA} \\
\mathrm{n}=7\end{array}$} \\
\hline & 43.03 & $(43.41 \pm 0.29)$ & 43.23 & $(43.20 \pm 0.35)$ \\
\hline MUFA & 19.05 & $(19.05 \pm 0.47)$ & 19.13 & $(18.76 \pm 0.31)$ \\
\hline total $n-6$ & 29.22 & $(29.24 \pm 0.39)$ & 30.00 & $(29.66 \pm 0.79)$ \\
\hline C18:3n-3 (ALA) & 0.10 & $(0.10 \pm 0.01)$ & 0.31 & $(0.33 \pm 0.03)^{*}$ \\
\hline$C 20: 5 n-3$ (EPA) & 0.58 & $(0.64 \pm 0.06)$ & 0.69 & $(0.68 \pm 0.10)$ \\
\hline C22:5n-3 (DPA) & 2.64 & $(2.61 \pm 0.13)$ & 2.65 & $(2.63 \pm 0.13)$ \\
\hline $\mathrm{C} 22: 6 n-3(\mathrm{DHA})$ & 3.66 & $(4.06 \pm 0.37)$ & 4.08 & $(3.82 \pm 0.33)$ \\
\hline total n-3 & 6.96 & $(7.45 \pm 0.52)$ & 7.56 & $(7.49 \pm 0.42)$ \\
\hline total trans & 0.78 & $(0.73 \pm 0.09)$ & 0.82 & $(0.78 \pm 0.04)$ \\
\hline
\end{tabular}

Values are medians (means \pm sem)

"Denotes a significant difference from the oleic acid group

Proportions of ${ }^{13} \mathrm{C}$ labeled fatty acids

Figure 4.1 shows the median proportions of ${ }^{13} \mathrm{C}$ labeled fatty acids during the course of the study. Proportions of ${ }^{13} \mathrm{C} 18: 3 n-3$ increased during the first 11 hours after tracer intake, while after 336 hours proportions of ${ }^{13} \mathrm{C} 18: 3 \mathrm{n}-3$ had almost returned to baseline. After 48 hours, median proportions of ${ }^{13} \mathrm{C} 20: 5 \mathrm{n}-3$ were highest, and after 336 hours proportions were still considerable as compared to after 48 hours. Proportions of ${ }^{13} \mathrm{C} 22: 5 n-3$ and ${ }^{13} \mathrm{C} 22: 6 n-3$ increased until 336 hours after tracer intake.

Median maximal proportions of ${ }^{13} \mathrm{C} 18: 3 n-3,{ }^{13} \mathrm{C} 20: 5 n-3,{ }^{13} \mathrm{C} 22: 5 n-3$, ${ }^{13} \mathrm{C} 22: 6 n-3$, total ${ }^{13} \mathrm{C}$ labeled $\mathrm{n}-3$ fatty acids $\left({ }^{13} \mathrm{C} 18: 3 \mathrm{n}-3+{ }^{13} \mathrm{C} 20: 5 \mathrm{n}-3+{ }^{13} \mathrm{C} 22: 5 \mathrm{n}-3+\right.$ $\left.{ }^{13} \mathrm{C} 22: 6 \mathrm{n}-3\right)$ and ${ }^{13} \mathrm{C} n-3$ LCPs $\left({ }^{13} \mathrm{C} 20: 5 \mathrm{n}-3+{ }^{13} \mathrm{C} 22: 5 \mathrm{n}-3+{ }^{13} \mathrm{C} 22: 6 \mathrm{n}-3\right)$ for the oleic and $\alpha$-linolenic acid groups are shown in table 4.2. No significant differences in proportions of ${ }^{13} \mathrm{C}$ labeled fatty acids between the two groups were observed. 

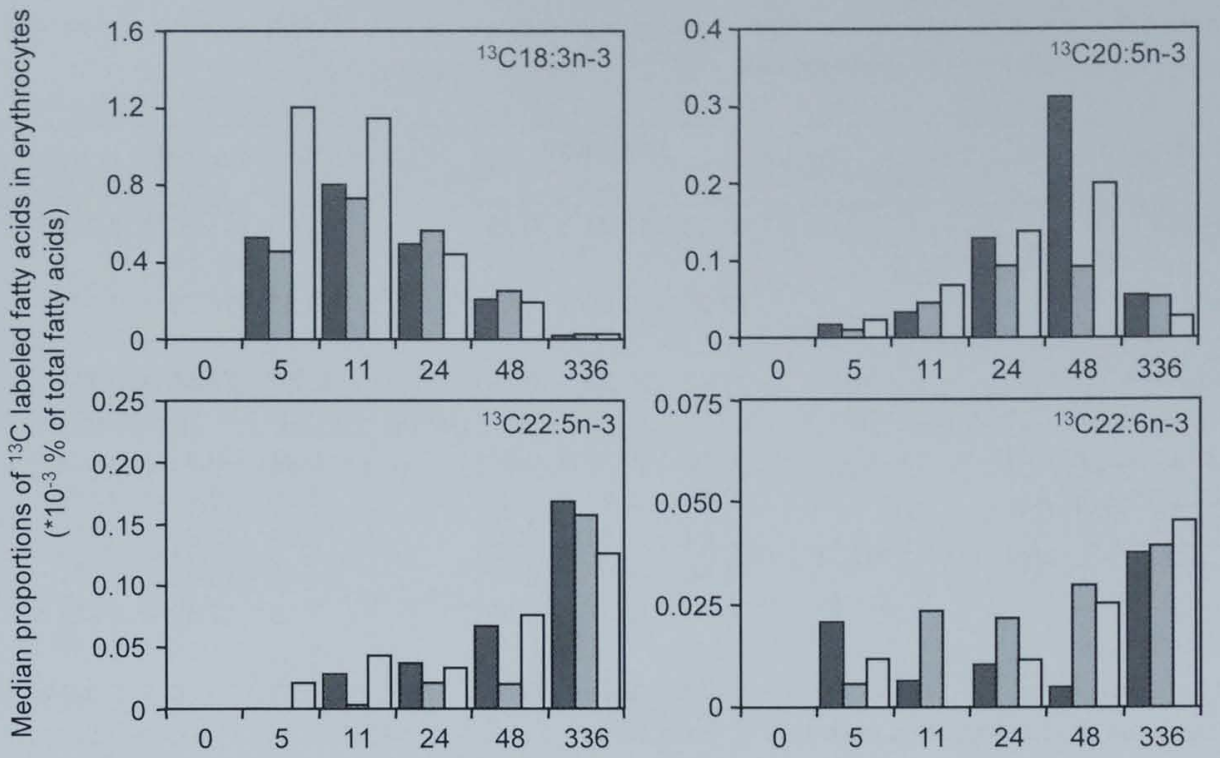

Time (hrs)

Oleic acid group

ALA group

EPA/DHA group

Figure 4.1 Median proportions (in $10^{-3} \%$ of total fatty acids) of erythrocyte ${ }^{13} \mathrm{C} 18: 3 \mathrm{n}-3,{ }^{13} \mathrm{C} 20: 5 \mathrm{n}-3$, ${ }^{13} \mathrm{C} 22: 5 n-3$ and ${ }^{13} \mathrm{C} 22: 6 n-3$ after a single dose of ${ }^{13} \mathrm{C} 18: 3 n-3$ on diets rich in oleic acid, $\alpha-$ linolenic acid (ALA) or eicosapentaenoic/docosahexaenoic acid (EPA/DHA) during the course of the study

Table 4.2 Median maximal proportions of ${ }^{13} \mathrm{C}$ labeled fatty acids in erythrocytes (\% of total fatty acids) on diets rich in oleic acid or $\alpha$-linolenic acid

\begin{tabular}{|c|c|c|c|c|}
\hline \multirow[b]{2}{*}{ Fatty acids } & \multicolumn{2}{|c|}{ Maximal proportion $\left({ }^{*} 10^{-3}\right)$} & \multicolumn{2}{|c|}{ Time to maximal proportion (hours) } \\
\hline & $\begin{array}{c}\text { Oleic acid } \\
n=5\end{array}$ & $\begin{array}{c}\text { ALA } \\
n=7\end{array}$ & $\begin{array}{c}\text { Oleic acid } \\
n=5\end{array}$ & $\begin{array}{l}\text { ALA } \\
n=7\end{array}$ \\
\hline${ }^{13} \mathrm{C} 18: 3 n-3$ & $1.06(1.64 \pm 0.72)$ & $0.83(4.11 \pm 3.21)$ & $11(11.2 \pm 3.5)$ & $11(13.9 \pm 2.7)$ \\
\hline${ }^{13} \mathrm{C} 20: 5 n-3$ & $0.31(0.27 \pm 0.08)$ & $0.09(0.17 \pm 0.06)$ & $48(48.0 \pm 0.0)$ & $48(41.1 \pm 4.4)$ \\
\hline${ }^{13} \mathrm{C} 22: 5 n-3$ & $0.17(0.19 \pm 0.06)$ & $0.16(0.18 \pm 0.05$ & $336(278.4 \pm 57.6)$ & $336(288.7 \pm 47.3)$ \\
\hline${ }^{13} \mathrm{C} 22: 6 n-3$ & $0.04(0.04 \pm 0.01)$ & $0.05(0.07 \pm 0.02)$ & $336(253.3 \pm 82.8)^{c}$ & $48(168.0 \pm 59.5)$ \\
\hline${ }^{13} \mathrm{C} n-3 \mathrm{FA}^{a}$ & $1.72(2.14 \pm 0.77)$ & $1.48(4.52 \pm 3.21)$ & & \\
\hline${ }^{13} \mathrm{C} n-3$ LCPs ${ }^{b}$ & $0.55(0.50 \pm 0.13)$ & $0.42(0.41 \pm 0.12)$ & & \\
\hline
\end{tabular}

Values are medians (means \pm sem)

${ }^{a}{ }^{13} \mathrm{C} n-3$ FA $\left({ }^{13} \mathrm{C} 18: 3 \mathrm{n}-3+{ }^{13} \mathrm{C} 20: 5 \mathrm{n}-3+{ }^{13} \mathrm{C} 22: 5 \mathrm{n}-3+{ }^{13} \mathrm{C} 22: 6 \mathrm{n}-3\right)$

${ }^{b}{ }^{13} \mathrm{C}$ n-3 LCPs $\left({ }^{13} \mathrm{C} 20: 5 \mathrm{n}-3+{ }^{13} \mathrm{C} 22: 5 \mathrm{n}-3+{ }^{13} \mathrm{C} 22: 6 \mathrm{n}-3\right)$

${ }^{c}$ Only for four subjects. In one subject no enrichment was detected. 


\section{Correlations}

In the present study, ${ }^{13} \mathrm{C}$ enrichments in breath and plasma were also measured. We have now calculated correlations between maximal proportions of ${ }^{13} \mathrm{C}$ labeled fatty acids in erythrocytes (as \% of total fatty acids), and total ${ }^{13} \mathrm{CO}_{2}$ in breath for the first 12 hours or maximal proportions of ${ }^{13} \mathrm{C}$ labeled fatty acids in plasma (as \% of total fatty acids) after intake of ${ }^{13} \mathrm{C} \alpha$-linolenic acid.

Results of the total ${ }^{13} \mathrm{C}$ recovery in breath $\left({ }^{13} \mathrm{CO}_{2}\right)$ derived from $\alpha$-linolenic acid and the appearance of ${ }^{13} \mathrm{C}$ labeled $\mathrm{n}-3$ fatty acids in plasma (in $\mathrm{mg}$ ) have been reported before (6). Median maximal proportions of ${ }^{13} \mathrm{C} 18: 3 n-3$ in plasma (as $\%$ of total fatty acids) were $33.5 * 10^{-3} \%$ in the oleic acid group and $20.9{ }^{*} 10^{-3} \%$ in the $\alpha$ linolenic acid group. Median maximal proportions in plasma total lipids were 1.01 * $10^{-3} \%$ and $0.45 * 10^{-3} \%$ for ${ }^{13} \mathrm{C} 20: 5 \mathrm{n}-3,0.34 * 10^{-3} \%$ and $0.19 * 10^{-3} \%$ for ${ }^{13} \mathrm{C} 22: 5 \mathrm{n}-3$, and $0.08 * 10^{-3} \%$ and $0.05 * 10^{-3} \%$ for ${ }^{13} \mathrm{C} 22: 6 \mathrm{n}-3$ in the oleic acid and $\alpha$-linolenic acid group, respectively. No significant differences between the groups were observed.

Maximal proportions of ${ }^{13} \mathrm{C} 20: 5 n-3 \quad(r=0.73, P=0.007),{ }^{13} \mathrm{C} 22: 5 n-3 \quad(r=0.62$, $P=0.033$ ), and total ${ }^{13} \mathrm{C} n-3$ LCPs $(r=0.80, P=0.002)$ in erythrocytes correlated with maximum proportions of ${ }^{13} \mathrm{C} 20: 5 n-3$ in plasma, but not with other plasma ${ }^{13} \mathrm{C} n-3$ LCPS. In addition, ${ }^{13} \mathrm{C}$ recovery in breath was not significantly correlated with maximal proportions of ${ }^{13} \mathrm{C}$ labeled fatty acids in erythrocytes.

\section{EPA/DHA group}

At baseline $(\mathrm{t}=0)$, proportions of total $\mathrm{n}-3$ fatty acids were higher on the EPA/DHA group (median of $10.68 \%$ of total fatty acids) as compared to the oleic acid $(6.96 \%$ of total fatty acids) and $\alpha$-linolenic acid group (7.56\% of total fatty acids), which was caused by higher proportions of $\mathrm{C} 20: 5 \mathrm{n}-3(1.99,0.58$, and $0.69 \%$ of total fatty acids for the EPA/DHA, oleic acid, and $\alpha$-linolenic acid groups, respectively), $C 22: 5 n-3$ $(3.40,2.64$, and $2.65 \%$ of total fatty acids, respectively) and $C 22: 6 n-3(5.00,3.66$, and $4.08 \%$ of total fatty acids, respectively). Proportions of total $n-6$ fatty acids were lower on the EPA/DHA rich diet $(26.0 \%$ of total fatty acids) than on the oleic acid rich (29.2\% of total fatty acids) and $\alpha$-linolenic acid rich diets $(30.0 \%$ of total fatty acids).

The median maximal proportion of ${ }^{13} \mathrm{C} 18: 3 n-3$ was $0.66 * 10^{-3} \%$ of total fatty acids was reached after 11 hours, and had almost returned to baseline after 336 hours. Maximal proportion of ${ }^{13} \mathrm{C} 20: 5 n-3$ was reached after 48 hours and was 0.09 * $10^{-3} \%$ of total fatty acids. The proportion of ${ }^{13} \mathrm{C} 22: 5 \mathrm{n}-3$ was highest after 336 hours, and was $0.12 * 10^{-3} \%$ of total fatty acids. The proportion of ${ }^{13} \mathrm{C} 22: 6 \mathrm{n}-3$ increased until $0.05^{*} 10^{-3} \%$ of total fatty acids after 336 hours.

\section{Additional experiment}

${ }^{13} \mathrm{C}$ Enrichments in C18:3n-3, after washing the erythrocytes with a physiological salt solution containing fatty acid free BSA and phloretin, were 146 and $233 \%$ after 5 and 24 hours, respectively. In addition, ${ }^{13} \mathrm{C}$ enrichments were detected for $\mathrm{C} 20: 5 n-3$ as 
well. These results indicated that at least a part of the ${ }^{13} \mathrm{C}$ labeled fatty acids were incorporated into the erythrocyte membrane.

\section{DISCUSSION}

After ingestion of a single bolus of ${ }^{13} \mathrm{C} \alpha$-linolenic acid, we found in human erythrocytes ${ }^{13} \mathrm{C}$ enrichments in C18:3n-3 and its LCPS, C20:5n-3, C22:5n-3 and C22:6n-3. This shows that not only dietary EPA and DHA are incorporated into erythrocytes $(3,4,14,15)$, but also $n-3$ longer chain metabolites derived from dietary $\alpha$ linolenic acid. Incorporation of ${ }^{13} \mathrm{C} \alpha$-linolenic acid as well as ${ }^{13} \mathrm{C}$-EPA and ${ }^{13} \mathrm{C}-\mathrm{DHA}$ into human erythrocytes was very fast and already observed after 5 hours.

As expected, after 6 weeks on an $\alpha$-linolenic acid rich diet providing $8.3 \mathrm{gram}$ $\alpha$-linolenic acid extra per day, proportions of erythrocyte C18:3n-3 were higher in the $\alpha$-linolenic acid group as compared to the oleic acid group. However, no significant changes were observed in the proportions of n-3 LCPs. As in other studies $(3,4,14)$, proportions of C20:5n-3 and C22:6n-3 were higher on the EPA/DHA rich diet as compared to the $\alpha$-linolenic and oleic acid rich diets.

We further examined effects of dietary $\alpha$-linolenic acid on incorporation of ${ }^{13} \mathrm{C}$ fatty acids into erythrocytes. The high mean maximal proportion of ${ }^{13} \mathrm{C} 18: 3 \mathrm{n}-3$ in the $\alpha$-linolenic acid group (table 4.2) was caused by values of one subject, and medians are therefore more informative. Maximal proportions of ${ }^{13} \mathrm{C} 20: 5 \mathrm{n}-3$ were, although not significantly, lower on the $\alpha$-linolenic acid diet as compared to the oleic acid diet. For plasma total lipids, differences in maximal amounts of ${ }^{13} \mathrm{C} 20: 5 \mathrm{n}-3$ (in $\mathrm{mg}$ ) did reach statistical significance (6), but differences in maximal proportions of plasma ${ }^{13} \mathrm{C} 20: 5 n-3$ were not significant. Furthermore, we found a significant correlation between maximal proportions of ${ }^{13} \mathrm{C} 20: 5 n-3$ in erythrocytes with those in plasma. Maximal proportions of ${ }^{13} \mathrm{C} 20: 5 n-3$ in erythrocytes were borderline significantly correlated with absolute maximal amounts of ${ }^{13} \mathrm{C} 20: 5 n-3$ in plasma (in mg) $(P=0.07$ ). Although suggestive, our results are not conclusive whether dietary $\alpha$-linolenic acid affects incorporation of LCPs derived from ${ }^{13} \mathrm{C} \alpha$-linolenic acid into erythrocytes.

In a small additional experiment, we have examined whether the ${ }^{13} \mathrm{C}$ labeled fatty acids were indeed incorporated into the erythrocytes or were only adsorbed to the erythrocyte membrane as non-esterified fatty acids. After adsorption, non-esterified fatty acids may cross the membrane (16-19) to become incorporated into phospholipids at the inner leaflet of the membrane (20) or bound to haemoglobin in the cytoplasm (21). A previous in vitro study with ${ }^{14} \mathrm{C}$ labeled palmitic, oleic and linoleic acid has shown that fatty acid free BSA may remove up to $88 \%$ of the nonesterified fatty acids adsorbed to the human erythrocyte membrane (22). Nonesterified fatty acids from the cytosol are hardly removed by fatty acid free albumin (21). In vitro the influx and efflux of ${ }^{14} \mathrm{C}$-oleic acid in rat adipocytes (12) and hepatocytes (13) is blocked by phloretin. In the additional experiment, we have also 
used phloretin to block the translocation of fatty acids across the membrane. The adsorbed non-esterified fatty acids were then removed from the membrane by using fatty acid free BSA. Consequently, these results reflected the ${ }^{13} \mathrm{C}$-labeled fatty acids truly incorporated into the erythrocyte, either esterified or as free fatty acid. We did find ${ }^{13} \mathrm{C}$ enrichments in $\mathrm{C} 18: 3 n-3$ and $\mathrm{C} 20: 5 n-3$, suggesting that at least a part of these fatty acids was truly incorporated into the erythrocyte and not simply adsorbed as nonesterified fatty acids to the membrane.

In conclusion, we found ${ }^{13} \mathrm{C} \alpha$-linolenic acid as well as its longer chain more unsaturated fatty acids in human erythrocytes. This suggests that $n-3$ longer chain metabolites derived from dietary $\alpha$-linolenic acid are also incorporated into erythrocytes. These incorporations were already evident after 5 hours. Whether incorporation of ${ }^{13} \mathrm{C}$ LCPs into erythrocytes is affected by dietary $\alpha$-linolenic acid is not clear. 


\section{REFERENCES}

1. Osmundsen $\mathrm{H}$, Bremer $\mathrm{J}$, and Pedersen $\mathrm{J}$. Metabolic aspects of peroxisomal $\beta$-oxidation. Biochim Biophys Acta 1991;1085:141-158.

2. Christensen E, Woldseth $B$, Hagve $T$, et al. Peroxisomal $\beta$-oxidation of polyunsaturated long chain fatty acids in human fibroblasts. The polyunsaturated and saturated long chain fatty acids are retroconverted by the same acyl-CoA oxidase. Scand J Clin Lab Invest 1993;53:6174.

3. Prisco D, Filippini M, Francalanci $I$, et al. Effect of n-3 polyunsaturated fatty acid intake on phospholipid fatty acid composition in plasma and erythrocytes. Am J Clin Nutr 1996;63:925932.

4. Katan MB, Deslypere J, Van Birgelen APJM, Penders M, and Zegwaard M. Kinetics of the incorporation of dietary fatty acids into serum cholesteryl esters, erythrocyte membranes, and adipose tissue: an 18-month controlled study. J Lipid Res 1997;38:2012-2022.

5. Su $H$, Bernardo $L$, Mirmiran $M$, et al. Bioequivalence of dietary $\alpha$-linolenic and docosahexaenoic acids as sources of docosahexaenoate accretion in brain and associated organs of neonatal baboons. Ped Res 1999;45:87-93.

6. Vermunt SHF, Mensink RP, Simonis, AMG, and Hornstra G. Effects of dietary $\alpha$-linolenic acid fatty acids on the conversion and oxidation of ${ }^{13} \mathrm{C}$ - $\alpha$-linolenic acid. Lipids 2000;35:147-152.

7. Emken EA, Adlof $R$, and Gulley R. Dietary linoleic acid influences desaturation and acylation of deuterium-labeled linoleic and linolenic acids in young adult males. Biochim Biophys Acta 1994;1213:277-288.

8. Astrup A, Toubro S, Cannon S, Hein P, Breum L, and Madson J. Caffeine: a double-blind, placebo-controlled study of its thermogenic, metabolic, and cardiovascular effects in healthy volunteers. Am J Clin Nutr 1990;51:759-767.

9. Folch J, Lees $M$, and Sloane Stanley G. A simple method for the isolation and purification of total lipids from animal tissues. J Biol Chem 1957;226:497-509.

10. Lepage $G$ and Roy $C$. Direct transesterification of all classes of lipids in a one-step reaction. $J$ Lipid Res 1986;27:114-120.

11. Andersen $\mathrm{BL}$, Tarpley HL, and Regen $\mathrm{DM}$. Characterization of $\beta$-hydroxybutyrate transport in rat erythrocytes and thymocytes. Biochim Biophys Acta 1978;508:525-538.

12. Abumrad NA, Perkins RC, Park JH, and Park CR. Mechanism of long chain fatty acid permeation in the isolated adipocyte. J Biol Chem 1981;256:9183-9191.

13. Stremmel $W$, and Berk $P$. Hepatocellular influx of $\left[{ }^{14} C\right]$ oleate reflects membrane transport rather than intracellular metabolism or binding. Proc Natl Acad Sci USA 1986;83:3086-3090.

14. Vidgren HM, Agren JJ, Schwab U, Rissanen T, Hänninen O, and Uusitupa, MIJ. Incorporation of n-3 fatty acids into plasma lipid fractions, and erythrocte membranes and platelet during dietary supplementation with fish, fish oil, and docosahexaenoic acid-rich oil among healthy young men. Lipids 1997;32:697-705.

15. Lemaitre-Delaunay D, Pachiaudi C, Laville M, Pousin J, Armstrong M, and Lagarde M. Blood compartmental metabolism of docosahexaenoic acid (DHA) in humans after ingestion of a single dose of $\left[{ }^{13} \mathrm{C}\right] \mathrm{DHA}$ in phosphatidylcholine. J Lipid Res 1999;40:1867-1874.

16. Hamilton JA. Fatty acid transport: difficult or easy? J Lipid Res 1998;39:467-481.

17. Glatz JFC, Luiken JJFP, Van Nieuwenhoven FA, Van de Vusse GJ. Molecular mechanism of cellular uptake and intracellular translocation of fatty acids. Prostaglandins Leukot Essent Fatty Acids 1997;57:3-9. 
18. McArthur MJ, Atshaves BP, Frolov A, Foxworth WD, Kier AB, and Schroeder F. Cellular uptake an intracellular trafficking of long chain fatty acids. J Lipid Res 1999;40:1371-1383.

19. Luiken JJFP, Schaap FG, Van Nieuwenhoven FA, Van de Vusse GJ, and Glatz JFC. Cellular fatty acid transport in heart and skeletal muscle as facilitated by proteins. Lipids 1999;34:S169-S175.

20. Renooy W, Van Golde LMG, Zwaal RFA, Roelofsen B, and Van Deenen LLM. Preferential incorporation of fatty acids at the inside of human erythrocyte membranes. Biochim Biophys Acta 1974;363:287-292.

21. Bröring $\mathrm{K}$, Haest $\mathrm{CWM}$, and Deuticke B. Translocation of oleic acid across the erythrocyte membrane. Evidence for a fast process. Biochim Biophys Acta 1989;986:321-331.

22. Dwight JFStJ, Mendes Riveiro AC, and Hendry, BM. Membrane incorporation of non-esterified fatty acids and effects on the sodium pump of human erythrocytes. Clin Sci 1992;82:99-104. 

Relationship between mRNA levels for $\Delta 5, \Delta 6$ and $\Delta 9$ desaturases in mononuclear blood cells and liver tissue in man

SHF Vermunt ${ }^{1}$, JW Greve ${ }^{2}$, G Hornstra' ${ }^{1}, \mathrm{~F}$ van Dielen ${ }^{2}$, RP Mensink ${ }^{1}$

${ }^{1}$ Department of Human Biology, Maastricht University, the Netherlands

${ }^{2}$ Department of Chirurgy, University Hospital Maastricht, the Netherlands 


\section{ABSTRACT}

Desaturase activity is mainly located in the liver, but has also been demonstrated in mononuclear blood cells. Since the liver is not easily accessible to investigate in humans, in the present study, desaturase mRNA levels were measured in both liver and mononuclear blood cells in order to examine the possibility to predict regulation of desaturases in the liver by measuring those in mononuclear blood cells. Patients who underwent cholecystectomy for symptomatic gallstones $(n=1)$, hemihepatectomie $(n=2)$, or with morbid obesity who underwent gastroplasty $(n=11)$ participated. During surgery, fasting venous blood was sampled, and a liver sample was collected. Total RNA was isolated from mononuclear blood cells and liver, and mRNA levels of $\Delta 5, \Delta 6$, and $\Delta 9$ desaturase were determined by reverse-transcription polymerase chain reaction. mRNA levels were expressed as ratios relative to $\beta$-actin.

Delta 6 desaturase mRNA in mononuclear blood cells was negatively correlated with $\Delta 6$ desaturase mRNA in liver $(r=-0.64 ; P=0.015)$, and $\Delta 9$ desaturase mRNAs in mononuclear blood cells was negatively correlated with $\Delta 9$ desaturase mRNA in liver ( $r=-0.83 ; P=0.001)$. Delta 5 desaturase mRNA in mononuclear blood cells was not correlated with that in liver. Within liver tissue, $\Delta 5$ and $\Delta 6$ desaturase mRNA, and $\Delta 6$ and $\Delta 9$ desaturase mRNA were positively correlated $(r=0.71$, $P=0.007$, and $r=0.59, P=0.034$, respectively). Within mononuclear blood cells, desaturases were not correlated with each other.

We conclude that $\Delta 6$ and $\Delta 9$ desaturase mRNAs in mononuclear blood cells may predict mRNA levels in the liver. 


\section{INTRODUCTION}

In men, fatty acids can be converted by alternate desaturation and elongation reactions into fatty acids with a higher degree of unsaturation and a longer chain length. The first desaturation step of most saturated fatty acids is often mediated by the $\Delta 9$ desaturase enzyme. In this way, oleic acid (C18:1n-9 $\Delta 9)$ is formed from stearic acid (C18:0). The essential fatty acids $\alpha$-linolenic acid $(C 18: 3 n-3 \Delta 9,12,15)$ and linoleic acid $(C 18: 2 n-6 \Delta 9,12)$ cannot be synthesized de novo by mammals, because they lack the required desaturase enzymes. However, they can be converted to longer chain more unsaturated fatty acids (LCPs) of the $n-3$ and $n-6$ families, respectively, which are important structural membrane components and play a major role in many physiological processes (1). In the further desaturation of oleic-, linoleic- and $\alpha$-linolenic acids, $\Delta 6$ and $\Delta 5$ desaturases are involved.

Desaturase activity is mainly located in the liver, which, for obvious reasons, is not easily accessible for studies in humans. Cunnane et al., however, have shown that human leukocytes also convert ${ }^{13} \mathrm{C}$ linoleic acid into di-homo- $\gamma$-linolenic acid $(C 18: 3 n-6)$ and arachidonic acid (C20:4n-6), indicating the presence of $\Delta 6$ and $\Delta 5$ desaturases in leukocytes (2). Therefore, it is likely that desaturase mRNA is present in leukocytes as well. If so, effects of drugs, diets, diseases, etcetera on expression of desaturases can possibly be investigated in leukocytes in stead of in liver. This requires, however, that desaturase regulation in human leukocytes relates to desaturase regulation in the liver. Such activity relationships between human mononuclear blood cells and liver have indeed been observed, for instance for the low density lipoprotein (LDL) receptor and for 3-hydroxy-3-methylglutaryl CoA reductase (HMGCoA) (3).

Recently, human $\Delta 5$ and $\Delta 6$ desaturase cDNAs have been cloned and characterised $(4,5)$. cDNA of human $\Delta 9$ desaturase has been sequenced as well $(6)$. This gives the possibility to examine in humans the relationships between mRNA levels of $\Delta 5, \Delta 6$ and $\Delta 9$ desaturase in mononuclear blood cells with those in the liver.

\section{SUBJECTS AND METHODS}

\section{Subjects}

The study was carried out at the University Hospital in Maastricht. Patients aged $<18$ years were excluded. Fourteen subjects (six men and eight women), who were aged between 25 and 74 years (mean \pm sem: $39.0 \pm 3.6$ years), weighed between 68 and $200 \mathrm{~kg}$ and had a body mass index between 24.8 and $57.2 \mathrm{~kg} / \mathrm{m}^{2}$ participated in this study (table 5.1). Patients with morbid obesity underwent gastroplasty $(n=11)$, while two subjects underwent hemi-hepatectomy and one cholecystectomy for symptomatic gallstones. The patient who underwent cholecystectomy had diabetes mellitus type 2. The study was approved by the Medical Ethical Committee of the 
Maastricht University Hospital. Before surgery, the protocol was fully explained to the patients, who have all given their written informed consent.

Table 5.1 Characteristics of the patients

\begin{tabular}{lllclll}
\hline Patient & Gender & $\begin{array}{l}\text { Age } \\
(\mathrm{yr})\end{array}$ & $\begin{array}{l}\text { Weight } \\
(\mathrm{kg})\end{array}$ & $\begin{array}{l}\text { Height } \\
(\mathrm{m})\end{array}$ & $\begin{array}{l}\mathrm{BMl} \\
\left(\mathrm{kg} / \mathrm{m}^{2}\right)\end{array}$ & Operation \\
\hline 1 & $\mathrm{M}$ & 38 & 132 & 1.65 & 48.4 & gastroplasty \\
2 & $\mathrm{~F}$ & 56 & 86 & 1.70 & 29.8 & hemi-hepatectomy \\
3 & $\mathrm{M}$ & 28 & 200 & 1.87 & 57.2 & gastroplasty \\
$4^{\mathrm{a}}$ & $\mathrm{M}$ & 74 & 85 & 1.85 & 24.8 & cholecystectomy \\
5 & $\mathrm{~F}$ & 34 & 91 & 1.53 & 38.7 & gastroplasty \\
6 & $\mathrm{~F}$ & 30 & 140 & 1.70 & 48.4 & gastroplasty \\
7 & $\mathrm{~F}$ & 50 & 68 & 1.64 & 25.3 & hemi-hepatectomy \\
8 & $\mathrm{~F}$ & 25 & 127 & 1.72 & 42.9 & gastroplasty \\
9 & $\mathrm{M}$ & 40 & 140 & 1.82 & 42.3 & gastroplasty \\
10 & $\mathrm{M}$ & 37 & 155 & 1.87 & 44.3 & gastroplasty \\
11 & $\mathrm{~F}$ & 34 & 111 & 1.61 & 42.8 & gastroplasty \\
12 & $\mathrm{~F}$ & 33 & 136 & 1.76 & 43.9 & gastroplasty \\
13 & $\mathrm{M}$ & 41 & 179 & 1.87 & 51.2 & gastroplasty \\
14 & $\mathrm{~F}$ & 26 & 142 & 1.77 & 45.3 & gastroplasty \\
\hline
\end{tabular}

${ }^{a}$ Patient with Diabetes Mellitus type 2

\section{Sample collection}

During surgery, fasting venous blood (about $30 \mathrm{ml}$ ) was sampled, and a liver tissue biopsy (about $30 \mathrm{mg}$ ) was taken from the caudal edge of segment III of the left lobe. Hemostasis was achieved in all patients with diathermia only. No complications related to the biopsies were observed. Immediately after blood was sampled in a syringe, about $6 \mathrm{ml}$ blood was transferred into a serum tube for measurement of liver enzymes, and the remainder into EDTA tubes for isolation of total RNA and for analysis of haematological variables (number of leukocytes, erythrocytes, and platelets, packed cell volume and haemoglobin concentration). Serum gammaglutamyltranspeptidase ( $\gamma$-GTP), alanineaminotransferase (ALAT) and total bilirubine levels showed no significant deviations from normal values. Liver samples were used for isolation of total RNA. After collection, liver tissues were directly placed in RNAlater (RNAlater ${ }^{\text {TM }}$; Ambion, Austin TX) for about 24 hours.

\section{RNA preparation}

Mononuclear blood cells were isolated by lymphoprep ${ }^{\mathrm{TM}}$ (Nycomed Pharma As, Oslo, Norway) according to the manufacturer's instructions. Liver samples were homogenized in RNA lysis buffer (Promega Corporation, Madison, WI, USA) with a homogenizer. Total RNA from mononuclear blood cells and liver was isolated using a 
kit of Promega (Promega Corporation, Madison, WI, USA). RNA was dissolved in nuclease-free water (Promega Corporation, Madison, WI, USA) and stored at $-20^{\circ} \mathrm{C}$ until polymerase chain reaction (PCR) amplification. Before PCR amplification, RNA concentrations were measured spectrophotometrically at $260 \mathrm{~nm}$.

\section{PCR amplification}

In both mononuclear blood cells and liver samples, the amounts of mRNA for $\triangle 5, \Delta 6$, and $\triangle 9$ desaturase were measured by reverse-transcription (RT) PCR. $600 \mathrm{ng}$ RNA from mononuclear blood cells or $1 \mu \mathrm{g}$ RNA from liver was first heated at $85^{\circ} \mathrm{C}$ for 5 minutes. Then, RNA was reverse transcribed into CDNA in a $20 \mu \mathrm{l}$ mixture of RT buffer $(250 \mathrm{mM}$ Tris- $\mathrm{HCl} \mathrm{pH} 8.3,375 \mathrm{mM} \mathrm{KCl}, 15 \mathrm{mM} \mathrm{MgCl} 2), 10 \mathrm{mM}$ dithiothreitol (DTT; Gibco, Life Technologies, Breda, the Netherlands), $200 \cup$ Moloney Murine Leukemia Virus Reverse Transcriptase (M-MLV RT; Gibco, Life Technologies, Breda, the Netherlands), $10 \mathrm{U} / \mu \mathrm{l}$ RNase inhibitor (Gibco, Life Technologies, Breda, the Netherlands), deoxyribonucleoside triphosphates (dNTP; $0.125 \mathrm{mmol}$ of each nucleotide; dATP, dCTP, dGTP and dTTP; Pharmacia Biotech, Roosendaal, the Netherlands), and $5 \mu \mathrm{M}$ random hexamers (Perkin Elmer, Applied Biosystems, Foster City, CA, USA). Samples were heated for 10 minutes at $22^{\circ} \mathrm{C}, 90 \mathrm{~min}$ at $37^{\circ} \mathrm{C}$ and 3 min at $95^{\circ} \mathrm{C}$, and then chilled at $4^{\circ} \mathrm{C} .5 \mu \mathrm{l}$ cDNA was amplified using a $50 \mu$ volume of PCR buffer (100 mM Tris- $\mathrm{HCl} \mathrm{pH} 8.8,500 \mathrm{mM} \mathrm{KCl}, 15 \mathrm{mM} \mathrm{MgCl}_{2}, 0.1 \%$ Triton X100 ), $0.05 \mathrm{mM}$ dNTP, and $30 \mathrm{pmol}$ of each primer (table 5.2) with an Amplitron ${ }^{\circledR} \|$ Thermolyne (Barnstead, Thermolyne Corporation, Dubuque, USA). After an annealing step of $2 \mathrm{~min}$ at $94^{\circ} \mathrm{C}, 2.5 \mathrm{U}$ taq polymerase (Pharmacia Biotech, Roosendaal, the Netherlands) was added.

Before start of the study, mRNA levels of the three desaturases and of $\beta$-actin in mononuclear blood cells were measured at $22,24,26,28,30$, and 32 cycles to determine the linear phase of the amplification curve. In the liver, mRNA levels were measured at 16 and 17 cycles (only for $\beta$-actin) and at $18,20,22,24,26,28$, and 30 cylces for the desaturases and $\beta$-actin. For the study, mRNA levels in respectively mononuclear blood cells and liver were determined at three different cycles which were part of the linear phase: $28,29,30$ and $18,19,20$ cycles for $\Delta 9$ desaturase, and $28,29,30$ and $20,21,22$ cycles for $\Delta 5$ and $\Delta 6$ desaturase. In addition, $\beta$-actin was quantified in triplicate using 23 cycles in mononuclear blood cells and 18 cycles in liver tissue.

PCR for measurement of desaturases consisted of denaturation at $94^{\circ} \mathrm{C}$ for 30 $\mathrm{s}$, primer annealing at $60^{\circ} \mathrm{C}$ for $\Delta 9$ desaturase and at $50^{\circ} \mathrm{C}$ for $\Delta 5$ and $\Delta 6$ desaturase for $30 \mathrm{~s}$ and extension at $72^{\circ} \mathrm{C}$ for $1 \mathrm{~min}$. PCR for measurement of $\beta$-actin consisted of denaturation at $94^{\circ} \mathrm{C}$ for $1 \mathrm{~min}$, primer annealing at $55^{\circ} \mathrm{C}$ for $45 \mathrm{~s}$ and extension at $72^{\circ} \mathrm{C}$ for 2 min. 
Table 5.2 Primer sequences for amplification of human RNA

\begin{tabular}{lllc}
\hline Gene & 5' Primers & 3' Primers & $\begin{array}{c}\text { Size of PCR } \\
\text { product (bp) }\end{array}$ \\
\hline$\Delta 5 D^{a}$ & 5'-GAATAAAGAGCTGACAGATGAG-3' & 5'-CCTGAACTGCACTGAGCA-3' & 202 \\
$\Delta 6 D^{a}$ & 5'-GGCAAGAACTCAAAGATCAC-3' & 5'-GAGAGGTAGCAAGAACAAAG-3' & 204 \\
$\Delta 9 D^{b}$ & $5^{\prime}$-GGAAGACGACATTCGCCCTG-3' & 5'-TGGTCACGAGCCCATTCATAGAC-3' & 347 \\
$\beta$-actin ${ }^{\circ}$ 5'-ACTGACTACCTCATGAAGAT-3' & 5'-CGTCATACTCCTGCTTGCTGAT-3' & 535 \\
\hline
\end{tabular}

${ }^{a}$ Primers as indicated in Cho et al. (5)

${ }^{b}$ Primers were made by the Amplify program (7) and checked by CPrimers (University of California, USA, 1995) on melting points and interfering structures

${ }^{c}$ Primers as indicated in Schrauwen et al. (8)

\section{PCR product detection}

PCR products were fractionated by electrophoresis on a $3 \%$ agarose gel in TBE (Tris-borate-EDTA) buffer (both containing $5 \%$ ethidium bromide) for $1.5 \mathrm{~h}$ at $125 \mathrm{~V}$, and quantitation of the PCR products were performed via densitometry (Imagemaster ${ }^{\circledR}$ VDS; Pharmacia Biotech). Figure 5.1 shows PCR products of liver $\Delta 5, \Delta 6$, and $\Delta 9$ desaturase.

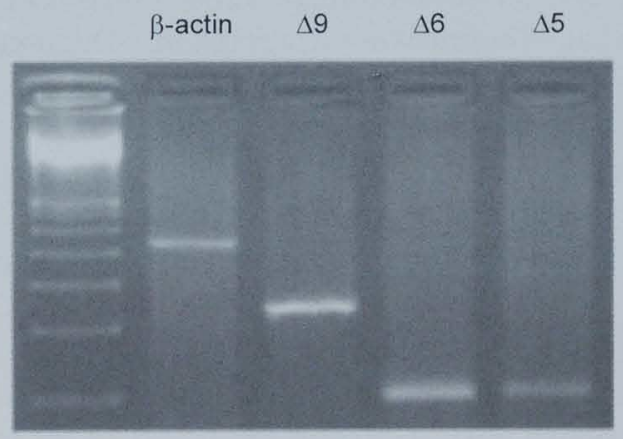

Figure 5.1 PCR products of liver $\Delta 5$ (202 bp), $\Delta 6$ (204 bp), and $\Delta 9$ desaturase ( $347 \mathrm{bp}$ ), and $\beta$-actin (535 bp). These mRNAs were determined using 19 cycles for $\Delta 9$ desaturase, 21 cycles for $\Delta 5$ and $\Delta 6$ desaturase, and 18 cycles for $\beta$-actin.

\section{Calculations and statistical analyses}

Signal intensities of the PCR products were plotted against the number of cycles. Then, regression lines were calculated and checked for linearity. If regression lines were not linear, analyses were repeated. Signal intensities of 29 and 19 cycles for the $\Delta 9$ desaturase, and 29 and 21 cycles for $\Delta 5$ and $\Delta 6$ desaturase for mononuclear 
blood cells and liver, respectively, were calculated using the regression equation. Levels of mRNA were expressed as the ratio of signal intensity for the $\Delta 5$, $\Delta 6$, or $\Delta 9$ desaturase PCR products relative to that of the PCR product of the house-keeping gene $\beta$-actin (9).

Pearson correlation coefficients were calculated using the Statistical Package for the Social Sciences (SPSS; SPSS Inc., Chicago, IL, USA) to determine the relationships between mRNA levels of $\Delta 5, \Delta 6$ and $\Delta 9$ desaturase in mononuclear blood cells with those in the human liver, between age and BMI with mRNA levels of $\Delta 5, \Delta 6$ and $\Delta 9$ desaturase in mononuclear blood cells and liver, and to determine the interrelationships between mRNA levels of the three different desaturases in both mononuclear blood cells and liver. Gender differences were tested by unpaired ttests. Differences between hepatic $\Delta 5$ and $\Delta 6$ desaturase mRNAs and between $\Delta 5$, $\Delta 6$ and $\Delta 9$ desaturase mRNAs in mononuclear blood cells were tested by paired ttests. Hepatic $\Delta 9$ desaturase mRNA could not be compared with $\Delta 5$ and $\Delta 6$ desaturase mRNAs because of different cycle numbers, as applied during the PCR amplification.

\section{RESULTS}

Mean ( \pm sem) $\Delta 5$ desaturase mRNA relative to $\beta$-actin was $0.94 \pm 0.02$ in liver and $0.90 \pm 0.02$ in mononuclear blood cells (table 5.3). Mean $\triangle 6$ desaturase mRNAs were $1.00 \pm 0.03$ and $0.90 \pm 0.02$, and mean $\Delta 9$ desaturase mRNAs were $1.01 \pm 0.03$ and $0.83 \pm 0.01$ in liver and mononuclear blood cells, respectively. Delta 9 desaturase mRNA in mononuclear blood cells was significantly lower than $\Delta 5$ and $\Delta 6$ desaturase mRNA levels in mononuclear blood cells $(P=0.003)$. The difference in hepatic $\Delta 5$ and $\triangle 6$ desaturase mRNA levels nearly reached statistical significance $(P=0.084)$. Desaturase mRNA levels did not differ between men and women.

Table 5.3 Mean ( \pm sem) mRNA levels of desaturase-enzymes (D) relative to $\beta$-actin in human liver and mononuclear blood cells $(n=14)$

\begin{tabular}{lcccc}
\hline Enzyme & \multicolumn{2}{c}{ Liver } & Mononuclear blood cells \\
\hline$\Delta 5 \mathrm{D}$ & 0.94 & \pm 0.02 & $0.90 \pm 0.02$ \\
$\Delta 6 \mathrm{D}$ & 1.00 & \pm 0.03 & $0.90 \pm 0.02$ \\
$\Delta 9 \mathrm{D}$ & $1.01 \pm 0.03$ & $0.83 \pm 0.01^{\mathrm{a}}$ \\
\hline
\end{tabular}

\footnotetext{
${ }^{a}$ Significantly different from $\Delta 5$ and $\Delta 6$ desaturase mRNA in mononuclear blood cells; $P=0.003$
} 


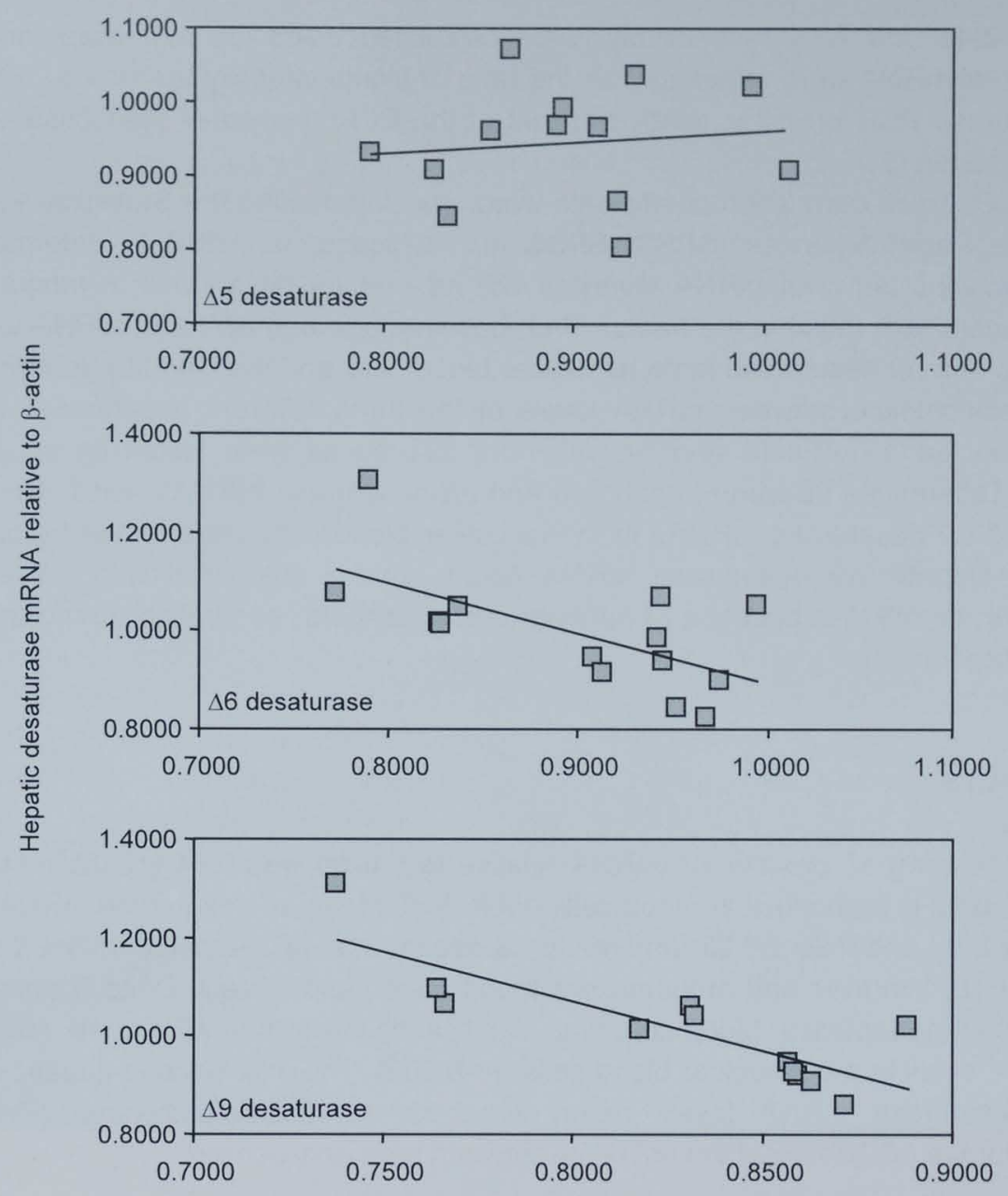

Desaturase mRNA relative to $\beta$-actin in mononuclear blood cells

Figure 5.2 Relationships between $\Delta 5, \Delta 6$ and $\Delta 9$ desaturase mRNA relative to $\beta$-actin in mononuclear blood cells and liver. mRNAs were determined with 29 and 19 cycles for the $\Delta 9$ desaturase, and 29 and 21 cycles for $\Delta 5$ and $\Delta 6$ desaturase for mononuclear blood cells and liver, respectively.

Delta 6 and $\Delta 9$ desaturase mRNAs in mononuclear blood cells were negatively correlated with $\Delta 6$ desaturase $(r=-0.64, P=0.015)$ and $\Delta 9$ desaturase mRNAs ( $r=-0.83, P=0.001)$ in liver, respectively (figure 5.2). No significant relationship was found for $\triangle 5$ desaturase mRNA in mononuclear blood cells and liver $(r=0.11, P=0.725)$. 
Correlations between desaturases within the liver and within mononuclear blood cells were also calculated. Within the liver, $\Delta 5$ and $\Delta 6$ desaturase mRNA, as well as $\Delta 6$ and $\Delta 9$ desaturase mRNA were positively correlated $(r=0.71, P=0.007$, and $r=0.59, P=0.034$, respectively). The relationship between liver $\Delta 5$ and $\Delta 9$ desaturase mRNAs was of borderline significance $(r=0.51, P=0.076)$. Desaturases were not significantly correlated with each other within the mononuclear blood cells.

BMI was not correlated with any of the desaturases, while age was positively correlated with $\triangle 6$ desaturase mRNA in liver $(r=0.60, P=0.023)$. However, when subject 4 (patient with Diabetes Mellitus type 2) was excluded from the analysis, age was not correlated with hepatic $\triangle 6$ desaturase mRNA.

\section{DISCUSSION}

The pivotal role of the liver in the conversion of fatty acids (10) is difficult to study in humans, because the liver is not an easily accessible organ. Circulating mononuclear blood cells, which are of course much easier to sample, may serve as a useful alternative, as these cells also elongate and desaturate fatty acids (2). It is not known, however, whether elongation and desaturation of fatty acids in these cells reflect that in the liver. In the present study, we have therefore examined in humans the relationships between mRNAs levels of the three desaturases in mononuclear blood cells with those in the liver.

Surprisingly, both $\Delta 6$ and $\Delta 9$ desaturase mRNA levels in mononuclear blood cells were negatively correlated with those in the liver. We do not have a clear explanation for this finding, but it can be speculated that an increased supply of precursor fatty acid will increase hepatic desaturase mRNA levels. This may result in increased hepatic LCP-formation and increased LCP-output via very low density lipoproteins (VLDL). In extra hepatic tissues and cells, these LCPs may downregulate the levels of extrahepatic $\Delta 6$ and $\Delta 9$ desaturase mRNAs. Studies with stable isotopes are not helpful to accept or refute this concept. It has been suggested that the relative conversions of ${ }^{13} \mathrm{C} \alpha$-linolenic acid (11) and of linoleic acid (12) are inhibited by the substrate itself. Likewise, the relative conversions of total linoleic acid and $\alpha$-linolenic acid are decreased when the diets are enriched with their elongation and desaturation products arachidonic acid and DHA, respectively $(13,14)$. This, however, does not necessarily mean that the absolute conversion - expressed as the absolute amount of the precursor fatty in the diet that is converted - is also decreased. Unfortunately, fatty acid conversions can not reliably be quantified after adminstration of a single dose of stable isotope (15), as done in these studies (1114). The concept that an increased output of LCPs by the liver may downregulate levels of extrahepatic $\Delta 6$ and $\Delta 9$ desaturase mRNAs seems to be contradicted, however, by the results of a short-term study in rats by Cho et al., who reported a 
decrease in hepatic $\Delta 5$ and $\Delta 6$ desaturase mRNA after supplementation of a high glucose, fat free diet with safflower oil (65\% linoleic acid) (5).

The negative correlation between $\Delta 6$ and $\Delta 9$ desaturase mRNAs in mononuclear blood cells with those in the liver does not necessarily mean that desaturase mRNAs in mononuclear blood cells can not be used to predict those in the liver. Whether mRNA levels in mononuclear blood cells can be used to examine effects of external factors, e.g. diets, on hepatic desaturase mRNA levels need to be examined in future research. In these studies, diet effects on mononuclear blood cell desaturase mRNA levels should be combined with results from stable isotope conversion studies.

We did not find a correlation between $\Delta 5$ desaturase mRNAs in the liver and in the mononuclear blood cells. Delta 5 desaturase mRNA in the liver was, however, significantly correlated with hepatic $\Delta 6$ desaturase and almost significantly correlated with hepatic $\Delta 9$ desaturase, while desaturases were not significantly correlated with each other within the mononuclear blood cells. Thus, the lack of a significant relationship between $\triangle 5$ desaturase mRNA in liver and mononuclear blood cells seems to be caused by mRNA levels in the mononuclear blood cells. This suggests that, unlike $\Delta 6$ and $\Delta 9$ desaturase in mononuclear blood cells and $\Delta 5, \Delta 6$ and $\Delta 9$ desaturase in liver tissue, $\Delta 5$ desaturase mRNA synthesis in mononuclear blood cells is regulated in a different way. Furthermore, if there is truly no relationship between $\Delta 5$ desaturase in mononuclear blood cells and in the liver, this would mean that results of mononuclear blood cells regarding this desaturase can not be extrapolated to liver. It should also be noted that most of our subjects were heavily obese. Whether this may have influenced the relationships observed, is not known, but certainly needs further investigation.

Delta 5 and $\Delta 6$ desaturases are both involved in the conversion of $n-3$ and n- 6 fatty acids, and their gene expressions may differ between tissues. Gene expressions of $\Delta 5$ and $\Delta 6$ desaturases are highest in human liver (5). Furthermore, in human heart, brain and lung also considerable amounts of mRNA are detected, whereas amounts in placenta, skeletal muscle, kidney and pancreas are small. In mononuclear blood cells, mRNA levels of $\Delta 6$ desaturase did not significantly differ from $\Delta 5$ desaturase mRNA, while in the liver the difference nearly reached statistical significance. Cho et al. reported higher $\Delta 6$ desaturase mRNA levels as compared to $\Delta 5$ desaturase mRNA levels in various human tissues (5).

We have observed a positive relationship between $\Delta 5$ and $\Delta 6$ desaturase mRNAs in the liver, which suggests that in man the expression of these two enzymes is regulated in parallel. This notion is supported by studies in rats, in which supplementation of a high glucose fat free diet with safflower or fish oil decreased hepatic mRNA levels of both $\Delta 5$ and $\Delta 6$ desaturase (5).

In mice, a polyunsaturated fatty acid diet reduced hepatic $\Delta 6$ desaturase mRNA (4). This was associated with a suppressed enzyme activity, which was measured in vitro in isolated microsomes using ${ }^{14} \mathrm{C}$ labeled linoleic acid. This 
suggests that - at least in mice - diet-induced changes in $\triangle 6$ desaturase mRNA levels affects $\Delta 6$ desaturase activity into the same direction. It should be kept in mind, however, that mRNA levels do not necessarily reflect the amounts of enzymes formed or enzyme activity.

To summarize, we found $\Delta 5, \Delta 6$ and $\Delta 9$ desaturase mRNAs in both human liver and mononuclear blood cells. Delta 6 and $\Delta 9$ desaturase mRNAs in mononuclear blood cells were negatively correlated with those in the liver, while $\Delta 5$ desaturase mRNA in liver was not correlated with that in the mononuclear blood cells. Hepatic $\Delta 5, \Delta 6$ and $\Delta 9$ desaturase mRNAs were positively correlated with each other. No such intercorrelations were observed within mononuclear blood cells. We conclude that $\Delta 6$ and $\Delta 9$ desaturase mRNAs in mononuclear blood cells may predict mRNA levels in the liver, however, further research is necessary. Combining mononuclear blood cell desaturase mRNA results with stable isotope studies can be expected to extend our knowledge of the conversion pathways of both essential and non-essential fatty acids.

\section{ACKNOWLEDGMENTS}

We gratefully acknowledge the surgeons and operating staff of the department of Chirurgy of the University Hospital Maastricht for providing tissue samples for this study, and we thank the patients for their participation. 


\section{REFERENCES}

1. Kinsella, J. 1991. $\alpha$-Linolenic acid: functions and effects on linoleic acid metabolism and eicosanoid-mediated reactions. In Advances in Food and Nutrition Research. J. Kinsella, editor. Academic Press, San Diego, USA 1-184.

2. Cunnane SC, Keeling PWN, Thompson RPH, and Crawford MA. Linoleic acid and arachidonic acid metabolism in human peripheral blood leucocytes: comparison with the rat. Brit $J$ Nutr 1984;51:209-217.

3. Powell EE, and Kroon PA. Low density lipoprotein receptor and 3-hydroxy-3-methylglutaryl coenzyme A reductase gene expression in human mononuclear leukocytes is regulated coordinately and parallels gene expression in human liver. $J$ Clin Invest 1994;93:2168-2174.

4. Cho HP, Nakamura MT, and Clarke SD. Cloning, expression, and nutritional regulation of the mammalian $\Delta 6$ desaturase. J Biol Chem 1999;274:471-477.

5. Cho HP, Nakamura MT, and Clarke SD. Cloning, expression, and fatty acid regulation of the human $\Delta-5$ desaturase. J Biol Chem 1999;274:37335-37339.

6. Li J, Ding S-F, Habib NA, Fermor BF, Wood CB, and Gilmour RS. Partial characterization of a cDNA for human stearoyl-CoA desaturase and changes in its mRNA expression in some normal and malignant tissues. Int $J$ Cancer 1994;57:348-352.

7. Engels WR. Contributing software to the Internet: the Amplify program. Trends Biochem Sci 1993;18:448-450.

8. Schrauwen P, Troost FJ, Xia J, Ravussin E, and Saris WH. Skeletal muscle UCP2 and UCP3 expression in trained and untrained male subjects. Int $J$ Obes Relat Metab Disord 1999;23:966-972.

9. Cleveland DW, Lopata MA, MacDonald RJ, Cowan NJ, Rutter WJ, and Kirschner MW. Number and evolutionary conservation of alpha- and beta-tubulin and cytoplasmic beta- and gamma-actin genes using specific cloned cDNA probes. Cell 1980;20:95-105.

10. Brenner RR. The desaturation step in the animal biosynthesis of polyunsaturated fatty acids. Lipids 1971;6:556-575.

11. Vermunt SHF, Mensink RP, Simonis AMG, and Hornstra G. Effects of dietary $\alpha$-linolenic acid fatty acids on the conversion and oxidation of ${ }^{13} \mathrm{C}$ - $\alpha$-linolenic acid. Lipids 2000;35:137-142.

12. Emken EA, Adlof RO, and Gulley RM. Dietary linoleic acid influences desaturation and acylation of deuterium-labeled linoleic and linolenic acids in young adult males. Biochim Biophys Acta 1994;1213:277-288.

13. Emken EA, Adlof RO, Duval SM, and Nelson GJ. Effect of dietary arachidonic acid on metabolism of deuterated linoleic acid by adult male subjects. Lipids 1998;33:471-480.

14. Emken EA, Adlof RO, Duval SM, and Nelson GJ. Effect of dietary docosahexaenoic acid on desaturation and uptake in vivo of isotope-labeled oleic, linoleic, and linolenic acids by male subjects. Lipids 1999;34:785-791.

15. Demmelmair $H$, Iser B, Rauh-Pfeiffer A, and Koletzko B. Comparison of bolus versus fractionated oral applications of $\left[{ }^{13} \mathrm{C}\right]$-linoleic acid in humans. Eur J Clin Invest 1999;29:603609. 


\title{
Health effects of trans fatty acids
}

\author{
SHF Vermunt, RP Mensink
}

Based on: Preventive Nutrition: Volume 2: Primary and Secondary Prevention (Bendich A and Deckelbaum RJ eds.) Totowa, NJ: Humana Press, 2001 


\section{INTRODUCTION}

Trans fatty acids differ from their cis counterparts in the trans configuration of at least one double bond. This means that both carbon (C)-atoms adjacent to the double bound are located at opposite sides of an imaginary 'plane' through the double bond. The position of the double bond in the carbon-chain can be counted from the carboxyl-end $(-\mathrm{COOH})$ of the molecule, which is symbolized as ' $\Delta$ ', or from the methyl-end $\left(-\mathrm{CH}_{3}\right)$, which is symbolized as ' $n$ minus'. Thus, ' $n-3$ ' means that the double bond is located at the third carbon atom from the methyl-end. Chain elongation and desaturation always occur at the carboxyl-end of the fatty acid molecule. Consequently, the position of the first double bond at the methyl-end will not change during conversion reactions. Figure 1.1 shows $\alpha$-linolenic acid (C18:3n-3), which belongs to the (n-3) family, and one of its trans isomers $C 18: 3 n-3$ $\Delta 9 c, 12 c, 15 t r$. These two molecules are geometrical isomers.

Trans fatty acids can be formed from dietary (poly-) unsaturated fatty acids by bacteria in the first stomach (rumen) of ruminant animals and by industrial hydrogenation and deodorization. In order to improve the chemical, physical and sensory characteristics, vegetable oils are often hydrogenated to make them suitable for food. During this industrial process, the cis double bonds of polyunsaturated fatty acids in particular are saturated (hydrogenated) by adding hydrogen to the oil. When all double bonds are hydrogenated, a saturated fatty acid is formed. However, the cis configuration may also isomerize without net uptake of hydrogen, which results in trans double bonds. Furthermore, the double bonds can migrate along the molecule, resulting in positional isomers. In this way, linoleic acid can be converted into many different molecules (figure 6.1). Trans monounsaturated fatty acids in particular are formed by hydrogenation.

Deodorization is the last step in the refining process, during which oils are prepared for use as an ingredient in margarine, shortening, cooking oil, etcetera Trans polyunsaturated fatty acids can be easily formed by deodorization of oil $(1,2)$. Finally, trans polyunsaturated fatty acids can be formed during heat or frying treatments (3).

This chapter focuses on the effects of trans fatty acids on various risk parameters for coronary heart disease (CHD), including lipids and lipoproteins, low density lipoprotein (LDL) oxidation and hemostasis, and on cancer. Furthermore, the metabolism of trans fatty acids and their effects on the desaturation and elongation of other fatty acids is discussed. 


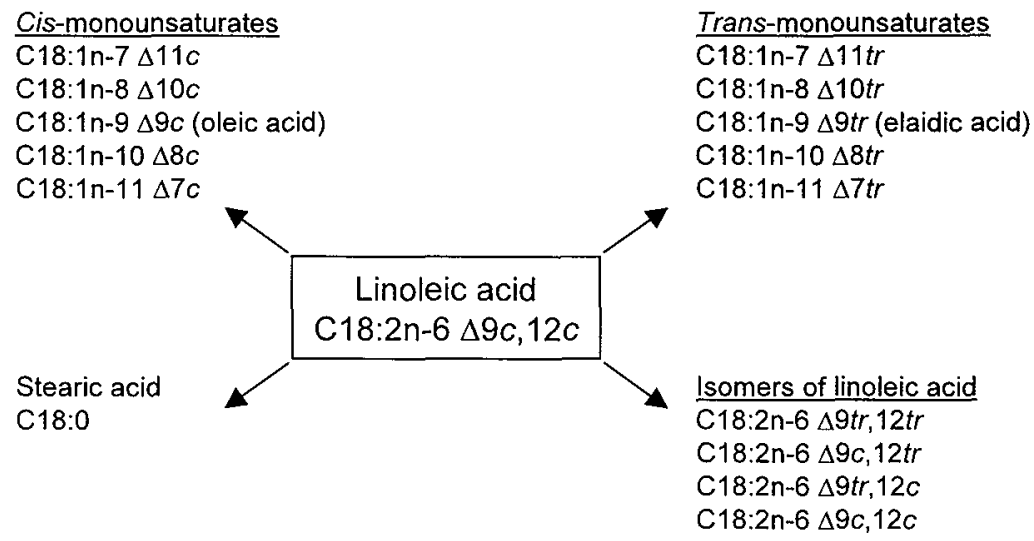

Figure 6.1 Potential conversions of linoleic acid into its positional and geometrical isomers

\section{TRANS FATTY ACIDS IN FOODS}

The trans fatty acid intake of the United States (US)-population has been estimated using availability or disappearance data, food frequency questionnaires, analysis of self selected diets, duplicate portion analysis and/or adipose tissue composition data. The most recent estimate of the daily total trans fatty acid intake in the US is $2.6 \%$ of energy or $7.4 \%$ of total fat intake for the total population aged 3 years and older (4). Estimates ranged from $2.6 \%$ to $2.8 \%$ and from $7.1 \%$ to $7.9 \%$, respectively across different age and gender groups. Values were based on results of the 1989-1991 Continuing Survey of Food Intakes by Individuals (CSFII) of the US Department of Agriculture (USDA), and the trans fatty acid contents of specific foods calculated from a database compiled by the USDA. In Europe, the daily total trans fatty acid intake varied between $0.5 \%$ of energy in Italy to $2.0 \%$ of energy in Iceland (5). These data were based on analysis of food samples and food consumption-survey data, which were collected in 1995-1996 in 14 European countries.

Trans monounsaturated fatty acids contribute about $85 \%$ of total trans fatty acids (4). Trans monounsaturates from milk and meat fat are produced by bacteria in the rumen of animals. The major trans isomer in fat from ruminants is vaccenic acid (C18:1n-7 $\Delta 11$ tr), although trans double bonds at the $\Delta 5$ to $\Delta 16$ positions are also present. Non-ruminants that are fed diets containing trans $\mathrm{C} 18: 1$ also have trans C18:1 isomers in their tissues.

More important sources of trans monounsaturated fatty acids, however, are partially hydrogenated vegetable oils and products made from these oils. Fried foods and stick margarine are the major contributors to the trans fatty acid intake in the US, as shown in table 6.1. Most trans double bonds are at the $\Delta 10, \Delta 9$ or $\Delta 8$ position. 
Trans polyunsaturated fatty acids are mainly formed during the deodorization process. In US vegetable oils, the degree of isomerisation of linoleic acid and $\alpha-$ linolenic acid range from $0.3 \%$ to $3.3 \%$ and from $6.6 \%$ to $37.1 \%$, respectively (6). Most trans polyunsaturated fatty acids are mono-trans isomers of linoleic and $\alpha$ linolenic acid, while only a few di-trans isomers are detected. Finally, trans polyunsaturated fatty acids are formed during heat treatment of vegetable oils, like during deep frying processes (3). Again most trans isomers are mono-trans isomers.

Table 6.1 Per capita consumption of trans fatty acids from primary food sources

\begin{tabular}{lccc}
\hline Food source & $\begin{array}{c}\text { Trans fatty acids } \\
\text { g/day }\end{array}$ & $\begin{array}{c}\text { Total fatty acids } \\
\text { g/day }\end{array}$ & $\begin{array}{c}\text { Trans fatty acids } \\
\text { \% of total fatty acids }\end{array}$ \\
\hline Fried foods & 0.8 & 3.9 & 20.5 \\
Margarine, stick & 0.5 & 1.7 & 29.4 \\
Bread, commercial & 0.3 & 4.0 & 7.5 \\
Cakes and related baked goods & 0.3 & 2.9 & 10.3 \\
Savory snacks & 0.3 & 2.3 & 13.0 \\
Margarine, soft and spreads & 0.2 & 1.2 & 16.7 \\
Cookies & 0.2 & 1.2 & 16.7 \\
Milk & 0.2 & 5.5 & 3.6 \\
Butter & 0.1 & 1.3 & 7.7 \\
Crackers & 0.1 & 0.5 & 20.0 \\
Household shortenings & 0.1 & 0.4 & 25.0 \\
Ground beef & 0.1 & 3.4 & 2.9 \\
\hline
\end{tabular}

Values are based on results of the 1989-1991 CSFII of the USDA, and the trans fatty acid composition data is adapted from Nutrient Data Bank Bulletin Board (USDA)

\section{METABOLISM}

Digestion, absorption and incorporation into blood lipids

Trans fatty acids in margarines and dairy fats are incorporated in triacylglycerols, while in meat trans fatty acids are found in phospholipids. Figure 6.2 shows the metabolic pathways of trans fatty acids after dietary intake. After ingestion, triacylglycerols are split by pancreatic lipase into free fatty acids and sn2monoglycerides. Small portions remain as diglycerides. Phospholipids are split by pancreatic phospholipases, which remove the fatty acid from the sn1 or sn2 position of the phospholipid. Consequently, lysophospholipids and free fatty acids are formed. The digestion of trans monounsaturated fatty acids does not differ from that of their cis-isomers (7). 


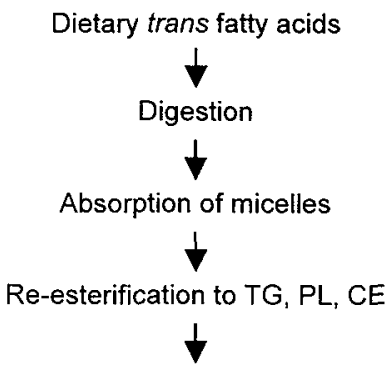

Transport as chylomicrons in lymph to the liver

Storage in adipose tissue (mainly as TG)
Incorporation into membrane lipids (mainly as PL)

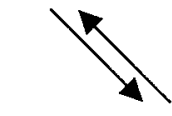

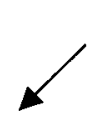

Oxidation to provide energy
Free fatty acids

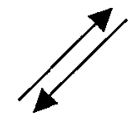

Elongation/desaturation

LC-PUFA

Figure 6.2 Simplified scheme of trans fatty acid metabolism in humans. TG, triacylglycerols; PL, phospholipids; CE, cholesteryl esters; LC-PUFA, long chain polyunsaturated fatty acids

After ingestion, fatty acids are absorbed by the enterocyte after formation of micelles. Absorption of oleic acid and its positional and geometrical isomers is comparable (8-11). In the enterocyte, free fatty acids, sn2-monoglycerides and diglycerides are re-esterified to triacylglycerols, cholesteryl esters and phospholipids. The incorporation of positional and geometrical isomers of $c 18: 1 n-9 \Delta 9 c$ in triacylglycerols, cholesteryl esters and phospholipids may differ from that of $\mathrm{C} 18: 1 \mathrm{n}-9$ $\Delta 9 c$ (11). After re-esterification, lipids may be taken up by chylomicrons, which transport the fatty acids through the lymph to the liver. Then, trans fatty acids are transported by lipoproteins through the blood stream. The incorporation of trans isomers of C18:1n-9 $\Delta 9$ into very low density lipoproteins (VLDL), low density lipoproteins (LDL) and high density lipoproteins (HDL) is lower than that of $\mathrm{C} 18: 1 \mathrm{n}-9$ $\Delta 9 c(9-11)$. 
Trans fatty acids may also be incorporated into tissue phospholipids, stored in adipose tissue, desaturated and elongated into longer chain polyunsaturated fatty acids or oxidized via $\beta$-oxidation and peroxisomal systems.

\section{Tissue levels}

In the human body, trans fatty acids are found in triacylglycerols, mainly at positions 1 and 3 . The trans fatty acid content of adipose tissue for US subjects is about $4 \%$ of total fatty acids (12). Approximately $70 \%$ of the trans fatty acids are C18:1 isomers, which have their double bonds on the $\Delta 8,9,10,11,12$ or 13 position. Trans $C 16: 1$ isomers, which originate mainly from dairy fat, are also found in adipose tissue. About $20 \%$ of the trans isomers in adipose tissue are trans $\mathrm{C} 18: 2 \mathrm{n}-6$ isomers. Both monotrans $(\Delta 9 c, 12 \operatorname{tr}$ and $\Delta 9 t r, 12 c)$ and di-trans $(\Delta 9 \operatorname{tr}, 12 \operatorname{tr}) \mathrm{C} 18: 2 \mathrm{n}-6$ isomers, and several trans $\mathrm{C} 18: 3$ isomers have been detected in adipose tissue.

Trans fatty acids in other tissues than adipose tissue are incorporated mainly into phospholipids predominantly at position 1. Trans C18:1 and C18:2 fatty acids have been found in human kidney, brain, heart, liver, aorta, jejunum and human milk $(13,14)$, while trans $\mathrm{C} 18: 3$ has been detected in platelets and human milk $(15,16)$.

\section{Desaturation and elongation}

Human liver microsomal complexes contain 3 different desaturation enzymes: $\Delta 9, \Delta 6$ and $\Delta 5$ desaturases, which insert double bonds at the $\Delta 9, \Delta 6$ or $\Delta 5$ position of the fatty acid molecule, respectively. Furthermore, fatty acids can be elongated by addition of a two-carbon unit to the fatty acids. In this way, stearic acid, linoleic acid and $\alpha$-linolenic acid are converted into their longer chain metabolites (figure 1.2), which play an important role in many physiological processes (17).

Trans fatty acids are desaturated by the same enzymes as cis fatty acids. Except for $\Delta 8, \Delta 9$ and $\Delta 10$ trans isomers, $C 18: 1$ positional isomers are good substrates for $\Delta 9$ desaturase (18). Consequently, cis,trans and trans,cis fatty acids are formed. Some trans isomers of $\mathrm{C} 18: 1$ are also substrates for $\Delta 6$ and $\Delta 5$ desaturase (19). In addition, C18:1 trans isomers can be elongated into C20 and C22 fatty acids.

Trans linoleic acid can be converted into trans isomers of arachidonic acid (C20:4n-6), however, this occurs at a lower rate than all-cis C18:2n-6 (20). Trans isomers of $\alpha$-linolenic acid can be converted into trans isomers of docosahexaenoic acid (DHA; C22:6n-3) $(21,22)$. Observations, however, are mainly based on animal and in vitro studies and may be different for the in vivo situation in man.

\section{Influence of trans fatty acids on desaturation and elongation}

Because trans and cis fatty acids can be converted by the same desaturase and elongase enzymes, competition between fatty acids exists. Both the cis and trans monoenoic positional isomers have been reported to inhibit the conversion of linoleic acid into arachidonic acid in cultured glioma cells (23). Furthermore, in human skin 
fibroblasts, C18:1n-9 $\Delta 9$ tr increased $\Delta 9$ desaturation of stearic acid, while C18:1n-7 $\Delta 11$ tr and C18:2n-6 $\Delta 9$ tr, 12 tr had no effect (24). In addition, C18:1n-9 $\Delta 9$ tr and C18:2n-6 $\Delta 9 \operatorname{tr}, 12 \operatorname{tr}$ inhibited $\Delta 6$ desaturation. However, because levels of cis $\mathrm{n}-3$ and $\mathrm{n}-6$ fatty acids in human tissues are much higher than levels of trans fatty acids, these fatty acids are physiologically more important competitive inhibitors for the conversion of linoleic acid into arachidonic acid and $\alpha$-linolenic acid into DHA as compared to trans isomers.

\section{Oxidation}

Only a few human studies have been carried out to examine the effects of trans fatty acids on fatty acid oxidation. So far, it is only known that the whole body oxidation, measured with ${ }^{13} \mathrm{C}$ labeled fatty acids, and oxidation rates by human heart homogenates were equal between the trans fatty acid elaidic acid and the non-trans fatty acid with equivalent chain length oleic acid $(25,26)$.

\section{EFFECTS OF TRANS MONOUNSATURATED FATTY ACIDS ON SERUM LIPIDS AND LIPOPROTEINS}

\section{Total cholesterol, $L D L$ and HDL cholesterol}

The effect of dietary trans monounsaturated fatty acids on serum cholesterol concentrations has been investigated since the early 1960 s. Most studies have found increased serum total cholesterol levels in humans consuming partially hydrogenated vegetable oil. Results, however, were not uniform (27). In addition, these earlier studies did not examine the relationship between dietary trans monounsaturated fatty acids and the distribution of cholesterol among lipoproteins. The first controlled intervention trial in which the effects of trans monounsaturated fatty acid intake on serum LDL and HDL cholesterol were examined, was reported in 1990 by Mensink and Katan (28). Twenty-five men and 34 women were fed a diet high in oleic acid, high in trans isomers of oleic acid or high in a mixture of the saturated fatty acids lauric and palmitic acid. Each diet was fed for 3 weeks. The level of trans C18:1 in the trans diet was $11 \%$ of total energy. Results showed that trans $\mathrm{C} 18: 1$ significantly raised total and $L D L$ cholesterol levels by $0.26 \mathrm{mmol} / \mathrm{l}$ and $0.37 \mathrm{mmol} / \mathrm{l}$, respectively, and lowered $\mathrm{HDL}$ cholesterol levels by $0.17 \mathrm{mmol} / \mathrm{l}$ as compared to oleic acid. Later studies investigated effects of lower intakes of trans fatty acids (table 6.2) (29-33). The general conclusion is that trans fatty acids and saturated fatty acids have similar effects on LDL cholesterol, but increase LDL cholesterol as compared to monounsaturated fatty acids and polyunsaturated fatty acids. Also, trans fatty acids lower HDL cholesterol as compared to the other major categories of fatty acids. Because of differences in trans fatty acid intake, intakes of other dietary fatty acids and experimental designs, results of studies are difficult to compare. Therefore, results of five studies have been combined and effects of trans fatty acids on 
lipoproteins were compared with those of oleic acid (27). It is suggested that each additional percent of dietary energy as trans monounsaturated fatty acids at expense of oleic acid results in an increase in LDL cholesterol levels of $0.040 \mathrm{mmol} / \mathrm{l}$ and a decrease in HDL cholesterol levels of $0.013 \mathrm{mmol} / \mathrm{l}$ (figure 6.3) (27). Such changes in $\mathrm{LDL}$ and HDL cholesterol are associated with an increased risk for CHD.

\section{Lipoprotein(a)}

Lipoprotein(a) $(L p(a))$ is a LDL molecule with an additional glycoprotein (apoprotein (a)), attached through a disulfide link. High levels of $L p(a)$ are associated with an increased risk for CHD (34). Therefore, effects of trans monounsaturated fatty acids on $L p(a)$ have been investigated in several intervention studies. Nestel et al. found that $L p(a)$ levels were significantly higher on a trans diet, as compared to palmitic acid, but not as compared to oleic acid (35). Mensink et al. reported significantly higher $L p(a)$ levels on trans fatty acids compared to saturated fatty acids, oleic acid, stearic acid and linoleic acid (36). Lichtenstein et al. did not find an increase in $L p(a)$ concentrations (37), while Almendingen et al. found increased $L p(a)$ levels when butter was exchanged for partially hydrogenated soybean oil or fish oil (29). Aro et al. observed increased $L p(a)$ levels on a trans fatty acid diet as compared to a dairy fat based diet (30). In conclusion, most studies showed that trans monounsaturated fatty acids may raise $L p(a)$ levels, in particular in subjects who already have high $L p(a)$ levels (36).

\section{Triacylglycerols}

An elevated fasting triacylglycerol level is also a risk marker for CHD (38). Katan et al. summarized studies concerning the trans monounsaturated fatty acid effect on fasting triacylglycerol levels. It was calculated that each additional percent of energy as trans monounsaturated fatty acids at the expense of oleic acid increases triacylglycerol levels by $0.013 \mathrm{mmol} / /(27)$.

\section{Conclusion}

Trans monounsaturated fatty acids raise serum $L D L$ cholesterol, $L p(a)$ and triacylglycerol levels, while HDL cholesterol levels are lowered. The effects of trans polyunsaturated fatty acids on serum lipids and lipoproteins are not yet known. 


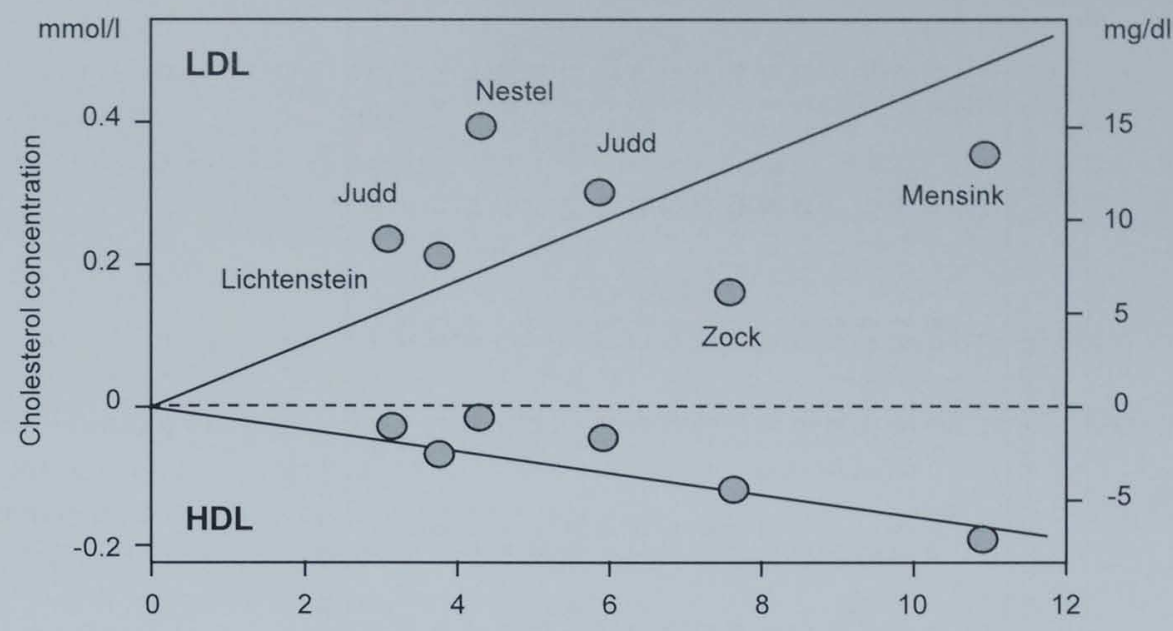

$\%$ of energy from trans-C18:1

Figure 6.3 Effects of exchanging oleic acid for trans monounsaturated fatty acids on LDL and HDL cholesterol levels. Data are derived from six previous studies. Regression coefficients are $0.040 \mathrm{mmol} / \mathrm{l}$ for $\mathrm{LDL}$ and $-0.013 \mathrm{mmol} / \mathrm{l}$ for $\mathrm{HDL}$ cholesterol, which represent the predicted changes in serum LDL and HDL cholesterol levels if $1 \%$ of daily energy intake from oleic acid is replaced by trans monounsaturated fatty acids (27).

\section{Mechanism}

Although a number of studies have shown that dietary trans fatty acids affect serum $\mathrm{LDL}$ and $\mathrm{HDL}$ cholesterol levels, the underlying mechanisms for these effects are still not understood. It has been hypothesized that cholesteryl ester transfer protein (CETP) is involved. CETP transfers cholesteryl esters from HDL to the apolipoprotein B-containing lipoproteins LDL and VLDL in exchange for triacylglycerol. Indeed, an increased CETP activity has been found in volunteers who consumed a trans fatty acid enriched diet $(39,40)$, and after addition of trans fatty acids to human plasma in vitro (41). However, some other studies did not confirm these results $(30,42)$.

Lecithin:cholesterol acyltransferase (LCAT) has also been suggested to be involved. LCAT, which is bound to HDL, esterifies free cholesterol from tissues by the transfer of an acyl group from phosphatidyl choline (PC). Since a significant part of the dietary trans fatty acids is incorporated into PC (11), a few studies have investigated the effect of trans fatty acids on LCAT. Subbaiah et al. reported a decrease of LCAT activity on trans fatty acids (43). Van Tol et al., however, did not demonstrate an effect of trans fatty acids on LCAT activity (40). 


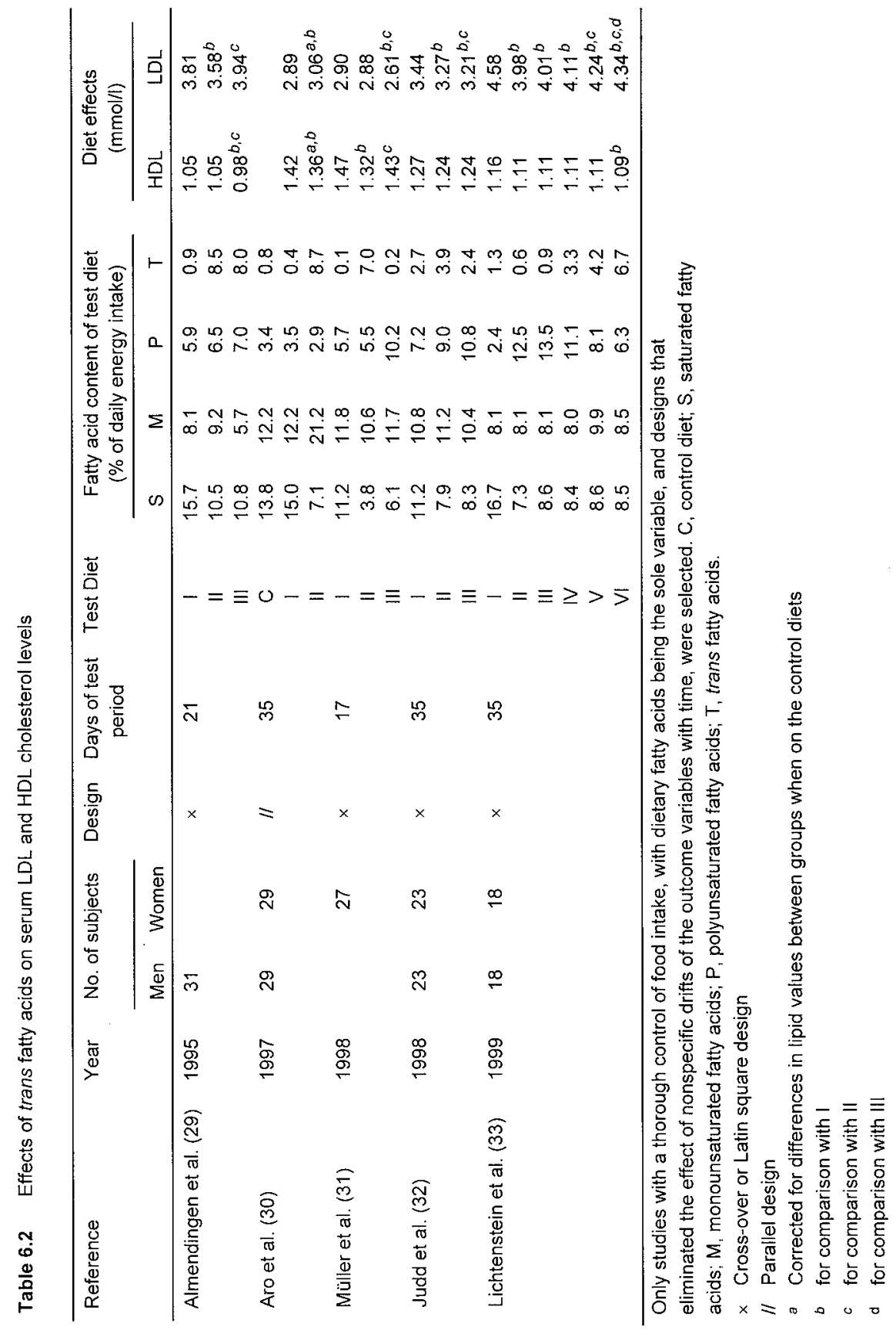


In the liver, fatty acids from chylomicrons are esterified to free cholesterol by acyl-CoA:cholesterol acyl transferase (ACAT). The affinity of ACAT differs for different fatty acids. A low affinity of the enzyme for a particular fatty acid may result in an increase of free cholesterol in the liver. This causes a decrease of the LDL receptor activity. Since the LDL receptor is involved in the uptake of LDL from plasma, a decreased LDL receptor activity may result in higher LDL concentrations in plasma. Thus, through this pathway dietary fatty acids may influence the plasma LDL cholesterol concentration. In a hamster study, Woollett et al. demonstrated that trans C18:1 decreased the cholesteryl ester concentration in the liver relative to oleic acid (44). This could suggest that the affinity of ACAT is lower for trans C18:1 as compared to oleic acid, which may result in higher free cholesterol levels in the liver. In addition, the plasma LDL cholesterol concentration was shown to be increased and the LDL receptor activity was decreased on trans C18:1. Possibly, trans C18:1 affects plasma LDL cholesterol via the pathway described above. This mechanism, however, has not been investigated in man. Finally, de novo cholesterol synthesis did not differ between a high trans-hydrogenated corn oil rich diet as compared to an unhydrogenated corn oil rich diet low in trans fatty acids in healthy volunteers (45).

\section{EFFECTS OF TRANS FATTY ACIDS ON OTHER RISK FACTORS FOR CORONARY HEART DISEASE}

\section{LDL oxidation}

Free radicals may initiate oxidation of polyunsaturated fatty acids in the LDL particle, which eventually may lead to formation of an atherosclerotic plaque. The fatty acid composition of the LDL particle is a reflection of the fatty acid composition of the diet. Consequently, increased dietary trans fatty acid intake leads to higher proportions of trans fatty acids in the LDL particle. Whether this influences the susceptibility for LDL to oxidation has been investigated in several intervention trials. However, no effect on in vitro LDL oxidation was found after consumption of trans monounsaturated fatty acids as compared to oleic acid or palmitic acid (35), of hydrogenated as compared to unhydrogenated corn oil (45), or of partially hydrogenated fish oil or partially hydrogenated soybean oil as compared to butter-fat (46). Therefore, it appears that, at least in vitro, trans fatty acids have not a major impact on LDL-oxidizability.

\section{Hemostasis}

Human studies investigating the effects of trans fatty acids on platelet aggregation, coagulation and fibrinolysis are limited. Almendingen et al. have found that a diet enriched in partially hydrogenated soybean oil increased concentrations of plasminogen activator inhibitor Type 1 (PAl-1) antigen and PAl-1 activity as compared with a diet high in partially hydrogenated fish oil or butter fat (47). This indicates an inhibition of the fibrinolytic pathway. Fibrinogen levels were increased on 
butter compared to partially hydrogenated fish oil, while levels of factor VII were not affected by the diets. It was therefore concluded that partially hydrogenated fish oil had the least unfavorable hemostatic effects, while partially hydrogenated soybean oil had the worst. Mutanen and Aro did not see differences in concentrations of fibrinogen, factor VII coagulation activity, tissue type plasminogen activity and PAl-1 activity between dietary trans fatty acids from partially hydrogenated vegetable oil and stearic acid in healthy subjects (48). However, collagen-induced platelet aggregation was significantly decreased on trans fatty acids, as compared to stearic acid (49). No effects of trans fatty acids were found on in vitro tromboxane $B_{2}$ production, adenosine diphosphate (ADP)-induced aggregation, and production of endothelial prostacyclin $\left(\mathrm{PGI}_{2}\right)(49)$.

Few other studies have investigated the effects of trans polyunsaturated fatty acids on human platelet aggregation. Collagen-induced platelet aggregation was less inhibited on trans isomers of the long chain polyunsaturated fatty acids from fish, eicosapentaenoic acid (EPA) and DHA as compared to their cis isomers when these fatty acids were incorporated into platelets (15). O'Keefe et al. has also shown this for EPA in arachidonic acid-induced platelet aggregation, but not for DHA (50).

In conclusion, the effects of trans fatty acids on aggregation, coagulation and fibrinolysis have hardly been investigated. At present, however, it does not seem that trans fatty acids have significant effects on hemostasis.

\section{EPIDEMIOLOGICAL STUDIES}

Various approaches have been used in epidemiological studies to examine the relationship between the intake of trans fatty acids and the risk for $\mathrm{CHD}$. Because serum LDL cholesterol levels are negatively associated with CHD and high levels of HDL cholesterol are thought to be anti-atherogenic, some epidemiological studies have focussed on the relation between the proportion of trans fatty acids in tissues, which reflects dietary intakes, or the dietary trans fatty acid intake and the lipid profile (51-53). In the cross-sectional study of Hudgins et al. no significant correlations between total trans fatty acids in adipose tissue and plasma HDL cholesterol, total to $\mathrm{HDL}$ and LDL to HDL cholesterol ratios, and triacylglycerol were observed in Caucasian men (51). On the contrary, in another cross-sectional study the energy adjusted trans fatty acid intake $(3.4 \pm 1.2 \mathrm{~g} /$ day, mean $\pm \mathrm{sd})$ was positively related to serum LDL cholesterol, and total to $\mathrm{HDL}$ and LDL to HDL cholesterol ratios and inversely related to HDL cholesterol (52). In the case-control study of Siguel and Lerman, the relationships between plasma trans fatty acids and lipid profile, and between plasma trans fatty acids and risk for CHD, were investigated (53). It was shown that trans-16:1 was positively related to plasma total and LDL cholesterol, triacylglycerol and risk for $\mathrm{CHD}$, and negatively related to $\mathrm{HDL}$ cholesterol and the $\mathrm{HDL}$ to total cholesterol ratio. Altogether, results of these studies are in agreement 
with dietary intervention studies reporting that trans fatty acids have a negative impact on the lipid profile. Most of these studies, however, did not address the question if high intakes of trans fatty acids are related to the risk for CHD.

In case control studies, the proportion of trans fatty acids in tissues or the dietary trans fatty acid intake of case subjects, e.g. subjects with CHD, has been compared with that of control subjects, e.g. subjects without CHD (13,54-60). Some studies suggested higher trans-C16:1 $(54,55)$ or total trans fatty acid intakes $(60)$ in cases as compared to controls, while other studies have not found any association between trans fatty acids and CHD-risk $(13,56,57,59,61)$. One study even showed that the proportion of trans-18:1 in adipose tissue was negatively associated with the risk for CHD (58). Case-controls studies, however, have the disadvantage that they are sensitive to information bias, selection bias and confounding.

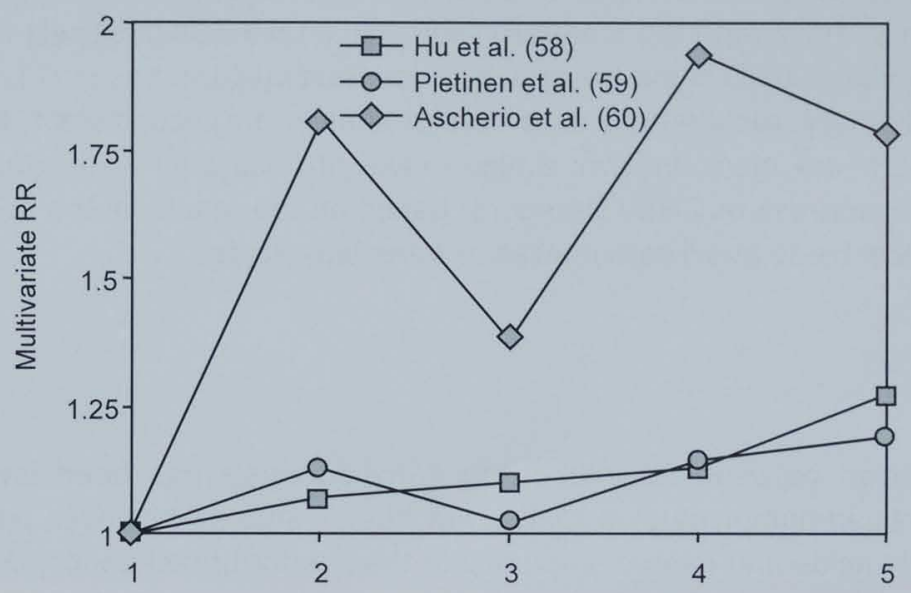

Quintile of trans fatty acid intake

Figure 6.4 Multivariate relative risk of coronary heart disease according to the quintiles of trans fatty acid intake of 3 cohort studies: The Nurses Health study of $\mathrm{Hu}$ et al. (62), the $\alpha$ Tocopherol, $\beta$-Carotene Cancer Prevention Study of Pietinen et al. (63), and The Health Professionals Follow-up Study of Ascherio et al. (64).

Prospective cohort studies suffer from less of the disadvantages attributed to case control studies. Four cohort studies have examined the potential relationship between the trans fatty acid intake and the risk for CHD. In the Nurses' Health Study, the relative risk (RR) of CHD was 1.27 (95\% confidence interval $(\mathrm{CI}), 1.03$ to 1.56$)$ for the highest quintile of trans fatty acid intake (mean intake of $2.9 \%$ of energy) relative to the lowest (mean intake of $1.3 \%$ of energy) after adjustment for age and other 
CHD risk factors (62). This means that women who consume $2.9 \%$ of energy as trans fatty acids per day, have a $27 \%$ higher risk for CHD as compared to women with a trans fatty acid intake of $1.3 \%$ of energy. Pietinen et al. found in the Finnish $\alpha$ Tocopherol, $\beta$-Carotene Cancer Prevention Study a positive association between the trans fatty acid intake and risk of coronary death after adjustment for age, supplementation group and several coronary risk factors (63). The RR for CHD was $1.39(95 \% \mathrm{Cl}, 1.09$ to 1.78$)$ for the highest quintile of trans fatty acid intake (median intake of $5.6 \mathrm{~g} /$ day) as compared to the lowest (median intake of $1.3 \mathrm{~g} /$ day). In addition, in the Health Professionals Follow-up Study, subjects in the highest quintile of trans intake (median intake of $4.3 \mathrm{~g} /$ day) had a $78 \%$ (RR of $1.78 ; 95 \% \mathrm{Cl}, 1.11$ to 1.84) higher risk on fatal CHD as compared to subjects in the lowest quintile of trans intake (median intake of $1.5 \mathrm{~g} / \mathrm{day}$ ) after controlling for age and several coronary risk factors (64). Multivariate RRs of these three cohort studies are summarized in figure 6.4 , which shows that multivariate RRs increase with trans fatty acid intakes. Finally, Kromhout et al. have reported that trans fatty acid intake was positively related to 25year mortality from CHD in the Seven Countries Study (65).

In summary, results from case control studies are inconsistent. In the cohort studies, results are more uniform: a high intake of trans fatty acids was associated with an increased risk of CHD. Therefore, based on the results of the cohort studies, it seems advisable to avoid high intakes of trans fatty acids.

\section{CANCER}

The association between fat intake and carcinogenesis has been investigated in many animal and human studies. Only a few human studies, however, have focussed on trans fatty acids and cancer, in particular the risk for breast cancer. Holmes et al. found in the Nurses' Healthy Study, a large prospective cohort study, a relative risk on breast cancer of $0.92(95 \% \mathrm{Cl}, 0.86-0.98)$ when the trans fatty acid intake would increase with $1 \%$ of energy (66).

Three case-control studies have related the trans fatty acid content of adipose tissue to cancer risk. In the EURAMIC study, the trans fatty acid content of subcutaneous adipose tissue was positively associated with risk for breast cancer (67). On the contrary, in women with breast cancer the trans fatty acid content in adipose tissue was negatively associated with having breast cancer as well as cancer in lymph nodes (68). Finally, London et al. did not find an association between the trans fatty acid content of subcutaneous adipose tissue and breast cancer risk (69).

Human studies investigating the relationship between trans fatty acids and other classes of cancers are scarce. In the EURAMIC study, a significant correlation was found between the amount of trans fatty acids in adipose tissue and the incidence of colon cancer. No association was found with prostate cancer $(70)$. In 
conclusion, there is not a consistent relationship from human studies between the intake and/or tissue levels of trans monounsaturated fatty acids and cancer risk.

\section{CONCLUSIONS AND RECOMMENDATIONS}

The digestion and absorption of trans monounsaturated fatty acids are comparable with those of their cis isomers. However, incorporation of various trans monoenoic isomers into lipid classes and lipoproteins appears to be lower than that of the cis isomers. Furthermore, both trans monounsaturated and polyunsaturated fatty acids can be desaturated and elongated into longer chain more unsaturated metabolites. However, conversion of trans linoleic acid may be less than that of linoleic acid. Trans monounsaturated fatty acids inhibit the conversion of linoleic acid, while conversion of stearic acid increases. The oxidation seems to be similar between cis and trans isomers. These processes, however, have mainly been investigated in animal and in vitro studies. More human in vivo studies are therefore necessary.

Most studies on the effects of trans fatty acids and health have focussed on trans monounsaturated fatty acids, and effects of trans polyunsaturated fatty acids are hardly known. Trans monounsaturated fatty acids increase serum LDL cholesterol, triacylglycerols and $L p(a)$ concentrations and decrease serum HDL cholesterol as compared with oleic acid. The underlying mechanisms for these effects are not exactly known. Furthermore, trans monounsaturated fatty acids seem to have no major impact on LDL-oxidizability, platelet aggregation, coagulation and fibrinolysis. Several prospective epidemiological studies have shown no correlation between trans fatty acids and cancer risk, while a positive association between trans fatty acids and the risk for CHD was reported. Therefore, a limitation of the trans fatty acid intake as recommended by the American Heart Association is justified (71). 


\section{REFERENCES}

1. Ackman R, Hooper S, and Hooper D. Linolenic acid artifacts from the deodorization of oils. JAOCS 1974;51:42-49.

2. Wolff R. Further studies on artificial geometrical isomers of $\alpha$-linolenic acid in edible linolenic acid-containing oils. JAOCS 1993;70:219-224.

3. Grandgirard A, Sébédio J, and Fleury J. Geometrical isomerization of linolenic acid during heat treatment of vegetable oils. JAOCS 1984;61:1563-1568.

4. Allison D, Egan S, Barraj L, Caughman C, Infante $M$, and Heimbach J. Estimated intakes of trans fatty and other fatty acids in the US population. J Am Diet Ass 1999;99:166-174.

5. Hulshof K, Van Erp-Baart M, Anttolainen M, et al. Intake of fatty acids in Western Europe with emphasis on trans fatty acids: The TRANSFAIR study. Eur J Clin Nutr 1999;53:143-157.

6. O'Keefe S, Gaskins-Wright S, Wiley V, and Chen Chen I. Levels of trans geometrical isomers of essential fatty acids in some unhydrogenated U.S. vegetable oils. J Food Lipids 1994;1:165-176.

7. Emken E. Do trans acids have adverse health consequences? In: Health effects of dietary fatty acids (Nelson G, ed.) Champaign, IL: American Oil Chemists Society, 1991:245-260.

8. Emken E, Dutton $H$, Rohwedder W, Rakoff $H$, and Adlof R. Distribution of deuterium-labeled cis and trans-12-octadecemoic acids in human plasma and lipoprotein lipids. Lipids 1980;15:864-871.

9. Emken E, Adlof R, Rohwedder W, and Gulley R. Incorporation of deuterium-labeled trans- and cis-13-octadecenic acids in human plasma lipids. J Lipid Res 1983;24:34-46.

10. Emken E, Rohwedder W, Adlof R, DeJarlais W, and Gulley R. Absorption and distribution of deuterium-labeled trans- and cis-11-octadecenoic acid in human plasma and lipoprotein lipids. Lipids 1986;21:589-595.

11. Emken E, Adlof R, Rohwedder W, and Gulley R. Incorporation of trans-8- and cis-8octadecenoic acid isomers in human plasma and lipoprotein lipids. Lipids 1989;24:61-69.

12. Kris-Etherton $P$, ed. Trans fatty acids and coronary heart disease risk. Am $J$ Clin Nutr 1995;62:655S-708S.

13. Heckers $\mathrm{H}$, Korner $\mathrm{M}$, Tuschen $\mathrm{T}$, and Melcher $\mathrm{F}$. Occurence of individual trans-isomeric fatty acids in human myocardium, jejunum and aorta in relation to different degrees of atherosclerosis. Atherosclerosis 1977;28:389-398.

14. Adlof $R$, and Emken E. Distribution of hexadecenoic, octadecenoic and octadecadienoic acid isomers in human tissue lipids. Lipids 1986;21:543-547.

15. Chardigny J, Sébédio J, Juanéda $P$, Vatèle J, and Grandgirard A. Occurrence of $n-3$ trans polyunsaturated fatty acids in human platelets. Nutr Res 1993;13:1105-1111.

16. Chardigny $J$, Wolff $R$, Mager $E$, Sébédio $J$, Martine $L$, and Juanéda $P$. Trans mono- and polyunsaturated fatty acids in human milk. Eur J Clin Nutr 1995;49:523-531.

17. Kinsella JE. $\alpha$-Linolenic acid: functions and effects on linoleic acid metabolism and eicosanoid-mediated reactions. In: Advances in Food and Nutrition Research (Kinsella JE, ed.) San Diego: Academic Press, 1991:1-184.

18. Mahfouz M, Valicenti A, and Holman R. Desaturation of isomeric trans-octadecenoic acids by rat liver microsomes. Biochim Biophys Acta 1980;618:1-12.

19. Pollard $M$, Gunstone $F$, James $A$, and Morris $L$. Desaturation of positional and geometric isomers of monoenoic fatty acids by microsomal preparations from rat liver. Lipids 1980;15:306-314. 
20. Beyers E, and Emken EA. Metabolites of cis,trans, and trans,cis isomers of linoleic acid in mice and incorporation into tissue lipids. Biochim Biophys Acta 1991;1082:275-284.

21. Grandgirard A, Piconneaux A, Sébédio J, O'Keefe S, Semon E, and Quere Le J. Occurrence of geometrical isomers of eicosapentaenoic acn docosahexaenoic acids in liver lipids of rats fed heated linseed oil. Lipids 1989;24:799-804.

22. Grandgirard A, Bourre J, Julliard F, et al. Incorporation of trans long-chain n-3 polyunsaturated fatty acids in rat brain structures and retina. Lipids 1994;29:251-258.

23. Cook $\mathrm{H}$, and Emken E. Geometric and positional fatty acid isomers interact differently with desaturation and elongation of linoleic and linolenic acids in cultured glioma cells. Biochem Cell Biol 1990;68:653-660.

24. Rosenthal $M$, and Whitehurst $M$. Selective effects of isomeric cis and trans fatty acids on fatty acyl $\Delta 9$ and $\Delta 6$ desaturation by human skin fibroblasts. Biochim Biophys Acta 1983;753:450-9.

25. Delany J, and Bray G. Differential oxidation of various fatty acids. Obesity Res 1993;1:41S.

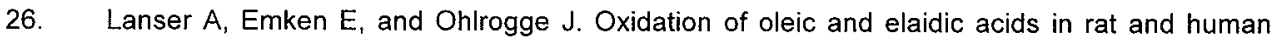
heart homogenates. Biochim Biophys Acta 1986;875:510-515.

27. Katan MB, Mensink RP, and Zock P. Trans fatty acids and their effects on lipoproteins in humans. Ann Rev Nutr 1995;15:473-493.

28. Mensink RP and Katan MB. Effect of dietary trans fatty acids on high-density and low-density lipoprotein cholesterol levels in healthy subjects. New Engl J Med 1990;323:439-445.

29. Almendingen $K$, Jordal $O$, Kierulf $P$, Sandstad $B$, and Pedersen J. Effects of partially hydrogenated fish oil, partially hydrogenated soybean oil, and butter on serum lipoproteins and $L p(a)$ in men. J Lipid Res 1995;36:1370-1384.

30. Aro $A$, Jauhiainen $M$, Partanen $R$, Salminen $I$, and Mutanen $M$. Stearic acid, trans fatty acids, and dairy fat: effects on serum and lipoprotein lipids, apolipoproteins, lipoprotein(a), and lipid transfer proteins in healthy subjects. Am J Clin Nutr 1997;65:1419-1426.

31. Müller $H$, Jordal $O$, Kierulf $P$, Kirkhus $B$, and Pedersen J. Replacement of partially hydrogenated soybean oil by palm oil in margarine without unfavorable effects on serum lipoproteins. Lipids 1998;33:879-887.

32. Judd J, Baer D, Clevidence $B$, et al. Effects of margarine compared with those of butter on blood lipid profiles related to cardiovascular disease risk factors in normolipemic adults fed controlled diets. Am J Clin Nutr 1998;68:768-77.

33. Lichtenstein A, Ausman L, Jalbert $M$, and Schaefer $E$. Effects of different forms of dietary hydrogenated fats on serum lipoprotein cholesterol levels. New Engl J Med 1999;340:193340.

34. Sandkamp M, Funke $H$, Schulte $H$, Kohler $E$, and Assmann G. Lipoprotein(a) is an independent risk factor for myocardial infarction at a young age. Clin Chem 1990;36:20-23.

35. Nestel $P$, Noakes $M$, Belling $B$, et al. Plasma lipoprotein lipid and $L p(a)$ changes with substitution of elaidic acid for oleic acid in the diet. J Lipid Res 1992;33:1029-1036.

36. Mensink RP, Zock P, Katan MB, and Hornstra G. Effect of dietary cis and trans fatty acids on serum lipoprotein(a) levels in humans. J Lipid Res 1992;33:1493-1501.

37. Lichtenstein A, Ausman L, Carrasco W, Jenner J, Ordovas J, and Schaefer E. Hydrogenation impairs the hypolipidemic effect of corn oil in humans. Art Thromb 1993;13:154-161.

38. Austin M. Plasma triglyceride and coronary heart disease. Art Thromb 1991;11:2-14.

39. Abbey $M$, and Nestel P. Plasma cholesteryl ester transfer protein activity is increased when trans-elaidic acid is substituted for cis-oleic acid in the diet. Atherosclerosis 1994;106:99-107.

40. Van Tol A, Zock P, Van Gent $T$, Scheek $L$, and Katan MB. Dietary trans fatty acids increase serum cholesteryl ester transfer protein activity in man. Atherosclerosis 1995;115:129-134. 
41. Lagrost L. Differential effects of cis and trans fatty acid isomers, oleic and elaidic acids, on the cholesteryl ester transfer protein activity. Biochim Biophys Acta 1992;1124:159-162.

42. Nishida $\mathrm{H}$, Arai $\mathrm{H}$, and Nishida $\mathrm{T}$. Cholesterol ester transfer mediated by lipid transfer protein as influenced by changes in the charge characteristics of plasma lipoproteins. $J$ Biol Chem 1993;268:16352-16360.

43. Subbaiah $P$, Subramanian $V$, and Liu $M$. Trans unsaturated fatty acids inhibit lecithin: cholesterol acyltransferase and alter its positional specificity. J Lipid Res 1998;39:1438-47.

44. Woollett L, Daumerie C, and Dietschy J. Trans-9-octadecenoic acid is biologically neutral and does not regulate the low density lipoprotein receptor as the cis isomer does in the hamster. $J$ Lipid Res 1994;35:1661-1673.

45. Cuchel $M$, Schwab $U$, Jones $P$, et al. Impact of hydrogenated fat consumption on endogenous cholesterol synthesis and susceptibility of low-density lipoprotein to oxidation in moderately hypercholesterolemic individuals. Metabolism 1996;45:241-247.

46. Halvorsen B, Almendingen K, Nenseter M, Pedersen J, and Christiansen E. Effects of partially hydrogenated fish oil, partially hydrogenated soybean oil and butter on the susceptibility of low density lipoprotein to oxidative modification in men. Eur J Clin Nutr 1996;50:364-370.

47. Almendingen K, Seljeflot I, Sandstad B, and Pedersen J. Effects of partially hydrogenated fish oil partially hydrogenated soybean oil and butter on hemostatic variables in men. Arterioscl Thromb Vasc Biol 1996;16:375-380.

48. Mutanen $M$, and Aro A. Coagulation and fibrinolysis factors in healthy subjects consuming high stearic or trans fatty acid diets. Thromb Haem 1997;77:99-104.

49. Turpeinen A, Wubert J, Aro A, Lorenz R, and Mutanen M. Similar effects of diets rich in stearic acid or trans-fatty acids on platelet function and endothelial prostacyclin production in humans. Arterioscl Thromb Vasc Biol 1998;18:316-322.

50. O'Keefe S, Lagarde M, Grandgirard A, and Sébédio J. Trans n-3 eicosapentaenoic and docosahexaenoic acid isomers exhibit different inhibitory effects on arachidonic acid metabolism in human platelets compared to the respective cis fatty acids. $J$ Lipid Res 1990;31:1241-1246.

51. Hudgins L, Hirsch J, and Emken E. Correlation of isomeric fatty acids in human adipose tissue with clinical risk factors for cardiovascular disease. Am J Clin Nutr 1991;53:474-482.

52. Troisi $R$, Willett $W$, and Weiss $S$. Trans-fatty acid intake in relation to serum lipid concentrations in adult men. Am J Clin Nutr 1992;56:1019-1024.

53. Siguel $E$ and Lerman R. Trans-fatty acid patterns in patients with angiographically documented coronary artery disease. Am J Cardiol 1993;71:916-920.

54. Thomas L, Winter J, and Scott R. Concentration of 18:1 and 16:1 trans unsaturated fatty acids in the adipose body tissue of decedents dying of ischaemic heart disease compared with controls: analysis by gas liquid chromatography. J Epid Comm Health 1983;37:16-21.

55. Thomas $L$ and Winter $J$. Ischaemic heart disease and consumption of hydrogenated marine oils. Hum Nutr: Food Sci Nutr 1987;41F:153-165.

56. Thomas L, Olpin S, Scott R, and Wilkins M. Coronary heart disease and the composition of adipose tissue taken at biopsy. Hum Nutr: Food Sci Nutr 1987;41F:167-172.

57. Aro A, Kardinaal A, Salminen $I$, et al. Adipose tissue isomeric trans fatty acids and risk of myocardial infarction in nine countries: the EURAMIC study. Lancet 1995;345:273-278.

58. Roberts T, Wood D, Riemersma R, Gallagher P, and Lampe F. Trans isomers of oleic and linoleic acids in adipose tissue and sudden cardiac death. Lancet 1995;345:278-282. 
59. Van de Vijver L, Van Poppel G, Van Houwelingen A, Kruyssen D, and Hornstra G. Trans unsaturated fatty acids in plasma phospholipids and coronary heart disease: a case-control study. Atherosclerosis 1996;126:155-61.

60. Ascherio A, Hennekens C, Buring J, Master C, Stampfer M, and Willett W. Trans-fatty acids intake and risk of myocardial infarction. Circulation 1994;89:94-101.

61. Tzonou A, Kalandidi A, Trichopoulou A, et al. Diet and coronary heart disease: a case-control study in Athens, Greece. Epidemiology 1993;4:511-516.

62. Hu F, Stampfer M, Manson J, et al. Dietary fat intake and the risk of coronary heart disease in women. New Engl J Med 1997;337:1491-1499.

63. Pietinen $P$, Ascherio $A$, Korhonen $P$, et al. Intake of fatty acids and risk of coronary heart disease in a cohort of Finnish men. Am J Epidemiol 1997;145:876-887.

64. Ascherio A, Rimm E, Giovannucci E, Spiegelman D, Stampfer M, and Willett W. Dietary fat and risk of coronary heart disease in men: cohort follow up study in the United States. Brit Med J 1996;313:84-90.

65. Kromhout $D$, Menotti $A$, Bloemberg $B$, et al. Dietary saturated and trans fatty acids and cholesterol and 25-year mortality from coronary heart disease: The Seven Countries Study. Prev Med 1995;24:308-315.

66. Holmes $M$, Hunter $D$, Colditz $G$, et al. Association of dietary intake of fat and fatty acids with risk of breast cancer. J Am Med Ass 1999;281:914-920.

67. Kohlmeier $L$, Simonsen $N$, Van het Veer $P$, et al. Adipose tissue trans fatty acids and breast cancer in the European community multicenter study on antioxidant, myocardial infarction, and breast cancer. Cancer Epidemiol Biom Prev 1997;6:705-710.

68. Petrek J, Hudgins L, Ho M, Bajorunas D, and Hirsch J. Fatty acid composition of adipose tissue and indication of dietary fatty acids, and breast cancer prognosis. $J$ Clin Oncol 1997; 15:1377-1384.

69. London S, Sacks F, Stampfer M, et al. Fatty acid composition of the subcutaneous adipose tissue and risk of proliferative benign breast disease and breast cancer. $J$ Nat Cancer Inst 1993;85:785-793.

70. Bakker N, Van het Veer P, Zock P, Euramic group. Adipose fatty acids and cancers of the breast, prostate and colon: an ecological study. Int J Cancer 1997;72:587-591.

71. Krauss $R$, Deckelbaum $R$, Ernst $N$, et al. Dietary guidelines for healthy American adults. Circulation 1996;94:1795-1800. 



\title{
The effect of dietary trans $\alpha$-linolenic acid on plasma lipids and platelet fatty acid composition: the TransLinE Study
}

\author{
JL Sébédio ${ }^{1}$, SHF Vermunt ${ }^{2}$, JM Chardigny ${ }^{1}$, B Beaufrère ${ }^{3}$, RP Mensink ${ }^{2}$, RA \\ Armstrong ${ }^{4}$, WW Christie ${ }^{5}, \mathrm{~J} \mathrm{Niemelä}^{6}, \mathrm{G} \mathrm{Hénon}^{7}$ \& RA Riemersma ${ }^{8}$ \\ ${ }^{1}$ INRA, Unité de Nutrition Lipidique, Dijon, France \\ ${ }^{2}$ Department of Human Biology, Maastricht University, the Netherlands \\ ${ }^{3}$ Laboratoire de Nutrition Humaine, CRNH, Université d'Auvergne, Clermont-Ferrand, France \\ ${ }^{4}$ Queen Margaret University College, Edinburgh, Scotland \\ ${ }^{5}$ Scottish Crop Research Institute, Dundee, Scotland \\ ${ }^{6}$ Raisio Group, Raisio, Finland \\ ${ }^{7}$ Lesieur Alimentaire, France \\ ${ }^{8}$ Cardiovascular Research Unit, University of Edinburgh, Scotland
}

Based on: European Journal of Clinical Nutrition, 2000;54:104-113 


\section{ABSTRACT}

The aim of the study was to investigate the incorporation of trans $\alpha$-linolenic acid into plasma and platelet lipids as part of a multicenter study examining the effect of dietary trans $\alpha$-linolenic acid on a variety of risk factors for coronary heart disease.

Eighty-eight male volunteers from three European countries (France, Scotland and the Netherlands) were recruited and the habitual diet assessed by a 4-day weighed record. Fatty acid composition of plasma and platelet lipids were determined by gas chromatography at baseline. After a 6 week run-in period on a trans free diet, volunteers were randomized to consume $0.6 \%$ of energy trans $\alpha$-linolenic acid or to continue with a diet low in trans $\alpha$-linolenic acid for 6 weeks. Rapeseed oil was deodorized especially to produce the trans free and high trans foods for this study. The incorporation trans $\alpha$-linolenic acid and its longer chain more unsaturated metabolites into plasma and platelet lipids was assessed by gas chromatography, and dietary compliance was verified by 4 -day weighed record.

Less trans $\alpha$-linolenic acid isomers are present into human plasma lipids in French volunteers than in Dutch or Scottish volunteers consuming their habitual diets. The high trans diet provided $1410 \pm 42 \mathrm{mg} / \mathrm{d}$ trans isomers of $\alpha$-linolenic acid, whilst the low trans group consumed $60 \pm 75 \mathrm{mg} / \mathrm{d}$. The change in plasma lipid and platelet fatty acid composition documented that trans $\alpha$-linolenic isomers are incorporated and converted to a trans isomer of eicosapentaenoic acid. Only the $\Delta 15$ trans $\alpha$-linolenic acid is incorporated into plasma cholesteryl esters. The group consuming low trans diet had a slightly higher intake of fat, especially saturated and monounsaturated fat.

In conclusion, dietary trans isomers of $\alpha$-linolenic acid are incorporated in plasma lipids and converted to long chain polyunsaturated fatty acids. 


\section{INTRODUCTION}

Dietary trans isomers of monounsaturated fatty acids, formed during partial hydrogenation of edible oils or by intestinal fermentation in ruminants, have been linked with an increased risk of coronary heart disease (CHD) (1-4). This is perhaps due to the fact that trans monounsaturated fatty acids when compared with cis monounsaturates raise serum low density lipoprotein (LDL) and reduce high density lipoprotein (HDL) cholesterol (5). The relative amount of trans fatty acids in adipose tissue and plasma phospholipids, arguably a measure of the average intake, has not been associated with an increased risk of coronary heart disease however (6-8) and some of the reasons for the contradictory results have been discussed $(4,9,10)$.

Trans isomers of polyunsaturated fatty acids are formed during deodorization of edible oils and numerous animal studies have shown that isomers of linoleic and linolenic acids are incorporated in rat tissues (11). $\Delta 9 t r, 12 c, 15 c-, \Delta 9 c, 12 t r, 15 c-$ and $\Delta 9 c, 12 c, 15 t r$ - $\alpha$-linolenic acid are converted by successive desaturation and elongation into trans isomers of eicosapentaenoic acid (EPA; C20:5n-3) $(12,13)$ and compete with $\alpha$-linolenic acid (C18:3n-3) at the $\Delta 6$ desaturation step (14). Dietary trans $\alpha$-linolenic acid can also inhibit the $\Delta 5$ desaturase and hence the biosynthesis of arachidonic acid (C20:4n-6) (15). Trans isomers of C20 or C22 n-3 fatty acids occur in up to $1 \%$ of fatty acids in all examined tissues, including the liver and the heart of the rat (12).

Much less is known about the metabolism of dietary trans polyunsaturated fatty acids in man. Human platelets do contain small amounts of these trans isomers of EPA and docosahexaenoic acid (DHA; C22:6n-3) (16). Trans isomers of $\alpha$ linolenic acid occur in human serum (17) and maternal milk $(18,19)$. This is not surprising since trans polyunsaturated fatty acids are found in heated vegetable oils and in numerous human food items (20), such as low calorie spreads (21) and infant formulas (22-24). The average intake of trans $\alpha$-linolenic acid in European men and women is not precisely known (because of difficulties separating trans C18:3n-3 and C20:1 by capillary gas chromatography in some laboratories). Nevertheless, the intake of the sum of these two isomers is low in comparison to trans isomers of C18:1 (25). As much as $50 \%$ of $\alpha$-linolenic acid can be in the trans form (19), suggesting the intake of trans $\alpha$-linolenic acid is likely to increase if more $\alpha$-linolenic acid would be consumed to prevent coronary heart disease (up to $1 \%$ of energy) as advised by an expert committee (26).

In view of these changing trends it is imperative to collect baseline data concerning the presence of trans fatty acids in plasma and platelet lipids and to study the effects of a diet low or high in trans $\alpha$-linolenic acid. 


\section{SUBJECTS AND METHODS}

\section{Design}

The purpose of the TransLinE (trans $\alpha$-linolenic acid in Europe) project in three European centers: Clermont-Ferrand (France), Edinburgh (Scotland) and Maastricht (the Netherlands) was to assess the effect of trans $\alpha$-linolenic acid on risk factors for $\mathrm{CHD}$ in male volunteers. A parallel design comparing low trans and high trans $\alpha-$ linolenic acid in the diet was adopted (see protocol below). The aim was to consume $0.6 \%$ of energy as trans at expense of all cis $\alpha$-linolenic acid from refined canola oil. Furthermore, subjects were asked to reduce the consumption of foods containing trans fatty acids as much as possible for the duration of the entire project. Consequently, the intake of ruminant meat, cheese (except goat cheese: low in trans), as well as foods containing hydrogenated fats were avoided. The main part of the trans fatty acid intake was reduced by replacing subjects usual oil and margarine by experimental products. In all other aspects the participants were encouraged to continue their normal lifestyle and physical activity.

The men gave informed consent and approval had been obtained from the 3 local ethical committees.

\section{Recruitment of volunteers}

Men were recruited from a panel of registered volunteers (Clermont-Ferrand), or local advertisement campaigns in Edinburgh (students and staff of the University) and in Maastricht (general population). Only clinically healthy subjects with a normal energy intake, body mass index $\left(\mathrm{BMI}<27 \mathrm{~kg} / \mathrm{m}^{2}\right.$ ) and plasma cholesterol levels $(<6.5 \mathrm{mmol} / \mathrm{l}$ measured on two separate occasions at least one week apart) were enrolled. A total of 91 men entered the study: 32 in Clermont-Ferrand, (16 during the spring and 16 during the autumn of 1996), 28 in Edinburgh (all during the spring of 1996) and 31 in Maastricht (all during the autumn of 1996). Thirty-one subjects completed the study in Clermont-Ferrand, whereas 26 subjects completed the study in Edinburgh. All the 31 volunteers completed the study in Maastricht. The French dropout used antiinflammatory medication interfering with the protocol and the two who dropped out in Edinburgh found the constraints of the study too hard. Baseline characteristics of the subjects at entry did not differ between the centers, except for a small difference in systolic blood pressure and smoking habits (table 7.1). The difference in these smoking habits was due to the fact that the target of $40 \%$ smokers was reached only in Clermont-Ferrand.

\section{Preparation of experimental oils}

The technology for the preparation of the experimental oils and fats, low or high in trans $\alpha$-linolenic acid, had to be developed for this project $(27)$. Canola oil $(360 \mathrm{~kg})$ containing $11.9 \%$ of $\alpha$-linolenic acid was deodorized at a low temperature $\left(180^{\circ} \mathrm{C}\right)$ for 
5 hours under a blanket of nitrogen at 2-3 mbar pressure (trans free). Another portion of the same batch of canola oil ( $350 \mathrm{~kg}$ ) was deodorized in a pilot plant for 52.5 hours at $205^{\circ} \mathrm{C}$ under $3 \mathrm{mbar}$ pressure. These conditions were optimized to yield a high amount of trans $\alpha$-linolenic acid with as little trans linoleic acid (C18:2n-6) as possible (27). Under these conditions $36.5 \%$ of $\alpha$-linolenic acid was converted to the trans form. The relative amount of trans linoleic acid rose from undetectable levels to $0.5 \%$ of fatty acids. Therefore, trans linoleic acid was added in the form of a highly isomerized sunflower oil (deodorized at $270^{\circ} \mathrm{C}$ for 18 hours) to the trans-free oil to arrive at the low trans oil. One batch of oil was rejected in the production of margarine by a tasting panel, but generally the oil had good sensory properties. The final fatty acid composition of the mixture of 5 batches used for the study is presented in table 7.2. Vitamin $E$ in the form of the free alcohol was added to the high trans oil in order to have the same amount of tocopherols in both the high trans and the low trans oils.

Table 7.1 Selected characteristics and fasting plasma lipid concentrations of the volunteers from Clermont-Ferrand, Edinburgh and Maastricht at baseline. Values are means $\pm \mathrm{sd}$.

\begin{tabular}{|c|c|c|c|c|c|c|c|c|c|}
\hline \multirow[b]{2}{*}{ Age $(y)$} & \multicolumn{3}{|c|}{$\begin{array}{c}\text { Clermont-Ferrand } \\
\qquad(n=31)\end{array}$} & \multicolumn{3}{|c|}{$\begin{array}{l}\text { Edinburgh } \\
\qquad(n=26)\end{array}$} & \multicolumn{3}{|c|}{$\begin{array}{l}\text { Maastricht } \\
(n=31)\end{array}$} \\
\hline & 32.4 & \pm & 8.3 & 33.6 & \pm & 11.5 & 34.2 & \pm & 9.4 \\
\hline Height $(m)$ & 1.78 & \pm & 0.06 & 1.78 & \pm & 0.08 & 1.81 & \pm & 0.08 \\
\hline Weight (kg) & 73.7 & \pm & 9.3 & 74.1 & \pm & 9.7 & 75.3 & \pm & 8.5 \\
\hline BMI $\left(\mathrm{kg} / \mathrm{m}^{2}\right)$ & 23.3 & \pm & 2.5 & 23.2 & \pm & 2.7 & 23.0 & \pm & 2.2 \\
\hline \multicolumn{10}{|l|}{ Blood Pressure $(\mathrm{mmHg})$} \\
\hline systolic & 127 & \pm & 9 & 121 & \pm & 8 & 122 & \pm & 8 \\
\hline diastolic & 72 & \pm & 10 & 72 & \pm & 8 & 74 & \pm & 7 \\
\hline \multicolumn{10}{|l|}{ Cholesterol (mmol/l) } \\
\hline Total & 4.77 & \pm & 0.86 & 4.45 & \pm & 0.54 & 4.77 & \pm & 0.89 \\
\hline $\mathrm{HDL}$ & 1.18 & \pm & 0.28 & 1.22 & \pm & 0.23 & 1.25 & \pm & 0.33 \\
\hline $\operatorname{LDL}^{a}$ & 3.16 & \pm & 0.78 & 2.86 & \pm & 0.52 & 3.09 & \pm & 0.80 \\
\hline Triacylglycerols $(\mathrm{mmol} / \mathrm{l})$ & 0.93 & \pm & 0.41 & 0.75 & \pm & 0.27 & 0.94 & \pm & 0.63 \\
\hline Smokers $(n)$ & & 12 & & & 1 & & & 3 & \\
\hline
\end{tabular}

${ }^{a}$ Derived by Friedewald equation

All between center comparisons are non-significant except systolic blood pressure $C F$ vs $E, P<0.05$

These oils were used to prepare margarine, cheese, biscuits and muffins. In Finland (Raisio Margarinii, Raisio), margarine was prepared by mixing the oils with a hard fat component, devoid of trans fatty acids. The fat mixture consisted of $77 \%$ of oil and $23 \%$ of the hard fat component. The margarines contained $70 \%$ fat and $0.5 \%$ salt with milk protein. The fatty acid composition of the margarine is given in table 7.3. Cheese was produced from homogenized pasteurized fat free milk, lecithin and 
experimental oil (30\%). The final fat content of the cheeses ( $200 \mathrm{~g}$ each), matured for 30 days, was $20 \%$ (Duboz \& Grappin, Poligny, France). Finally, some chocolate flavored muffins and orange flavored biscuits (CRNH, Clermont-Ferrand) were produced to vary the sources of oils in the diet. These were prepared using $13.70 \mathrm{~g}$ margarine $/ 100 \mathrm{~g}$ biscuits or cookies. In Maastricht cheese, muffins and biscuits were not provided, but a fruit pie (Limburgse vlaai), cakes and biscuits prepared by a local baker using the experimental margarines were given. All oils and food items were color coded (yellow trans free, orange and green for the high and low trans, respectively, to maintain the double-blind nature of the study).

Table 7.2 Fatty acid composition of experimental oil and margarine fat blends

\begin{tabular}{|c|c|c|c|c|c|c|}
\hline \multirow[b]{2}{*}{ Individual FA } & \multicolumn{3}{|c|}{ Oil } & \multicolumn{3}{|c|}{ Margarine } \\
\hline & Trans free & Low trans & High trans & Trans free & Low trans & High trans \\
\hline $\mathrm{C} 16: 0$ & 3.4 & 3.5 & 3.5 & 8.5 & 8.5 & 8.5 \\
\hline C18:0 & 1.7 & 1.8 & 1.7 & 8.1 & 8.1 & 8.1 \\
\hline C18:1 & 59.0 & 58.6 & 59.2 & 45.7 & 45.5 & 46.1 \\
\hline $\mathrm{C} 18: 2 \mathrm{cis}$ & 21.5 & 21.6 & 21.1 & 16.5 & 16.8 & 16.4 \\
\hline C18:2 trans & - & 0.5 & 0.5 & - & $0.4^{d}$ & 0.4 \\
\hline $\mathrm{C} 18: 3 \mathrm{cis}^{\mathrm{a}}$ & 12.6 & 12.4 & 7.8 & 9.4 & 9.4 & 6.0 \\
\hline C18:3 trans & 0.1 & 0.1 & 4.5 & 0.1 & 0.1 & 3.4 \\
\hline$\sum$ Saturated & 5.9 & 6.2 & 6.0 & $27.7^{c}$ & 27.2 & 27.2 \\
\hline$\sum$ Monounsaturated ${ }^{b}$ & 59.6 & 59.2 & 59.8 & 46.1 & 46.0 & 46.6 \\
\hline$\sum$ Polyunsaturated ${ }^{b}$ & 34.1 & 34.1 & 29.0 & 25.9 & 26.2 & 22.4 \\
\hline$\sum$ trans & 0.1 & 0.6 & 5.1 & 0.2 & 0.6 & 3.9 \\
\hline
\end{tabular}

Including $\mathrm{C} 20: 1$ in margarines

${ }^{b}$ cis only

${ }^{c}$ The amount of $\mathrm{C} 6: 0$ to $\mathrm{C} 14: 0$ in margarines ranged from $9.7-10.2 \%$ of fatty acids and did not differ between the 3 types

${ }^{d}$ Trans linoleic acid added to same level as in high trans oil or margarine

\section{Laboratory methods}

The principle of centralized laboratory analyses was adopted to avoid systematic bias in results from the three countries, except that the platelet aggregation studies were carried out immediately after blood collection using a standardized method. Determination of plasma total, LDL and HDL cholesterol, and triacylglycerols will be described elsewhere. Fatty acid composition of plasma lipids was determined in Dijon. Plasma lipids were extracted according to Moilanen \& Nikkari (28) and were separated by thin layer chromatography on precoated silica gel plates (SDS, Peypin, France). Phospholipids (remaining at the origin), triacylglycerols (Rf value 0.35 ) and cholesteryl esters (Rf 0.45) were scraped off the plates and the fatty acid methyl esters obtained by trans-methylation according to Morrison \& Smith (29). Methyl 
esters were prepared by direct trans-methylation of extracted lipids from the oil, margarine, cheese and biscuit used for the study. The methyl esters were then analyzed by capillary gas chromatography using Hewlett Packard 6890 GC with an automatic injector, a BPX 70 column $(50 \mathrm{~m} \times 0.25 \mathrm{~mm}$ internal diameter, SGE, Melbourne, Australia) and a flame ionization detector. The error in the determination of fatty acid methyl esters depends on the relative amount of a particular component in the sample. Thus for peaks representing $>1 \%$ of fatty acids, the coefficient of variation is less then $10 \%$. For smaller peaks of 0.2 or $<0.1 \%$ of fatty acids these errors are in the order of 40 and $100 \%$ respectively. Fractionation of the lipid fractions by high pressure liquid chromatography could have reduced the errors, but this was not possible for this project due to the large number of samples.

\section{Dietary analyses}

The fatty acid composition of the diet (weighed record) was calculated separately for the three centers, using country specific food tables and the composition of the experimental fats, oils and foods. The dietary record was made over 4 days including at least 1 weekend day. In Edinburgh Comp-Eat4 (Nutrition Systems, London, UK) was used and the fatty acid composition including trans was obtained from manufacturers, existing food tables (Foodbase, Institute of Brain Chemistry and Human Nutrition, London, UK) and laboratory analyses. However, there are still a number of foods with missing and/or doubtful trans fatty acid data. The intake of fat from these represents some 10 to $15 \%$ of total fat consumption. In Maastricht and Clermont-Ferrand the food composition was calculated in a similar manner using the Dutch Food Composition Table (31) and the Répertoire Général des Aliments in France (32), respectively. The energy intake of trans fatty acids could not be calculated as these two food tables do not list trans fatty acid contents. The intake of trans $\alpha$-linolenic acid is, however, based on the analyses of the fatty acid composition of the experimental foods.

\section{Protocol}

After recruitment and analysis of their habitual diet by a 4-day weighed record, the men attended the clinic each week for the duration of the study (12 weeks) to collect food items and also to be weighed without shoes and heavy clothes. If necessary, energy intake was adjusted to maintain stable body weight. On the first visit, the men attended in the fasting state (from at least 10:00 p.m.), blood pressure (after 5 min rest) was recorded before the collection of blood samples (EDTA) for the analysis of plasma lipids and lipoproteins. A large needle $(1.2 \mathrm{~mm}$ diameter; Strausz cannula, Süddeutsche Feinmechanik, D6480 Wächtersbach, Germany) was used without stasis and the first $5 \mathrm{ml}$ blood discarded. In addition, a large volume of citrated blood $(100 \mathrm{ml})$ was collected for the isolation of platelets. Aliquots were stored for the analysis of fatty acid composition of plasma and platelets. All men then were instructed how to avoid foods containing trans fatty acids and consumed foods 
prepared with trans free rapeseed oil or margarine for a period of 6 weeks (run-in). Blood samples for lipids were collected again at weeks 3, 5 and 6. A second large blood sample was collected to isolate platelets at week 6 (figure 7.1). Blood pressure measurement was repeated and a second 4-day weighed dietary record was made during week 6.

The men stratified by age, BMI and smoking in the three cities, were then randomly allocated to either a low trans or high trans diet by the Edinburgh center. The test period lasted 6 weeks and all measurements and blood sampling after overnight fast were repeated at identical intervals as described for the run-in period. During week 12 a third and final 4-day weighed dietary record was made (figure 7.1).

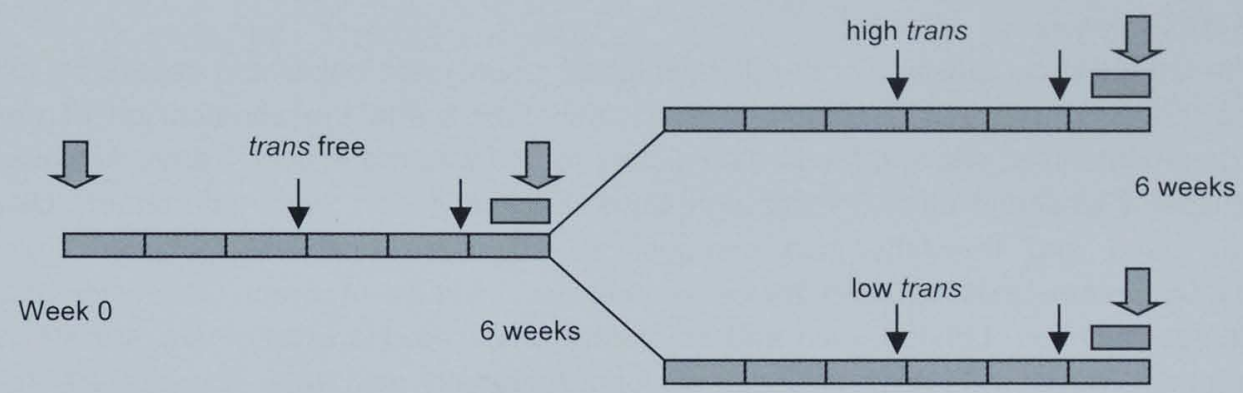

6 weeks

Figure 7.1 The schematic diagram of the protocol of the human feeding study.

The double-blind feeding study comprised two successive periods of 6 weeks. After the first run-in period ( $0-6$ weeks), when all subjects consumed a trans free diet, the volunteers were randomly switched to a low or a high trans $\alpha$-linolenic acid diet $(0.6 \%$ of energy) for the second 6 week period. Small arrows denote fasting blood samples for the measurement of lipids (and haemostatic factors), whilst big arrows denote a larger blood sample that allowed also platelet fatty acid composition (and function) to be determined. Hatched bar indicates a 4-day weighed dietary record in that week.

\section{Statistical methods}

Differences between centers were tested by chi-squared or Mann-Whitney tests and differences between the randomized treatment groups after the test period were tested by analysis of covariance adjusting for the level of the corresponding measurement at the end of the first 6 weeks on a trans free diet (run-in period). 
Table 7.3 Selected fatty acids (wt\%) in plasma triacylglycerols, phospholipids, cholesteryl esters and platelets of subjects from Clermont-Ferrand, Edinburgh, and Maastricht at baseline. Values are means \pm sd

\begin{tabular}{|c|c|c|c|c|c|c|}
\hline & \multirow[b]{2}{*}{$C F(n=28)$} & \multirow[b]{2}{*}{$E(n=25)$} & \multirow[b]{2}{*}{$M(n=29)$} & \multicolumn{3}{|c|}{ Significance } \\
\hline & & & & CF vs E & CF vs $M$ & Evs $M$ \\
\hline \multicolumn{7}{|l|}{ Triacylglycerols } \\
\hline C18:1 trans & $1.17 \pm 0.64$ & $1.71 \pm 0.82$ & $1.52 \pm 0.81$ & ** & & \\
\hline C18:2 cis & $19.3 \pm 6.71$ & $18.4 \pm 4.86$ & $20.9 \pm 4.78$ & & & \\
\hline C18:2 trans & $0.64 \pm 0.21$ & $0.51 \pm 0.18$ & $0.89 \pm 0.32$ & & $\star \star \star \star$ & 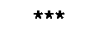 \\
\hline $\mathrm{C} 18: 3 \mathrm{cis}$ & $0.70 \pm 0.40$ & $1.02 \pm 0.39$ & $1.06 \pm 0.32$ & ** & $\star \star \star \star$ & \\
\hline C18:3 trans & $0.10 \pm 0.04$ & $0.16 \pm 0.12$ & $0.18 \pm 0.09$ & & $\star \star \star \star$ & \\
\hline$\sum$ Saturated & $30.4 \pm 4.48$ & $30.7 \pm 4.83$ & $27.2 \pm 4.26$ & & ** & * \\
\hline$\sum$ Monounsaturated & $42.3 \pm 4.00$ & $42.8 \pm 4.08$ & $42.9 \pm 4.26$ & & & \\
\hline$\sum n-3$ & $2.32 \pm 0.72$ & $2.56 \pm 1.22$ & $2.61 \pm 0.90$ & & & \\
\hline$\sum n-6$ & $22.8 \pm 6.97$ & $21.1 \pm 6.06$ & $24.5 \pm 5.21$ & & & ** \\
\hline$\sum$ trans & $1.91 \pm 0.77$ & $2.41 \pm 0.82$ & $2.58 \pm 1.01$ & * & ** & \\
\hline \multicolumn{7}{|l|}{ Phospholipids } \\
\hline C18:1 trans & $0.51 \pm 0.28$ & $0.80 \pm 0.44$ & $0.80 \pm 0.36$ & ** & ** & \\
\hline C18:2 cis & $21.7 \pm 2.84$ & $23.7 \pm 3.02$ & $24.0 \pm 2.68$ & & ** & \\
\hline C18:2 trans & $0.22 \pm 0.07$ & $0.26 \pm 0.10$ & $0.27 \pm 0.08$ & & & \\
\hline $\mathrm{C} 18: 3 \mathrm{cis}$ & $0.14 \pm 0.06$ & $0.21 \pm 0.11$ & $0.20 \pm 0.06$ & 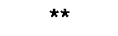 & $\star \star \star \star$ & \\
\hline C18:3 trans & $0.02 \pm 0.02$ & $0.06 \pm 0.03$ & $0.04 \pm 0.04$ & *** & & \\
\hline$\sum$ Saturated & $42.3 \pm 1.16$ & $41.6 \pm 1.31$ & $41.7 \pm 0.99$ & & & \\
\hline$\sum$ Monounsaturated & $12.7 \pm 1.64$ & $12.9 \pm 1.58$ & $2.4 \pm 1.48$ & & & \\
\hline$\sum n-3$ & $5.81 \pm 1.47$ & $5.71 \pm 1.64$ & $5.48 \pm 1.06$ & & & \\
\hline$\sum n-6$ & $34.5 \pm 2.13$ & $37.6 \pm 2.67$ & $38.6 \pm 1.65$ & & $\star \star \star$ & \\
\hline$\sum$ trans & $0.76 \pm 0.33$ & $1.13 \pm 0.52$ & $1.11 \pm 0.41$ & ** & $\star \star$ & \\
\hline \multicolumn{7}{|l|}{ Cholesteryl esters } \\
\hline C18:1 trans & $0.15 \pm 0.09$ & $0.21 \pm 0.11$ & $0.39 \pm 0.14$ & & $* *$ & \\
\hline C18:2 cis & $53.6 \pm 4.06$ & $54.9 \pm 7.29$ & $56.0 \pm 3.73$ & & & \\
\hline C18:2 trans & $0.25 \pm 0.06$ & $0.29 \pm 0.13$ & $0.43 \pm 0.17$ & & 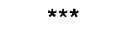 & $\star \star$ \\
\hline $\mathrm{C} 18: 3 \mathrm{cis}$ & $0.41 \pm 0.10$ & $0.52 \pm 0.17$ & $0.55 \pm 0.13$ & & $\star \star \star$ & \\
\hline $\mathrm{C} 18: 3$ trans & $0.08 \pm 0.04$ & $0.11 \pm 0.05$ & $0.15 \pm 0.07$ & 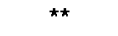 & $\star \star \star$ & \\
\hline$\sum$ Saturated & $12.8 \pm 1.22$ & $12.9 \pm 2.46$ & $11.8 \pm 1.38$ & & $\star \star$ & \\
\hline$\sum$ Monounsaturated & $22.0 \pm 2.69$ & $21.3 \pm 4.43$ & $20.4 \pm 2.51$ & & & \\
\hline$\sum n-3$ & $1.91 \pm 0.74$ & $2.00 \pm 0.89$ & $1.91 \pm 0.59$ & & & \\
\hline$\sum n-6$ & $62.1 \pm 3.74$ & $62.7 \pm 7.06$ & $64.4 \pm 3.14$ & & & \\
\hline$\sum$ trans & $0.48 \pm 0.13$ & $0.62 \pm 0.23$ & $0.82 \pm 0.32$ & * & $\star \star \star$ & \\
\hline \multicolumn{7}{|l|}{ Platelets } \\
\hline $\mathrm{C} 18: 1$ trans & $0.76 \pm 0.25$ & $1.25 \pm 0.58$ & $1.15 \pm 0.69$ & *** & $\star \star \star \star *$ & \\
\hline C18:2 cis & $5.87 \pm 0.92$ & $6.79 \pm 1.23$ & $8.12 \pm 2.08$ & $\star \star *$ & $\star \star \star *$ & \\
\hline C18:2 trans & $0.29 \pm 0.14$ & $0.30 \pm 0.23$ & $0.62 \pm 0.38$ & & *** & ** \\
\hline C18:3 cis & $0.02 \pm 0.02$ & $0.03 \pm 0.03$ & $0.10 \pm 0.06$ & & 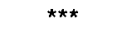 & $\star \star \star$ \\
\hline C18:3 trans & $0.00 \pm 0.00$ & $0.02 \pm 0.06$ & $0.00 \pm 0.00$ & & & \\
\hline $\mathrm{C} 20: 4 \mathrm{cis}$ & $22.1 \pm 2.65$ & $23.1 \pm 2.24$ & $19.6 \pm 4.01$ & & & *** \\
\hline $\mathrm{C} 20: 5 \mathrm{cis}$ & $0.34 \pm 0.16$ & $0.37 \pm 0.29$ & $0.40 \pm 0.13$ & & & \\
\hline $\mathrm{C} 20: 5$ trans & $0.03 \pm 0.03$ & $0.00 \pm 0.00$ & $0.03 \pm 0.04$ & *** & & $\star \star \star \star$ \\
\hline$\sum$ Saturated & $42.8 \pm 4.17$ & $39.8 \pm 2.75$ & $42.5 \pm 3.80$ & $\star \star \star$ & $\star \star \star$ & ** \\
\hline$\sum$ Monounsaturated & $16.2 \pm 1.05$ & $18.4 \pm 1.58$ & $18.0 \pm 1.91$ & 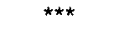 & 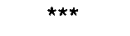 & \\
\hline$\sum n-3$ & $32.1 \pm 3.49$ & $34.4 \pm 2.97$ & $32.0 \pm 3.35$ & & & * \\
\hline$\sum n-6$ & $3.93 \pm 1.12$ & $4.43 \pm 1.10$ & $3.56 \pm 1.17$ & & & \\
\hline$\sum$ trans & $1.09 \pm 0.32$ & $1.57 \pm 0.64$ & $1.80 \pm 0.82$ & ** & & \\
\hline
\end{tabular}

${ }^{\star} P<0.017,{ }^{\star \star} P<0.01,{ }^{\star \star \star} P<0.001$. CF, Clermont-Ferrand; E, Edinburgh; M, Maastricht 


\section{RESULTS}

\section{Plasma and platelet fatty acid composition during habitual diet}

Trans isomers of individual fatty acids and the total amount of trans fatty acids in plasma lipid fractions differed between the three countries. The relative amounts of trans $\alpha$-linolenic acid in plasma triacylglycerols was higher in Maastricht and in phospholipids was higher in Edinburgh than in Clermont-Ferrand. Values between Edinburgh and Maastricht were not significant. The relative amounts of cis $\alpha$-linolenic acid in plasma lipids and platelets showed similar trends: similar values in Dutch and Scottish and lower levels in the French volunteers (table 7.3). Only traces of trans $\alpha$ linolenic acid were found in platelet membranes. Despite this, slightly higher amounts of trans EPA were observed in platelet membranes of Dutch and French volunteers (table 7.3). The levels of total trans fatty acids were higher in plasma triacylglycerols than in cholesteryl esters or phospholipids. As expected the major trans fatty acids in plasma triacylglycerols, phospholipids and platelets were trans monounsaturated fatty acids (trans c18:1). Only in the cholesteryl ester fraction were the relative amounts of trans isomers from linoleic and $\alpha$-linolenic acid higher or similar to those of trans C18:1.

\section{Nutrient intake in the intervention trial}

First careful, low temperature deodorization of a canola oil containing some $12.4 \% \alpha$ linolenic acid did not result in trans $\alpha$-linolenic acid $(\sim 0.1 \%$ of fatty acids). Almost $40 \%$ of $\alpha$-linolenic acid was isomerized during the production of the high trans canola oil.

Eighty-eight volunteers completed the dietary intervention trial. At the end of the run-in period, when all the volunteers had been consuming a trans free diet for 6 weeks, the nutrient intake did not differ between the two groups assigned to the low or high trans diet for the next 6 weeks. The average intake of fat was in the order of $35 \%$ of energy and contained little trans fatty acids (table 7.4). After 6 weeks on the high trans diet, the intake of trans $\alpha$-linolenic acid increased some 20 fold, but did not change in the group consuming the low trans diet (table 7.4). These changes in trans $\alpha$-linolenic acid intake did not differ significantly between the three centers (not shown). The intake of fat, particularly of saturated and monounsaturated fat increased slightly in the group on the low trans diet, whereas there was the opposite trend in the high trans group. The difference was significant for the total, saturated and monounsaturated fat intake. The intake of energy and other nutrients did not differ between the two dietary groups. 
Table 7.4 Mean daily energy and nutrient intakes at the end of the run-in period and test period with a low or high trans diet. Values are means $\pm s d$.

\begin{tabular}{|c|c|c|c|c|c|c|}
\hline \multirow[b]{2}{*}{ Energy (MJ/day) } & \multicolumn{3}{|c|}{$\begin{array}{c}\text { Low trans } \\
(\mathrm{n}=44)\end{array}$} & \multicolumn{2}{|c|}{$\begin{array}{l}\text { High trans } \\
(n=44)\end{array}$} & \multirow[t]{2}{*}{ Significance $^{a}$} \\
\hline & & & & & & \\
\hline run-in & 11.1 & \pm & 2.5 & 11.0 & 1.8 & \\
\hline test period & 11.1 & \pm & 2.8 & 10.7 & 1.9 & \\
\hline \multirow{2}{*}{\multicolumn{7}{|c|}{ Protein (En\%) }} \\
\hline & & & & & & \\
\hline run-in & 15.7 & \pm & 3.2 & 15.1 & 2.7 & \\
\hline test period & 15.2 & \pm & 3.2 & 15.4 & 3.3 & \\
\hline change & -0.5 & \pm & 2.6 & 0.3 & 2.3 & \\
\hline \multicolumn{7}{|l|}{ Fat $(E n \%)$} \\
\hline run-in & 32.4 & \pm & 6.3 & 35.3 & 5.9 & \\
\hline test period & 34.5 & \pm & 6.9 & 34.1 & 6.1 & \\
\hline change & 2.1 & \pm & 5.7 & -1.1 & 5.4 & * \\
\hline \multicolumn{7}{|l|}{ SAFA } \\
\hline run-in & 8.6 & \pm & 3.4 & 9.9 & 3.3 & \\
\hline test period & 9.6 & \pm & 3.9 & 9.4 & 3.3 & \\
\hline change & 1.1 & \pm & 2.2 & -0.5 & 1.9 & $\star \star$ \\
\hline \multicolumn{7}{|l|}{ MUFA } \\
\hline run-in & 14.1 & \pm & 2.8 & 15.1 & 2.5 & \\
\hline test period & 15.2 & \pm & 3.0 & 14.5 & 2.7 & \\
\hline change & 1.1 & \pm & 2.7 & -0.5 & 2.3 & * \\
\hline \multicolumn{7}{|l|}{ PU FA } \\
\hline run-in & 7.1 & \pm & 1.4 & 7.7 & 1.8 & \\
\hline test period & 7.2 & \pm & 1.8 & 7.4 & 1.6 & \\
\hline change & 0.1 & \pm & 1.9 & -0.3 & 1.5 & \\
\hline \multicolumn{7}{|c|}{ Trans C18:1 (mg) ${ }^{b}$} \\
\hline run-in & 364 & & 252 & 496 & \pm 484 & \\
\hline test period & 269 & & 161 & 366 & \pm 213 & \\
\hline change & -95 & & 322 & -130 & \pm 365 & \\
\hline \multicolumn{7}{|c|}{ Trans C18:3n-3(mg) ${ }^{b}$} \\
\hline run-in & 49 & \pm & 53 & 66 & \pm 102 & \\
\hline test period & 60 & \pm & 75 & 1410 & \pm 427 & \\
\hline change & 10 & \pm & 67 & 1344 & \pm 428 & $\star \star \star \star$ \\
\hline \multicolumn{7}{|c|}{ Carbohydrates (En\%) } \\
\hline run-in & 49.1 & \pm & 6.9 & 45.8 & 6.9 & \\
\hline test period & 47.4 & \pm & 6.8 & 46.7 & 6.6 & \\
\hline change & -1.7 & \pm & 6.3 & 0.9 & 5.6 & \\
\hline \multicolumn{7}{|l|}{ Alcohol (En\%) } \\
\hline run-in & 2.7 & \pm & 4.1 & 3.7 & 5.5 & \\
\hline test period & 2.8 & \pm & 3.1 & 3.7 & 5.1 & \\
\hline change & 0.1 & \pm & 4.0 & -0.1 & 2.6 & \\
\hline \multicolumn{7}{|c|}{ Cholesterol (mg/MJ) } \\
\hline run-in & 24.8 & \pm & 14.2 & 25.2 & 14.9 & \\
\hline test period & 27.5 & \pm & 16.1 & 25.4 & $\pm \quad 11.4$ & \\
\hline change & 2.7 & \pm & 13.7 & 0.2 & $\pm \quad 12.1$ & \\
\hline \multicolumn{7}{|c|}{ Dietary fiber ( $\mathrm{g} / \mathrm{MJ}$ ) } \\
\hline run-in & 2.0 & \pm & 0.5 & 1.9 & 0.6 & \\
\hline test period & 1.9 & \pm & 0.5 & 2.0 & 0.6 & \\
\hline change & -0.1 & \pm & 0.5 & 0.1 & 0.4 & \\
\hline
\end{tabular}


Mean body weight of the volunteers decreased slightly in the group consuming the low trans diet, whereas it increased in the high trans group: $-0.4 \pm 1.2$ vs $0.2 \pm 1.1$ $\mathrm{kg}$. The difference between the two dietary groups was significant $(P<0.05)$ after adjustment for the initial body weight (at the end of the run-in period). Changes in body weight of volunteers consuming the low or high trans diet differed between the three centers $(P<0.01)$. In Clermont-Ferrand both dietary groups tended to lose weight, whereas in Edinburgh and Maastricht there was a tendency to lose weight on the low and to gain weight on the high trans diet (not shown). The mean systolic and diastolic pressures varied between 120 and $124 \mathrm{~mm} \mathrm{Hg}$, and 70 and $73 \mathrm{~mm} \mathrm{Hg}$, respectively, without any significant difference before and during the 6-week experimental period.

Table 7.5 Change in n-3 fatty acid composition ( $w$ t \%) of plasma triacylglycerols, phospholipids and cholesteryl esters in healthy volunteers consuming a low trans or a high trans $\alpha$-linolenic acid diet for 6 weeks. Values are means \pm sd.

\begin{tabular}{|c|c|c|c|c|c|c|c|}
\hline Triacylglycerols & \multicolumn{3}{|c|}{$\begin{array}{l}\text { Low trans } \\
\qquad(n=44)\end{array}$} & \multicolumn{3}{|c|}{$\begin{array}{l}\text { High trans } \\
(n=44)\end{array}$} & Significance ${ }^{a}$ \\
\hline C18:3 cis $^{b}$ & -0.29 & \pm & 1.00 & -0.33 & \pm & 0.84 & \\
\hline C18:3 trans & -0.02 & \pm & 0.09 & 0.37 & \pm & 0.28 & $\star \star \star$ \\
\hline $\mathrm{C} 20: 5 \mathrm{cis}$ & -0.02 & \pm & 0.25 & -0.03 & \pm & 0.36 & \\
\hline $\mathrm{C} 20: 5$ trans & -0.01 & \pm & 0.03 & 0.03 & \pm & 0.05 & * \\
\hline \multicolumn{8}{|l|}{ Phospholipids } \\
\hline C18:3 cis & 0.06 & \pm & 0.14 & -0.03 & \pm & 0.12 & $\star$ \\
\hline C18:3 trans & 0.00 & \pm & 0.02 & 0.14 & \pm & 0.10 & $* \star *$ \\
\hline $\mathrm{C} 20: 5 \mathrm{cis}$ & 0.08 & \pm & 0.64 & -0.14 & \pm & 0.64 & \\
\hline C20:5 trans & 0.00 & \pm & 0.01 & 0.07 & \pm & 0.04 & $* * *$ \\
\hline \multicolumn{8}{|c|}{ Cholesteryl esters } \\
\hline $\mathrm{C} 18: 3 \mathrm{cis}$ & -0.02 & \pm & 0.25 & -0.24 & \pm & 0.22 & $\star \star \star$ \\
\hline C18:3 trans & 0.00 & \pm & 0.07 & 0.26 & \pm & 0.20 & $\star \star \star *$ \\
\hline $\mathrm{C} 20: 5 \mathrm{cis}$ & 0.03 & \pm & 0.66 & -0.12 & \pm & 0.44 & \\
\hline $\mathrm{C} 20.5$ trans & 0.00 & \pm & 0.01 & 0.02 & \pm & 0.04 & $* \star \star$ \\
\hline
\end{tabular}

${ }^{a}$ Low vs high trans ${ }^{*} P<0.05,{ }^{* *} P<0.01,{ }^{* * *} P<0.001$

${ }^{b}$ Cis isomers only

\section{Changes in fatty acid composition}

The changes in the cis and trans n-3 fatty acid composition were as expected. The relative amount of trans $\alpha$-linolenic acid increased in plasma triacylglycerol, phospholipid and cholesteryl ester fractions of volunteers consuming the high trans diet (table 7.5). Trans $\alpha$-linolenic acid comprised one third of the total amount of $\alpha$ linolenic acid in plasma phospholipids and cholesteryl esters. Interestingly the only 
trans isomer of $\alpha$-linolenic acid that was incorporated in the cholesteryl ester fraction was the $\Delta 9 c, 12 c, 15 t r$-form (figure 7.2). At the same time the percentage of cis $\alpha$ linolenic acid decreased in these fractions, except in plasma triacylglycerol fraction. The $\mathrm{n}-3$ fatty acid composition was stable in the group consuming the low trans diet and the difference between the low and high trans groups was significant. There was an increase in the small amount of trans EPA in plasma triacylglycerols, phospholipids and cholesteryl esters, but without a change in the amount of cis EPA. The relative amounts of trans isomers of oleic and linoleic acid in these fractions remained stable during the experimental dietary periods (not shown).
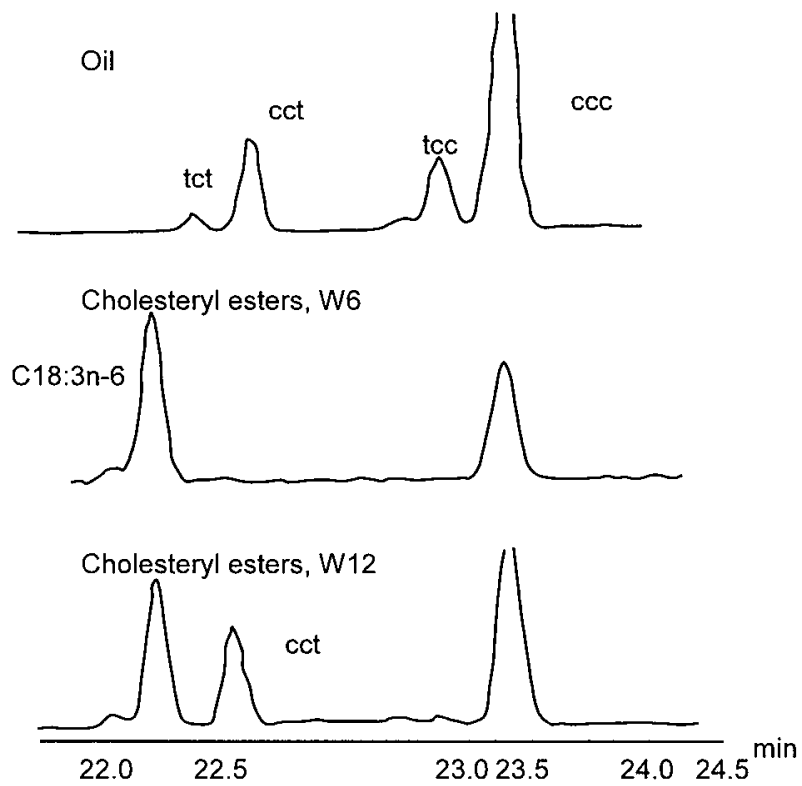

Figure 7.2 The capillary gas chromatogram demonstrating the separation of the different trans isomers of $\alpha$-linolenic acid as the methyl esters in a sample of the high trans oil (top panel), and of the plasma cholesteryl ester fraction of the same male volunteer at the end of a period of 6 weeks on the trans free diet (run-in period; middle panel) and at the end of a 6 week period on the high trans fat diet (bottom panel). Note the absence of the $\Delta 9 t r, 12 c, 15 c$ - isomer of $\alpha$-linolenic acid in the cholesteryl ester fraction.

The identifications tct, $c c t$, tcc refer to $\Delta 9 t r, 12 c, 15 t r-\Delta 9 c, 12 c, 15 t r$ - and $\Delta 9 t r, 12 c, 15 c$ isomers of $\alpha$-linolenic acid (ccc) respectively. $\gamma$-Linolenic methyl ester peak in the cholesteryl ester fraction is labeled with C18:3n-6.

As expected the relative amount of trans isomers of $\mathrm{C} 18: 1$ in plasma triacylglycerol and cholesteryl esters in the volunteers consuming the trans fat free 
diet for 6 weeks decreased from $1.37 \pm 0.08$ to $0.97 \pm 0.09$ and from $0.25 \pm 0.05$ to $0.14 \pm 0.02 \%$ of fatty acids, respectively (both $P<0.05$ ). However the level did not decline further in the group continuing with the low trans diet for 6 weeks with values of $0.91 \pm 0.09$ and $0.11 \pm 0.01 \%$ of fatty acids respectively, nor did the levels decline in the group switched to the high trans diet (not shown). What is perhaps surprising is that levels of these trans isomers in plasma phospholipids never changed at all: 0.69 \pm 0.04 (control), $0.63 \pm 0.04$ (6 weeks trans free) and $0.59 \pm 0.04 \%$ of fatty acids (trans free followed by 6 weeks low trans).

The high trans diet did not influence the relative amounts of $n-6$ polyunsaturated fatty acids linoleic, $\gamma$-linolenic, dihomo- $\gamma$-linolenic and arachidonic acid (not shown).

\section{DISCUSSION}

Trans fatty acids at baseline

Our results confirm earlier observations $(6,25)$ that the relative amount of trans fatty acids in plasma lipids, adipose tissue or in the diet differ between European populations. Our French volunteers had lower trans C18:1 levels than their Dutch or Scottish counterparts and almost certainly this reflects the higher intake of trans fats and of hydrogenated oils in Northern Europe than in the Southern countries $(21,25)$. The same geographical trend across Europe is not observed for the trans isomers of linoleic and $\alpha$-linolenic acid. Trans isomers of these fatty acids are formed during the deodorization of linoleic and $\alpha$-linolenic acid-rich vegetable oils at high temperatures $(27,33)$. It is known that there are large variations in the relative amount of $\alpha$-linolenic acid isomerized in vegetable oils $(21,24)$. In fact one may think that the quantity of these trans polyunsaturated fatty acids in biological samples may reflect primarily the quality, rather than the quantity of the ingested refined oil and ultimately they reflect the conditions under which the oil was refined. Thus if well-deodorized, the intake of trans $\alpha$-linolenic acid could be negligible. What this project did show is that it is indeed possible to obtain well-refined oils rich in $\alpha$-linolenic acid with good organoleptic properties and yet low in trans polyunsaturated fatty acids.

The information about trans $\alpha$-linolenic acid in foods is virtually non-existent. However, the average levels of trans $\alpha$-linolenic acid in plasma lipids at baseline when compared with the increase during the experimental period when given $1.4 \mathrm{~g} / \mathrm{d}$ should indicate the relative amount consumed habitually. The estimates for the Dutch and Scottish subjects average some $0.6,0.7$ and $0.5 \mathrm{~g} / \mathrm{d}$ using the fatty acid composition of plasma triacylglycerol, cholesteryl ester and phospholipid data, respectively. For the French subjects the trans $\alpha$-linolenic acid intake is estimated to be in the order of 0.2 to $0.4 \mathrm{~g} / \mathrm{d}$. However, these approximations depend on small concentrations of trans $\alpha$-linolenic acid, which are determined with relatively large analytical errors. We also assume a linear relation between intake and incorporation 
into plasma lipid fractions. This is not entirely the case, as certain trans $\alpha$-linolenic acid isomers are not incorporated into the cholesterol ester fraction (see figure 7.2). Nevertheless the similarity in estimates based on plasma triacylglycerol, cholesterol ester and phospholipid composition suggests that they are a reasonable first estimate.

One word of caution is necessary. Our volunteers were recruited from a panel of volunteers in Clermont-Ferrand and from an advertising campaign in Maastricht and in Edinburgh. Obviously they were self-selected and do not represent a random population sample. Therefore, the levels of trans fatty acids in these volunteers do not necessarily reflect those of the French, Dutch and Scottish populations with great accuracy. Nevertheless the results are in line with those of the Transfair project which specifically examined dietary intake of trans fatty acids in European populations by analyzing the trans fatty acid content in up to 100 food samples representative of the total fat intake of the 14 countries (34).

\section{Effects of a high and low trans fat diet}

All volunteers consumed a diet low in trans fatty acids for 6 weeks to decrease the relative amounts of trans fatty acids in plasma lipids (and readily exchangeable tissue pools). Obviously starting from a low baseline would make it easier to demonstrate any putative effect of trans $\alpha$-linolenic acid. The question is whether our run-in period was long enough if we aimed to reduce all trans fatty acids, in particular trans C18:1. Interestingly the reduced level of trans C18:1 in plasma triacylglycerol and cholesteryl esters did not fall significantly further in the group that continued with the low trans diet for another 6 weeks and the levels of these C18 trans isomers in phospholipids were not influenced by the low trans diet at all. Perhaps some of these trans isomers originated from adipose tissue. Another source might be biscuits (prepared with partially hydrogenated oils) consumed by the subjects. It is possible that despite our careful instructions our volunteers did continue to consume, perhaps unwittingly trans fatty acids. Indeed our dietary analyses in Edinburgh men where the intake of trans C18:1 could be assessed support the view that this may have been so and only in a study conducted under strict metabolic ward conditions would one be able to obtain perfect compliance. It must be remembered that some partners of these volunteers actually prepared the food. As this was expected, free food was also offered to the entire family to prevent inadvertently mixing of our experimental oils and fats with similar products kept in the household. The volunteers were actively encouraged to discard or return all other fats and oils at the start of each dietary period.

Whatever the reason for the relatively steady c18:1 trans levels after the 6 week run-in period, the biological effects in our study are not affected by changes in C18:1 trans. Trans isomers of $\mathrm{C} 20: 5$ did also not change further in the group consuming low trans. Thus their production was close to a steady state.

Our dietary record also documented that the amount of trans $\alpha$-linolenic acid consumed was on average close to what was intended. What was surprising was that 
the group consuming a low trans diet tended to increase the intake of dietary fat, whereas the opposite was true for the high trans group. The difference was significant and can affect the outcome of our study. It is well known that a saturated fat diet increases total cholesterol and a fatty diet can raise high density cholesterol $(35,36)$. However statistical analysis of covariance can easily adjust for this unexplained finding.

An important aspect is the dose of trans $\alpha$-linolenic acid we used. Some $40 \%$ of the total dietary $\alpha$-linolenic acid was in the trans form, close to highest values observed in human milk samples from a large Canadian study (19). On that basis it may appear that our study tested rather an extreme dietary amount of trans $\alpha$ linolenic acid. However, the amount is still within the range that can be observed in the free-living population. The level in human milk samples could be misleading if there is a marked discrimination against trans $\alpha$-linolenic acid during the absorption and incorporation into milk and perhaps also into lipids.

Our data already shows that after 6 weeks on a diet rich in trans $\alpha$-linolenic acid isomers, there was an increase in these trans isomers as well as that of trans EPA in all plasma lipid classes. These results confirm that the conversion of $\triangle 15$ trans $\alpha$-linolenic to a trans isomer of EPA is not restricted to the rat (12). Most interestingly, while the different trans isomers were incorporated into plasma triacylglycerol and phospholipids, only the $\Delta 15$ trans $\alpha$-linolenic acid was detected in plasma cholesteryl esters. A similar preferential incorporation of this trans isomer into cardiolipin, a phospholipid rich in linoleic acid, suggests that this trans isomer containing three carbon-carbon double bonds, is recognized as linoleic acid (37). Preferential incorporation of $\Delta 15$ trans $\alpha$-linolenic acid into plasma cholesteryl esters could be due to a higher affinity of lecithin cholesterol acyl transferase (LCAT) for this than for the other trans isomers. It is well known that this enzyme selectively transfers linoleic acid from lecithin to cholesterol (38). The fatty acid composition of plasma cholesteryl esters and/or phospholipids are used as a marker of compliance of fatty acid intake (39-43). Our data suggest that caution should be taken because of the selectivity of LCAT. Interestingly, these trans isomers do not appear to be incorporated into plasma lipids at the expense of $\alpha$-linolenic acid, illustrated by the fact that the total content of $\alpha$-linolenic acid (cis+trans) remains constant irrespective of whether volunteers were consuming a low or high trans diet. Also the amount of trans monounsaturated fatty acids in plasma phospholipids (unlike in triacylglycerol and cholesteryl esters) did not decline in volunteers consuming a diet low in these trans isomers for 12 weeks altogether.

Our results do not support the view that trans $\alpha$-linolenic acid inhibits the activity of $\Delta 6$ desaturation of linoleic acid, since there were no changes in the composition of $n-6$ polyunsaturated fatty acids in plasma lipids. However, this indirect index of $\Delta 6$ desaturation has been criticized previously. The conversion of stable isotope labeled linoleic acid in volunteers consuming alternatively a diet low and high in trans $\alpha$-linolenic acid will be examined. 
In conclusion, trans isomers are absorbed from the diet, incorporated in plasma lipids and some trans isomers are converted to long chain polyunsaturated fatty acids. 


\section{REFERENCES}

1. Thomas LH. Ischaemic heart disease and consumption of hydrogenated marine oils in England and Wales. J Epidemiol Com Health 1992;46:78-82.

2. Willett WC, Stampfer MJ, Manson JE, et al. Intake of trans fatty acids and risk of coronary heart disease among women. Lancet 1993;341:581-585.

3. Ascherio A, Rimm EB, Giovannucci EL, Spiegelman D, Stampfer MJ, and Willett WC. Dietary fat and risk of coronary heart disease in men: cohort follow up study in the United States. $\mathrm{Br}$ Med J 1996;313:84-90.

4. Hu FB, Stampfer MJ, Manson JE, et al. Dietary fat intake and the risk of coronary heart disease in women. N Engl J Med 1997;337:1491-1499.

5. Mensink RP and Katan MB. Trans monounsaturated fatty acids in nutrition and their impact on serum lipoprotein levels in man. Prog Lipid Res 1993;32:111-122.

6. Aro A, Kardinaal AFM, Salminen I, et al. Adipose tissue isomeric trans fatty acids and risk of myocardial infarction in nine countries: the EURAMIC study. Lancet 1995;345:273-278.

7. Roberts TL, Wood DA, Riemersma RA, Gallagher PJ, and Lampe FC. Trans isomers of oleic and linoleic acids in adipose tissue and sudden cardiac death. Lancet 1995;345:278-282.

8. Van de Vijver LPL, Van Poppel G, Van Houwelingen A, Kruyssen DACM, and Hornstra G. Trans unsaturated fatty acids in plasma phospholipids and coronary heart disease: a casecontrol study. Atherosclerosis 1996;126:155-161.

9. McKeigue P. Trans fatty acids and coronary heart disease: weighing the evidence against hardened fat. Lancet 1995;345:269-270.

10. Aro A. Epidemiological studies of trans fatty acids and coronary heart disease. In: Trans fatty acids in human nutrition (Sébédio JL and Christie WW eds.) Dundee: The Oily Press Ltd, 1998:235-260.

11. Sébédio $\mathrm{JL}$ and Chardigny $\mathrm{JM}$. Biochemistry of trans polyunsaturated fatty acids. In: Trans fatty acids in human nutrition (Sébédio $\mathrm{JL}$ and Christie WW eds.) Dundee: The Oily Press Ltd., 1998:191-215.

12. Grandgirard A, Piconneaux A, Sébédio JL, O'Keefe SF, Sémon E, and Le Quéré J. Occurrence of geometrical isomers of eicosapentaenoic and docosahexaenoic acids in liver lipids of rats fed heated linseed oil. Lipids 1989;24:799-804.

13. Chardigny JM, Sébédio JL, Grandgirard $A$, Martine $L$, Berdeaux $P$, and Vatèle JM. Identification of novel trans isomers of $20: 5 n-3$ in liver lipids of rats fed a heated oil. Lipids 1996;31:165-168.

14. Chardigny JM, Blond JP, Bretillon L, et al. Conversion of $18: 3 \Delta 9$ cis, 12 cis, 15 trans in rat liver microsomes. Lipids 1997;32:731-735.

15. Blond JP, Henchiri C, Précigou P, Grandgirard A, and Sébédio JL. Effects of 18:3 (n-3) trans isomers on the biosynthesis of arachidonic acid in rats. Nutr Res 1990;10:69-79.

16. Chardigny JM, Sébédio JL, Juanéda $P$, Vatèle JM, and Grandgirard A. Occurrence of $n-3$ trans polyunsaturated fatty acids in human platelets. Nutr Res 1993;13:1105-1111.

17. Wolff RL. Recent applications of capillary gas-liquid chromatography to some difficult separations of positional or geometrical isomers of unsaturated fatty acids. In: New trends in lipid and lipoprotein analysis (Sébédio JL and Perkins EG, eds) Champaign: AOCS Press, 1995:147-180.

18. Chardigny JM, Wolff RL, Mager E, Sébédio JL, Martine $L$, and Juanéda P. Trans mono- and polyunsaturated fatty acids in human milk. Eur J Clin Nutr 1995;49:523-531. 
19. Chen ZY, Pelletier G, Hollywood R, and Ratnayake WMN. Trans fatty acid isomers in Canadian human milk. Lipids 1995;30:15-21.

20. Chardigny JM, Sébédio JL, and Berdeaux $O$. Trans polyunsaturated fatty acids: occurence and nutritional implications. In: Adv Applied Lipid Res (Padley FB, ed.) London, UK: JAI Press, 1996:1-33.

21. Wolff RL and Sébédio JL. Geometrical isomers of linolenic acid in low calorie spreads marketed in France. JAOCS 1994;68:719-725.

22. O'Keefe SF, Wiley V, and Gaskins, S. Geometrical isomers of essential fatty acids in liquid infant formulas. Food Res Int 1994;27:7-13.

23. Chardigny JM, Wolff RL, Mager E, Sébédio JL, Martine L, and Ratnayake WMN. Fatty acid composition of French infant formulas with emphasis on the content and detailed profile of trans fatty acids. JAOCS 1996;73:1593-1601.

24. Ratnayake WMN, Chardigny JM, Wolff RL, Bayard CC, Sébédio JL, and Martine L. Essential fatty acids and their trans geometrical isomers in powdered and liquid infant formulas sold in Canada. J Pediatr Gastroenterol Nutr 1997;25:400-407.

25. Transfair. TRANSFAIR: Trans fatty acid intake and risk factors for cardiovascular disease in Europe. Final Report of Contract AIR3-CT94-2421. European Communities DirectorateGeneral XII. Brussels: Science, Research and Development, 1998.

26. De Deckere EAM, Korver O, Verschuren PM, and Katan MB. Health aspects of fish and n-3 polyunsaturated fatty acids from plant and marine origin. Eur J Clin Nutr 1998;52:749-753.

27. Hénon G, Kemeny Z, Recseg K, Zwobada F, and Kovari K. Deodorization of vegetable oils. Part I: Modeling the geometrical isomersization of polyunsaturated fatty acids. JAOCS 1999;76:73-81.

28. Friedewald WT, Levi RI, and Fredrickson DS. Estimation of the concentration of low-density lipoprotein cholesterol in plasma, without use of the preparative ultracentrifuge. Clin Chem 1972;18:499-502.

29. Moilanen $T$ and Nikkari $T$. The effect of storage on the fatty acid composition of human serum. Clin Chim Acta 1981;114:111-116.

30. Morrison WR and Smith LM. Preparation of fatty acid methyl esters and dimethylacetals from lipids with boron fluoride-methanol. J Lipid Res 1964;5:600-608.

31. Stichting NEVO. NEVO tabel, Nederlands voedingsstoffenbestand (Dutch food composition table). Den Haag: Voorlichtingsbureau voor de Voeding, 1989.

32. Favier SC, Ireland-Ripert $J$, Toque $C$, and Feinberg M. Répertoire Général des Aliments. TeC \& Doc. INRA, Ciqual ed. Paris, 1991.

33. Wolff RL. Further studies on artificial geometrical isomers of $\alpha$-linolenic acid in edible linolenic acid-containing oils. JAOCS 1993;70:219-224.

34. Van Poppel G. Intake of trans fatty acids in Western Europe: the TRANSFAIR study. Lancet 1998;351:1099.

35. Knuiman JL, West CE, Katan MB, and Hautvast JGAJ. Total cholesterol and high-densitylipoprotein cholesterol levels in populations differing in fat and carbohydrate intake. Arteriosclerosis 1987;7:612-619.

36. Katan MB, Zock PL, and Mensink RP. Effects of fats and fatty acids on blood lipids in humans: an overview. Am J Clin Nutr 1994;60:S1017-S1022.

37. Wolff RL, Combe N, Entressangles B, Sébédio JL, and Grandgirard A. Preferential incorporation of dietary cis-9, cis-12, trans-15 18:3 acid into rat cardiolipins. Biochem Biophys Acta 1993;1168:285-291. 
38. Jonas A. Synthetic substrates of lecithin:cholesterol acyltransferase. J Lipid Res 1986;27:689698.

39. De Genes JL, Doumith R, Hamon P, and Truffert J. Etude dynamique de la modification du profil des acides gras des fractions lipidiques sériques, sous regime riche en acides gras polinsaturés. Ann Nutr Aliment 1980;34:291-304.

40. Gustafson IB, Boberg J, Karlstrom B, Lithell H, and Vessby B. Similar serum lipoprotein reductions by lipid-lowering diets with different polyunsaturated: saturated fat values. BrJ Nutr 1983;50:531-537.

41. Blaton V, de Buyzere $M$, Declerq $B$, et al. Effect of polyunsaturated isocaloric fat diets on plasma lipids, apolipoproteins and fatty acids. Atherosclerosis 1984;53:9-20.

42. Moilanen $T$, Rasanen $L$, Viikari $J$, et al. Fatty acid composition of serum cholesteryl esters in 3- to 18 year old Finnish children and its relation to diet. Am J Clin Nutr 1985;42:708-713.

43. Zock PL, Mensink RP, Harryvan J, de Vries JMH, and Katan MB. Fatty acids in serum cholesteryl esters as quantitative biomarkers of dietary intake in humans. Am J Epidemiol 1997:145:1114-1122. 


\title{
8
}

\section{Dietary trans $\alpha$-linolenic acid from deodorized rapeseed oil and} plasma lipids and lipoproteins in healthy men: the TransLinE Study

\author{
SHF Vermunt ${ }^{1}$, B Beaufrère ${ }^{2}$, RA Riemersma ${ }^{3}$, \\ JL Sébédio ${ }^{4}, J_{M}$ Chardigny ${ }^{4}, R P$ Mensink ${ }^{1}$ for the TransLinE investigators \\ ${ }^{1}$ Maastricht University, Department of Human Biology, Maastricht, the Netherlands \\ ${ }^{2}$ Laboratoire de Nutrition Humaine, Université d'Auvergne CRNH, Clermont-Ferrand, France \\ ${ }^{3}$ University of Edinburgh, Cardiovascular Research Unit, Edinburgh, Scotland \\ ${ }^{4}$ INRA, Unité de Nutrition Lipidique, Dijon, France
}

Based on: British Journal of Nutrition 2001;85:387-392 


\section{ABSTRACT}

Trans isomers of $\alpha$-linolenic acid, which are formed by deodorization of refined vegetable oils, can be found in significant amounts in edible oils. Effects of trans $\alpha$ linolenic acid on plasma lipoproteins are unknown. We, therefore, investigated the effects of trans $\alpha$-linolenic acid on plasma lipids and lipoproteins in healthy European men.

Eighty-eight healthy men from three European countries (France, Scotland and the Netherlands) first consumed for 6 weeks a diet with experimental oils 'free' of trans fatty acids (run-in period). For the next 6 weeks, they were randomly allocated to a diet with experimental oils 'high' or 'low' in trans $\alpha$-linolenic acid. Daily total trans $\alpha$-linolenic acid intake in the high trans group was 1410 (Range 583-2642) mg. Experimental oils were provided as such, or incorporated into margarines, cheeses, muffins and biscuits.

The high trans $\alpha$-linolenic acid diet significantly increased the plasma low density lipoprotein (LDL) to high density lipoprotein (HDL) cholesterol ratio by $8.1 \%$ $(95 \% \mathrm{Cl} 1.4,15.3, P=0.02)$, and the total to $\mathrm{HDL}$ cholesterol ratio by $5.1 \%(95 \% \mathrm{Cl}$ $0.4,9.9, P=0.03$ ), compared to the low trans diet. This was largely explained by an increase in LDL cholesterol on the high trans diet, while no change was observed in the low trans group (mean treatment effect of $4.7 \%(95 \% \mathrm{Cl}-0.8,10.5), \mathrm{P}=0.10)$. No effects were found on total and HDL cholesterol, triacylglycerols, lipoprotein $B$ and $A-1$, and lipoprotein(a) concentrations.

in conclusion, trans $\alpha$-linolenic acid may increase plasma LDL to HDL cholesterol and total to HDL cholesterol ratios. Whether diet-induced changes in these ratios truly affects the risk for coronary heart disease remains to be established. 


\section{INTRODUCTION}

Trans monounsaturated fatty acids from industrially hydrogenated oils increase cholesterol concentrations in the atherogenic serum low density lipoproteins (LDL) and decrease those of the anti-atherogenic high density lipoproteins (HDL). Therefore, a reduction in the intake of hydrogenated oils has been advocated (1). However, not only trans monounsaturated fatty acids, which represent most of the intake of trans fatty acids, are found in processed fats. Trans isomers of polyunsaturated fatty acids are also formed during oil processing (2). In particular, $\alpha$ linolenic acid is easily converted into trans $\alpha$-linolenic acid.

Soybean oil and canola oil (low erucic acid rapeseed oil) are important sources of $\alpha$-linolenic acid (3) and trans isomers may represent up to $40 \%$ of $\alpha$ linolenic acid $(2,4-6)$. There is an increasing recognition that the intake of $n-3$ fatty acids (such as $\alpha$-linolenic acid and fish oil fatty acids) should increase. The growing consumption of n-3 fatty acid containing vegetable oils over the last few years (7) may therefore result in an increased intake of trans $\alpha$-linolenic acid from refined oils. Although such trans n-3 polyunsaturated fatty acids are absorbed and incorporated into tissue lipids by man (8-10), their health effects have hardly been investigated. Therefore, we have studied the effects of a high trans $\alpha$-linolenic acid diet vs a low trans $\alpha$-linolenic acid diet on plasma lipid and lipoprotein concentrations in healthy men.

\section{SUBJECTS AND METHODS}

\section{Experimental design}

The study was designed as a controlled, parallel intervention trial, which was carried out under standardized conditions in three different centers: 1) Université d'Auvergne, Laboratoire de Nutrition Humaine, Clermont-Ferrand, France, 2) Cardiovascular Research Unit, University of Edinburgh, Scotland, and 3) Department of Human Biology, Maastricht University, the Netherlands. The study was a part of the TransLinE project (Trans $\alpha$-Linolenic acid in Europe), in which the health impact of trans polyunsaturated fatty acids in European populations was examined.

The experiment consisted of two consecutive periods of 6 weeks. During the first period (run-in), all subjects received experimental products made of oil free of trans isomers of oleic, linoleic and $\alpha$-linolenic acid $(<0.1 \%$ trans fatty acids) (trans 'free' diet). Thereafter, subjects were randomly allocated to a 'high' or 'low' trans diet. For the next 6 weeks, subjects in the high trans group received on average $1.4 \mathrm{gram}$ trans $\alpha$-linolenic acid per day (assessed by food diaries), which was provided by an oil containing $4.5 \mathrm{~g} / 100 \mathrm{~g}$ product trans $\alpha$-linolenic acid and a margarine containing $3.4 \mathrm{~g} / 100 \mathrm{~g}$ product trans $\alpha$-linolenic acid. Also, foods prepared from the oil or margarine were provided (cheese, muffins, pies and biscuits). Identical experimental 
products free of trans $\alpha$-linolenic acid were given to the low trans group. The high trans $\alpha$-linolenic acid products had a reduced all-cis $\alpha$-linolenic acid content, but in all other aspects the high and low trans products did not differ (11). During the preparation of the trans $\alpha$-linolenic acid rich oil, formation of trans linoleic acid could not be avoided (12). Therefore, for the low trans group a trans-free rapeseed oil was mixed with an isomerized sunflower oil $(50: 1 \mathrm{v} / \mathrm{v})$, in order to compensate for the unavoidable formation of $0.5 \%$ trans isomers of linoleic acid during deodorization of the rapeseed oil for the high trans group. All products were color coded so as to blind the subjects.

For the duration of the study, subjects were advised to avoid consuming trans fatty acids: intake of ruminant meat, cheese (except for goat cheese, which is low in trans), and foods containing hydrogenated fats were avoided. The main part of the trans fatty acid intake was, however, reduced by replacing subjects usual oil and margarine by experimental products. Before and during week 5 and week 11 , subjects recorded their food intake for 4 days, of which at least 1 was in the weekend, to allow us to estimate their energy and nutrient intakes. Energy and nutrient composition of the diets were calculated separately for the three centers using country specific food tables and the composition of the experimental fats, oils and products. Unfortunately, no reliable information on the trans fatty acid content of French and Dutch products was available. Therefore, it was not possible to estimate the amount of trans fatty acid in the background diet of subjects from ClermontFerrand and Maastricht. Trans C18:1 intake of the Scottish subjects was about 400 $\mathrm{mg}$ (11). Overall, $30 \%$ of the fat of the habitual diet was replaced by foods prepared with the experimental fats and oils. Subjects visited the dietician of the department once every week to receive a new supply of products and to measure their body weights.

Subjects recorded in diaries any signs of illness, medication used and any deviations from the protocol. In addition, except for avoid consuming trans fatty acids, subjects were urged not to change their background diets, level of physical exercise, smoking habits, or use of alcohol during the study. The protocol and the aim of the study were fully explained to the subjects, who gave their written informed consent. The study had been approved by the local Medical Ethical Committees.

\section{Subjects}

A total of 91 men, recruited from a panel of volunteers (Clermont-Ferrand, $n=32$ ), university staff and students (Edinburgh, $n=28$ ) and from the general population (Maastricht, $n=31$ ), entered the study. Volunteers were aged between 18 and 55 years, non-obese, clinically healthy, normotensive and normolipidaemic. During the study, one subject from Clermont-Ferrand dropped out because of use of a deviation from the protocol interfering with another aspect of this study, and two subjects from Edinburgh because of the constraints of the study. A detailed description of the study design has been reported elsewhere (11). 


\section{Blood sampling and analyses}

Free-flowing blood was sampled after an overnight fast at weeks $0,3,5,6,9,11$ and 12 for lipid and lipoprotein analyses, and at weeks 0,6 and 12 for measurement of fatty acid composition of plasma cholesteryl esters. Additional measurements will be reported elsewhere. In each center, all punctures were performed by the same technician, at the same location, and as much as possible at the same time of the same day of the week. All blood samples were taken before $11 \mathrm{a} . \mathrm{m}$.

Plasma was obtained by centrifugation at $2000 \times \mathrm{g}$ for 30 minutes at $4^{\circ} \mathrm{C}$ and stored at $-80^{\circ} \mathrm{C}$. Plasma total and HDL cholesterol (CHOD-PAP method; Monotest cholesterol, Roche, Germany) and triacylglycerols (GPO-Trinder; Sigma Diagnostics, St Louis, USA) were analyzed enzymatically. LDL cholesterol was calculated with the Friedewald equation (13). Plasma apolipoprotein A-1 (apoA-1) and apolipoprotein B (apoB) were measured using an immunoturbidimetric reaction (UNI-KIT ApoA-1 and UNI-KIT ApoB, Roche, Switzerland) with antiserum raised in sheep and rabbits, respectively. Lipoprotein(a) (Lp(a)) was measured using a kit from Biopool (Biopool, TintElize; Umeå, Sweden). The technicians were blinded to treatment status. All lipid and lipoprotein analyses were centralized in Maastricht in order to eliminate any possible systematic analytical bias between centers. All samples from one subject were analyzed within one run, while each run contained samples from each center.

To monitor dietary compliance, the fatty acid composition of plasma cholesteryl esters was determined gas chromatographically by the INRA (Dijon, France) as reported elsewhere (11)

\section{Statistical analyses}

Analysis of covariance was used using the Statistical Package for the Social Sciences (SPSS; SPSS Inc., Chicago, IL, USA) to examine the effect of a high trans diet versus a low trans diet (treatment effect) on the week $11+12$ means, adjusted for the week $5+6$ means, and to check whether results were consistent across the three centers. Because the distributions of triacylglycerols, Lp(a), LDL to HDL cholesterol ratio, total to $\mathrm{HDL}$ cholesterol ratio and apoB to apoA-1 ratio were skewed, a logarithmic transformation was applied to these measurements before analysis. Treatment effects were then expressed as percent changes and their $95 \%$ confidence intervals $(95 \% \mathrm{Cl})$ by taking antilogs. For the sake of uniformity, a similar procedure was used for the other lipid related variables. All P-values are two-tailed, and differences were considered statistically significant when $P<0.05$.

\section{RESULTS}

The intake of trans $\alpha$-linolenic acid, as estimated by food records, increased from run-in levels of $66 \mathrm{mg}$ (Range 19-585) (0\% of energy (Range $0-0.2)$ ) to $1410 \mathrm{mg}$ (Range $583-2642)(0.5 \%$ of energy (Range $0.3-0.8)$ ) on the high trans diet (increase 
of $1344 \mathrm{mg}$ (Range $543-2612)(0.5 \%$ of energy (Range $0.2-0.8)$ ). On the low trans diet, trans $\alpha$-linolenic acid intake increased from run-in levels of $49 \mathrm{mg}$ (Range 16$310)(0.01 \%$ of energy (Range $0-0.1))$ to $60 \mathrm{mg}$ (Range $2-404)(0 \%$ of energy $(0-0.2))$ (increase of $10 \mathrm{mg}$ (Range $-236-300)(0 \%$ of energy $(-0.1-0.2)) \quad(P<0.01)$. As expected, the proportion of trans $\alpha$-linolenic acid (after adjustment for week 6 values, the mean treatment effect was $0.26 \mathrm{~g} / 100 \mathrm{~g}$ fatty acid $(95 \% \mathrm{Cl} 0.21,0.32), \mathrm{P}<0.001)$ in plasma cholesteryl esters increased significantly on the high trans diet (from 0.11 $\mathrm{g} / 100 \mathrm{~g}$ fatty acid (Range $0-0.39$ ) to $0.36 \mathrm{~g} / 100 \mathrm{~g}$ fatty acid (Range 0.02-0.74)) compared to the low trans diet (from $0.11 \mathrm{~g} / 100 \mathrm{~g}$ fatty acid (Range $0.03-0.28$ ) to $0.10 \mathrm{~g} / 100 \mathrm{~g}$ fatty acid (Range $0-0.21$ )) (figure 8.1). What was surprising was that the men consuming a low trans diet following the run-in period tended to increase the intake of dietary fat $(2.1 \pm 5.7 \%$ of energy) whereas the opposite was true for the men of the high trans group $(-1.1 \pm 5.4 \%$ of energy). The difference in changes nearly reached statistical significance $(P=0.051)$. Changes in the intakes of saturated fatty acids and monounsaturated fatty acids also differed (table 8.1). The changes in protein and carbohydrate intake did not differ between the low trans $(-0.5 \pm 2.6 \%$ of energy and $-1.7 \pm 6.3 \%$ of energy, respectively $)$ and the high trans group $(0.3 \pm 2.3 \%$ of energy and $0.9 \pm 5.6 \%$ of energy, respectively). Further details of energy and nutrient intakes have been reported elsewhere (11).

Mean body weight of the subjects was increased by $0.2 \pm 1.1 \mathrm{~kg}$ in the high trans group, which differed significantly from the decrease of $0.4 \pm 1.2 \mathrm{~kg}$ in the low trans group (mean treatment effect of $0.6 \pm 2.4 \mathrm{~kg}(95 \% \mathrm{Cl} 0.1,1.1), \mathrm{P}=0.03)$.

Changes in plasma lipids and lipoproteins were corrected for weight changes and changes in the intakes of saturated and monounsaturated fatty acids. The consumption of trans $\alpha$-linolenic acid did not change plasma total cholesterol or triacylglycerol concentrations (table 8.2). LDL cholesterol concentrations tended to increase in the men consuming the high trans $\alpha$-linolenic acid diet, whilst it remained unchanged in the group who consumed the low trans diet following the run-in period. However, the treatment effect of $4.7 \%$ failed to reach significance $(P=0.10)$. The reverse was observed for plasma HDL cholesterol concentrations, where the concentrations tended to increase slightly in the low trans group, whilst there was no change in the men consuming the high trans $\alpha$-linolenic acid diet. The treatment effect did not reach statistical significance. However, the ratios of total to HDL and $\mathrm{LDL}$ to $\mathrm{HDL}$ cholesterol increased significantly by $5.1 \%(P=0.03)$ and $8.1 \%(P=0.02)$ on the high trans diet compared to the low trans diet. 


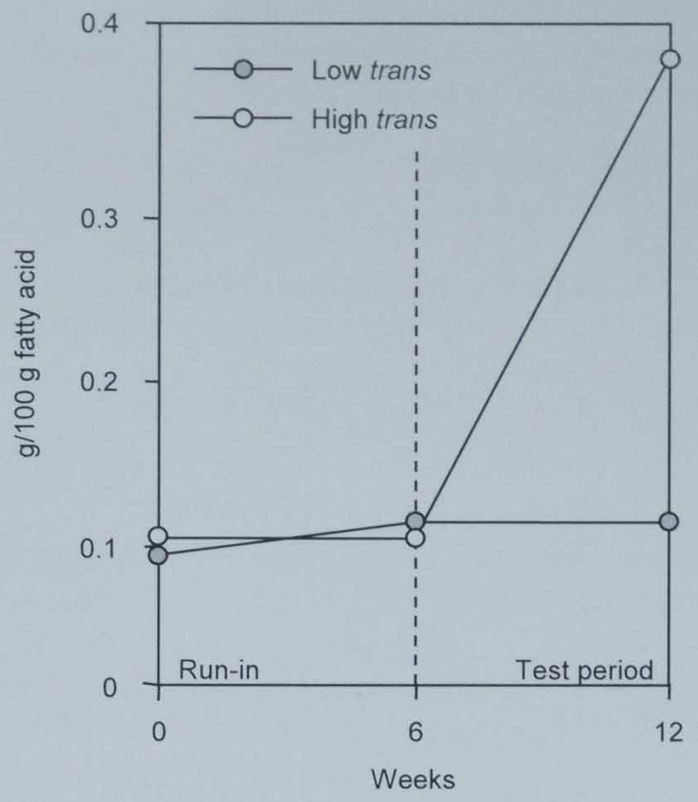

Figure 8.1 Median proportions of trans $\alpha$-linolenic acid in plasma cholesteryl esters during the run-in period ( $0-6$ weeks) $(n=43$ in both groups on $t=0 ; n=44$ in both groups on $t=6)$ and test period of low $(n=44)$ or high trans $\alpha$-linolenic acid $(n=42)(6-12$ weeks)

Table 8.1 Mean daily energy and nutrient intake

\begin{tabular}{|c|c|c|c|c|c|c|}
\hline \multirow{2}{*}{ Fat $(E n \%)$} & \multicolumn{3}{|c|}{$\begin{array}{l}\text { Low trans } \\
\qquad(\mathrm{n}=44)\end{array}$} & \multicolumn{3}{|c|}{$\begin{array}{l}\text { High trans } \\
\quad(n=44)\end{array}$} \\
\hline & & & & & & \\
\hline run-in & 32.4 & \pm & 6.3 & 35.3 & \pm & 5.9 \\
\hline change & 2.1 & \pm & 5.7 & -1.1 & \pm & 5.4 \\
\hline \multicolumn{7}{|l|}{ SAFA } \\
\hline run-in & 8.6 & \pm & 3.4 & 9.9 & \pm & 3.3 \\
\hline change & 1.1 & \pm & 2.2 & -0.5 & \pm & 1.9 ** \\
\hline \multicolumn{7}{|l|}{ MUFA } \\
\hline run-in & 14.1 & \pm & 2.8 & 15.1 & \pm & 2.5 \\
\hline change & 1.1 & \pm & 2.7 & -0.5 & \pm & $2.3^{*}$ \\
\hline \multicolumn{7}{|l|}{ PUFA } \\
\hline run-in & 7.1 & \pm & 1.4 & 7.7 & \pm & 1.8 \\
\hline change & 0.1 & \pm & 1.9 & -0.3 & \pm & 1.5 \\
\hline
\end{tabular}

SAFA, saturated fatty acids; MUFA, monounsaturated fatty acids, PUFA, polyunsaturated fatty acids. Differences between diet groups ${ }^{*} P<0.05,{ }^{*} \mathrm{P}<0.01$ 
Table 8.2 Plasma lipids and lipoproteins concentrations after 6 weeks of a diet low or high in trans $\alpha$-linolenic acid (mean values and standard deviations, and $95 \%$ confidence intervals for treatment effect (high vs low trans))

\begin{tabular}{|c|c|c|c|c|c|c|}
\hline \multirow{2}{*}{ Total cholesterol } & \multicolumn{2}{|r|}{$\begin{array}{l}\text { Low trans } \\
(n=44)\end{array}$} & \multicolumn{2}{|c|}{$\begin{array}{l}\text { High trans } \\
(n=44)\end{array}$} & Mean $(95 \% \mathrm{Cl})$ & \multirow[t]{2}{*}{ P-value } \\
\hline & & & & & & \\
\hline run-in (mmol/l) & 4.45 & \pm 0.76 & 4.21 & \pm 0.80 & & \\
\hline treatment effect $(\%)$ & 1.1 & & 2.7 & & $1.7(-2.2$ to 5.7$)$ & 0.41 \\
\hline \multicolumn{7}{|l|}{ LDL cholesterol } \\
\hline run-in (mmol/l) & 2.79 & \pm 0.65 & 2.59 & \pm 0.71 & & \\
\hline treatment effect $(\%)$ & -0.4 & & 4.0 & & $4.7(-0.8$ to 10.5$)$ & 0.10 \\
\hline \multicolumn{7}{|l|}{ HDL cholesterol } \\
\hline run-in $(\mathrm{mmol} / \mathrm{l})$ & 1.27 & \pm 0.28 & 1.22 & \pm 0.26 & & \\
\hline treatment effect $(\%)$ & 3.8 & & 0.3 & & $-2.7(-6.8$ to 1.6$)$ & 0.22 \\
\hline \multicolumn{7}{|l|}{ Triacylglycerols } \\
\hline run-in $(\mathrm{mmol} / \mathrm{l})$ & 0.85 & \pm 0.38 & 0.87 & 0.44 & & \\
\hline treatment effect $(\%)$ & -1.4 & & -1.6 & & $2.6(-9.1$ to 15.8$)$ & 0.68 \\
\hline \multicolumn{7}{|l|}{ LDL:HDL cholesterol ratio } \\
\hline run-in & 2.30 & \pm 0.75 & 2.25 & 0.82 & & \\
\hline treatment effect $(\%)$ & -4.0 & & 3.6 & & $8.1 \quad(1.4$ to 15.3$)$ & 0.02 \\
\hline \multicolumn{7}{|c|}{ Total:HDL cholesterol ratio } \\
\hline run-in & 3.63 & \pm 0.91 & 3.60 & 0.98 & & \\
\hline treatment effect (\%) & -2.6 & & 2.3 & & $5.1 \quad(0.4$ to 9.9$)$ & 0.03 \\
\hline
\end{tabular}

Treatment effects are expressed as percent changes.

Treatment effects did not differ between the three centers.

Treatment effects (high versus low trans) were corrected for changes in dietary saturated and monounsaturated fatty acid intake and in body weight.

Trans $\alpha$-linolenic acid did not affect plasma apoB and apoA-1 concentrations and their ratio (table 8.3). $L p(a)$ concentrations tended to fall in men consuming the low trans $\alpha$-linolenic acid diet, whilst concentrations remained constant in the group that was switched to a high trans $\alpha$-linolenic acid diet (data not shown). The treatment effect did not reach statistical significance. 
Table 8.3 Plasma apolipoprotein A-1 and B after 6 weeks of a diet low or high in trans $\alpha$-linolenic acid (Mean values and standard deviations, and $95 \%$ confidence intervals for treatment effect (high vs low trans))

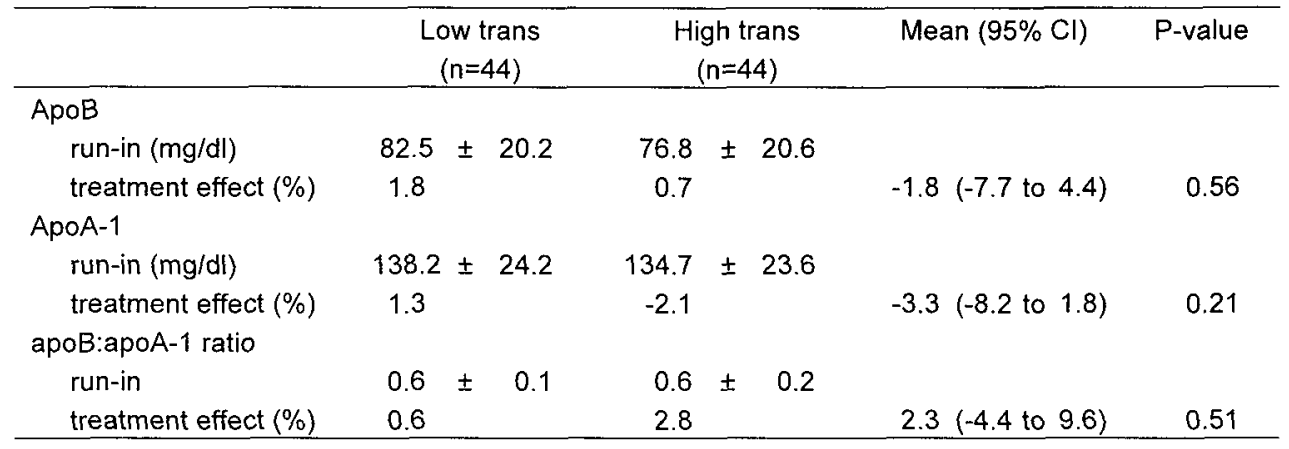

Treatment effects are expressed as percent changes

Treatment effects did not differ between the three centers

Treatment effects (high versus low trans) were corrected for changes in dietary saturated and monounsaturated fatty acid intake and in body weight

\section{DISCUSSION}

In this multi-center study with healthy normolipidaemic male volunteers, we did not find any unfavorable effects of high, but not unrealistic intakes of trans isomers from $\alpha$-linolenic acid on plasma total or HDL cholesterol concentrations. LDL cholesterol concentrations, however, tended to increase, while the ratios of LDL to HDL and total to HDL cholesterol were significantly increased on the high trans diet compared to the low trans diet. These effects were observed in each center and were already evident after 3 weeks consumption of the experimental diets (data not shown). Results were corrected for differences in fatty acid intake and body weight between the two groups.

We found a difference in the total to HDL cholesterol ratio of 0.15 between the low and the high trans group. This ratio may predict the risk for $\mathrm{CHD}$ even better than total or LDL cholesterol concentrations $(14,15)$. It has been suggested that an increase of 1 unit in the serum cholesterol over HDL ratio may increase the risk of myocardial infarction by $53 \%$ (16). This would suggest that the risk for CHD would decrease by $8 \%$, when $1334 \mathrm{mg}$ trans $\alpha$-linolenic acid is replaced by dietary cis $\alpha$ linolenic acid. It remains to be established, however, if diet-induced changes in HDL to total cholesterol ratio affect coronary heart disease risk.

So far, most previous studies have focused on the effects of trans monounsaturated fatty acids on the serum lipoprotein profile (17). Trans monounsaturates have been found to increase LDL cholesterol and to decrease HDL concentrations relative to its cis isomers (17). As a consequence trans 
monounsaturated fatty acid increase the total to HDL cholesterol ratio as in our study. Triacylglycerol concentrations were also increased on diets high in trans monounsaturated fatty acids (17). However, we did not observe effects of trans $\alpha$ linolenic acid on triacylglycerols. Possibly, intakes of trans isomers were even be too low, resulting in a limited power of the present study to detect such effects. Alternatively, trans $\alpha$-linolenic acid may act differently than trans monounsaturated fatty acids. $L p(a)$ was also not affected by an intake of $1.4 \mathrm{~g}$ trans $\alpha$-linolenic acid. Studies using trans monounsaturated fatty acids at high intakes, however, showed increased $L p(a)$ levels (17). One study has reported that partially hydrogenated fish oil, which contains trans isomers of the longer chain polyunsaturated fatty acids, elevated plasma total cholesterol, LDL cholesterol, and the LDL cholesterol to HDL cholesterol ratio relative to a partially hydrogenated soy-bean oil rich in trans monounsaturated fatty acids (18). However, results from that study are difficult to interpret because of differences in the composition of other fatty acids between the two hydrogenated oil diets.

Studies with trans monounsaturated fatty acids found that effects were similar for women and men (19-21) and for subjects with normal and mildly elevated triacylglycerol levels $(22,23)$. Whether this is also true for trans polyunsaturated fatty acids, should be examined in future studies. Furthermore, it remains to be determined what would be the longer-term effects of a high intake of trans $\alpha$-linolenic acid.

In our study subjects consumed on average $1410 \mathrm{mg}$ trans $\alpha$-linolenic acid. Hulshof et al. reported that for men the mean daily trans $\alpha$-linolenic acid plus trans 20:1 intake - these two fatty acids could not be separated by gas chromatography - in 14 Western European countries varied between $20 \mathrm{mg}$ in Italy and $490 \mathrm{mg}$ in Iceland (24). Based on the fatty acid composition of cholesteryl esters, we considered as a first reasonable estimate that the mean habitual diet in Edinburgh and Maastricht provided approximately $600 \mathrm{mg}$ trans $\alpha$-linolenic acid per day and in ClermontFerrand about $300 \mathrm{mg}$ (11). Proportions of $\alpha$-linolenic acid in serum cholesteryl esters from the Dutch cohort was about 1.7 times higher as in $1990(25)(0.55 \%$ vs. $0.32 \%$ ), suggesting that $\alpha$-linolenic acid intake has increased during the last years. In general, data on the intake of $\alpha$-linolenic acid does not suggest that the habitual intake of trans $\alpha$-linolenic acid is as high as we have used. Thus, the amount of trans $\alpha$-linolenic acid $(1.4 \mathrm{~g} / \mathrm{d})$ seemed to be high but not unrealistic. Standard deviations and ranges in trans $\alpha$-linolenic acid intake were rather large. This was due to inaccuracies inherent to the method, used to estimate food intake (food record) and to differences in compliance. The oil for this study was deodorized especially for this study, but the composition of the different trans isomers (14\% trans, cis, cis-, $19 \%$ cis, cis, trans- and $3.2 \%$ trans, cis, trans- $\alpha$-linolenic acid) is typical for commercially available oils $(5,26)$.

In conclusion, our study suggests that a high, but not unrealistic intake of trans $\alpha$-linolenic acid, which is formed during oil processing, may influence the total to $\mathrm{HDL}$ 
cholesterol ratio in an unfavorable way. Increasing the dietary intake of cis, cis, cis- $\alpha$ linolenic acid has been recommended by an expert panel (27) and obviously it does not make sense to provide $\alpha$-linolenic acid in the trans form. Careful deodorization prevents the formation of trans $\alpha$-linolenic acid (12) and may help to improve the diet, deliver more cis $\alpha$-linolenic acid and thereby possibly reduce ischaemic heart disease (28). 


\section{REFERENCES}

1. FAO/WHO expert consultation on fats and oils in human nutrition (1993) General conclusions and recommendations of the consultation. Rome: FAONWHO

2. Ackman RG, Hooper SN and Hooper DL. Linolenic acid artifacts from the deodorization of oils. J Am Oil Chem Soc 1974;51:42-49.

3. Hunter JE. n-3 Fatty acids from vegetable oils. Am J Clin Nutr 1990;51:809-814.

4. Ratnayake WMN, Hollywood R, and O'Grady E (1991) Fatty acids in Canadian margarines. Can Inst Food Sc Techn J 1990;24:81-86.

5. Wolff RL. trans-Polyunsaturated fatty acids in French edible rapeseed and soybean oils. J Am Oil Chem Soc 1992;69:106-110.

6. Wolff RL. Further studies on artificial geometrical isomers of $\alpha$-linolenic acid in edible linolenic acid-containing oils. Journal Am Oil Chem Soc 1993;70:219-224.

7. FAO. Faostat Nutrition data. Food Balance Sheets Report. 2000 http://apps.fao.org/lim500/nph-wrap.pl?FoodBalanceSheet\&Domain=FoodBalanceSheet

8. Chardigny JM, Sébédio JL, Juanéda $P$, Vatèle JM, and Grandgirard A. Occurrence of $n-3$ trans polyunsaturated fatty acids in human platelets. Nutr Res 1993;13:1105-1111.

9. Chardigny JM, Wolff RL, Mager E, Sébédio JL, Martine $L$, and Juanéda P. Trans mono- and polyunsaturated fatty acids in human milk. Eur J Clin Nutr 1995;49:523-531.

10. Wolff RL. Recent applications of capillary gas-liquid chromatography to some difficult separations of positional or geometrical isomers of unsaturated fatty acids. In: New trends in lipid and lipoprotein analysis (Sébédio $\mathrm{J}$ and Perkins $\mathrm{E}$, eds) Champaign: AOCS Press, 1995:147-180.

11. Sébédio JL, Vermunt SHF, Chardigny JM, et al. The effect of dietary trans $\alpha$-linolenic acid on plasma lipids and platelet fatty acid composition: the TransLinE study. Eur J Clin Nutr 2000;54:104-113.

12. Hénon $G$, Kemény $Z$, Recseg $K$, Zwobada F, and Kovari $K$. Deodorization of vegetable oils. Part I: Modeling the geometrical isomersization of polyunsaturated fatty acids. J Am Oil Chem Soc 1999;76:73-81.

13. Friedewald WT, Levy RI, and Fredrickson DS. Estimation of the concentration of low-density lipoprotein cholesterol in plasma, without use of the preparative ultracentrifuge. Clin Chem 1972;18:499-502.

14. Castelli WP, Garrison RJ, Wilson PWF, Abbott RD, Kalousdian S, and Kannel WB. Incidence of coronary heart disease and lipoprotein cholesterol levels. JAMA 1986;265:2835-2838.

15. Kinosian B, Glick H, and Garland G. Cholesterol and Coronary Heart Disease: predicting risks by levels and ratios. Ann Int Med 1994;121:641-647.

16. Stampfer MJ, Sacks FM, Salvini S, Willett WC, and Hennekens CH (1991) A prospective study of cholesterol, apolipoproteins, and the risk of myocardial infarction. New Engl J Med 325, 373-381.

17. Katan MB, Mensink RP, and Zock PL. Trans fatty acids and their effects on lipoproteins in humans. Ann Rev Nutr 1995;15:473-493.

18. Almendingen $K$, Jordal $O$, Kierulf $P$, Sandstad $B$, and Pedersen JI. Effects of partially hydrogenated fish oil, partially hydrogenated soybean oil, and butter on serum lipoproteins and Lp[a] in men. J Lipid Res 1995;36:1370-1384.

19. Mensink RP and Katan MB. Effect of dietary trans fatty acids on high-density and low-density lipoprotein cholesterol levels in healthy subjects. New Engl J Med 1990;323:439-445. 
20. Mensink RP, Zock PL, Katan MB, and Hornstra G. Effect of dietary cis and trans fatty acids on serum lipoprotein(a) levels in humans. J Lipid Res 1992;33:1493-1501.

21. Judd JT, Clevidence BA, Muesing RA, Wittes J, Sunkin ME, and Podczasy J. Dietary trans fatty acids: effects on plasma lipids and lipoproteins of healthy men and women. Am J Clin Nutr 1994;59:861-868.

22. Nestel PJ, Noakes M, Belling GB, McArthur R, Clifton PM, Janus E, and Abbey M. Plasma lipoprotein lipid and Lp[a] changes with substitution of elaidic acid for oleic acid in the diet. $J$ Lipid Res 1992;33:1029-1036.

23. Nestel P, Noakes M, Belling GB, McArthur R, Clifton PM, and Abbey M. Plasma cholesterollowering potential of edible-oil blends suitable for commercial use. Am J Clin Nutr 1992;55:4650 .

24. Hulshof KFAM, Van Erp-Baart MA, Anttolainen $M$, et al. Intake of fatty acids in Western Europe with emphasis on trans fatty acids: The TRANSFAIR study. Eur J Clin Nutr 1999;53:143-157.

25. Voskuil DW, Feskens EJM, Katan MB, and Kromhout D. Intake and sources of $\alpha$-linolenic acid in Dutch elderly men. Eur J Clin Nutr 1996;50:784-787.

26. O'Keefe S, Gaskins-Wright S, Wiley V, and Chen IC. Levels of trans geometrical isomers of essential fatty acids in some unhydrogenated U.S. vegetable oils. J Food Lipids 1994;1:165176.

27. De Deckere EAM, Korver O, Verschuren PM, and Katan MB. Health aspects of fish and n-3 polyunsaturated fatty acids from plant and marine origin. Eur J Clin Nutr 1998;52:749-753.

28. De Lorgeril M, Renaud S, Mamelle N, et al. J. Mediterranean alpha-linolenic acid-rich diet in secondary prevention of coronary heart disease. Lancet 1994;343:1454-1459. 

The studies described in this thesis examined metabolic aspects of dietary cis and trans polyunsaturated fatty acids. The two essential cis polyunsaturated fatty acids, linoleic and $\alpha$-linolenic acid, have to be provided by the diet and are converted in the human body into longer chain more unsaturated fatty acids (LCPs) by alternate desaturation and elongation. In vivo conversion of these fatty acids as well as their oxidation have, however, hardly been studied in humans. Furthermore, since cDNAs of human desaturases have only recently been cloned, gene expressions of these enzymes have not been extensively investigated in humans.

Dietary unsaturated fatty acids occur in two configurations: the cis and trans form. Trans monounsaturated fatty acids are formed by bacteria in the first stomach of ruminants and by industrial hydrogenation, and have a negative impact on serum lipoproteins. Trans polyunsaturated fatty acids are mainly formed during the deodorization process, but their effects on risk parameters of coronary heart disease (CHD) have not been investigated. Since an increment of $\alpha$-linolenic acid intake has been recommended (1), which could result in an increased intake of trans $\alpha$-linolenic acid, it is necessary to investigate the health effects of trans isomers of $\alpha$-linolenic acid as well.

This thesis describes four studies investigating (i) the in vivo metabolism of essential fatty acids (linoleic and $\alpha$-linolenic acid) in healthy subjects using ${ }^{13} \mathrm{C}$ tracers (chapters 2 and 3), (ii) effects of dietary $\alpha$-linolenic acid on the metabolism of ${ }^{13} \mathrm{C} \alpha$-linolenic acid (chapter 3 ), (iii) incorporation of ${ }^{13} \mathrm{C} \alpha$-linolenic acid and its longer chain metabolites into human erythrocytes (chapter 4), (iv) the relationship between $\Delta 5, \Delta 6$, and $\Delta 9$ desaturase mRNAs in human liver and mononuclear blood cells (chapter 5), (v) the incorporation of trans $\alpha$-linolenic acid into plasma and platelet lipids (chapter 7) and (vi) effects of trans $\alpha$-linolenic acid on plasma lipids and lipoproteins (chapter 8).

\section{IN VIVO CONVERSION AND OXIDATION OF N-3 AND N-6 FATTY ACIDS}

\section{Design of the tracer-studies}

The metabolism of both linoleic acid and $\alpha$-linolenic acid has been studied in vivo in healthy subjects using a single bolus of $45 \mathrm{mg}$ uniformly ${ }^{13} \mathrm{C}$ labeled fatty acids dissolved in olive oil. The dose of $45 \mathrm{mg}$ was established by a pilot study, in which three subjects were given 15,45 or $60 \mathrm{mg}{ }^{13} \mathrm{C}$ linoleic acid $\left({ }^{13} \mathrm{C} 18: 2 \mathrm{n}-6\right)$. We detected ${ }^{13} \mathrm{CO}_{2}$ in breath (figure 9.1), and ${ }^{13} \mathrm{C} 18: 2 \mathrm{n}-6,{ }^{13} \mathrm{C} 18: 3 \mathrm{n}-6,{ }^{13} \mathrm{C} 20: 3 \mathrm{n}-6$, and ${ }^{13} \mathrm{C} 20: 4 \mathrm{n}-6$ (arachidonic acid) in plasma total lipids (figure 9.2) at all doses. Plasma ${ }^{13} \mathrm{C}$ enrichments of these fatty acids were highest on a dose of $60 \mathrm{mg}$, while differences between doses of 15 and $45 \mathrm{mg}$ were only marginal. On the other hand, we could detect ${ }^{13} \mathrm{C} 22: 4 \mathrm{n}-6$ and ${ }^{13} \mathrm{C} 22: 5 \mathrm{n}-6$ with 45 and $60 \mathrm{mg}$ tracer, but not with $15 \mathrm{mg}$. 
Therefore, we concluded that $45 \mathrm{mg}$ could be used to study the oxidation of ${ }^{13} \mathrm{C}$ linoleic acid and its conversion into LCPs (chapter 2).

After plasma analyses of all volunteers in the linoleic acid study, however, ${ }^{13} \mathrm{C}$ enrichments of C20:4n-6 were low in three of the six subjects (chapter 2). Therefore, a dose of $45 \mathrm{mg}$ was on the low side to study conversion of ${ }^{13} \mathrm{C}$ linoleic acid into arachidonic acid. Demmelmair et al. used a bolus of $1 \mathrm{mg}{ }^{13} \mathrm{C}$ linoleic acid per kilogram body weight, corresponding to a mean dose of about $62 \mathrm{mg}$, to study linoleic acid metabolism in healthy adults (2). Reported plasma labeled linoleic acid concentrations were comparable with our results (chapter 2), while levels of arachidonic acid also seems to be very low in some subjects (2). Based on results of both studies it may therefore be recommended to use a three to fourfold higher dose of ${ }^{13} \mathrm{C}$ linoleic acid when using a single bolus. Furthermore, since ${ }^{13} \mathrm{C}$ enrichments of some fatty acid metabolites still increased 2 weeks after tracer ingestion (chapter 2), it seems necessary to sample over a longer time period.

Plasma pools of $n-3$ fatty acids are lower than those of $n-6$ fatty acids. Consequently, $45 \mathrm{mg}$ of ${ }^{13} \mathrm{C} \alpha$-linolenic acid would result in higher ${ }^{13} \mathrm{C}$ enrichments in $\mathrm{n}-3$ fatty acids as compared to ${ }^{13} \mathrm{C}$ enrichments in $\mathrm{n}-6$ fatty acids after $45 \mathrm{mg}$ of ${ }^{13} \mathrm{C}$ linoleic acid. We, therefore, reasoned that $45 \mathrm{mg}{ }^{13} \mathrm{C} \alpha$-linolenic acid should be adequate to study $\alpha$-linolenic acid metabolism (chapter 3 and 4 ). Indeed, ${ }^{13} \mathrm{C} \alpha$ linolenic acid metabolism could be studied well using $45 \mathrm{mg}$ tracer.

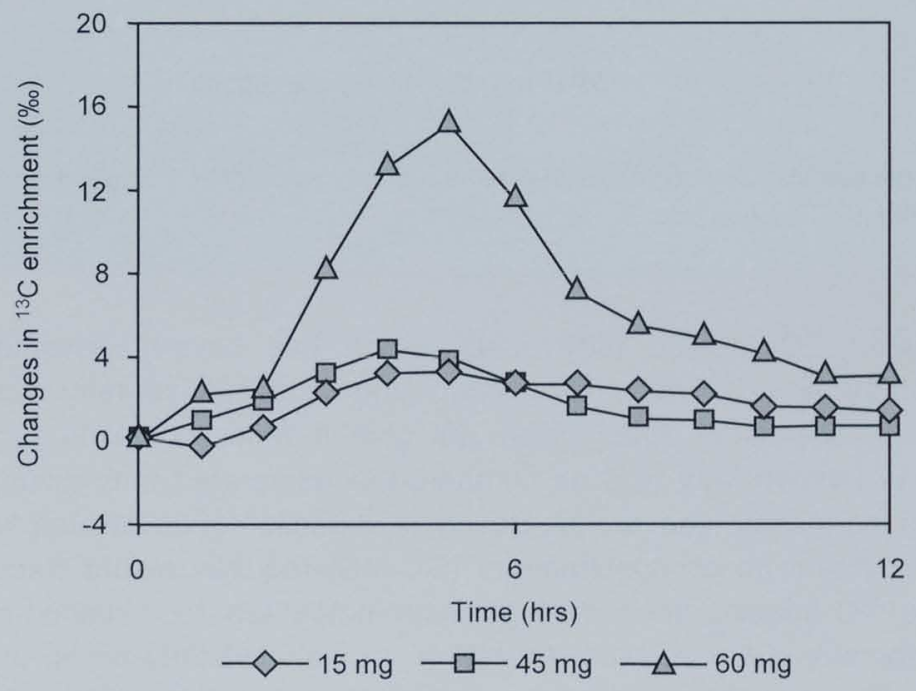

Figure 9.1 Changes in ${ }^{13} \mathrm{C}$ enrichment in breath (\%) after intake of a single dose of ${ }^{13} \mathrm{C}$ linoleic acid 


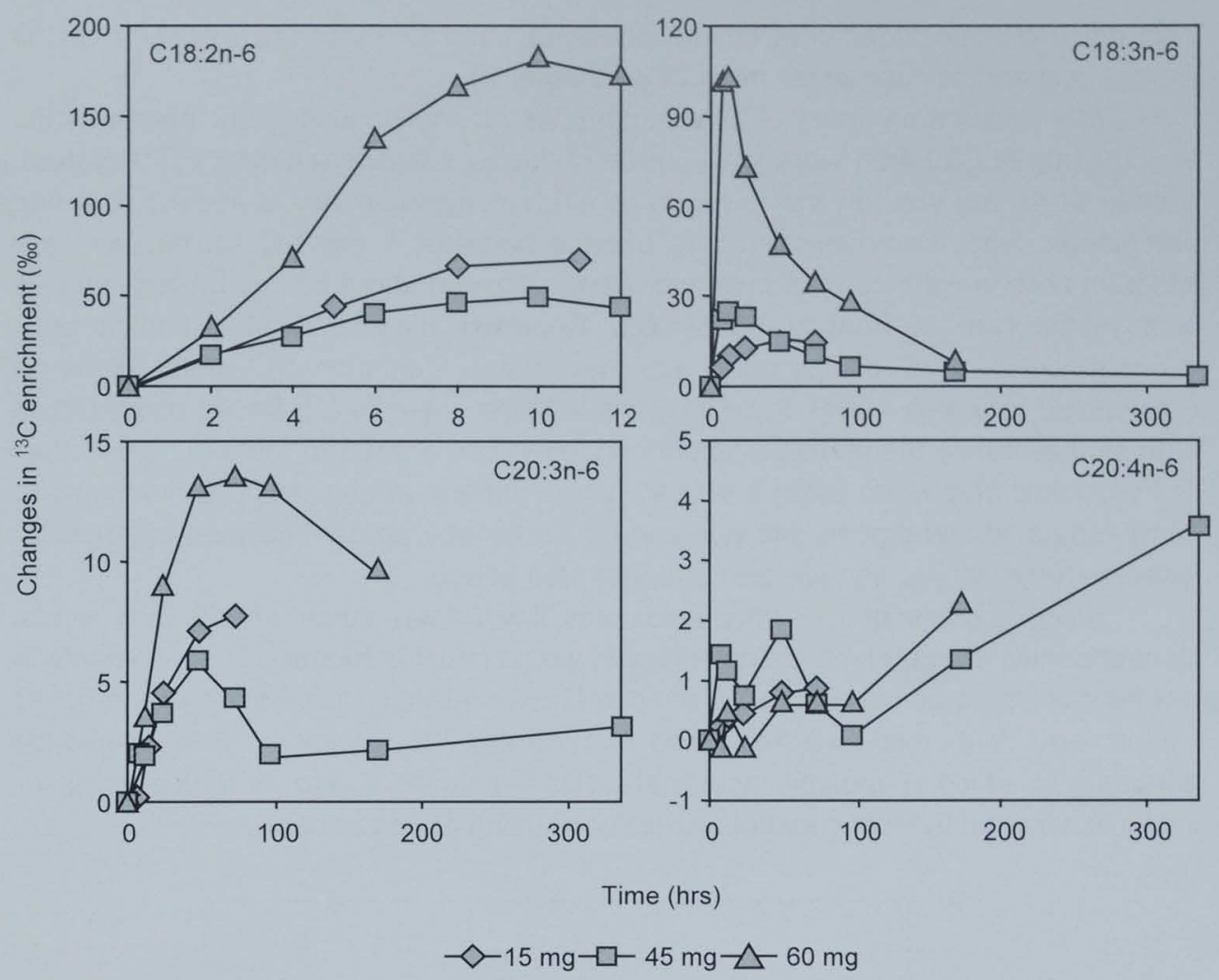

Figure 9.2 Changes in ${ }^{13} \mathrm{C}$ enrichments of plasma $\mathrm{n}-6$ fatty acids after a single dose of 15,45 , and $60 \mathrm{mg}{ }^{13} \mathrm{C}$ linoleic acid

We have used ${ }^{13} \mathrm{C}$ labeled fatty acids, which has several advantages above deuterated fatty acids. Firstly, conversion and oxidation of fatty acids can be investigated at the same time, which will give a more complete picture of the metabolism of labeled fatty acid as compared to deuterated fatty acids, which can only be used to measure conversion. Secondly, detection of deuterated fatty acids by gas chromatography mass spectrometry (GC-MS) requires higher tracer doses as compared to ${ }^{13} \mathrm{C}$ tracer detection by gas chromatography-combustion-isotope ratio mass spectrometry (GC-C-IRMS). Therefore, ${ }^{13} \mathrm{C}$ labeled fatty acids, in contrast to deuterated fatty acids will hardly influence the $n-3$ and $n-6$ fatty acid intake. This may be of importance because of the competition of $n-3$ and $n-6$ fatty acids for desaturases. In a previous study, participants were provided with $3.0 \mathrm{~g}$ of deuterated linoleic acid (3), which is about $23 \%$ of the daily intake in US (4). In some subjects, this was combined with 3.0 or $3.5 \mathrm{~g}$ deuterated $\alpha$-linolenic acid (3), which is more 
than $100 \%$ of the daily $\alpha$-linolenic acid intake (4). This certainly affected the absolute amounts of n-3 and n-6 fatty acids in the diet. Whether it also affects conversion reactions - and consequently interpretation of the results - remains to be established.

Human tracer studies are regularly carried out with only a small number of subjects. Previous fatty acid studies have used 2 to 13 subjects in each study group $(3,5-9)$, and some of them found differences between groups with only 2 or 3 subjects in each group $(3,6-8)$. As in other studies $(5,9)$, standard errors in tracer enrichments between subjects were rather large in our studies. The number of 5 to 7 subjects in our studies seems not unusual, and significant diet effects on the conversion of ${ }^{13} \mathrm{C}$ $\alpha$-linolenic acid were found (chapter 3 ). Although this may suggest that diet effects can be rather strong, it is advicable to look for strategies to reduce the variability between and within subjects, e.g. by using a cross-over design or repeated measures.

\section{Oxidation of ${ }^{13} \mathrm{C}$ labeled linoleic and $\alpha$-linolenic acid}

Figure 9.3 shows the individual cumulative ${ }^{13} \mathrm{C}$ recovery of both ${ }^{13} \mathrm{C}$ linoleic acid (chapter 2) and ${ }^{13} \mathrm{C} \alpha$-linolenic acid (chapter 3 ) in breath during the first 12 hours after intake of a single bolus of $45 \mathrm{mg}$ tracer. Cumulative ${ }^{13} \mathrm{C}$ recovery of ${ }^{13} \mathrm{C} \alpha$-linolenic acid in breath after 12 hours was not significantly affected by dietary $n-3$ fatty acids (20.4\% on an $\alpha$-linolenic acid rich diet, $15.7 \%$ on an oleic acid rich diet, and $24.8 \%$ on an eicosapentaenoic acid (EPA) / docosahexaenoic acid (DHA) rich diet), and was on average $19.7 \pm 1.4 \%$ (mean \pm sem) for the whole group. Mean cumulative ${ }^{13} \mathrm{C}$ recovery of ${ }^{13} \mathrm{C}$ linoleic acid in breath was $20.9 \%$. This may suggest that $\alpha$-linolenic acid and linoleic acid are oxidized at the same rate. A recent study using ${ }^{13} \mathrm{C}$ linoleic acid in lactating women, reported a recovery of 17.7 to $24.0 \%$, depending on the week of lactation (5), which agrees with our results. In newborn infants, ${ }^{13} \mathrm{C}$ recovery during the first 6 hours after ${ }^{13} \mathrm{C}$ linoleic acid ingestion was $7.4 \%(10)$, which was lower than in our study ( $12 \%$ after 6 hours). This suggest that age may affect oxidation of ${ }^{13} \mathrm{C}$ linoleic acid. It would therefore be interesting to further investigate oxidation of ${ }^{13} \mathrm{C}$ labeled fatty acids in different age-groups. Peak ${ }^{13} \mathrm{C}$ enrichments in breath were obtained $3-5$ hours after tracer intake for both ${ }^{13} \mathrm{C}$ labeled $\alpha$-linolenic acid and linoleic acid, which corresponds to the time to peak ${ }^{13} \mathrm{C}$ enrichments in breath of lactating women (5). 


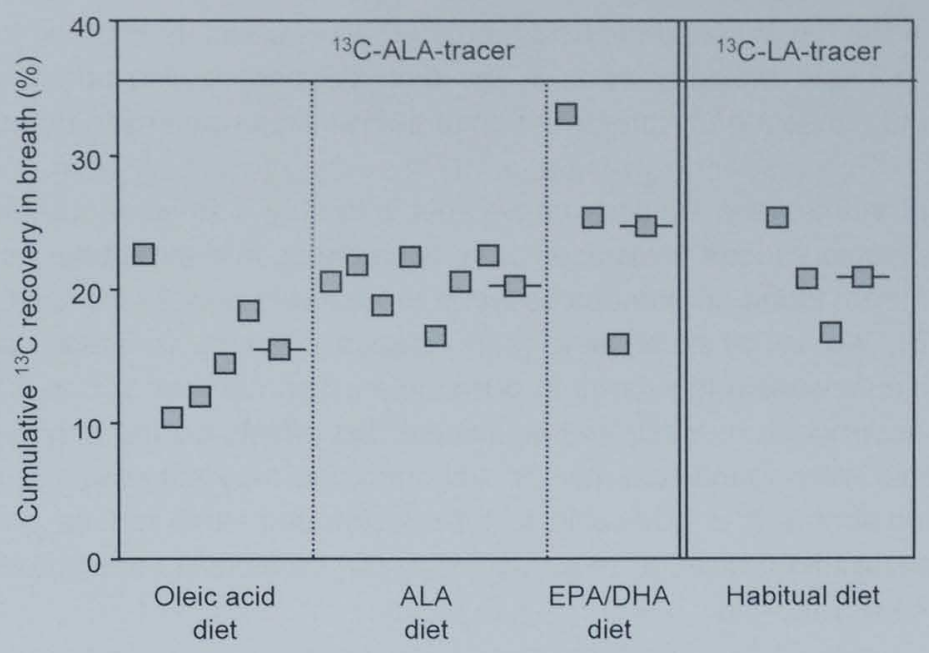

Figure 9.3 Individual cumulative ${ }^{13} \mathrm{C}$ recovery of ${ }^{13} \mathrm{C}$ linoleic acid and ${ }^{13} \mathrm{C} \alpha$-linolenic acid in breath during the first 12 hours after intake of a single bolus of $45 \mathrm{mg}$ tracer

Incorporation of ${ }^{13} \mathrm{C}$ labeled linoleic and $\alpha$-linolenic acid into plasma total lipids

Maximal amounts of plasma ${ }^{13} \mathrm{C} \alpha$-linolenic acid in the $\alpha$-linolenic acid study, which were 5 to $10 \%$ of the given dose, were not affected by dietary $n-3$ fatty acids (chapter 3 ). Emken et al. also found no effect of dietary DHA on deuterated $\alpha$-linolenic acid concentrations in plasma total lipids, after intake of a single bolus of deuterated $\alpha-$ linolenic acid, as compared to a low DHA diet (8). Dietary linoleic acid, however, decreased deuterated $\alpha$-linolenic acid concentrations in plasma total lipids as compared to dietary saturated fatty acids (3).

The mean maximal amount of ${ }^{13} \mathrm{C}$ linoleic acid $(7 \%$ of given dose) was not essentially different from the amount of ${ }^{13} \mathrm{C} \alpha$-linolenic acid in the $\alpha$-linolenic acid group ( $6 \%$ of given dose), and the amount of ${ }^{13} \mathrm{C} \alpha$-linolenic acid in the oleic acid group (10\% of given dose), as shown in figure 9.4 . Thus, incorporation of ${ }^{13} \mathrm{C}$ linoleic acid in plasma total lipids seems to be nearly equal to that of ${ }^{13} \mathrm{C} \alpha$-linolenic acid.

\section{Conversion of ${ }^{13} \mathrm{C}$ labeled linoleic and $\alpha$-linolenic acid into their LCPS}

Several previous in vivo studies have shown longer chain more unsaturated metabolites after administration of ${ }^{14} \mathrm{C}$ labeled, ${ }^{13} \mathrm{C}$ labeled or deuterated linoleic and $\alpha$-linolenic acid in plasma of adults $(3,7,9,11)$, in plasma of infants $(10,12-15)$, and in milk of lactating women (5). Human in vivo studies reporting diet effects on conversion of essential fatty acids are, however, limited. We found significantly lower mean maximal amounts of ${ }^{13} \mathrm{C}$-EPA in the $\alpha$-linolenic acid group $(0.04 \mathrm{mg})$ as compared to the oleic acid group $(0.12 \mathrm{mg})$. In addition, although not statistically tested, amounts of ${ }^{13} \mathrm{C}$-EPA were lower in the EPA/DHA group $(0.03 \mathrm{mg})$ as 
compared to the other groups (chapter 3), suggesting that $n-3$ LCPs decrease the conversion of ${ }^{13} \mathrm{C} \alpha$-linolenic acid. Hence, the relative conversion of plasma total $\alpha$ linolenic acid $\left({ }^{13} \mathrm{C}\right.$ plus $\left.{ }^{12} \mathrm{C}\right)$ may be inhibited by the substrate itself or by its products. Because of a higher quantity of substrate in the $\alpha$-linolenic acid group, however, the absolute conversion of plasma total $\alpha$-linolenic acid is still higher in this group as compared to the oleic acid group. Emken et al. reported lowered deuterated n-3 LCP levels after deuterated $\alpha$-linolenic acid administration on a high DHA diet as compared to a low DHA diet (8), which agrees with our study. In an intervention study with infants no effects of dietary $\alpha$-linolenic acid on the conversion of ${ }^{13} \mathrm{C} \alpha$-linolenic acid into DHA was found, while conversion of ${ }^{13} \mathrm{C}$ linoleic acid into arachidonic acid was inhibited (13). In addition, dietary arachidonic acid decreased the conversion of deuterated linoleic acid into arachidonic acid (7). Conversion of both deuterated linoleic and $\alpha$-linolenic acid is reduced by dietary linoleic acid in adult males (3). Figure 9.5 shows the individual maximal amounts of ${ }^{13} \mathrm{C}$ EPA $\left({ }^{13} \mathrm{C} 20: 5 n-3\right)$ and ${ }^{13} \mathrm{C}$ arachidonic acid $\left({ }^{13} \mathrm{C} 20: 4 n-6\right)$ after a dose of ${ }^{13} \mathrm{C}$ labeled $\alpha$-linolenic acid and linoleic acid, respectively. Mean peak amount of ${ }^{13} \mathrm{C}$ EPA was $0.3 \%$ of the given dose on the oleic acid diet and $0.09 \%$ on the $\alpha$-linolenic acid diet, while mean peak amount of ${ }^{13} \mathrm{C}$ arachidonic acid was $0.05 \%$ of the given dose. Results are difficult to compare due to differences in background diets, which may have affected fatty acid conversions.

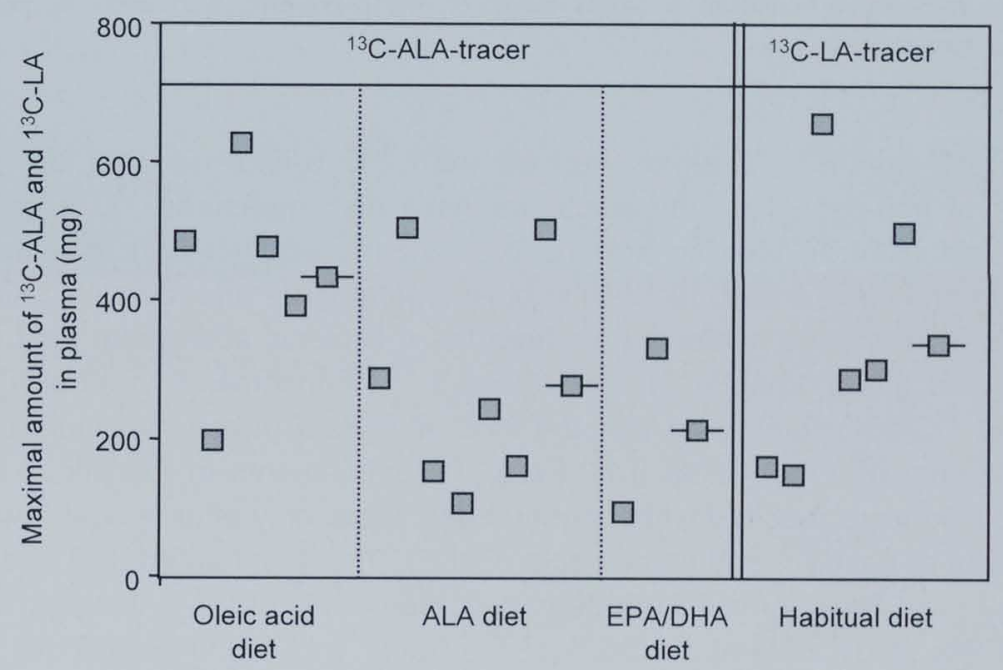

Figure 9.4 Individual maximal amounts of ${ }^{13} \mathrm{C} \alpha$-linolenic acid in plasma on diet rich in oleic acid $(n=5), \alpha$-linolenic acid $(n=7)$, or EPA/DHA $(n=3)$ and of ${ }^{13} \mathrm{C}$ linoleic acid on an habitual diet $(n=6)$ after intake of a single bolus of ${ }^{13} \mathrm{C} \alpha$-linolenic acid and ${ }^{13} \mathrm{C}$ linoleic acid, respectively 


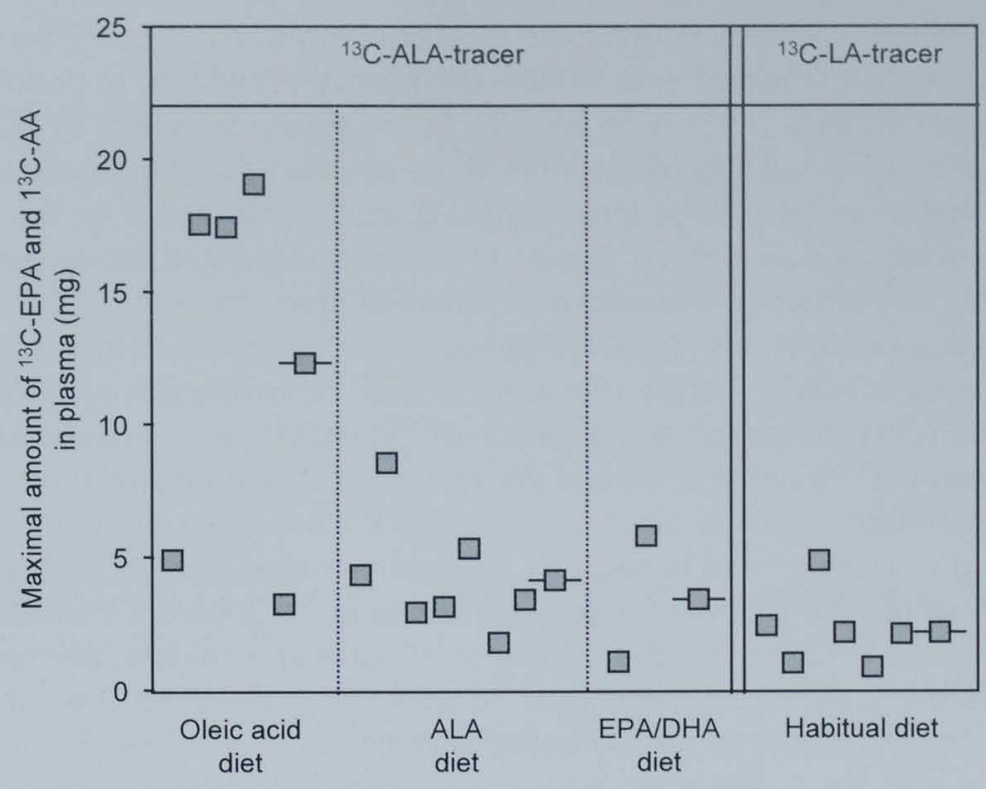

Figure 9.5 Individual maximal amounts of ${ }^{13} \mathrm{C}$-EPA in plasma on diet rich in oleic acid $(n=5), \alpha-$ linolenic acid $(n=7)$, or EPA/DHA $(n=3)$ and of ${ }^{13} \mathrm{C}$ arachidonic acid on an habitual diet $(n=6)$ after intake of a single bolus of ${ }^{13} \mathrm{C} \alpha$-linolenic acid and ${ }^{13} \mathrm{C}$ linoleic acid, respectively

To elucidate whether ${ }^{13} \mathrm{C}$-atoms derived from ${ }^{13} \mathrm{C} \alpha$-linolenic acid are used for synthesis of non-essential fatty acids, we have also measured ${ }^{13} \mathrm{C}$ enrichment in myristic acid (C14:0), palmitic acid (C16:0), stearic acid (C18:0), palmitoleic acid $(\mathrm{C} 16: 1 \mathrm{n}-7)$ and oleic acid $(\mathrm{C} 18: 1 \mathrm{n}-9)$ in plasma total lipids after administration of ${ }^{13} \mathrm{C}$ $\alpha$-linolenic acid in three subjects (two from the $\alpha$-linolenic acid group, and one from the oleic acid group; chapter 3 ). We detected ${ }^{13} \mathrm{C}$ enrichments in all of these fatty acids, and ${ }^{13} \mathrm{C}$ palmitoleic acid was the most abundant (mean maximum change in ${ }^{13} \mathrm{C}$ enrichment of $11 \%$ ) (table 9.1). Peak ${ }^{13} \mathrm{C}$ enrichments of myristic, palmitoleic, and oleic acid were reached within the first day, while only after almost 2 weeks ${ }^{13} \mathrm{C}$ enrichments of palmitic, and stearic acid peaked. These saturated, $n-9$ and n-7 fatty acids may have been formed from degradation products of ${ }^{13} \mathrm{C} \alpha$-linolenic acid or its LCPs. In this study, only about $0.2 \%$ of the tracer was found as myristic, palmitic, stearic, palmitoleic or oleic acid. Therefore, the low recovery of ${ }^{13} \mathrm{C} \alpha$-linolenic acid (chapter 3 and 4 ) may not be explained by its conversion into non-essential fatty acids. 
Table 9.1 Maximal ${ }^{13} \mathrm{C}$ enrichment of myristic acid (C14:0), palmitic acid (C16:0), stearic acid (C18:0), palmitoleic acid (C16:1n-7) and oleic acid (C18:1n-9) in plasma total lipids after administration of ${ }^{13} \mathrm{C} \alpha$-linolenic acid in three subjects (two after an $\alpha$-linolenic acid rich diet, and one after an oleic acid rich diet)

\begin{tabular}{lccccc}
\hline & \multicolumn{2}{c}{ Maximal ${ }^{13} \mathrm{C}$ enrichment $(\%)$} & & \multicolumn{2}{c}{ Time to peak ${ }^{13} \mathrm{C}$ enrichment (hours) } \\
\cline { 2 - 3 } Fatty acid & Median & Mean & & Median & Mean \\
\hline C14:0 & 3.35 & 3.08 & & 5 & 7 \\
C16:0 & 1.17 & 1.92 & & 336 & 232 \\
C18:0 & 0.81 & 2.27 & & 336 & 232 \\
C16:1n-7 & 10.85 & 11.17 & & 5 & 5 \\
C18:1n-9 & 1.35 & 1.55 & & 24 & 20 \\
\hline
\end{tabular}

In order to gain our insight into the distribution of labeled fatty acids among the human body, incorporation of ${ }^{13} \mathrm{C} \alpha$-linolenic acid and its LCP into erythrocytes has been investigated. We did not found differences in ${ }^{13} \mathrm{C} n-3$ fatty acid incorporation between the $\alpha$-linolenic acid and oleic acid group (chapter 4). We have also checked for incorporation of ${ }^{13} \mathrm{C}$ linoleic acid and its metabolites into human erythrocytes in three subjects of the linoleic acid study (chapter 2), and we found ${ }^{13} \mathrm{C}$ enrichments of linoleic acid, C20:3n-6, arachidonic acid (C20:4n-6), and C22:4n-6 (C18:3n-6 and $\mathrm{C} 22: 5 \mathrm{n}-6$ were not measured). Table 9.2 shows median and mean maximal proportions of $\mathrm{n}-3$ fatty acids after ${ }^{13} \mathrm{C} \alpha$-linolenic acid intake (chapter 4 ) and that of $\mathrm{n}-6$ fatty acids after ${ }^{13} \mathrm{C}$ linoleic acid intake (from the study described in chapter 2 ). As already described in chapter 4 , the high mean proportion of ${ }^{13} \mathrm{C} 18: 3 n-3$ in the $\alpha$ linolenic acid group was caused by one subject. Median proportions of ${ }^{13} \mathrm{C}$ linoleic acid seem to be higher than of ${ }^{13} \mathrm{C} \alpha$-linolenic acid. The mean maximal proportion of ${ }^{13} \mathrm{C} 20: 4 n-6$ was the highest of all $n-6$ and $n-3$ LCPs. Incorporation of ${ }^{13} \mathrm{C}$ linoleic acid into erythrocytes, however, occurred at a slower rate as compared to that of ${ }^{13} \mathrm{C} \alpha$ linolenic acid, as evidenced from the time to peak proportions of 48 hours for ${ }^{13} \mathrm{C}$ linoleic acid and of 11 hours for ${ }^{13} \mathrm{C} \alpha$-linolenic acid. 
Table 9.2 Maximal proportions of ${ }^{13} \mathrm{C}$ labeled fatty acids in erythrocytes (\% of total fatty acids) after intake of ${ }^{13} \mathrm{C} \alpha$-linolenic acid (ALA; on diets rich in oleic acid or $\alpha$-linolenic acid) (chapter 4) and after intake of ${ }^{13} \mathrm{C}$ linoleic acid (LA; habitual diet) (chapter 2)

\begin{tabular}{|c|c|c|c|c|}
\hline \multicolumn{5}{|c|}{ Maximal proportions $\left({ }^{\star} 10^{-3} \%\right.$ of total fatty acids) } \\
\hline & \multicolumn{2}{|c|}{${ }^{13} \mathrm{C}-\mathrm{ALA}$ tracer } & \multicolumn{2}{|c|}{${ }^{13} \mathrm{C}$-LA tracer } \\
\hline & Oleic acid $(n=5)$ & $A L A(n=7)$ & & $(n=3)$ \\
\hline${ }^{13} \mathrm{C} 18: 3 n-3$ & $1.06(1.64 \pm 0.72)$ & $0.83(4.11 \pm 3.21)$ & ${ }^{13} \mathrm{C} 18: 2 \mathrm{n}-6$ & $2.17(4.01 \pm 2.53)$ \\
\hline${ }^{13} \mathrm{C} 20: 5 \mathrm{n}-3$ & $0.31(0.27 \pm 0.08)$ & $0.09(0.17 \pm 0.06\rangle$ & ${ }^{13} \mathrm{C} 20: 3 n-6$ & $0.08(0.13 \pm 0.06)$ \\
\hline${ }^{13} \mathrm{C} 22: 5 n-3$ & $0.17(0.19 \pm 0.06)$ & $0.16(0.18 \pm 0.05)$ & ${ }^{13} \mathrm{C} 20: 4 n-6$ & $0.55(0.55 \pm 0.28)$ \\
\hline${ }^{13} \mathrm{C} 22: 6 n-3$ & $0.04(0.04 \pm 0.01)$ & $0.05(0.07 \pm 0.02)$ & ${ }^{13} \mathrm{C} 22: 4 n-6$ & $0.11(0.11 \pm 0.06)$ \\
\hline
\end{tabular}

Values are medians (means \pm sem)

\section{Conclusion tracer-studies}

To summarize, after administration of a single bolus of $45 \mathrm{mg}{ }^{13} \mathrm{C} \alpha$-linolenic acid to healthy subjects, about $20 \%$ was recovered as ${ }^{13} \mathrm{CO}_{2}$ in breath after 12 hours, and at least 5 to $10 \%$ appeared as precursor and $0.1-0.3 \%$ as LCPs in plasma total lipids. In addition, a small part of the tracer was detected as precursor or metabolite in erythrocytes, and at least $0.2 \%$ may have been converted into non-essential fatty acids. This means that a large part of the tracer is still missing. In our studies, we have only investigated oxidation, and incorporation of the tracer in plasma and erythrocyte total lipids. The labeled fatty acids may also have been incorporated into other tissues. More importantly, the recovery of the tracer may have been underestimated because our data were based on one single time point (maximal changes).

When a single bolus is used to investigate fatty acid conversion, like in our studies, quantification of conversion of fatty acids is difficult because the appearance and disappearance of fatty acid tracers in plasma may overlap. Demmelmair et al. have compared a single bolus of ${ }^{13} \mathrm{C}$ linoleic acid with fractionated tracer doses ( 9 equal portions over 3 days) (2), and used three methods to describe conversion: compartmental modeling, integrating tracer concentration-time curves, and tracer concentrations of LCPs relative to linoleic acid at specific time points. Fractional conversion of ${ }^{13} \mathrm{C}$ linoleic acid into ${ }^{13} \mathrm{C} 20: 3 \mathrm{n}-6$ was significantly higher in the group which received the fractionated doses $(2.1 \%$ per day) than in the bolus group $(1.5 \%$ per day). When calculating area under the curves, conversions were $4.1 \%$ and $5.1 \%$, respectively. The authors suggested that the area under the curve overestimate the amount of ${ }^{13} \mathrm{C}$ labeled fatty acids converted (2). Using specific time points to describe conversion has the disadvantage that tracer enrichments are dependent on the time of sampling and turn-over times of the fatty acids. When we would have used one specific time point in the ${ }^{13} \mathrm{C} \alpha$-linolenic acid study (chapter 3 ), for example $\mathrm{t}=5$ hours $-{ }^{13} \mathrm{C} \alpha$-linolenic acid enrichments are maximal at this point - we would not have been able to detect differences in ${ }^{13} \mathrm{C}$ enrichments of LCPs between the $\alpha$-linolenic acid 
rich and the oleic acid rich diet (figure 3.3). So far, there is no optimum method to describe in vivo conversion of fatty acids.

\section{Desaturase mRNAs in human mononuclear blood cells and liver tissue}

Three desaturase enzymes are involved in the conversion of essential and nonessential fatty acids: $\Delta 5, \Delta 6$ and $\Delta 9$ desaturase. Desaturase activity mainly takes place in the liver, but this is not an easy accessible organ to investigate in humans. Since a previous study has demonstrated that ${ }^{13} \mathrm{C}$ linoleic acid is converted into its LCPs in human leukocytes (16), we reasoned that desaturase mRNA could be present in human leukocytes as well. In order to predict desaturase mRNA levels of liver by measuring those in leukocytes, desaturase regulation in human leukocytes should be related to desaturase regulation in the liver. Such a relationship has been found between low density lipoprotein (LDL) receptor mRNA and 3-hydroxy-3methylglutaryl CoA reductase (HMGCoA) mRNA levels in mononuclear blood cells with those in human liver, suggesting that regulation of gene expressions of the LDL receptor and $\mathrm{HMGCOA}$ in leukocytes parallels that in the liver (17).

Desaturase mRNA levels were measured in patients with morbid obesity who underwent gastroplasty, patients who underwent hemi-hepatectomy, and patients who underwent cholecystectomy for symptomatic gallstones (chapter 5). Although absolute amounts of desaturase mRNA in these patients may deviate from that of healthy subjects, there is no need to assume that the correlation of desaturase gene expression between liver and mononuclear blood cells - if any - is different. These patients underwent an operation close to the liver, which makes the liver accessible for liver biopsy. An extra operation is not necessary. These patients are therefore more suitable for participating in this study than any other population. One disadvantage is, however, that the in vivo enzyme activity, measured by stable isotopes, could not be investigated at the same time, because this would have been too demanding for the patients. In vitro measurement of enzyme activity in liver was not possible, because 3-4 g liver is needed for isolation of an adequate amount of microsomes (18; personal communication), which is unethical to collect.

We found $\Delta 5, \Delta 6$ and $\Delta 9$ desaturase mRNAs in both human liver and human mononuclear blood cells (chapter 5). Delta 6 and $\Delta 9$ desaturase mRNAs in mononuclear blood cells were negatively correlated with $\Delta 6$ and $\Delta 9$ desaturase mRNAs in the liver, while $\triangle 5$ desaturase mRNA in liver was not correlated with that in the mononuclear blood cells. We do not have a clear explanation for these negative correlations. Results of our study (chapter 3 ) and of other previous studies $(3,7,8)$ suggest that the relative conversions of linoleic and $\alpha$-linolenic acid - expressed as the proportion of the total amount of linoleic or $\alpha$-linolenic acid $\left({ }^{13} \mathrm{C}\right.$ plus $\left.{ }^{12} \mathrm{C}\right)$ in the diet that is converted - may be inhibited by the substrate itself as well as by its products. Absolute conversions - expressed as the absolute amount of $\alpha$-linolenic acid in the diet that is converted - may, however, still be higher because of the higher 
quantity of substrate in the diet. We speculated that an increased supply of substrate will first reach the liver via chylomicron and chylomicron remnants and may here increase mRNA levels of $\triangle 6$ desaturase. This will result in increased LCP-formation and LCP-output via very low density lipoprotein (VLDL). These LCPs may subsequently lower mRNA of $\triangle 6$ desaturase in extra hepatic tissues and cells. This pathway may result in a negative correlation between hepatic and extra hepatic desaturase levels, as observed in our study (chapter 5).

\section{EFFECTS OF TRANS $\alpha$-LINOLENIC ACID ON PLASMA LIPIDS AND LIPOPROTEINS}

\section{Study performance}

The TRANSLinE study investigated the incorporation of fatty acids into plasma lipids and platelets, and effects on plasma lipids after a trans $\alpha$-linolenic acid enriched diet in male subjects. The study was performed in three centers located in three European Countries, France (Clermont-Ferrand), Scotland (Edinburgh) and the Netherlands (Maastricht), under comparable conditions. In each center, all punctures were performed by the same technician, at the same location, and as much as possible at the same time of the same day of the week. Laboratory analyses were centralized in order to eliminate any possible systematic analytical bias between centers.

The TRANSLinE study was well controlled: Subjects visited the centers every week to control for body weight and to collect experimental products. If necessary, energy intake was adjusted to maintain a stable body weight. Furthermore, subjects were urged not to change smoking habits, background diets, alcohol use or physical exercise during the study, and any deviations from the protocol, medication used and any signs of illness were recorded in diaries. All subjects were assigned a random number, which was used for labeling the tubes and cups. In addition, food items were color coded. In this way, both subjects and technicians were blinded. Compliance was checked by food diaries and by changes in the fatty acid compositions of plasma cholesteryl esters, phospholipids, triacylglycerols and platelets.

The high trans $\alpha$-linolenic acid diet provided on average $0.5 \%$ of energy (or $1410 \mathrm{mg}$ ) from trans $\alpha$-linolenic acid. A previous study reported daily intakes of trans $\alpha$-linolenic acid plus trans 20:1 between $20 \mathrm{mg}$ and $490 \mathrm{mg}$ in Western European countries (19). Based on the fatty acid composition of cholesteryl esters of the subjects before the start of the study, we considered $300 \mathrm{mg}$ (in Clermont-Ferrand) to $600 \mathrm{mg}$ (in Edinburgh and Maastricht) trans $\alpha$-linolenic acid per day as a reasonable estimate (chapter 7 and 8). 


\section{Results}

Proportions of trans fatty acids differed between European countries $(20,21)$; trans monounsaturated were the highest in the Northern European countries. In our study, the total trans fatty acid contents in plasma triacylglycerols, phospholipids, cholesteryl esters and platelets at baseline were higher in Edinburgh and Maastricht as compared to Clermont-Ferrand (chapter 7). Proportions of trans monounsaturated fatty acids were lowest in Clermont-Ferrand, while no differences between Edinburgh and Maastricht were observed. In Edinburgh, subjects were recruited by advertisement in the university bulletin and posters, while French and Dutch subjects were recruited mainly from the general population (among a panel in Clermont Ferrand and through announcements in university and local newspapers in Maastricht). Different backgrounds of the subjects may have biased comparisons of fatty acid compositions at baseline. Subjects in Maastricht had higher proportions of trans linoleic acid in plasma triacylglycerols and cholesteryl esters compared to Clermont-Ferrand and Edinburgh, and higher proportions of trans $\alpha$-linolenic acid in plasma triacylglycerols, and cholesteryl esters compared to Clermont-Ferrand (chapter 7). The EURAMIC study also showed that in 1991/92, the Dutch cohort had the highest proportions of the trans total fatty acids in adipose tissue (22), which reflects dietary intakes (23). Since 1995, the trans fatty acid content of Dutch margarines and spreads is reduced (24), which should result in a lower intake of trans fatty acids. Our study now suggest that intakes of both trans monounsaturates and polyunsaturates are relatively high in the Netherlands.

After a diet with experimental oils high in trans $\alpha$-linolenic acid, the relative amount of trans $\alpha$-linolenic acid increased in plasma triacylglycerols, phospholipids and cholesteryl esters (chapter 7). Furthermore, on the high trans $\alpha$-linolenic acid diet trans eicosapentaenoic acid was raised by $0.04 \%$ of total fatty acids in plasma triacylglycerols, by $0.07 \%$ of total fatty acids in plasma phospholipids and by $0.02 \%$ of total fatty acids in plasma cholesteryl esters as compared to the low trans diet. This suggests that trans isomers of $\alpha$-linolenic acid are elongated and desaturated by man. Trans isomers of oleic acid and linoleic acid, as well as other cis polyunsaturated fatty acids in plasma cholesteryl esters, were not affected by the diets (chapter 7).

In the TRANSLinE study, we found increased total to HDL cholesterol and LDL to HDL cholesterol ratios on trans $\alpha$-linolenic acid as compared to cis $\alpha$-linolenic acid. Trans $\alpha$-linolenic acid did not affect other plasma lipids (chapter 8 ). On the contrary, trans monounsaturates did affect plasma LDL and HDL cholesterol, triacylglycerol and in some studies lipoprotein (a) (24).

Effects of trans monounsaturated fatty acids on plasma lipids have been reported in several previous studies (24). Katan et al. have combined results of five studies, and suggested that each additional percent of dietary energy as trans monounsaturated fatty acids at expense of oleic acid results in an increase in LDL 
cholesterol levels of $0.040 \mathrm{mmol} / \mathrm{l}$ and a decrease in HDL cholesterol levels of 0.013 $\mathrm{mmol} / \mathrm{l}$ (24). From a previous study of Almendingen et al. it can be calculated that each percent of dietary energy as trans isomers of the LCPS from partially hydrogenated fish oil elevated plasma LDL cholesterol by $0.071 \mathrm{mmol} / \mathrm{l}$, and decreased HDL cholesterol concentrations by $0.001 \mathrm{mmol} / /$ relative to carbohydrates (25). We found an increase in LDL cholesterol of $0.22 \mathrm{mmol} / \mathrm{l}$ and a decrease in HDL cholesterol of $0.04 \mathrm{mmol} / \mathrm{l}$ on each percent of dietary energy on trans $\alpha$-linolenic acid as compared to cis $\alpha$-linolenic acid. Figure 9.6 shows the effects of these three trans fatty acids relative to carbohydrates (27). Results suggest that the relative effects of trans $\alpha$-linolenic acid may even be stronger than that of trans monounsaturated fatty acids. Intake of trans monounsaturated fatty acids will, however, be higher than that of trans polyunsaturated fatty acids.

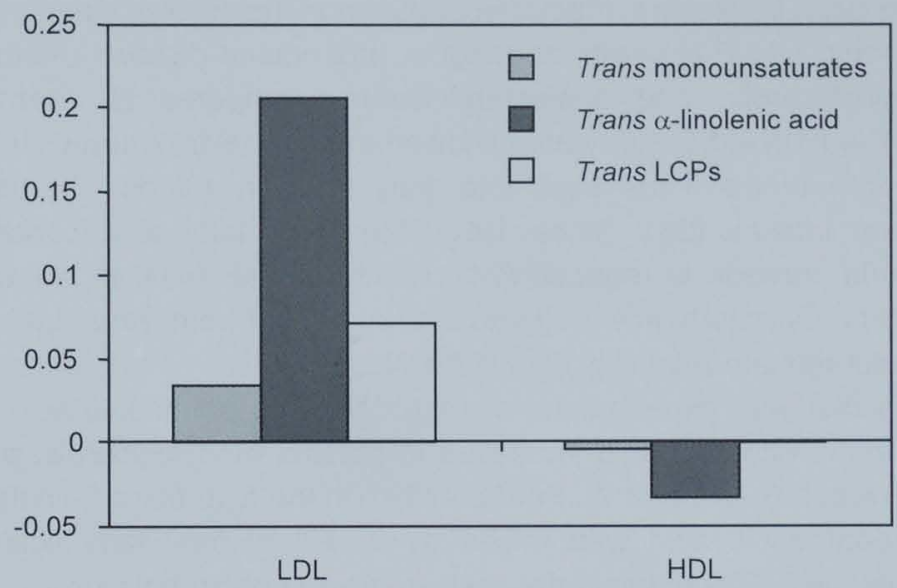

Figure 9.6 Changes in LDL and HDL cholesterol levels on each percent of dietary energy as trans monounsaturated fatty acids (24), trans $\alpha$-linolenic acid (chapter 8 ), and partially hydrogenated fish oil rich in trans polyunsaturated fatty acids (LCPs) (25) relative to carbohydrates

The underlying mechanisms for effects of both trans mono- and polyunsaturated fatty acids are still not understood. Cholesteryl ester transfer protein (CETP) and lecithin:cholesterol acyltransferase (LCAT) have been suggested to be involved. CETP transfers cholesteryl esters from HDL to the apolipoprotein B-containing lipoproteins LDL and VLDL in exchange for triacylglycerol. Some previous studies found an increased CETP activity in volunteers who consumed a trans fatty acid enriched diet $(28,29)$, and after addition of trans fatty acids to human plasma in vitro 
(30), while others did not confirm these results $(31,32)$. LCAT is bound to HDL and esterifies free cholesterol from tissues. A decrease of LCAT activity on trans fatty acids has been reported (33), although this was not supported by another study (34). Furthermore, a low affinity of acyl-CoA:cholesterol acyl transferase (ACAT), which esterifies fatty acids from chylomicrons, for trans C18:1 have been reported (35), which may eventually result in increased levels of LDL cholesterol by a decrease of the liver LDL receptor activity. Further research is needed to investigate these mechanisms.

\section{CONCLUSIONS AND RECOMMENDATIONS}

The studies described in this thesis showed that after ingestion of ${ }^{13} \mathrm{C}$ labeled linoleic and $\alpha$-linolenic acid to healthy volunteers, the precursors as well as their longer chain $n-6$ and $n-3$ fatty acids are incorporated into plasma total lipids. This suggests that ${ }^{13} \mathrm{C}$ linoleic and $\alpha$-linolenic acid are converted into longer chain more unsaturated fatty acids in humans. The conversion of ${ }^{13} \mathrm{C} \alpha$-linolenic acid was decreased by an $\alpha-$ linolenic acid rich diet, as compared to an oleic acid rich diet. Part of the ${ }^{13} \mathrm{C}$ linoleic and $\alpha$-linolenic acid is oxidized and excreted by breath as ${ }^{13} \mathrm{CO}_{2}$. Another part of the tracer is incorporated into erythrocytes as precursor and as metabolite. Incorporation of ${ }^{13} \mathrm{C} \alpha$-linolenic acid into erythrocytes was not affected by dietary $\alpha$-linolenic acid. We detected only about $30 \%$ of the tracer, which means that a large part of the tracer is still missing.

Linoleic and $\alpha$-linolenic acid are converted by alternate elongation and desaturation. We have now detected $\Delta 5$ and $\Delta 6$ desaturase mRNA in human liver and mononuclear blood cells. In addition, mRNA of $\triangle 9$ desaturase, which is involved in the conversion of non-essential fatty acids, was measured. We found a negative correlation between $\Delta 6$ and $\Delta 9$ desaturase mRNA in mononuclear blood cells with those in the liver, which may be explained as follows. Absolute conversion of fatty acids may be higher when more substrate is supplied. An increased supply of substrate may increase hepatic $\Delta 6$ desaturase mRNA, which results in increased LCP-formation and LCP-output via VLDL. This may subsequently lower $\Delta 6$ desaturase mRNA in extra hepatic tissue. It would now also be interesting to examine effects of external factors, e.g. diets, on desaturase mRNA levels in mononuclear blood cells, in order to examine whether desaturase mRNAs in mononuclear blood cells can indeed be used to examine fatty acid conversions. Combining the stable isotope technique with determinations of desaturase mRNAs and possible other enzymes involved in the metabolism of essential and non-essential fatty acids, as well as qualification of the amounts of enzymes in human tissues by using antibodies seem to be useful to increase our understanding on the regulation of essential fatty acid metabolism. 
Dietary trans isomers of $\alpha$-linolenic acid are incorporated into plasma lipids and converted into longer chain polyunsaturated fatty acids. Furthermore, trans $\alpha$ linolenic acid increases plasma LDL to HDL cholesterol and total to HDL cholesterol ratios, which are important risk parameters for CHD. Increasing the cis $\alpha$-linolenic acid intake, as recommended, may also increase the intake of $\alpha$-linolenic acid in the trans form. Careful deodorisation may prevent the formation of trans $\alpha$-linolenic acid and may help to improve the diet, deliver more cis $\alpha$-linolenic acid and thereby possibly reduce risk for $\mathrm{CHD}$. 


\section{REFERENCES}

1. FAO/WHO expert consultation on fats and oils in human nutrition (1993) General conclusions and recommendations of the consultation. Rome: FAONHO.

2. Demmelmair $H$, Iser B, Rauh-Pfeiffer A, and Koletzko B. Comparison of bolus versus fractionated oral applications of $\left[{ }^{13} \mathrm{C}\right]$-linoleic acid in humans. Eur J Clin Invest 1999;29:603609.

3. Emken EA, Adlof RO, and Gulley RM. Dietary linoleic acid influences desaturation and acylation of deuterium-labeled linoleic and linolenic acids in young adult males. Biochim Biophys Acta 1994;1213:277-288.

4. Allison DB, Egan SK, Barraj LM, Caughman C, Infante M, and Heimbach JT. Estimated intakes of trans fatty and other fatty acids in the US population. J Am Diet Assoc 1999;99:166174.

5. Demmelmair $H_{1}$ Baumheuer $M$, Koletzko $B$, Dokoupil $K$, and Kratl $G$. Metabolism of $U^{13} C$ labeled linoleic acid in lactating women. $J$ Lipid Res 1998;39:1389-1396.

6. Emken EA, Adlof RO, Duval SM, and Nelson GJ. Influence of dietary arachidonic acid on metabolism in vivo of 8cis, 11cis, 14-eicosatrienoic acid in humans. Lipids 1997;32:441-448.

7. Emken EA, Adlof RO, Duval SM, and Nelson GJ. Effect of dietary arachidonic acid on metabolism of deuterated linoleic acid by adult male subjects. Lipids 1998;33:471-480.

8. Emken EA, Adlof RO, Duval SM, and Nelson GJ. Effect of dietary docosahexaenoic acid on desaturation and uptake in vivo of isotope-labeled oleic, linoleic, and linolenic acid by male subjects. Lipids 1999;34:785-791.

9. Salem N, Pawlosky R, Wegher B, and Hibbeln J. In vivo conversion of linoleic acid to arachidonic acid in human adults. Prostaglandins Leukot Essent Fatty Acids 1999;60:407-410.

10. Szitanyi $\mathrm{P}$, Koletzko $\mathrm{B}$, Mydlilova $\mathrm{A}$, and Demmelmair $\mathrm{H}$. Metabolism of ${ }^{13} \mathrm{C}$-labeled linoleic acid in newborn infants during the first week of life. Pediatr Res 1999;45:669-673.

11. Nichaman MZ, Olson RE, and Sweeley CC. Metabolism of linoleic acid- $1-{ }^{14} \mathrm{C}$ in normolipemic and hyperlipemic humans fed linoleate diets. Am J Clin Nutr 1967;20:1070-1083.

12. Carnielli VP, Wattimena DJL, Luijendijk IHT, Boerlage A, Degenhart HJ and Sauer PJJ. Ther very low birth weight premature infant is capable of synthesizing arachidonic and docosahexaenoic acids from linoleic and linolenic acids. Pediatr Res 1996;40:169-174.

13. Sauerwald TU, Hachey DL, Jensen CL, Chen H, Anderson RE, and Heird WC. Effect of dietary $\alpha$-linolenic acid intake on incorporation of docosahexaenoic and arachidonic acids into plasma phospholipids of term infants. Lipids 1996;31:S131-S135.

14. Salem N, Wegher B, Mena $P$, and Uauy R. Arachidonic and docosahexaenoic acdis are biosynthesized from their 18-carbon precursors in human infants. Proc Natl Acad Sci USA 1996;93:49-54.

15. Sauerwald TU, Hachey DL, Jensen CL, Chen H, Anderson RE and Heird WC. Intermediates in endogenous synthesis of $\mathrm{C} 22: 6 \omega 3$ and $\mathrm{C} 20: 4 \omega 6$ by term and preterm infants. Pediatr Res 1997;41:183-187.

16. Schulz H. Beta oxidation of fatty acids. Biochim Biophys Acta 1991;1081:109-120.

17. Rodriguez A, Sarda $P$, Nessmann $C$, Boulot $P$, Leger $C L$, and Descomps $B$. $\Delta 6$ - and $\Delta 5$ desaturase activities in the human fetal liver: kinetic aspects. J Lipid Res 1998;39:1825-1832.

18. Cunnane, S. C., P. W. N. Keeling, R. P. H. Thompson, and M. A. Crawford. 1984. Linoleic acid and arachidonic acid metabolism in human peripheral blood leucocytes: comparison with the rat. Brit J Nutr 51: 209-217. 
19. Powell, E. E., and P. A. Kroon. 1994. Low density lipoprotein receptor and 3-hydroxy-3methylglutaryl coenzyme A reductase gene expression in human mononuclear leukocytes is regulated coordinately and parallels gene expression in human liver. $J$ Clin Invest 93: 21682174

20. Hulshof KFAM, Van Erp-Baart MA, Anttolainen M, Becker W, Church SM, Couet C, HermannKunz E, Kesteloot H, Leth T, Martins I, Moreiras O, Moschandreas J, Pizzoferrato L, Rimestad $\mathrm{AH}$, Thorgeirsdottir $\mathrm{H}$, Van Amelsvoort JMM, Aro A, Kafatos AG, Lanzmann-Petithory $D$ and Van Poppel G. Intake of fatty acids in Western Europe with emphasis on trans fatty acids: The TRANSFAIR study. Eur J Clin Nutr 1999;53:143-157.

21. Van Poppel G. Intake of trans fatty acids in western Europe: the TRANSFAIR study. Lancet 1998;351:1099.

22. Aro A, Kardinaal AFM, Salminen 1 et al. Adipose tissue isomeric trans fatty acids and risk of myocardial infarction in nine countries: the EURAMIC study. Lancet 1995;345:273-278.

23. Bakker N, van 't Veer P, Zock PL, and the EURAMIC study group. Adipose fatty acids and cancers of the breast, prostate and colon: an ecological study. In J Cancer 1997;72:587-591.

24. Garland M, Sacks FM, Colditz GA, Rimm EB, Sampson LA, Willett WC, and Hunter DJ. The relation between dietary intake and adipose tissue composition of selected fatty acids in US women. Am J Clin Nutr 1998;67:25-30.

25. Katan MB, Mensink RP, and Zock P. Trans fatty acids and their effects on lipoproteins in humans. Ann Rev Nutr 1995;15:473-493.

26. Almendingen $K$, Jordal $O$, Kierulf $P$, Sandstad $B$ and Pedersen Jl. Effects of partially hydrogenated fish oil, partially hydrogenated soybean oil, and butter on serum lipoproteins and Lp[a] in men. J Lipid Res 1995;36:1370-1384.

27. Mensink RP and Katan MB. Effect of dietary fatty acids on serum lipids and lipoproteins. A meta-analysis of 27 trials. Arterioscler Thromb 1992;12:911-919.

28. O'Keefe $S$, Gaskins-Wright $S$, Wiley $V$ and Chen Chen I. Levels of trans geometrical isomers of essential fatty acids in some unhydrogenated US vegetable oils. J Food Lipids 1994;1:165176.

29. Wolff RL. Trans polyunsaturated fatty acids in French edible rapeseed and soybean oils. $J$ Am Oil Chem Soc 1992;69:106-110.

30. Lagrost L. Differential effects of cis and trans fatty acid isomers, oleic and elaidic acids, on the cholesteryl ester transfer protein activity. Biochim Biophys Acta 1992;1124:159-162.

31. Nishida $\mathrm{H}$, Arai $\mathrm{H}$, and Nishida $\mathrm{T}$. Cholesterol ester transfer mediated by lipid transfer protein as influenced by changes in the charge characteristics of plasma lipoproteins. $J$ Biol Chem 1993;268:16352-16360.

32. Aro $A$, Jauhiainen M, Partanen R, Salminen I, and Mutanen M. Stearic acid, trans fatty acids, and dairy fat: effects on serum and lipoprotein lipids, apolipoproteins, lipoprotein(a), and lipid transfer proteins in healthy subjects. Am J Clin Nutr 1997;65:1419-1426.

33. Subbaiah $P$, Subramanian $V$, and Liu $M$. Trans unsaturated fatty acids inhibit lecithin:cholesterol acyltransferase and alter its posititional specificity. I Lipid Res 1998;39:1438-1447.

34. Van Tol A, Zock P, Van Gent T, Scheek L, and Katan MB. Dietary trans fatty acids increase serum cholesterylester transfer protein activity in man. Atherosclerosis 1995;115:129-134.

35. Woollett L, Daumerie C, and Dietschy J. Trans-9-octadecemoic acid is biologically neutral and does not regulate the low density lipoprotein receptor as the cis isomer does in the hamster. $J$ Lipid Res 1994;35:1661-1673. 


\section{Fatty acid nomenclature and abbreviations}

\section{Fatty acid nomenclature}

Cis fatty acids
C14:0
C16:0
C16:1n-7 $(\Delta 9)$
C17:0

C18:0

C18:1n-9 $(\Delta 9 c)$

C20:3n-9 $(\Delta 5,8,11)$

C22:3n-9 $(\Delta 7,10,13)$

C18:2n-6 $(\Delta 9,12)$

C18:3n-6 $(\Delta 6,9,12)$

C20:3n-6 $(\Delta 8,11,14)$

C20:4n-6 $(\Delta 5,8,11,14)$

C22:4n-6 $(\Delta 7,10,13,16)$

C22:5n-6 $(\Delta 4,7,10,13,16)$ myristic acid

palmitic acid

palmitoleic acid

triheptadecanoic acid

stearic acid

oleic acid

Mead acid

dihomo-Mead acid

linoleic acid

$\gamma$-linolenic acid

dihomo- $\gamma$-linolenic acid

arachidonic acid

adrenic acid

Osbond acid

C18:3n-3 $(\Delta 9,12,15)$

$\alpha$-linolenic acid

C20:5n-3 $(\Delta 5,8,11,14,17)$

eicosapentaenoic acid

C22:5n-3 $(\Delta 7,10,13,16,19)$ docosapentaenoic acid

C22:6n-3 $(\Delta 4,7,10,13,16,19)$ docosahexaenoic acid

\section{Trans fatty acids}

C18:1n-9 $(\Delta 9 t r)$

elaidic acid

C18:1n-7 ( $(\Delta 11$ tr $)$

vaccenic acid

\section{Abbreviations}

ACAT acyl-CoA:cholesterol acyltransferase

ADP adenosine diphosphate

ALA $\quad \alpha$-linolenic acid

Apo apolipoprotein

ATP adenosine triphosphate

BMI body mass index 


\begin{tabular}{|c|c|}
\hline BSA & bovine serum albumin \\
\hline CETP & cholesteryl ester transfer protein \\
\hline $\mathrm{Cl}$ & confidence interval \\
\hline CHD & coronary heart disease \\
\hline CSFII & Continuing Survey of Food Intakes by Individuals \\
\hline EDTA & ethylenediaminetetracetic acid \\
\hline EPA & eicosapentaenoic acid \\
\hline DHA & docosahexaenoic acid \\
\hline dNTP & deoxyribonucleoside triphosphate \\
\hline DPA & docosapentaenoic acid \\
\hline EFA & essential fatty acid \\
\hline FA & fatty acid \\
\hline FAME & fatty acid methyl ester \\
\hline GC-C-IRMS & gas chromatography-combustion-isotope ratio mass spectrometry \\
\hline GC/FID & gas chromatography coupled with a flame ionization detector \\
\hline HDL & high density lipoprotein \\
\hline HETE & hydroxyeicosatetraenoic acid \\
\hline HHT & 12-hydroxy heptadecatrienoic acid \\
\hline HPETE & hydroxyperoxyeicosatetraenoic acid \\
\hline LCAT & lecithin:cholesterol acyltransferase \\
\hline LCP & long chain polyunsaturated fatty acid \\
\hline LDL & low density lipoprotein \\
\hline Lp(a) & lipoprotein(a) \\
\hline LT & leukotriene \\
\hline MDA & malondialdehyde \\
\hline mRNA & messenger ribonucleic acid \\
\hline MUFA & monounsaturated fatty acid \\
\hline PAl-1 & plasminogen activator inhibitor type 1 \\
\hline PC & phosphatidylcholine \\
\hline PDB & Pee Dee Belemate \\
\hline PG & prostaglandin \\
\hline $\mathrm{PGl}_{2}$ & prostacyclin \\
\hline PUFA & polyunsaturated fatty acid \\
\hline $\mathrm{RR}$ & relative risk \\
\hline RT-PCR & reverse transcription-polymerase chain reaction \\
\hline SAFA & saturated fatty acid \\
\hline SD & standard deviation \\
\hline SEM & standard error of the mean \\
\hline TTR & tracer/tracee ratio \\
\hline Tx & tromboxane \\
\hline USDA & US Department of Agriculture \\
\hline VLDL & very low density lipoprotein \\
\hline
\end{tabular}




\section{Summary}

Dietary polyunsaturated fatty acids are mainly incorporated into triacylglycerols and phospholipids. Triacylglycerols are an important source of energy, while phospholipids are essential components of membranes. Some polyunsaturated fatty acids are precursors of eicosanoids, which have important physiological functions in humans like in inflammatory processes, immunological reactions and platelet aggregation. The polyunsaturated fatty acids linoleic (C18:2n-6) and $\alpha$-linolenic acid (C18:3n-3) are essential fatty acids, which can be converted into their longer chain more unsaturated fatty acids (LCPS) by chain elongation and desaturation. In vivo conversion of these fatty acids as well as their oxidation have, however, hardly been studied in humans.

The double bonds in dietary linoleic and $\alpha$-linolenic acid have a cis configuration. However, trans polyunsaturated fatty acids are also part of the diet. It is known that trans monounsaturated fatty acids have a negative impact on serum lipoproteins, but effects of trans polyunsaturated fatty acids on risk parameters of coronary heart disease (CHD) have not been extensively investigated. Since increment of dietary $\alpha$-linolenic acid intake has been recommended, which could result in an increased intake of trans $\alpha$-linolenic acid, it would be interesting to investigate the health effects of trans isomers of $\alpha$-linolenic acid as well. Therefore, the studies presented in this thesis were aimed at examining the metabolic aspects of dietary cis and trans polyunsaturated fatty acids.

The in vivo conversion and oxidation of fatty acids can be measured safely in humans by using stable isotopes. The stable isotope of carbon $\left({ }^{12} \mathrm{C}\right)$ is ${ }^{13} \mathrm{C}$, which has a natural abundance of $1.11 \%$. Chapter 2 examines the in vivo conversion of $45 \mathrm{mg}$ ${ }^{13} \mathrm{C}$ linoleic acid in 6 healthy volunteers. Blood was sampled before and at several time points up to 2 weeks after ${ }^{13} \mathrm{C}$ linoleic acid ingestion. About 17 hours after intake of ${ }^{13} \mathrm{C}$ linoleic acid, amounts of ${ }^{13} \mathrm{C}$ linoleic acid in plasma total lipids were maximal and were $8 \%$ of the given dose. Also ${ }^{13} \mathrm{C} 18: 3 n-6,{ }^{13} \mathrm{C} 20: 3 n-6,{ }^{13} \mathrm{C} 20: 4 n-6$ (arachidonic acid), ${ }^{13} \mathrm{C} 22: 4 \mathrm{n}-6$ and ${ }^{13} \mathrm{C} 22: 5 \mathrm{n}-6$ were detected in plasma total lipids, suggesting that ${ }^{13} \mathrm{C}$ linoleic acid is converted into its LCPs. Amounts of ${ }^{13} \mathrm{C} 20: 4 \mathrm{n}-6$ increased until 2 weeks, but were rather low. The $\mathrm{C} 22$ fatty acids ${ }^{13} \mathrm{C} 22: 4 n-6$ and ${ }^{13} \mathrm{C} 22: 5 \mathrm{n}-6$ could not be detected in all subjects. The peak amount ${ }^{13}{ }^{13} \mathrm{C}$ LCPs $\left({ }^{13} \mathrm{C} 18: 3 n-6+{ }^{13} \mathrm{C} 20: 3 n-6+{ }^{13} \mathrm{C} 20: 4 n-6\right)$ was $0.15 \%$ of the ${ }^{13} \mathrm{C}$ linoleic acid dose. We therefore recommend to use a higher dose of ${ }^{13} \mathrm{C}$ linoleic acid to investigate its conversion into arachidonic acid. After 12 hours, about $21 \%$ of the ${ }^{13} \mathrm{C}$ linoleic acid was recovered as ${ }^{13} \mathrm{CO}_{2}$ in breath. 
Effects of a diet rich in $\alpha$-linolenic acid ( 8.3 gram/day for 6 weeks) versus an oleic acid rich diet on the oxidation and the in vivo conversion of $45 \mathrm{mg}{ }^{13} \mathrm{C} \alpha$ linolenic acid into LCPs in 12 healthy subjects is described in chapter 3 . Six percent of the ${ }^{13} \mathrm{C} \alpha$-linolenic acid on the $\alpha$-linolenic acid rich diet and $10 \%$ of the ${ }^{13} \mathrm{C} \alpha$ linolenic acid on the oleic acid rich diet was found as ${ }^{13} \mathrm{C} \alpha$-linolenic acid in plasma total lipids. Furthermore, eicosapentaenoic acid (EPA; ${ }^{13} \mathrm{C} 20: 5 n-3$ ), ${ }^{13} \mathrm{C}$ docosapentaenoic acid (DPA; $\left.{ }^{13} \mathrm{C} 22: 5 n-3\right)$ and ${ }^{13} \mathrm{C}$ docosahexaenoic acid (DHA; $\left.{ }^{13} \mathrm{C} 22: 6 n-3\right)$ were detected in plasma total lipids. Maximal amounts of ${ }^{13} \mathrm{C}$-EPA in plasma total lipids were significantly lower in the $\alpha$-linolenic acid group $(0.04 \mathrm{mg})$ than in the oleic acid group $(0.12 \mathrm{mg})$. Amounts of ${ }^{13} \mathrm{C}$-DPA and ${ }^{13} \mathrm{C}$-DHA tended to be lower as well. These findings suggest that the relative conversion of ${ }^{13} \mathrm{C} \alpha$-linolenic acid into its LCPs may be decreased on diets rich in $\alpha$-linolenic acid. The proportion of tracer recovered as ${ }^{13} \mathrm{CO}_{2}$ in breath after 12 hours was $20 \%$ in the $\alpha$-linolenic acid group and $16 \%$ in the oleic acid group, which was not significantly different. In addition, part of the ${ }^{13} \mathrm{C} \alpha$-linolenic acid and ${ }^{13} \mathrm{C}$ LCPs was incorporated into human erythrocytes (chapter 4). This incorporation does not seems to be affected by dietary $\alpha$-linolenic acid. Because about $20 \%$ of the tracer was recovered as ${ }^{13} \mathrm{CO}_{2}$ in breath, $5-10 \%$ appeared as precursors and $0.1-0.3 \%$ as LCPs in plasma total lipids, and a small part was detected as precursor or metabolite in erythrocytes, it is concluded that an important part of the tracer is still missing which may be incorporated into other tissues.

Linoleic and $\alpha$-linolenic acids are converted into their LCPs by elongase and $\Delta 5$ and $\Delta 6$ desaturases, which occur mainly in the liver. In addition, $\Delta 9$ desaturase is involved in the conversion of non-essential fatty acids. The liver is not an easy accessible organ to investigate in humans, while leukocytes can be collected in a relatively easy way. Therefore, it was investigated whether gene expressions of these desaturases in human leukocytes reflects that in the liver. Both mononuclear blood cells and human liver samples were collected from 14 patients who underwent an operation close to the liver (chapter 5). Delta 6 and $\Delta 9$ desaturase mRNAs in mononuclear blood cells were negatively correlated with $\Delta 6(r=-0.64)$ and $\Delta 9$ desaturase mRNAs $(r=0.83)$ in liver, respectively. This does, however, not necessarily mean that desaturase mRNAs in mononuclear blood cells can not be used to predict those in the liver. Hepatic $\Delta 5$ and $\Delta 6$ desaturase mRNA $(r=0.71)$, and $\Delta 6$ and $\triangle 9$ desaturase mRNA ( $r=0.59$ ) were positively correlated.

Most dietary trans fatty acids are trans monounsaturated fatty acids, which are formed by bacteria in the first stomach of ruminant animals and by industrial hydrogenation. Trans polyunsaturated fatty acids are mainly formed during the deodorization process. Effects of trans $\alpha$-linolenic acid from deodorized rapeseed oil on its incorporation into plasma lipids (chapter 7) and on plasma lipids and lipoproteins (chapter 8) have now been investigated in a large multicenter study. Eighty-eight male volunteers from three European university research departments, Clermont-Ferrand, Edinburgh and Maastricht, received $0.5 \%$ of energy $(1.4$ 
gram/day) trans $\alpha$-linolenic acid for 6 weeks versus a low trans fatty acid diet 60 $\mathrm{mg} /$ day). Less total trans fatty acids were incorporated into plasma triacylglycerols, phospholipids, cholesteryl esters and platelets in French volunteers $(1.9,0.8,0.5$, and $1.1 \%$ of total fatty acids, respectively) than in Dutch $(2.6,1.1,0.8$, and $1.8 \%$ of total fatty acids, respectively) or Scottish volunteers $(2.4,1.1,0.6$ and $1.6 \%$ of total fatty acids, respectively) consuming their habitual diets. In addition, trans isomers of $\alpha$-linolenic acid and monounsaturated fatty acids were also lowest in plasma triacylglycerols, phospholipids and cholesteryl esters, and trans monounsaturated fatty acids in platelets in the Clermont-Ferrand. Results suggest that trans fatty acid intake still differs between European countries. Changes in plasma lipid and platelet fatty acid composition documented that trans $\alpha$-linolenic isomers were incorporated and converted to a trans isomer of EPA. The high trans $\alpha$-linolenic acid diet significantly increased the plasma low density lipoprotein (LDL) to high density lipoprotein (HDL) cholesterol ratio by $8.1 \%$, and the total to HDL cholesterol ratio by $5.1 \%$, compared to the low trans diet. This was largely explained by an increase in LDL cholesterol on the high trans $\alpha$-linolenic acid diet, while no change was observed on the low trans diet. No effects were found on total and HDL cholesterol, triacylglycerols, lipoprotein B and A-1, and lipoprotein(a) concentrations. It is concluded that dietary trans isomers of $\alpha$-linolenic acid are incorporated in plasma lipids and converted to LCPS. In addition, trans $\alpha$-linolenic acid may increase plasma LDL to HDL cholesterol and total to HDL cholesterol ratios, which are important risk parameters for coronary heart disease. It is recommended, in addition to a reduction of trans monounsaturated fatty acids, to reduce consumption of trans polyunsaturated fatty acids.

In chapter 9 findings from the four studies described are discussed. The in vivo metabolism of essential fatty acids has been investigated by using two methods, the stable isotope technique and molecular biology. Whether mononuclear blood cells are suitable for investigation of fatty acids conversion should be investigated in future research focussing on effects of external factors, e.g. diets, on desaturase mRNA levels in mononuclear blood cells. In addition, combining different techniques seems to be useful in future research. 



\section{Samenvatting}

Meervoudig onverzadigde vetzuren uit de voeding worden in het lichaam met name ingebouwd in triglyceriden en fosfolipiden. Triglyceriden spelen een belangrijke rol als energieleverancier, terwijl fosfolipiden een belangrijke structurele component zijn van celmembranen. Daarnaast kunnen sommige meervoudig onverzadigde vetzuren worden omgezet in eicosanoïden, die betrokken zijn bij het aansturen van vele lichaamsprocessen. De meervoudig onverzadigde vetzuren linolzuur (C18:2n-6) en $\alpha$-linoleenzuur (C18:3n-3) zijn essentiëel, en kunnen in het lichaam door elongatie en desaturatie worden omgezet in vetzuren met een langere ketenlengte en met meer dubbele bindingen, de zogenaamde 'long chain polyunsaturated fatty acids' (LCPs). Over de in vivo omzetting en oxidatie van essentiële vetzuren bij de mens is nog niet veel bekend.

De dubbele bindingen in linolzuur en $\alpha$-linoleenzuur hebben de zogenaamde cis vorm. In de voeding komen echter ook meervoudig onverzadigde vetzuren voor met de trans vorm. Het is reeds bekend dat trans enkelvoudig onverzadigde vetzuren een negatieve invloed hebben op lipoproteïnenconcentraties in serum. Naar de effecten van trans meervoudig onverzadigde vetzuren op risicofactoren voor hart- en vaatziekten is veel minder onderzoek gedaan. De huidige voedingsrichtlijnen zijn er onder andere op gericht om de inname van $\alpha$-linoleenzuur te verhogen, hetgeen kan resulteren in een toename in de trans $\alpha$-linoleenzuurinname. Het is daarom van belang om ook de gezondheidseffecten van trans isomeren van $\alpha$-linoleenzuur te bestuderen. De studies uit dit proefschrift hebben dan ook tot doel om meer inzicht te krijgen in de metabole aspecten van cis en trans meervoudig onverzadigde vetzuren.

Een veilige manier om bij de mens de in vivo omzetting en oxidatie van vetzuren te bestuderen is met behulp van stabiele isotopen. Het stabiele isotoop van koolstof $\left({ }^{12} \mathrm{C}\right)$ is ${ }^{13} \mathrm{C}$ en beslaat in de natuur $1,11 \%$ van het totaal aantal koolstofatomen. In hoofdstuk 2 wordt de in vivo omzetting van $45 \mathrm{mg}{ }^{13} \mathrm{C}$ gelabeld linolzuur bij 6 gezonde vrijwilligers beschreven. Tot 2 weken na inname van het ${ }^{13} \mathrm{C}$ linolzuur werd op verschillende tijdstippen bloed afgenomen, waarin verrijkingen van ${ }^{13} \mathrm{C}$ gelabelde vetzuren werden bepaald. Ongeveer 17 uur na inname van ${ }^{13} \mathrm{C}$ linolzuur werd een maximum bereikt in de hoeveelheid ${ }^{13} \mathrm{C}$ linolzuur in plasma. Dit maximum was $8 \%$ van de toegediende dosis. Daarnaast werden ook de volgende LCPS in plasma gevonden: ${ }^{13} \mathrm{C} 18: 3 n-6,{ }^{13} \mathrm{C} 20: 3 n-6,{ }^{13} \mathrm{C} 20: 4 n-6$ (arachidonzuur), ${ }^{13} \mathrm{C} 22: 4 n-6$ en ${ }^{13} \mathrm{C} 22: 5 n-6$. De hoeveelheden ${ }^{13} \mathrm{C} 20: 4 n-6$ waren erg klein, en stegen tot 2 weken na inname van ${ }^{13} \mathrm{C}$ linolzuur. De $\mathrm{C} 22$ vetzuren ${ }^{13} \mathrm{C} 22: 4 \mathrm{n}-6$ en ${ }^{13} \mathrm{C} 22: 5 \mathrm{n}-6$ konden niet bij alle personen worden aangetoond. De totale maximale hoeveelheid ${ }^{13} \mathrm{C}$ gelabelde LCPs $\left({ }^{13} \mathrm{C} 18: 3 n-6+{ }^{13} \mathrm{C} 20: 3 n-6+{ }^{13} \mathrm{C} 20: 4 n-6\right)$ was slechts $0,15 \%$ van de 
toegediende dosis. De resultaten wijzen erop dat ${ }^{13} \mathrm{C}$ linolzuur wordt omgezet in langere keten vetzuren. Om echter de omzetting in arachidonzuur te besturen, wordt een hogere dosis aanbevolen. $\mathrm{Na} 12$ uur werd bovendien ongeveer $21 \%$ van het ${ }^{13} \mathrm{C}$ linolzuur teruggevonden als ${ }^{13} \mathrm{CO}_{2}$ in de uitademingslucht.

De effecten van een $\alpha$-linoleenzuurrijke voeding $(8,3 \mathrm{gram} / \mathrm{dag}$ gedurende 6 weken) versus een oliezuurrijke voeding op de oxidatie en in vivo omzetting van 45 $\mathrm{mg}{ }^{13} \mathrm{C} \alpha$-linoleenzuur in LCPs bij 12 gezonde proefpersonen worden beschreven in hoofdstuk 3. $\mathrm{Na}$ de $\alpha$-linoleenzuurrijke voeding werd $6 \%$ en na de oliezuurrijke voeding werd $10 \%$ van het toegediende ${ }^{13} \mathrm{C} \alpha$-linoleenzuur teruggevonden als ${ }^{13} \mathrm{C} \alpha$ linoleenzuur in het plasma. Daarnaast waren er ook hoeveelheden ${ }^{13} \mathrm{C}$ gelabeld eicosapentaeenzuur (EPA; ${ }^{13} \mathrm{C} 20: 5 n-3$ ), ${ }^{13} \mathrm{C}$ gelabeld docosapentaeenzuur (DPA; ${ }^{13} \mathrm{C} 22: 5 n-3$ ) en ${ }^{13} \mathrm{C}$ gelabeld docosahexaeenzuur (DHA; ${ }^{13} \mathrm{C} 22: 6 n-3$ ) in plasma aanwezig. De absolute maximale hoeveelheid ${ }^{13} \mathrm{C}$-EPA in plasma was significant lager in de $\alpha$-linoleenzuurgroep $(0,04 \mathrm{mg})$ dan in de oliezuurgroep $(0,12 \mathrm{mg})$. Hoeveelheden ${ }^{13} \mathrm{C}$-DPA en ${ }^{13} \mathrm{C}$-DHA leken ook verlaagd. Deze resultaten suggereren dat de relatieve omzetting van ${ }^{13} \mathrm{C} \alpha$-linoleenzuur in zijn LCPs verlaagd wordt door een $\alpha$-linoleenzuurrijke voeding. Na 12 uur werd $20 \%$ van de tracer in de $\alpha$ linoleenzuurgroep en $16 \%$ in de oliezuurgroep als ${ }^{13} \mathrm{CO}_{2}$ teruggevonden in de uitademingslucht. Dit verschilde niet significant tussen de groepen. Daarnaast werd een deel van de ${ }^{13} \mathrm{C} \alpha$-linoleenzuur en ${ }^{13} \mathrm{C}$ LCPs ingebouwd in de erythrocyten (hoofdstuk 4). Deze inbouw leek niet te worden beïnvloed door de hoeveelheid $\alpha$ linoleenzuur uit de voeding. Samenvattend kan worden gesteld dat in deze studie slechts ongeveer $20 \%$ van het ${ }^{13} \mathrm{C} \alpha$-linoleenzuur als ${ }^{13} \mathrm{CO}_{2}$ in de uitademingslucht, en $5-10 \%$ als precursor en $0,1-0,3 \%$ als LCPs in het plasma is teruggevonden, terwijl slechts een klein deel als precursor of metaboliet in de erythrocyten werd ingebouwd. Een deel van het ${ }^{13} \mathrm{C} \alpha$-linoleenzuur hebben we dus niet aan kunnen tonen, en zal mogelijk zijn opgenomen in andere weefsels van het lichaam.

Linolzuur en $\alpha$-linoleenzuur worden omgezet in hun LCPs door elongase en $\Delta 5$ - en $\Delta 6$ desaturase. Deze reacties vinden voornamelijk in de lever plaats. Daarnaast is $\Delta 9$ desaturase betrokken bij de omzetting van niet-essentiële vetzuren. Aangezien de lever vaak niet toegankelijk is om omzettingen van vetzuren te bestuderen, terwijl het verzamelen van leukocyten niet erg belastend is, is er onderzocht of de gen-expressies van deze desaturases in de leukocyten van de mens de gen-expressies in de lever weerspiegelen. Hiertoe werden zowel mononucleaire bloedcellen als humaan leverweefsel van 14 patiënten verzameld. Deze patiënten ondergingen een operatie vlak bij de lever, zodat het mogelijk was om een leverbiopt te nemen (hoofdstuk 5). In tegenstelling tot de verwachting waren $\Delta 6$ en $\Delta 9$ desaturase mRNAs in mononucleaire bloedcellen negatief gecorreleerd met respectievelijk $\Delta 6(r=-0,64)$ en $\Delta 9$ desaturase $(r=-0,83)$ mRNAs in de lever. Mogelijk kunnen desaturase mRNAs in mononucleaire bloedcellen echter wel gebruikt worden om waarden in de lever te voorspellen. In deze studie bleken de 
hepatische $\Delta 5$ en $\Delta 6$ desaturase mRNAs $(r=0,71)$, en $\Delta 6$ en $\Delta 9$ desaturase mRNAs $(r=0,59)$ positief te zijn gecorreleerd.

De meeste trans vetzuren uit de voeding zijn trans enkelvoudig onverzadigde vetzuren, welke worden gevormd door bacteriën in de lebmaag van herkauwers en bij industriële hydrogenatie. Trans meervoudig onverzadigde vetzuren worden voornamelijk gevormd tijdens het deodorizeren van oliën. Effecten van trans $\alpha-$ linoleenzuur uit gedeodoriseerde raapzaadolie op de inbouw van plasmalipiden (hoofdstuk 7) en op plasmalipiden en -lipoproteïnenconcentraties (hoofdstuk 8) zijn onderzocht in een grote multicenter studie. Achtentachtig mannelijke vrijwilligers uit drie Europese steden, Clermont-Ferrand, Edinburgh en Maastricht, kregen 0,5 energie\% (1,4 gram/dag) trans $\alpha$-linoleenzuur gedurende 6 weken versus een 'laag trans vetzuren voeding' (60 mg/dag). Voor aanvang van de studie waren de totale trans vetzurenconcentraties in plasma triglyceriden, fosfolipiden en cholesteryl esters, en bloedplaatjes lager bij de Franse vrijwilligers (respectievelijk 1,9,0,8,0,5, en $1,1 \%$ van totaal vetzuren) in vergelijking met die van de Nederlandse (respectievelijk $2,6,1,1,0,8$, en $1,8 \%$ van totaal vetzuren) en Schotse vrijwilligers (respectievelijk $2,4,1,1,0,6$ en $1,6 \%$ van totaal vetzuren). Bovendien waren ook het trans $\alpha$-linoleenzuur en de trans enkelvoudig onverzadigde vetzuren in de plasmalipidenfracties en trans enkelvoudig onverzadigde vetzuren in bloedplaatjes het laagst in Clermont-Ferrand. Aangezien de waarden bij aanvang van de studie de samenstelling van de gebruikelijke voeding weergaven, blijken er dus verschillen te bestaan in trans vetzureninname tussen Europese landen. Uit de veranderingen in de vetzuursamenstelling van plasmalipiden en bloedplaatjes na de 6 weken durende trans $\alpha$-linoleenzuurrijke voeding bleek dat trans $\alpha$-linoleenzuur werd ingebouwd en werd omgezet in trans isomeren van EPA. De trans $\alpha$-linoleenzuurrijke voeding leidde bovendien tot een significante verhoging van de plasma 'low density lipoprotein' (LDL) / 'high density lipoprotein' (HDL) cholesterol ratio met $8,1 \%$, en de totaal/HDL cholesterol ratio met $5,1 \%$, in vergelijking met de 'laag trans vetzuren voeding'. Dit werd grotendeels veroorzaakt door een toename in LDL cholesterol na de trans $\alpha$-linoleenzuurrijke voeding, terwijl er geen verandering optrad na de 'laag trans vetzuren voeding'. Er werden geen effecten van trans $\alpha$-linoleenzuur uit de voeding gevonden op het totaal en HDL cholesterol, triglyceriden, lipoproteïne $B$ and A-1, and lipoproteine (a). Uit de resultaten blijkt dat de trans isomeren van $\alpha$ linoleenzuur uit de voeding worden ingebouwd in plasmalipiden en omgezet in LCPS. Bovendien verhoogt trans $\alpha$-linoleenzuur de plasma LDL/HDL cholesterol en de totaal/HDL cholesterol ratios, twee belangrijke risicoparameters voor hart- en vaatziekten. Het wordt daarom aanbevolen naast de inname van trans enkelvoudig onverzadigde vetzuren, ook zo min mogelijk trans meervoudig onverzadigde vetzuren in te nemen. 
In hoofdstuk 9 worden de bevindingen uit de verschillende studies bediscussieerd. Met behulp van twee onderzoekstechnieken (stabiele isotopen onderzoek en bepaling van desaturase mRNA), is het in vivo metabolisme van de essentiële vetzuren bestudeerd. Toekomstig onderzoek, waarin effecten van externe factoren, zoals bijvoorbeeld voeding, op desaturase mRNA in mononucleaire bloedcellen worden onderzocht, zal verder uit moeten wijzen of leukocyten geschikt zijn om bij bestudering van vetzuuromzettingen te gebruiken. Daarnaast lijkt het waardevol om, binnen een studie, bovengenoemde onderzoekstechnieken te combineren. 


\section{Dankwoord}

Alvorens dit dankwoord door te gaan lezen raad ik eenieder aan eerst hoofdstuk 1 tot en met 9 door te werken. Op deze manier kan namelijk beter worden begrepen waarom ik onderstaande personen wil bedanken voor hun bijdrage aan de totstandkoming van dit proefschrift.

Allereerst wil ik mijn beide promotoren, Ronald Mensink en Gerard Hornstra, bedanken voor de mogelijkheid die zij mij hebben gegeven om dit onderzoek uit te voeren. Ronald, bedankt voor je prettige begeleiding bij de opzet, uitvoering en rapportage van de onderzoeken. Ik heb veel geleerd van je kritische opmerkingen (al dacht ik soms dat er nooit een eind aan kwam) en onze vele zinvolle en onzinnige discussies. In ieder geval heb je nu weer een proefschrift minder om door te werken. Gerard bedank ik voor zijn waardevolle ideeën voor mijn onderzoeken en voor het kritisch doorwerken van mijn manuscripten.

I would like to thank Prof. Dr. Ir. W.H.M. Saris, Prof. Dr. T.W.A. de Bruin, Dr. J.F.C. Glatz, Prof. Dr. Ir. M.B. Katan, Prof. Dr. B. Koletzko and Dr. H. Demmelmair for their critical evaluation of my thesis.

Een aantal collega's van de capaciteitsgroep Human Biologie wil ik bedanken voor hun hulp, advies en prettige samenwerking. Bij de isotopen-studies waren met name Ton Wagenmakers en Marianne Simonis betrokken. Ton bedank ik voor zijn nuttige tips en adviezen over stabiele isotopen onderzoek in het algemeen, en Marianne wil ik bedanken voor de enorme hoeveelheid analyses die zij heeft uitgevoerd. Frank Cox, Rene Offermans en Jo Wierts ${ }^{\dagger}$, jullie stonden altijd paraat bij de uitvoer van onderzoeken en hebben ook vele analyses voor jullie rekening genomen. Bedankt daarvoor. Voor hulp en advies over het moleculaire werk kon ik terecht bij Jogchum Plat en Arjen Bakker. Jogchum, mede dankzij jouw hulp ben ik dat gefreubel met dat onzichtbare RNA zelfs leuk gaan vinden. Paul Schoffelen en Loek Wouters: helaas heb ik regelmatig een beroep op jullie moeten doen. Bedankt voor jullie ondersteuning als ik weer eens problemen had met mijn Mac. Liesbeth Temme, met name bij de uitvoering van het onderzoek heb ik veel gehad aan jouw ervaring, voorbeeld-documenten en tips. Carin Wensing bedank ik voor de samenwerking bij de $\alpha$-linoleenzuur studie.

Van de afdeling Chirugie van het AZM wil ik Jan Willem Greve, artsen en OKpersoneel bedanken voor hun medewerking bij het verkrijgen van leverbiopten en bloedmonsters. François van Dielen bedankt voor je hulp om alle patiënten bij elkaar te krijgen. Jan Glatz en Joost Luiken van de capaciteitsgroep Fysiologie bedank ik voor hun adviezen bij het wassen van de erythrocyten. 
I thank Dr. Jean-Louis Sébédio, Dr. Jean-Michel Chardigny, Prof. Dr. Rudolph Riemersma, Prof. Dr. Bernard Beaufrère and all members of the TransLinE study for a pleasant cooporation.

Alle proefpersonen wil ik bedanken voor hun enthousiaste deelname aan de onderzoeken en de patiënten van het AZM voor hun bereidwilligheid om weefsel af te staan voor onderzoek.

Naast een aantal van hen die ik reeds heb genoemd, wil ik ook mijn overige collega's en met name de 'middenlob-collega's van Humane Biologie, waaronder mijn kamergenoten Marjolien en Jogchum, bedanken voor de gezellige tijd die ik in Maastricht heb gehad. Trein-collega Annelies, bedankt voor de gezellige treinreizen terug naar Eindhoven.

Familie en vele vrienden hebben belangstelling getoond voor mijn voortgang en de vraag 'hoe staat het met je boekje?' heb ik vele malen moeten horen. Helaas kon ik daar nooit een duidelijk antwoord opgeven, maar gelukkig kan ik sinds kort antwoorden met 'goed, het is af!'. Twee vriendinnen wil ik in het bijzonder bedanken. Claudie, bedankt dat je (jullie) mijn paranimf wilt zijn. Karin, jammer dat we tegenwoordig niet meer zo vaak samen kunnen lunchen; ik vind het erg leuk dat je mijn paranimf wilt zijn.

Tot slot wil ik graag mijn ouders bedanken voor het vertrouwen en de steun die zij mij al deze jaren hebben gegeven. Mama, het overbrengen van jouw interesse voor voeding en gezondheid aan mij heeft uiteindelijk tot dit proefschrift geleid.

En lieve Paul, jouw bijdrage aan dit proefschrift is enorm geweest. Bedankt voor al je hulp, steun en vertrouwen, en vooral voor het feit dat je voor altijd bij mij bent. 


\section{Curriculum vitae}

Susanne Hanneke Francisca Vermunt was born on July 14 1970, in Prinsenbeek, the Netherlands. After graduation from secondary education at 'Markenhage' in Breda, she completed a higher education for dietician at the 'Hogeschool Nijmegen' in Nijmegen in 1993. As part of the training she spent 5 months of practical research at TNO Nutrition and Food Research of the Netherlands Organization for Applied Scientific Research (TNO) in Zeist. In 1993, she started her academic education at Maastricht University in Maastricht, where she studied Biological Health Sciences. As part of the training she spent 5 months of practical research at the Department of Urology at the University Hospital in Maastricht, during which she studied the effects of an animal protein and sodium restricted diet on the composition of urine in patients with hypercalciuria. She graduated in 1995. For a period of 6 months she worked as a research assistant at the Department of Human Biology, Maastricht University, during which the effects of a fermented milk product on serum lipoproteins in healthy subjects were studied. She started in March 1995 as a PhD-fellow at the Department of Human Biology, Maastricht University. She conducted an international intervention study with healthy men on the effects of trans polyunsaturated fatty acids on lipoproteins. Furthermore, she conducted stable isotope studies with healthy subjects on the metabolism of polyunsaturated fatty acids and studies on mRNA levels of desaturase enzymes by molecular biology. Parts of research findings have been presented at international conferences in Maastricht (the Netherlands), Edinburgh (Scotland) and Lyon (France). From May 2000 on, she appointed at TNO Nutrition and Food Research in Zeist. 



\section{Publications}

\section{FULL PAPERS, BOOK CHAPTERS, AND ABSTRACTS}

* Vermunt SHF, Mensink RP, Simonis AMG, and Hornstra G. Effects of age, dietary $\alpha$-linolenic acid or EPA/DHA, on the oxidation of ${ }^{13} \mathrm{C}-\alpha$-linolenic acid. Prostaglandins Leukot Essent Fatty Acids 1998;57:219 (Abstract).

* Vermunt SHF, Mensink RP, Simonis AMG, and Hornstra G. Effects of age and dietary $\mathrm{n}-3$ fatty acids on the metabolism of $\left[{ }^{13} \mathrm{C}\right] \alpha$-linolenic acid. Lipids 1999;34:S127 (Abstract).

* Vermunt SHF, Mensink RP, Wagenmakers AJM, Simonis AMG, and Hornstra G. The metabolism of ${ }^{13} \mathrm{C}$-linoleic acid in healthy men and women. Proc Nutr Soc 1999;58:167A (Abstract).

* Sébédio JL, Vermunt SHF, Chardigny JM, Beaufrère B, Mensink RP, Armstrong RA, Christie WW, Niemelä J, Hénon G, and Riemersma RA. The effect of dietary trans $\alpha$-linolenic acid on plasma lipids and platelet fatty acid composition: the TransLinE Study. Eur J Clin Nutr 2000;54:104-13.

- Vermunt SHF, Mensink RP, Simonis AMG, and Hornstra G. Effects of dietary $\alpha$ linolenic acid on the conversion and oxidation of ${ }^{13} \mathrm{C}-\alpha$-linolenic acid. Lipids 2000;35:137-42.

- Armstrong RA, Chardigny JM, Beaufrère B, Bretillon L, Vermunt SHF, Mensink RP, McVean A, Elton RA, Sébédio JL, and Riemersma RA. No effect of dietary trans isomers of $\alpha$-linolenic acid on platelet aggregation and haemostatic factors in European healthy men: the TRANSLinE Study. Thromb Res 2000;100:133141.

* Vermunt SHF and Mensink RP. Health effects of trans fatty acids. In: Preventive Nutrition, Volume II: Primary and Secondary Prevention (A Bendich and RJ Deckelbaum eds.) Totowa, NJ: Humana Press, 2001 (Book chapter).

- Vermunt SHF, Beaufrère B, Riemersma RA, Sébédio JL, Chardigny JM, and Mensink RP for the TransLinE investigators. Dietary trans $\alpha$-linolenic acid from deodorised rapeseed oil and plasma lipids and lipoproteins in healthy men: the TransLinE Study. Br J Nutr 2001;85:387-392.

* Vermunt SHF, Mensink RP, Simonis AMG, Wagenmakers AJM, and Hornstra G. The metabolism of linoleic acid in healthy subjects after intake of a single dose of ${ }^{13}$ C-linoleic acid. Eur J Clin Nutr 2001;55:321-326. 


\section{SUBMITTED PAPERS}

- Vermunt SHF, Greve JW, Mensink RP, and Hornstra G. Relationship between mRNA levels for $\Delta 5, \Delta 6$ and $\Delta 9$ desaturases in mononuclear blood cells and the liver.

* Vermunt SHF, Mensink RP, Simonis AMG, and Hornstra G. Incorporation of ${ }^{13} \mathrm{C}$ $\alpha$-linolenic acid and its longer chain metabolites into human erythrocyte. 